Studien aus dem Max-Planck-Institut

für Sozialrecht und Sozialpolitik

Daniel Eryk Lach/Ulrich Becker (Hrsg.)

Die öffentliche Gesundheitsversorgung in Polen

Verfassungsrechtliche Vorgaben und das System der Gesundheitsfürsorge 
Studien aus dem Max-Planck-Institut für Sozialrecht und Sozialpolitik

Band 65 
Daniel Eryk Lach/Ulrich Becker (Hrsg.)

\section{Die öffentliche Gesundheits- versorgung in Polen}

Verfassungsrechtliche Vorgaben und das System der Gesundheitsfürsorge

\section{Nomos}


Das Projekt wurde aus Mitteln des polnischen Nationalen Wissenschaftszentrum (Narodowe Centrum Nauki - NCN) finanziert, die aufgrund der Entscheidung Nr. DEC2013/08/A/HS1/00079 zuerkannt sind.

Die Deutsche Nationalbibliothek verzeichnet diese Publikation in der Deutschen Nationalbibliografie; detaillierte bibliografische Daten sind im Internet über http://dnb.d-nb.de abrufbar.

ISBN 978-3-8487-3885-4 (Print)

ISBN 978-3-8452-8220-6 (ePDF)

\section{Auflage 2017}

(c) Nomos Verlagsgesellschaft, Baden-Baden 2017. Gedruckt in Deutschland. Alle Rechte, auch die des Nachdrucks von Auszügen, der fotomechanischen Wiedergabe und der Übersetzung, vorbehalten. Gedruckt auf alterungsbeständigem Papier. 


\section{Vorwort}

Am 11. Dezember 2015 fand in Posen ein Workshop zum deutschen und polnischen Sozial- und Verfassungsrecht unter dem Titel: „Verfassungsrechtliche Vorgaben für den Aufbau von Systemen der Gesundheitsversorgung in Deutschland und Polen" statt. Er war Teil eines interdisziplinären wissenschaftlichen Projektes, das von der Jagiellonen-Universität in Krakau zum Thema „Gerechtigkeit in der Gesundheitsversorgung” durchgeführt wurde.

Der Workshop bot Möglichkeiten zur Diskussion und zur Vergleichung von verfassungsrechtlichen Vorgaben für die Gesundheitsversorgung in den Nachbarländern. Insbesondere wurden die Grundsätze der Gerechtigkeit und Solidarität als Leitgedanken der deutschen gesetzlichen Krankenversicherung und des polnischen Systems der „Gesundheitsfürsorge“ diskutiert. Besprochen wurde ferner das Prinzip der Gleichheit, sowohl in Bezug auf den Zugang zu den Leistungen als auch deren Gewährung.

Die in den Verfassungen beider Länder, in der polnischen Verfassung von 1997 und im Grundgesetz von 1949, enthaltenen Grundsätze sind ähnlich. Die polnische Verfassung bestimmt, dass die Republik Polen ein demokratischer Rechtsstaat ist, der die Grundsätze gesellschaftlicher Gerechtigkeit verwirklichen soll (Art. 2), und dass die Würde des Menschen, die diesem angeboren und unveräußerlich ist, die Quelle der Freiheiten und Rechte aller Menschen und der Staatsbürger bildet (Art 30). Auch das Grundgesetz betont die Unantastbarkeit der Menschenwürde als Grundlage jeder menschlichen Gemeinschaft, des Friedens und der Gerechtigkeit in der Welt (Art. 1). Die Bundesrepublik Deutschland ist ein demokratischer und sozialer Bundesstaat (Art 20). Gleichzeitig werden bedeutsame Unterschiede sichtbar. Während darauf verzichtet wurde, im Grundgesetz soziale Rechte zu verankern, sieht die polnische Verfassung in Art 67 und 68 das Recht von Staatsbürgern auf die soziale Sicherung im Fall der Arbeitsunfähigkeit wegen Krankheit oder Invalidität sowie nach Erreichung des Ruhealters vor; finden diese ohne eigene Schuld keine Beschäftigung und besitzen keine anderen Mittel zum Unterhalt, ist die öffentliche Gewalt verpflichtet, einen gleichen Zutritt zur Gesundheitsfürsorge, die aus öffentlichen Mitteln finanziert wird, zu sichern; zudem wird ein allge- 
meines Recht auf den Schutz der Gesundheit festgeschrieben. Ferner nimmt die polnische Verfassung sowohl in der Präambel als auch in verschiedenen Vorschriften auf grundlegende Werte (z.B. Wahrheit, Gerechtigkeit, Schönheit, Freiheit, Solidarität, Subsidiarität) Bezug.

Die Unterschiede zwischen beiden Verfassungen sind Ausdruck der jeweiligen historischen Erfahrungen und verschiedener Entstehungszeiten. Auch die Anlage der Gesundheitssysteme ist in beiden Ländern von Unterschieden geprägt. Obwohl beide Systeme auf eine Leistungserbringung durch Dritte setzen und dementsprechend ein Leistungserbringungsdreieck kennen, differieren sie nicht nur hinsichtlich der Höhe von Beiträgen und dem Katalog der Leistungen. Die Unterschiede sind grundlegender. Während die deutschen Krankenkassen als Versicherungsträger anzusehen sind, handelt es sich bei dem polnischen Nationalen Gesundheitsfonds um einen treuhänderischen Verwalter, der auch die Verhältnisse zu den Leistungserbringern beeinflusst und gestaltet. Während das deutsche Leistungserbringungsrecht öffentliches Recht ist, werden die im polnischen System geschlossenen Verträge als besonders regulierte privatrechtliche Verträge qualifiziert. Daraus folgen auch Unterschiede in der rechtlichen Situation der Leistungsberechtigten.

Angesichts dessen war es von besonderem Interesse zu untersuchen, was es bedeutet, wenn in beiden Ländern einerseits die Gesundheitssysteme unterschiedlich strukturiert und die verfassungsrechtlichen Vorgaben unterschiedlich dicht sind, andererseits beide Systeme aber auf gleiche Leitideen gestützt, in beiden Ländern aus den Grundrechten Rechte auf Schutz des Lebens und der Gesundheit abgeleitet und Zugang und Leistungsgewährung nach dem Gleichheitsprinzip verteilt werden. Die während des Workshops gehaltenen Referate wurden in Polen veröffentlicht. Im Laufe unserer Diskussionen sind wir zu der Überzeugung gekommen, dass es auch für deutsche Leser interessant ist, zu erfahren, wie die verfassungsrechtlichen Vorgaben die Gesundheitsversorgung in Polen beeinflussen und wie das polnische System der Gesundheitsfürsorge aufgebaut ist. Deshalb werden im Folgenden die polnischen Referate auf Deutsch abgedruckt. Sie behandeln zunächst als Ausgangspunkte die verfassungsrechtlichen Vorgaben für die Gesundheitsversorgung, die allgemeinen Grundsätze der Gleichheit, der (sozialen) Gerechtigkeit und Solidarität sowie die in der Verfassung Polens verankerten sozialen Rechte. Vor diesem Hintergrund wird dann das polnische System der Gesundheitsfürsorge in einem Überblick dargestellt. 
Wir danken den Referenten dafür, dass Sie uns ihre überarbeiteten Manuskripte zur Verfügung gestellt haben, den Mitarbeiterinnen und Mitarbeitern des Max-Planck-Instituts für Sozialrecht und Sozialpolitik dafür, dass sie die Texte in eine lesbare Form gebracht haben, Herrn Julian Zinn für die Vorbereitung der Publikation und der Universität Krakau für die finanzielle Unterstützung.

Daniel Lach

Mai 2017

Ulrich Becker 
Inhalt

Über die Axiologie des Sozialrechts 11

Walerian Sanetra

Soziale Gerechtigkeit in der Verfassung der Republik Polen

Renata Babińska-Górecka/Herbert Szurgacz

Zur sozialen Solidarität in der Gesundheitsversicherung

Daniel Eryk Lach

Grundsatz des gleichen Zuganges zu den Leistungen der

Gesundheitsfürsorge

Daniel Eryk Lach

Grundriss des polnischen Systems der öffentlichen

Gesundheitsfürsorge

Daniel Eryk Lach 


\title{
Über die Axiologie des Sozialrechts
}

\author{
Walerian Sanetra
}

1. Wenn von Axiologie die Rede ist, meint man damit einerseits einen bestimmten Wissensbereich, gleichzeitig aber auch bestimmte Werte bzw. mehr oder minder geordnete Wertekomplexe oder gar Systeme von, zumindest im Ansatz, richtungsweisenden Rechtsgütern, insbesondere für den Gesetzgeber. ${ }^{1}$ Werte und Wertungen nehmen Bezug auf verschiedene Lebensbereiche, mitunter das besonders wichtige Rechtswesen. In unserer Rechtswissenschaft wurden jedoch die Probleme der Axiologie über Jahre hinweg nicht wahrgenommen. Mit der Zeit ändert sich die Lage jedoch, was vor allem der fortschreitenden Doktrin der Menschenrechte geschuldet ist und sich vorwiegend in der Hervorhebung der sog. axiologischen Dimension des Rechts manifestiert. Die Grundfragen der Rechtstheorie beziehen sich auf Themen wie: ,Was ist Recht?" (die ontologische Frage), „Wie lässt sich das Recht erschließen?“ (Gegenstand der Epistemologie) sowie „Welches Recht ist wertvoll?“ (Axiologie). An dieser Stelle lohnt ein Blick auf die folgenden fünf in der Literatur ${ }^{2}$ vorgeschlagenen Gruppen von grundlegenden Antworten: 1. Recht besteht aus Normen (einem Normsystem), stellt also eine bestimmte sprachliche Bezeichnung dar, 2. Recht stellt eine soziale Tatsache dar, 3. Recht gleicht einer geistigen Tatsache, also einer Erlebniswahrnehmung, 4. Recht ist ein Wert (oder die Wiederspiegelung eines Wertes) sowie 5. Recht bildet ein komplexes ontologisches Phänomen. Eng verbunden mit dieser Unterscheidung sind ferner die Ebenen des Rechts (Ebenen, auf denen sich das Recht betrachten lässt): 1. die logisch-sprachliche Ebene, 2. die soziologische Ebene, 3. die psychologische Ebene und 4. die axiologische Ebene (sowie 5. die ,Vielschichtigkeit", die regelmäßig von der Annahme ausgeht, dass ein Rechtsphänomen eine komplexe ontologische Struktur darstellt). ${ }^{3}$

1 Nach Ziembiński, Wstęp do aksjologii dla prawników, Warschau 1990, S. 58 f. wird ein „Wert" als die Bestimmung von Objekteigenschaften, als Unterscheidungsmerkmal für eine Objektklasse sowie als ein bestimmtes Gut verstanden.

2 Lang/Wróblewski/Zawadzki, Teoria państwa i prawa, Warschau 1986, S. 22 ff.

3 Lang/Wróblewski/Zawadzki (Fn. 2), S. 37 f. 
2. In unserer arbeitsrechtlichen Doktrin wurden Fragen zur Axiologie dieses Rechtsgebietes - im Hinblick auf naturalrechtliche Überlegungen erst von Zieliński in seiner 1988 erschienen Monographie aufgeworfen. ${ }^{4}$ Seiner Ansicht nach gehören zu den angeborenen Menschenrechten - gemäß dem von ihm postulierten objektivierten Verständnis dieses Begriffs - vor allem das Recht auf Arbeit (welches im Recht auf Leben im weiteren Sinne mit inbegriffen ist), die Freiheit der Arbeit sowie die Freiheit, sich in Organisationen zur Förderung des Lebens in der Gemeinschaft zusammenzuschließen, die Koalitionsfreiheit und das Recht auf Kollektivverhandlungen, das Recht auf Erholung sowie der Grundsatz der Beschränkung des Arbeitstags auf acht und der Arbeitswoche auf 46 Stunden. Dies zeigt, dass axiologische Fragen nicht lediglich der allgemeinen Rechtstheorie oder -philosophie angehören, sondern ebenso für die einzelnen Rechtszweige und -disziplinen von Bedeutung sind. Überdies sind Überlegungen zur axiologischen Rechtfertigung einzelner Rechtsinstitute oder konkreter Rechtsnormen oftmals unerlässlich und treten immer häufiger in Erscheinung. Aus verschiedenen Gründen verweist man in der Praxis bei der Begründung von konkreten Auslegungsvorgängen von Rechtsvorschriften immer häufiger nicht ausschließlich auf grammatikalisch-logische (formelle) oder praxeologische, sondern auch auf axiologische Gründe, insbesondere in Bezug auf Gerechtigkeitsverständnis oder -anspruch. Mehr oder minder bewusst wird dabei auf die Annahme abgestellt, dass neben den das gesamte Rechtswesen prägenden allgemeinen Werten auch solche bestünden, die den einzelnen Rechtszweigen und -disziplinen zu eigen sind bzw. dass die allgemeinen Werte im Rahmen der bestimmten Rechtszweige und -disziplinen einer Konkretisierung oder gewissen inhaltlichen Änderung bedürfen.

3. Wie erwähnt, löste insbesondere die Fortbildung der Menschenrechtsdoktrin Überlegungen zur Axiologie des Rechts, ihrer einzelnen Zweige, Institute und Normen aus, was vor allem die Tatsache widerspiegelt, dass diese Doktrin Einzug in konkrete Vorschriften des (universellen und regionalen) Völker- und Unionsrechts fand. Von entscheidender Bedeutung war, vom Gesichtspunkt unserer Rechtsdoktrin aus, der mit der Verfassung der Republik Polen von 1997 erreichte Ausbau der Regelungen in

4 Zieliński, Podstawy rozwoju prawa pracy, Warschau - Krakau 1988, S. 71 ff. 
Bezug auf Menschen- bzw. Bürgerfreiheiten, -rechte und -pflichten (Kapitel II, Art. 30 bis 86) in Anlehnung an völkerrechtlich (u.a. im UN- oder ILO-Recht) sowie europarechtlich allgemein anerkannte universelle Lösungen (insbesondere aus der EMRK, der Europäischen Sozialcharta sowie der EU-Grundrechtecharta). Nicht ohne Bedeutung ist dabei auch die Tatsache, dass der Begriff „Wert“ (oder „Werte“), der als Kernbegriff der Axiologie gilt und oftmals gar mit dieser gleichgesetzt wird, in den Wortlaut des geltenden Rechts aufgenommen worden ist.

Es kann von einer bestimmten Verrechtlichung der Axiologie und ihrer Grundkategorien gesprochen werden. Mit anderen Worten haben wir es hier mit einem Prozess der Übernahme von axiologischer, also einem Bereich der Philosophie und Ethik zugehöriger, Terminologie durch Rechtsvorschriften zu tun. In diesem Kontext lohnt sich ein erneuter Blick auf die von Wróblewski ${ }^{5}$ vorgeschlagene Einteilung von Werten. Er unterschied zwischen ,internen“ (für die Normen des geltenden Rechts immanenten) und „externen“ (außerhalb des Rechts liegenden) Werten, ,grundlegenden“ (nicht relativ bewerteten) und ,instrumentalen“ (instrumental relativierten) sowie - in Bezug auf die richterliche Rechtsanwendung „übertragene“ (interne, externe, grundlegende und instrumentale Werte des Rechts an sich, die Einzug in die Wertungen der Rechtsanwendung in gerichtlichen Entscheidungen gefunden haben, unter der Voraussetzung, dass diese Rechtsprechung rechtmäßig ist), „selbstständige“ (sie transponieren die im Recht vorgenommene Wertung nicht auf die Wertung der Rechtsanwendung) und die dazwischenliegenden „mittelbaren“ Werte. Nach seinem Verständnis kommt den „selbstständigen“ Werten der gerichtlichen Rechtsanwendung ein „operativer“ Charakter zu, sodass sie grundsätzlich - nicht dem Wortlaut der angewandten Rechtsnormen untergeordnet sind und in dem Sinne einen „formellen“ Charakter aufweisen, dass sie nicht davon abhängen, ob und wie man die angewandten Vorschriften wertet. $\mathrm{Zu}$ den „selbstständigen“ Werten rechnete er derweil auch die Übereinstimmung einer Entscheidung mit geltendem Recht in Gestalt der Werte Legalität und Rechtmäßigkeit, Sicherheit der gerichtlichen Rechtsanwendung mitsamt der einhergehenden Uniformität, Objektivität sowie praxeologische Werte der gerichtlichen Rechtsanwendung (insbesondere ihre Effektivität und Schnelligkeit). Gerechtigkeit und Billigkeit zählte er hingegen zur Kategorie der „mittelbaren“ Werte.

5 Wróblewski, Wartości a decyzja sądowa, Warschau 1973, S. 51-60. 
4. Werte werden in den Wortlaut geltender Gesetze aufgenommen, um eine fundamentale und bewertende Dimension zum Ausdruck zu bringen, stellen aber gleichzeitig Begrifflichkeiten dar. Deshalb drängt sich die Feststellung auf, dass eine grundlegende Bedeutung - insbesondere für Überlegungen im Rahmen der Rechtswissenschaft - in heutiger Zeit der Unterscheidung zwischen ,normativen“ (,innerlichen“) und ,außernormativen" (,äußerlichen") Werten zukommt. Wie bereits erwähnt, sind unter all den auf die eine oder andere Weise in Normen festgehaltenen Werten jene besonders gewichtig, die tatsächlich in den Wortlaut völkerrechtlicher (unionsrechtlicher) Vorschriften sowie unserer Verfassung aufgenommen worden sind. Der Begriff von Verfassungswerten wird in unserer Rechtsordnung in erster Linie mit den Vorschriften des II. Kapitels der polnischen Verfassung assoziiert („Freiheiten, Rechte und Pflichten des Menschen und des Staatsbürgers"), angefangen mit Art.30, aus dem hervorgeht, die Würde des Menschen ist ihm angeboren und unveräußerlich; sie bildet die Quelle der Freiheiten und Rechte des Menschen und des Staatsbürgers; sie ist unverletzlich, ihre Beachtung und ihr Schutz sind Verpflichtungen der öffentlichen Gewalt. Axiologische Fragen lassen sich auch nicht auf die Problematik von Menschen- bzw. Bürgerrechten und -freiheiten reduzieren. ${ }^{6}$ Die axiologischen Grundlagen des Rechtssystems werden nämlich auch von jenen fundamentalen verfassungsrechtlichen Grundsätzen ausgedrückt (definiert, normiert), die keinen Bezug auf die Problematik von Menschen- und Bürgerrechten nehmen. Das Problem besteht hier gleichermaßen in der Bestimmung, welche der verfassungsmäßigen Grundsätze als axiologisches Grundgerüst der Rechtsordnung anzusehen sind, und welchen diese Eigenschaft nicht zukommt. Ähnlich verhält es sich mit der völker- und europarechtlichen Dimension dieses Themenfeldes.

5. Auf der Ebene von einzelnen Rechtszweigen und Teilgebieten des Rechts finden spezielle axiologische Hintergründe zusätzlich auch in nor-

6 Vgl. z.B. Piechowiak, Dobro wspólne jako fundament porządku konstytucyjnego, Warschau 2012. Der Autor vertritt dabei die Auffassung, dass das Gemeinwohl (Art. 1 der Verfassung der Republik Polen) metaaxiologische Eigenschaften besitzt (S. 295 ff.), sodass es, auch im Verhältnis zur Menschenwürde als eigenständigen Wert, eine übergeordnete Stellung innehat (S. 358), was den Gemeinwohlgrundsatz zum verfassungsrechtlichen Grundsatz aller Grundsätze macht (S. 442). 
mativen Grundsätzen Ausdruck, ganz gleich ob diese deutlich in den betreffenden Vorschriften festgeschrieben oder erst durch Auslegung zu ermitteln sind. ${ }^{7} \mathrm{Zu}$ den axiologischen Grundlagen eines bestimmten Rechtszweigs oder Teilgebiets des Rechts gehören zudem auch Grundsätze im beschreibenden Sinne bzw. die Grundlagen - oftmals von unklarer rechtlicher Natur - auf denen diese Grundsätze aufbauen. Die Axiologie des Sozialrechts kann demzufolge nicht auf Werte wie Gerechtigkeit, Gleichheit, Solidarität oder sonstige der Bewertung des Rechts als Ganzem dienende Werte, wie etwa die Menschenwürde, Freiheit, Demokratie, Rechtmäßigkeit (Rechtsstaatlichkeit), Pluralismus oder Toleranz reduziert werden. Bei den Überlegungen zur Axiologie von einzelnen Rechtszweigen oder Rechtsgebieten (hier des Sozialrechts) scheint es demnach am bedeutendsten - einerseits - gewisse Unterschiede bei der Wahrnehmung von den die gesamte Rechtsordnung durchziehenden (und in diesem Sinne universellen) Werten, wie den eben genannten, zu verdeutlichen und - andererseits - die Werte aufzuzeigen, die ihnen eigen sind und die Rolle von rechtlichen Grundsätzen oder fundamentalen Leitideen für die dort angenommenen Lösungen einnehmen. Erweist sich die Axiologie eines bestimmten Rechtszweigs oder Rechtsgebiets (des Sozialrechts) als fehlerbehaftet, was auch davon abhängt, auf welchen Grundprinzipien und Grundsätzen diese beruhen, lässt sich daraus nur schwer schlussfolgern, das gesamte Recht beruhe auf diesem bestimmten Wert oder dessen Erscheinung.

Neben den erwähnten Unterscheidungen und Einteilungen sollte auch angemerkt werden, dass die Einführung eines bestimmten Begriffs (z.B. Gerechtigkeit, soziale Gerechtigkeit) in den Wortlaut einer Vorschrift nicht damit gleichbedeutend ist, dass dieser bestimmte Wert aufhört, ein externer Wert zu sein, weil z.B. die Art und Weise, wie Gerechtigkeit oder soziale Gerechtigkeit als Auslegungsresultat einer gewissen Vorschrift (etwa durch den Verfassungsgerichtshof) verstanden wird, nicht mit dem vom Naturrecht oder einer bestimmten politischen bzw. wirtschaftlichen Doktrin abgeleiteten Verständnis übereinstimmen muss. Anzumerken ist jedoch, dass nach einigen Ansichten der Zweck des Rechts in der Gewähr-

7 Ähnlich Ślebzak, Aksjologiczne podstawy prawa ubezpieczeń społecznych ze szczególnym uwzględnieniem solidarności i sprawiedliwości, in: Skapski/Ślebzak (Hrsg.), Aksjologiczne podstawy prawa pracy i ubezpieczeń społecznych, Posen 2014, S. 246, der die Auffassung vertritt, dass Werte als Leitgedanken des Sozialversicherungswesens, Grundsatzforderungen oder Normgrundsätze des Sozialversicherungsrechts verstanden werden können. 
leistung von Gerechtigkeit liegt (und nicht z.B. in der Anwendung unmittelbaren Zwangs - „der Staat als Knüppel“ - oder zum Schutz der Interessen der besitzhabenden Klassen), was zur Annahme veranlasst, Gerechtigkeit sei ein oberster Wert, während die anderen Werte - sofern sie überhaupt existieren - lediglich einen untergeordneten oder instrumentalen Charakter aufweisen, weil sie nur bis zu dem Grad bestehen, in dem sie der Gerechtigkeit dienen.

6. Wie vorstehend angemerkt und in Anlehnung an genauere Erörterungen $^{8}$, findet der Terminus „Wert“ („Werte“) immer öfter Einzug in den Wortlaut des geltenden Rechts. Dies bedeutet nicht, dass lediglich solche Werte als normativ anzusehen sind, die in einem Normtext bestimmt worden sind, sondern dass es zu einer präziseren Abgrenzung zwischen den Kategorien (Gütern), die als normative Werte zu bezeichnen sind und denen, die nicht unter diesen Begriff fallen, kommen muss. Allerdings führt ein solches Vorhaben - zumindest nach meiner Überzeugung - zu zusätzlichen Zweifeln und terminologischen Komplikationen. In der Präambel des EU-Vertrages findet sich die Feststellung, dass das Vertragswerk aus dem kulturellen, religiösen und humanistischen Erbe Europas schöpft, aus dem sich die unverletzlichen und unveräußerlichen Rechte des Menschen sowie Freiheit, Demokratie, Gleichheit und Rechtsstaatlichkeit als universelle Werte entwickelt haben. Das suggeriert eine Gegenüberstellung von Menschenrechten (als allgemeinen Werten) und Rechtsgütern wie Freiheit, Demokratie, Gleichheit und Rechtsstaatlichkeit. Andere Schlüsse ergeben sich jedoch aus der Analyse von Art. 2 EU-Vertrag, gemäß dem sich die Union auf den Werten Menschenwürde, Freiheit, Demokratie, Gleichheit, Rechtsstaatlichkeit und der Wahrung der Menschenrechte einschließlich der Rechte der Personen, die Minderheiten angehören, gründet. Diese Werte sind allen Mitgliedstaaten in einer Gesellschaft, die sich durch Pluralismus, Nichtdiskriminierung, Toleranz, Gerechtigkeit, Solidarität und durch die Gleichheit von Frauen und Männern auszeichnet, gemein. Obwohl eine reine Wortlautanalyse des Art. 2 EUV zu gegenteiligen Schlüssen verleitet, lässt sich - meines Erachtens - annehmen, dass der in dieser Vorschrift vorkommende Terminus „Werte“, neben Kategorien wie Menschenwürde, Freiheit, Demokratie, Gleichheit und Rechtsstaatlichkeit

8 Sanetra, Aksjologiczne podstawy prawa ubezpieczeń społecznych, in: Frieskel Przychodzaj (Hrsg.), Ubezpieczenia społeczne w procesie zmian. 80 lat Zakładu Ubezpieczeń społecznych, Warschau 2014, S. 29 ff. 
auch Rechtsgüter wie Pluralismus, Nichtdiskriminierung, Toleranz, Gerechtigkeit, Solidarität und die Gleichheit von Frauen und Männern umfasst.

7. Eine eigenständige Überlegung gebührt an dieser Stelle der Präambel der EU-Grundrechtecharta, in der festgeschrieben wurde, dass die Völker Europas entschlossen sind, auf der Grundlage gemeinsamer Werte eine friedliche Zukunft zu teilen, indem sie sich zu einer immer engeren Union verbinden. Die Union gründet sich auf die unteilbaren und universellen Werte der Würde des Menschen, der Freiheit, der Gleichheit und der Solidarität. Sie beruht auf den Grundsätzen der Demokratie und der Rechtsstaatlichkeit. Dies führt zur Konklusion, dass die Würde des Menschen, die Freiheit, Gleichheit und Solidarität nach dem Verständnis der Grundrechtecharta universelle (und unteilbare) Werte darstellen, während Demokratie und Rechtsstaat zwar sehr wohl gemeinschaftliche Werte bilden würden, ohne jedoch einen allgemeinen Charakter zu haben. Des Weiteren kann - obwohl dies nicht aus der sprachlichen Analyse der Vorschriften der Grundrechtecharta hervorgeht -angenommen werden, dass die dort festgehaltenen Rechte (sowie Freiheiten und Grundsätze) eine eigenständige Gruppe von spezielleren Werten darstellen. ${ }^{9}$

Gemäß Art. 34 (soziale Sicherheit und soziale Unterstützung) der EUGrundrechtecharta erkennt die Union nach Maßgabe des Unionsrechts und der einzelstaatlichen Rechtsvorschriften und Gepflogenheiten das Recht auf Zugang zu den Leistungen der sozialen Sicherheit und zu den sozialen Diensten, die in Fällen wie Mutterschaft, Krankheit, Arbeitsunfall, Pflegebedürftigkeit oder im Alter sowie bei Verlust des Arbeitsplatzes Schutz gewährleisten, an. Jede Person, die in der Union ihren rechtmäßigen Wohnsitz hat und ihren Aufenthalt rechtmäßig wechselt, hat Anspruch auf die Leistungen der sozialen Sicherheit, die sozialen Vergünstigungen und

9 Vgl. z.B. Wróbel (Hrsg.), Karta Praw Podstawowych w europejskim i krajowym porządku prawnym, Warschau 2009. Die angegebene Behauptung findet eine zusätzliche Begründung, wenn als Grundsatz angenommen wird, dass die Menschenwürde die Quelle von Menschen- und Bürgerrechten und -freiheiten (Art. 30 der Verfassung der Republik Polen) darstellt, was die Annahme rechtfertigen würde, dass sich aus dem allgemeinen (unteilbaren, angeborenen, unveräußerlichen) Wert Menschenwürde speziellere Werte herleiten lassen, die unter dem Begriff „Freiheiten und Rechte des Menschen und des Staatsbürgers“ (Art. 30 der Verfassung) bzw. den ,, EU-Grundrechten“ (,Rechte, Freiheiten, Grundsätze“ der Europäischen Union) zusammengefasst worden sind. 
Unterstützung für die Wohnung nach den genannten Vorschriften, um die soziale Ausgrenzung und die Armut zu bekämpfen und allen, die nicht über ausreichende Mittel verfügen, ein menschenwürdiges Dasein zu ermöglichen,.$^{10}$ Art. 34 der Grundrechtecharta drückt - gegenüber der Menschenwürde - den spezielleren Wert aus, der zu den normativen (inneren) Werten des Unionsrechts zählt. Man unterscheidet dabei zwischen sozialer Sicherheit und sozialer Unterstützung.

Ein ähnlich verfasstes Recht auf soziale Sicherung (,Alle Arbeitnehmer und ihre Angehörigen haben das Recht auf soziale Sicherheit") beinhaltet die Europäische Sozialcharta (Teil I Pkt. 12, Art. 12). In diesem Kontext sollte auch die Europäische Ordnung der Sozialen Sicherheit sowie die Konventionen der Internationalen Arbeitsorganisation über soziale Sicherheit und ihre verschiedenen Aspekte bedacht werden. ${ }^{11}$

8. Im analysierten Kontext ist weiterhin zu beachten, dass die Verfassung der Republik Polen - verständlicherweise - die von ihr in Schutz genommenen (bzw. benannten), zugelassenen oder gar zur Verwirklichung bestimmten Werte weder definiert noch aus ihnen einen Katalog bildet. Dies bedeutet freilich nicht, dass die Begriffe „Wert“ bzw. „Werte“ gar nicht erscheinen, wie die folgenden Fragmente aus ihrer Präambel zeigen: „,...] alle Staatsbürger der Republik, sowohl diejenigen, die an Gott als die Quelle der Wahrheit, Gerechtigkeit, des Guten und des Schönen glauben, als auch diejenigen, die diesen Glauben nicht teilen, sondern diese universellen Werte aus anderen Quellen ableiten“ (daraus geht hervor, dass Wahrheit, Gerechtigkeit, Güte und Schönheit universelle Werte bilden und dass diese als besonders wichtig erachtet werden, da sie schließlich Erwähnung in der Präambel der polnischen Verfassung fanden) sowie ,in Dankbarkeit für die Kultur, die im christlichen Erbe des Volkes und in allgemeinen menschlichen Werten verwurzelt ist" (was hingegen bedeutet,

10 Die Vorschrift des Art. 34 der Grundrechtecharta zählt zur Kategorie von Vorschriften, die gleichzeitig Elemente von Rechten und Pflichten vorweisen (auf der Grundlage der Terminologie der Grundrechtecharta). Vgl. Kamiński, Karta Praw Podstawowych jako połączenie praw i zasad - strukturalna wada czy szansa?, in: Wróbel (Hrsg.), Karta Praw Podstawowych w europejskim i krajowym porządku prawnym, Warschau 2009, S. 44.

11 Vgl. z.B. die Beiträge von Szurgacz, Europejska Konwencja o zabezpieczeniu społecznym, und Uściński, Prawo zabezpieczenia społecznego Rady Europy, in: Florek (Hrsg.), Europejskie prawo pracy i ubezpieczeń społecznych, Warschau 1996, S. 278 ff. und $313 \mathrm{ff}$. 
dass neben „universellen Werten“ auch „allgemeine menschliche Werte“ existieren).

Aus den in der Präambel der Verfassung der Republik Polen verwendeten Formulierungen sollte nicht der Schluss gezogen werden, dass sie als universelle Werte lediglich Wahrheit, Gerechtigkeit, Güte und Schönheit ansieht und einzig Güter mit universellem oder allgemeinmenschlichem Charakter Werte darstellen können. Die bloße Hervorhebung einer solchen Wertekategorie zum Schluss steht der Annahme nicht entgegen, dass es auch andere Werte, mitunter lediglich von regionaler (z.B. unionsweiter) oder gar staatlicher Dimension gibt.

Aus den obigen Überlegungen zu unionsrechtlichen Normen geht unzweideutig hervor, dass die Würde des Menschen in diesem Rechtsgebiet als besonders bedeutendes Rechtsgut anerkannt ist, weswegen die Annahme fernliegt, dass die Menschenwürde, von der in Art. 30 der Verfassung der Republik Polen die Rede ist, keinen (normativen, verfassungsrechtlichen) Wert innehat und dementsprechend auch die in ihr wurzelnden Menschen- und Bürgerfreiheiten und -rechte keine Werte darstellen würden. Bis zu einem gewissen Grad stellt dies auch ein Indiz für die These dar, dass neben den praktisch die gesamte Rechtsordnung durchdringenden Werten wie Gerechtigkeit, Freiheit, Gleichheit, Demokratie, Pluralismus, Nichtdiskriminierung, Toleranz, Solidarität usw. auch partikuläre Werte im Rahmen der einzelnen Rechtsgebiete zu verzeichnen sind, mitunter im Rahmen des Sozialrechts. Es besteht hier jedoch die Gefahr, dass wir nun alle in den Rechtsvorschriften (des Sozialrechts) hervorgehobenen und von ihnen geschützten Güter als Werte bezeichnen und Vorschriften, die diese Werte ausdrücken, als axiologische Grundlage betrachten, was kaum zu billigen wäre. Die Axiologie (des Sozialrechts) ist nämlich in $\mathrm{Zu}-$ sammenhang mit allgemeinen und grundlegenden Rechtsgütern und Wertungen (Pflichten) anstelle von rechtspositivistischen Lösungen zu betrachten. Gleichzeitig sind rechtliche Vorschriften (etwa des Verfassungsrechts oder Grundätze des Arbeitsrechts aus dem Arbeitsgesetzbuch), die an sich einen bestimmten Wert darstellen, von der axiologischen Rechtfertigung einzelner, konkreter Rechtsinstitute und -vorschriften zu unterscheiden.

Allgemein kann jedoch festgehalten werden, dass das Aufzeigen von als Werten wahrgenommenen Zwecken, Gütern, Eigenschaften, Erscheinungen und Wertungen in Rechtsvorschriften von zahlreichen Diskrepanzen und Zufällen sowie Widersprüchen und Folgewidrigkeiten beherrscht wird. Dementsprechend muss, aktuell wie künftig, mit einem gewissen 
$\mathrm{Maß}$ an Mehrdeutigkeit, Willkür und Subjektivität bei der Bestimmung der Axiologie des Rechts und seiner einzelnen Zweige und Gebiete, der Bestimmung der Reichweite von axiologischen Grundlagen und der axiologischen Begründung von Rechtsvorschriften gerechnet werden.

Unabhängig davon tragen die vorstehend dargestellten Umstände und Faktoren u.a. dazu bei, dass die Frage nach axiologischen Grundlagen im gesamten Rechtssystems sowie den einzelnen Rechtszweigen und -gebieten immer häufiger reges Interesse in der Rechtsliteratur weckt. Als Beispiel können hier die zahlreichen Beiträge aus dem Werk „Axiologische Grundlagen des Arbeits- und Sozialrechts" 12 genannt werden.

9. Wie bereits am Titel ersichtlich, betrifft der vorliegende Beitrag die Axiologie des Sozialrechts. In Anbetracht der Mannigfaltigkeit der Probleme und der Komplexität der erwogenen axiologischen Fragestellungen erscheint es verständlich, dass sich die nachfolgende Aufarbeitung lediglich auf ausgewählte Themen beschränkt, ohne die Gesamtheit dieser Problematik zu umfassen. Hinzuzufügen ist noch, dass bereits der Begriff des Sozialrechts nach wie vor umstritten und nur spärlich erforscht ist. Im weiteren Sinne umfasst er das Arbeitsrecht (als Ganzes oder lediglich einen Teil seiner Vorschriften), das Sozialversicherungsrecht i.e.S. (Sozial- und Krankenversicherung, soziale Sicherung), das Sozialhilferecht sowie die Vorschriften zur sozialen Unterstützung und zum Schadensersatz in Sozialangelegenheiten. ${ }^{13}$ Am weitestgehendsten wurde bislang die Axiologie des Arbeitsrechts erschlossen, was u.a. einer fortgeschrittenen, im Arbeitsgesetzbuch verankerten Normierung von arbeitsrechtlichen Grundprinzipien und den mit ihr einhergehenden Vorschriften der polnischen Verfassung geschuldet ist. ${ }^{14}$ Ein geringeres Interesse weckte bisher

12 Skapski/Ślebzak (Fn. 7), vgl. auch Sanetra (Fn. 8).

13 Vgl. jüngst zum Thema Sozialversicherung Szurgacz, Ewolucja urządzeń zabezpieczenia socjalnego w Polsce oraz ich prawne kwalifikacje (szkic rozwoju), in: Hajn/Skupień (Hrsg.), Przyszłość prawa pracy. Liber amicorum. W pięćdziesięciolecie pracy naukowej Profesora Michała Seweryńskiego, Lodz 2015, S. $721 \mathrm{ff}$.

14 In dieser Hinsicht vgl. vor allem folgende Beiträge von Sanetra, Ogólnie o aksjologicznych podstawach prawa pracy; Sobczyk, Prawo i człowiek pracujący - miedzy ochrona godności a równości; $L i s z c z$, W sprawie sprawiedliwości w prawie pracy; Mitrus, Godność jako podstawa aksjologiczna praw pracowniczych; Nowik, Aksjologia w prawie pracy; Pisarczyka, Wstęp do Konstytucji Rzeczypospolitej Polskiej - poszukując aksjologii w prawie pracy; Świątkowski/Wujczyk, Bezpiec- 
die Axiologie der Sozial- und Krankenversicherung, während Anmerkungen zur Axiologie sonstiger Vorschriften des Sozialversicherungs- bzw. des Sozialhilferechts geradezu eine Seltenheit darstellen. Im weiteren Verlauf widme ich meine Aufmerksamkeit lediglich ausgewählten axiologischen Problemen der sozialrechtlichen Teilgebiete Sozial- und Krankenversicherungsrecht.

Aus dem derzeitigen Meinungsstand geht hervor, dass interne axiologische Grundlagen des Sozialversicherungsrechts vor allem in unserer Verfassung, in europa- und völkerrechtlichen Vorschriften sowie in unserer nationalen Gesetzgebung zu verorten sind. Das axiologische Fundament des Sozialversicherungsrechts im Verfassungsrecht bildet Art. 67 der polnischen Verfassung. Er statuiert das Recht der Staatsbürger auf soziale Sicherung, was insbesondere bedeutet, dass die Vorschriften des Sozialversicherungsrechts die Ausgestaltung dieses Rechts sowie die Gewährleistung seiner faktischen Umsetzung und nicht etwa andere Zwecke verfolgen (wie etwa die Verwirklichung wirtschaftlicher Ziele, die Entwicklung der Wertpapierbörse oder das Erreichen von fiskalischen Zielsetzungen des Staates). Weil in diesem Fall von einem besonderen Wert (Recht) i. S. einer lex specialis ausgegangen wird, liegt die Annahme nahe, er gehe den ebenfalls in der Verfassung verankerten wirtschaftlichen oder fiskalischen Zielen vor. Dies bedeutet jedoch nicht, dass letztere Ziele bei der Ausgestaltung der Vorschriften im Sozialversicherungsrechts völlig außer Acht zu lassen sind. Die Pflicht zur Zahlung von Sozialversicherungsbeiträgen, die Ausgestaltung ihrer Erhebung und „Verwaltung“ sowie der Aufbau von Organisationsstrukturen zur Verwirklichung des staatlichen Versicherungsauftrags und die anwendbaren Verfahrensarten werden allesamt kaum als verfassungswidrig einzustufen sein. Die diesen Fragen gewidmeten Lösungen sind nämlich instrumental der Verwirklichung des in Art. 67 der Verfassung aufgestellten Rechts untergeordnet. Sie sollten danach bewertet werden, ob sie der Verwirklichung des grundlegenden Wertes, in dem Fall des Grundrechts auf soziale Sicherung im funktionalen Sinne (gut oder mangelhaft) dienen, also ob sie das verfassungsrechtliche Gebot des Schutzes der dort bestimmten Interessen von Bürgern im Falle der Be-

zeństwo prawne i socjalne pracowników jako uniwersalna aksjologiczna podstawa współczesnego prawa pracy i zabezpieczenia społecznego. Wybrane zagadnienia; sowie Walczak, Aksjologiczne podstawy wynagradzania zatrudnionych w gospodarce postindustrialnej - wybrane zagadnienia, in dem oben erwähnten Buch: Aksjologiczne podstawy prawa pracy i ubezpieczeń społecznych (Fn. 7). 
rufsunfähigkeit, des Eintritts des Rentenalters bzw. (unfreiwilliger) Arbeitslosigkeit hinreichend konkretisieren. In Anlehnung an den Wortlaut der Norm lässt sich durchaus vertreten, dass Schutzgegenstand - vorliegend Schutzgüter (geschützte Werte) - von Art. 67 der polnischen Verfassung die Arbeitsunfähigkeit, der Eintritt ins Rentenalter sowie die unfreiwillige Arbeitslosigkeit sind, auch wenn dies recht absonderlich klingen mag. Im Grunde genommen besteht der geschützte Wert (das Rechtsgut) jedoch in den besonderen Interessen (Bedürfnissen) des Bürgers, die aufgrund der Verwirklichung eines sozialen Risikos entstanden sind. Nach dieser Maßgabe stellt nicht etwa Art. 67 der polnischen Verfassung (bzw. alle in ihm enthaltenen Normen) oder das in seinem Wortlaut verbuchte Grundrecht den entsprechenden Wert (bzw. das Rechtsgut) dar, sondern das auf diese Weise definierte Interesse des schutzberechtigten Bürgers (an der Absicherung mittels Anwendung ,sozialer“ Methoden, deren Wesen aus den vorhergehenden Normen und der Praxis bekannt ist), über welches infolge der Rechtsetzung ein Schutzbereich gespannt worden ist. Aufgrund der Verwirklichung des sozialen Risikos entstehen auf Seiten des Bürgers neue (zusätzliche) Bedürfnisse, die, in Anlehnung an den im Vorfeld historisch gestalteten Begriff des sozialen Risikos und der sozialen Sicherung im institutionellen Sinne, befriedigt werden sollen. Unter diesem Gesichtspunkt bilden Werte (rechtlich) geschützte Rechtsgüter, obwohl regelmäßig bereits der Schutz selbst als Wert verstanden wird. Gleichsam lässt sich kaum leugnen, dass der Terminus „Wert“ - unter Berücksichtigung der immer stärker verbreiteten sprachlichen Bräuche ebenso gleichbedeutend mit der Gesamtheit einer bestimmten gesetzlichen Regelung (z.B. geht aus Art. 2 EU-Vertrag vor, dass die Rechtsstaatlichkeit per se einen eigenständigen Wert darstellt) oder auch dem in ihr festgeschriebenen subjektiven Grundrecht sein kann. Aus praktischen Gründen ist überdies die Annahme gerechtfertigt, dass der verfassungsrechtlich geschützte - und einen grundlegenden Bestandteil der Axiologie des Sozialversicherungsrechts bildende - Wert vielmehr in dem in Art. 67 der polnischen Verfassung vorgesehenen Recht auf soziale Sicherung oder gar in der bloßen Vorschrift an sich liegt. Obwohl es sich um eine verfassungsrechtliche Vorschrift handelt, kann und sollte sie dennoch zu den axiologischen Grundlagen des Sozialversicherungsrechts gezählt werden.

Mit der Einführung der Verfassung der Republik Polen wurde das Sozialversicherungssystem grundlegend reformiert, wobei die Einrichtung der sog. zweiten Säule der Sozialversicherung eine der wichtigsten eingeführten Neuheiten darstellt. Die Verfassung liefert meiner Ansicht nach keine 
axiologische Begründung dafür, dass die zweite Säule im Wesentlichen weniger eine Form der Sozialversicherung als vielmehr eine Variante der Privatversicherung darstellt. Dies hat zur Folge, dass sie nicht vom Recht auf soziale Sicherung i.S.v. Art. 67 der Verfassung erfasst werden kann, wobei es in der Verfassung auch andernorts an Regelungen (Werten) fehlt, die potentiell als Grundlage für die Einführung dieser Lösung fungieren könnten. ${ }^{15}$

10. Wie aufgezeigt, wird das Sozialversicherungsrecht von Werten durchzogen, die dem gesamten Rechtssystem (bzw. den Rechtssystemen) zu eigen sind. Nach Maßgabe des genauen Wortlauts der polnischen Verfassung (ihrer Präambel) sowie des EU-Vertrags (Art. 2) und der EU-Grundrechtecharta (ihrer Präambel) handelt es sich um die Werte, welche die allgemeinen axiologischen Grundlagen des Rechtssystems (der Rechtssysteme) bilden, nämlich um Werte wie Gerechtigkeit, Menschenwürde, Freiheit, Demokratie, Gleichheit, Rechtsstaatlichkeit, Menschenrechte sowie Pluralismus, Nichtdiskriminierung, Toleranz, Solidarität und Gleichberechtigung von Frauen und Männern. Diese Werte durchdringen auch die einzelnen Rechtszweige (-gebiete) und werden in diesen verwirklicht, mitunter mittels Regelungen aus dem Sozialversicherungsrecht.

Auf der Grundlage dieses Rechts werden die genannten Werte konkretisiert, verifiziert und verändert. Gelegentlich erweist sich etwas, das als allgemeiner Wert für das Rechtssystem durchaus annehmbar erscheint, als impraktikabel mit Blick auf einen konkreten Rechtszweig. Das System der Sozialversicherungen als komplexer Rechtsmechanismus basiert beispielsweise auf dem Prinzip der Zwangsversicherung anstelle der allgemeinen Handlungsfreiheit (Freiwilligkeit). Ähnlich verhält es sich mit der Krankenversicherung. Für die Verwirklichung von Werten wie Gerechtigkeit und Solidarität im Sozialversicherungswesen ist ein Ausschluss, oder prä-

15 Eine breitere axiologische Begründung für diese Auffassung vorgestellt in: Sanetra, in: Aksjologiczne podstawy prawa ubezpieczeń społecznych (Fn 14), S. 33 f.; nach Pacuda, Wartości ekonomiczne jako podstawy aksjologiczne prawa ubezpieczeń społecznych, w: Aksjologiczne podstawy prawa pracy i ubezpieczeń społecznych, Posen 2014, S. 67, da aus Art. 67 der Verfassung der Republik Polen ein Optimierungsgebot bei der Schaffung von sozialversicherungsrechtlichen Normen hervorgeht, weswegen im Falle von ,diesen Geboten” nicht nur verfassungsimmanente, sondern auch äußerliche ökonomische Werte berücksichtigt werden sollten. 
ziser, eine wesentliche Einschränkung der Handlungsfreiheit von Versicherten und Versicherern notwendig.

Bemerkenswert erscheint hierbei, dass eine Wortlautanalyse der entsprechenden Formulierungen im zweiten Titel der EU-Grundrechtecharta zu dem Schluss führt, dass Freiheit in einem „Recht“ (dem „Recht auf Freiheit“) oder einem „Schutz" bestehen kann, was zur Folge hat, dass eine die Auslegung des geltenden Rechts behindernde, schwer zu überkommende terminologische Nachsichtigkeit und eine gewisse Unordnung herrschen, da man den Begriff „Freiheit“ im rechtlichen Diskurs nahezu frei durch die Worte „Recht“ und „Schutz“ „ersetzen“ bzw. den Begriff „Freiheit" verwenden kann, wenn man eine Aussage über ein Recht oder einen Schutz treffen will. Dieser Zustand erschwert bedeutend eine präzise Analyse und konsequente Anwendung des Wortlauts in der besagten Problematik, obgleich der Anspruch an eine möglichst weitgehende Genauigkeit bei der Verwendung von Begriffen schon allein deswegen notwendig erscheint, weil wir es mit geltenden Rechtstexten von fundamentaler Bedeutung zu tun haben.

„Freiheiten“ als Werte in der Regelungssphäre des Sozial- und Krankenversicherungsrechts sind keineswegs einzig mit der Sphäre des Privatlebens (der Privatfreiheit) des Einzelnen zu assoziieren, da sie auch den wirtschaftlichen, sozialen und politischen Lebensbereich betreffen. Dies hat zur Folge, dass jegliche Zwänge, versichert zu sein (Zwangsversicherungen), einer derart begriffenen „Freiheit“ widersprechen oder aber diese zumindest grundlegend einschränken.

11. Ähnlich verhält es sich bis zu einem gewissen Grad mit dem Wert „Demokratie“, der im Sozialversicherungswesen vor allem in Form von Selbstverwaltungen auf Seiten der Versicherten und Versicherer realisiert werden kann und sollte. Von der Einrichtung derartiger Selbstverwaltungsstrukturen wurde jedoch in unserem Sozialversicherungswesen abgesehen, was - meines Erachtens - eine kritische Einschätzung rechtfertigt. Der derzeitige Stand unserer Rechtsordnung gibt keinen Anlass zur Annahme, der Demokratiegrundsatz werde im Sozialversicherungswesen tatsächlich erfüllt. Daraus lässt sich schließen, dass der Wert „Demokratie“ im Grunde genommen keine axiologische Grundlage für unser Sozialversicherungsrecht darstellt und insbesondere nicht den in unserem System angewandten Lösungen zugrunde liegt. Diese Feststellung gilt auch für das Krankenversicherungsrecht. 
Vor diesem Hintergrund wäre eine Anführung des von Art. 2 EUV statuierten Pluralismusgrundsatzes, der - so mein Empfinden - auf Sozialund Krankenversicherungen ebenso wenig Anwendung findet, wünschenswert. Unser Sozialversicherungswesen ist vor allem von einem Organisationsmonopolismus gekennzeichnet, was die Monopolstellung der polnischen staatlichen Versicherungsanstalten ZUS und KRUS (letztere für die Versicherung von Landwirten - Anm. d. Übers.) belegt. ${ }^{16}$ Diese These wird nicht schon dadurch widerlegt, dass auch offene Rentenfonds (der Altersversicherung) und die Beitragszahler selbst den öffentlichen Sozialversicherungsauftrag wahrnehmen. Mit einem Organisationsmonopol haben wir es ebenfalls - insbesondere nach Auflösung der Krankenkassen im Falle des Krankenversicherungswesens zu tun. Obwohl die gesundheitsfördernden Leistungen verschiedener Dienstleister erbracht werden, ist es dennoch der Nationale Gesundheitsfonds (Narodowy Fundusz Zdrowia), der als Monopolist über die dafür zur Verfügung stehenden, aus Beiträgen finanzierten, Mittel verfügt.

Sofern die Einschränkung der Idee der Handlungsfreiheit in Bezug auf Sozial- und Krankenversicherungen gerechtfertigt und verständlich erscheint, weckt der Verzicht auf Allgemeinwerte wie Demokratie (Selbstverwaltung der Versicherten) und Pluralismus durch das Ausschalten jeglicher Einflussnahme auf die Gestaltung und Anwendung von Lösungen von Seiten der von ihnen betroffenen Versicherten sowie die Einrichtung monopolistischer Organisationsstrukturen sehr wohl Zweifel.

12. Solidarität stellt einen der grundlegenden vom Sozial- und Krankenversicherungswesen (bzw. -recht) gewährleisteten (und dessen axiologische Grundlage bildenden) Wert dar. Sie wird überdies als eigenständiger Wert in der Präambel der EU-Grundrechtecharta, aber auch in Art. 2 EUV anerkannt. Von Solidarität ist auch in der Präambel sowie in Art. 20 unserer Verfassung die Rede, obwohl die Bezeichnung „Wert“ in diesem Kontext keine Verwendung findet.

Im Rahmen des Titels IV der EU-Grundrechtecharta - „Solidarität“ finden sich Regelungen über folgende Rechte: Recht der Arbeitnehmer auf Unterrichtung und Anhörung im Unternehmen, Recht auf Kollektivverhandlungen und Kollektivmaßnahmen, Recht auf Zugang zu Arbeitsver-

16 Eine detailliertere Darstellung der Problematik von Freiheit, Demokratie und Pluralismus in der Sozialversicherung findet sich in: Sanetra, Aksjologiczne podstawy prawa ubezpieczeń społecznych (Fn 14), S. 34 ff. 
mittlungsdiensten, Schutz bei ungerechtfertigter Entlassung, gerechte und angemessene Arbeitsbedingungen, Verbot der Kinderarbeit und Schutz der Jugendlichen am Arbeitsplatz, Familien- und Berufsleben, Soziale Sicherheit und soziale Unterstützung, Gesundheitsschutz, Zugang zu Dienstleistungen von allgemeinem wirtschaftlichen Interesse, Umweltschutz und Verbraucherschutz. Bei derartiger Betrachtung stellt das Recht auf soziale Sicherung (Sozialversicherung) sowie auf Schutz der Gesundheit eine Konkretisierung bzw. eine Erscheinungsform des Wertes „Solidarität“ dar.

Nach unserem Verfassungsverständnis hingegen bildet das Recht auf soziale Sicherung einen allgemeinen, für das Sozialversicherungsrecht richtungsweisenden und auf dessen Vorschriften einflussnehmenden Wert, der gleichzeitig das Verständnis und die Ausgestaltung des Solidaritätsprinzips (als Wert) im Sozialversicherungswesen prägt. Mit anderen Worten: Um soziale Sicherung (im funktionellen Sinn) zu gewährleisten, ist eine Ausgestaltung des Sozialversicherungsrechts unter Anwendung des Solidaritätsprinzips im besonderen Sinne notwendig. Das Sozialversicherungsrecht verliert ohne Solidarität - im engeren Sinn - seine „soziale“ Eigenschaft und seinen Zweck. Ähnlich verhält es sich mit dem Recht auf Gesundheitsschutz, insbesondere mit dem staatlichen Auftrag der Gewährleistung eines gleichen, einkommensunabhängigen Zugangs zu Leistungen im staatlich getragenen Gesundheitswesen (Art. 68 Abs. 2 Verfassung der Republik Polen).

Gemeint ist in diesem Fall weder die allgemeinmenschliche Solidarität noch die rechtstechnische Bedeutung dieses Begriffs (Solidarschuld i.S.e. Gesamtschuld - Art. 366 poln. Zivilgesetzbuch, Gesamtgläubigerschaft Art. 367 poln. Zivilgesetzbuch) noch Solidarität als Folge eines gemeinsam nach privatrechtlichen Grundsätzen aufgenommenen Risikos, wie dies z.B. bei Vermögens- oder Personenversicherungen der Fall ist. Im Sozial- und Krankenversicherungswesen genießen die wirtschaftlich schlechter Gestellten einen vergleichbar besseren Schutz als wohlhabendere Personen. Bis zu einem bestimmten Grad dient der Solidaritätsgrundsatz im Sozialversicherungswesen auch dem Ausgleich von Einkommensunterschieden und sozialen Diskrepanzen zwischen Versicherten. Aus diesem Grund führte die unmittelbare Verknüpfung der Rentenhöhe mit der Gesamthöhe der vom Versicherten eingezahlten Beiträge (der Umstieg vom System der definierten Leistung zu einem System des definierten Beitrags) dazu, dass das reformierte System der Altersvorsorge, vom analysierten Gesichtspunkt betrachtet, weniger „solidarisch“ geworden ist. Trotzdem ist die Behauptung kaum vertretbar, dass dadurch der Solidaritätsgrund- 
satz - vom axiologischen Standpunkt aus eine bezeichnende Solleigenschaft des Sozialversicherungssystems - verworfen worden ist. Zweifelsfrei wurde diese „Solidarität“ größtenteils geschwächt, obwohl man sich vor Augen halten sollte, dass Art. 67 der polnischen Verfassung ein Recht auf „soziale Sicherung“ verbürgt, welches grundsätzlich schon auf der Idee des Ausgleichs gesellschaftlicher Unterschiede beruht und dessen Schutzrichtung vor allem auf die sozial schwächsten Gruppen und Personen gerichtet ist. Das Sozialversicherungswesen darf demnach nicht derart ausgestaltet werden, dass der Anspruch des Bürgers auf Absicherung im Falle des Eintritts von Arbeitsunfähigkeit oder Ruhestand praktisch gänzlich ausgehöhlt wird. Das wäre eine Pervertierung des Solidaritätsgedankens (-wertes), der im Recht der sozialen Absicherung bzw. dem Sozialversicherungsrecht als dessen Teilgebiet gelten sollte. ${ }^{17}$

Bezeichnend erscheint die Tatsache, dass sich der Grundsatz der Gleichbehandlung aller Versicherten im polnischen Sozialversicherungsgesetz vom 13. Oktober $1998^{18}$ widerfand, während der Gesetzgeber auf eine Bezugnahme auf den Solidaritätsgrundsatz gänzlich verzichtete. ${ }^{19}$ Dies ist - so meine Überzeugung - nicht dem Zufall geschuldet, da der

17 Das Thema der Solidarität im Sozialversicherungswesen vertiefend: Sanetra Aksjologiczne podstawy prawa ubezpieczeń społecznych (Fn 14), S. 36 f. Eine genauere Aufarbeitung liefert Ślebzak in seinem Beitrag Zasada solidarności w ubezpieczeniu społecznym, in: Kubot/Kuczyński (Hrsg.), Z zagadnień prawa pracy i prawa socjalnego. Księga jubileuszowa Profesora Herberta Szurgacza, Warschau 2011, S. 538 ff.; ebendieser (Fn. 7), S. 250-257. Jończyk, Prawo zabezpieczenia społecznego, Kraków 2001, S. 38, vertritt hierbei die Auffassung, dass „das Problem der Solidarität Pflichten, Lasten, individuelle Beiträge, gemeinsame Anstrengungen, und nicht etwa die Aufteilung von Geldwerten oder Sachleistungen betrifft“, „im Kontext der Leistungsaufteilung hingegen vielmehr von Gerechtigkeit als von Solidarität die Rede sei“. Diese Auffassung akzeptiert und entwickelt Lach im sozialversicherungsrechtlichen Kontext fort in: O solidarności społecznej w „ubezpieczeniu zdrowotnym“, in: Skapski/Ślebzak (Hrsg.), Aksjologiczne podstawy prawa pracy i ubezpieczeń społecznych, Posen 2014, S. $282 \mathrm{ff}$.

18 Einheitstext: Dz. U. z 2009 r. Nr 205, poz. 1585 ze zm.

19 Obwohl bedacht werden muss, dass es sich bei den Krankenversicherungen anders verhält. Gem. Art. 4 des Gesetzes über die allgemeine Versicherung im Nationalen Gesundheitsfonds vom 23. Januar 2003 (Dz. U. nr 45, poz. 391 ze zm.) basierten Krankenversicherungen auf den Grundsätzen der Gleichbehandlung und der sozialen Solidarität. Auch Art. 1a des Gesetzes über die allgemeine Krankenversicherung vom 6. Februar 1997 (Dz. U. nr 28, poz. 153 ze zm.) berief sich auf den Grundsatz der sozialen Solidarität. Im aktuellen Gesetz über krankenversicherungsrechtliche Leistungen in öffentlicher Trägerschaft vom 27. August 2004 
Gesetzgeber, angesichts der strikten Bindung der Rentenhöhe an die Gesamthöhe der eingezahlten Beiträge und der zusätzlichen Einführung einer Teilversicherung der Altersvorsoge, was dem System privater Versicherungsverhältnisse stark ähnelt (der zweiten Säule der Altersvorsoge), an einer klaren Erklärung, dass das Solidaritätsprinzip dem Sozialversicherungssystem zugrunde liegen soll, gehindert ist.

13. Begriff und Reichweite der sozialversicherungsrechtlichen Axiologie kann und sollte man nicht allein mit universellen oder auf der Grundlage der europäischen Rechtsordnung allgemein angenommenen Werten verknüpfen, sondern vielmehr mit spezielleren An- und Grundsätzen, auf denen dieses Recht beruht. Als Ausfluss seiner axiologischen Grundlagen können - meiner Ansicht nach - beispielsweise die eben angeführten Grundsätze der Sozialrechtsreform angesehen werden, wie etwa: die „Systematik" von Sozialversicherungen, ihre Komplexität, ihr allgemeiner Charakter, der beschränkte Kreis von Rechtsträgern bei Sozialversicherungen, deren Zwangscharakter oder die Verknüpfung der Rentenhöhe mit der Einzahlung von Beiträgen. ${ }^{20}$ Zumeist haben wir es mit technisch-legislativen Grundprämissen (Grundsätzen) zu tun, weswegen man auch von eigenständigen Gruppen von technisch-legislativen Werten des Sozialversicherungsrechts sprechen kann. Auch hier sieht die Lage bei Krankenversicherungen ähnlich aus.

Angesichts des für Sozialversicherungen äußerst relevanten Schutzbedürfnisses in Bezug auf erworbene bzw. in Erwerbsanwartschaft stehende Rechte, sollte der Problematik von Gesetzesänderungen, vornehmlich im Hinblick auf Rentenvorschriften, und den dabei verfolgten Werten besondere Aufmerksamkeit gewidmet werden. In Rede stehen spezielle Werte für Gesetzesänderungen. Vom Verfassungsgerichthof häufig aus dem verfassungsrechtlichen Rechtsstaatsprinzip hergeleitet, finden diese Werte ihren Ausdruck u.a. in Grundsätzen wie dem Schutz rechtmäßig erworbener Rechtspositionen, dem Rückwirkungsverbot, dem Gebot der Einhaltung einer angemessenen Übergangszeit, dem Vertrauensgrundsatz gegenüber dem Staat und dem von ihm gesetzten Recht oder dem Recht auf eine

(einheitliche Fassung: Dz. U. z 2008 r. Nr 164, poz. 1027 ze zm.) wurde der Grundsatz der sozialen Gerechtigkeit in Art. 65 verschoben.

20 Sanetra, Założenia reformy ubezpieczeń społecznych, in: Wagner/Malaka (Hrsg.), Ewolucja ubezpieczeń społecznych w okresie transformacji ustrojowej, Bromberg 2011, S. 9 ff. 
zuverlässige Gesetzgebung. Die genannten Werte können dabei grundsätzlich mitunter als Werte technisch-legislativer Natur eingeordnet werden. Wie erwähnt, kommt ihnen in Bezug auf Sozialversicherungen ein besonderes Gewicht $\mathrm{zu}$ - weswegen sie gelegentlich vom polnischen Verfassungsgerichtshof als ein auf besondere Weise erfasster Maßstab angewandt werden - wovon u.a. die hohe Zahl von verfassungsrechtlichen Entscheidungen unter Berufung auf diese Werte (Grundsätze) zeugen. ${ }^{21}$

14. Von den jüngsten Tagen der Zivilisation an wurden das menschliche Leben und die Gesundheit als wichtigste Werte angesehen und in den Schutzbereich von rechtlichen Normierungen aufgenommen. Beispielhaft hierfür können der Grundsatz „Auge um Auge“ und das biblische Gebot „Du sollst nicht töten“ herangezogen werden. Einerseits handelt es sich hierbei an sich um elementare Werte, anderseits stellen auch die dafür geschaffenen Schutzvorschriften solche dar. Anfangs war der rechtlich verbürgte Schutz von Leben und Gesundheit vor allem gegen Handlungen anderer Menschen gerichtet, während mit der Zeit vor allem Vorschriften zum Schutz dieser Werte vor Krankheiten geschaffen worden sind. Im 19. und 20. Jahrhundert wurde der Schutz von Leben und Gesundheit dementsprechend zum vorherrschenden Gegenstand von sozialversicherungsrechtlichen Vorschriften. Dies war die Ausgangslage für Polen in der Zwischen- sowie der unmittelbaren Nachkriegszeit, bis zu dem Moment der Einrichtung eines öffentlichen Gesundheitsdienstes in der Volksrepublik Polen und der damit einhergehenden Einstellung der Finanzierung des Gesundheitswesens aus Versicherungsbeiträgen. Auch Krankenversicherungen (in Form von nichtgeldwerten Sachleistungen) beruhten als Teil des Systems sozialer Sicherung - verständlicherweise - auf denselben Grundlagen wie das gesamte ihnen übergeordnete System. Mitunter hatte dies auch zur Folge, dass Krankenversicherungen (die nichtgeldwerte Sachleistungen im Krankheitsfall umfassten) und das sonstige Sozialversicherungswesen gemeinsame axiologische Grundlagen teilten.

Im Zuge der Sozialversicherungsreform 1997-98 entschied sich der Gesetzgeber gegen eine Rückkehr zu den bereits seit 1933 unter dem Zusammenführungsgesetz geltenden Lösungen. Demzufolge wurde neben dem Gesetz über das Sozialversicherungssystem von 1998, welches in den ein-

21 Vgl. Babińska-Górecka, Skutki orzeczeń Trybunału Konstytucyjnego w dziedzinie ubezpieczenia społecznego, Warschau 2014. 
zelnen Versicherungsgesetzen weiter konkretisiert worden ist, auch das Krankenversicherungsgesetz von 1997 eingeführt. Dies geschah aus unterschiedlichen Gründen. Einer davon war die Tatsache, dass die Verfassung der Republik Polen das Recht auf soziale Sicherung (Art. 67) und das Recht eines jeden Einzelnen auf Schutz der Gesundheit, und in dessen Rahmen den staatlichen Auftrag der Gewährleistung eines aus öffentlichen Mitteln finanzierten allgemeinen, freien Zugangs (Art. 68 Abs. 1 und 2) als unterschiedliche Regelungsmaterien behandelt. Der letzte der beiden genannten Artikel betont das Gleichheitsgebot beim Zugang zu Leistungen des Gesundheitswesens. Das bedeutet, dass jeder Träger dieses allgemeinen Rechts unabhängig von der Höhe der von ihm getragenen öffentlichen Lasten (Beiträge) die aus diesem Recht folgenden Ansprüche geltend machen kann, während Art. 67 der Verfassung gerade kein entsprechendes Gleichheitsgebot bei der Geltendmachung von sozialversicherungsrechtlichen Ansprüchen vorsieht. Dies verdeutlicht den grundsätzlich unterschiedlichen Ansatz des im Zuge der Reform von 1998 neugestalteten Sozial- und Krankenversicherungsrechts in Bezug auf Gleichheit (Zahlengleichheit, verhältnismäßige Gleichheit) und damit auch auf Solidarität. Das ins Leben gerufene Krankenversicherungssystem enthält Elemente von verschiedenartigen rechtlichen Charakteren, bei deren Gestaltung auf mannigfache Rechtskonstruktionen und Techniken (Formen, Methoden) zurückgegriffen wurde. Es umfasst typische Elemente sowohl des Sozialversicherungsrechts (Beitragszahlungen, die jedoch mit der Zeit einer öffentlichen Abgabe immer ähnlicher wurden, Kontrahierungszwang) als auch des öffentlichen Rechts (Verwaltungsrecht - Aufbau des Gesundheitsfonds, die Rechtsnatur von Patientenrechten, der Verwaltungsrechtsweg) sowie des Privatrechts (das Eingehen von Verträgen mit sog. Dienstleistern im Gesundheitswesen). Ähnliche Elemente finden sich auch im Sozialversicherungsrecht, sie sind dort jedoch auf eine gänzlich andere Art ausgestaltet und verknüpft. Daher fällt auch die Annahme schwer, das Sozial- und das Krankenversicherungsrecht schützten die ihnen zugeordneten Werte auf die gleiche Weise, mitunter, dass sie das gleiche Verständnis von Gerechtigkeit und Solidarität von Versicherungen haben oder dass sie denselben axiologischen Grundsätzen folgen würden.

15. Die allgemeinen axiologischen Prämissen des Krankenversicherungsrechts sind in der polnischen Verfassung (allen voran in Art. 68 Abs. 2) verankert. Sie treten des Weiteren in den Grundsatzregelungen des Gesetzes über krankenversicherungsrechtliche Leistungen in öffentlicher Trä- 
gerschaft vom 27. August 2004 in den folgenden beiden Grundsätzen in Erscheinung: 1. der Gleichbehandlung und der sozialen Solidarität und 2. der Gewährleistung des freien Zugangs zu Gesundheitsleistungen und der freien Wahl des Dienstleisters (Art. 65). Gleichartig wurden die Grundsätze der Gleichbehandlung aller Bürger und der sozialen Solidarität sowie der Gewährleistung des freien Zugangs zu Gesundheitsleistungen und der freien Wahl des Dienstleisters durch die Versicherten ins Gesetz über die allgemeine Versicherung im Nationalen Gesundheitsfonds vom 23. Januar 2003 (Art.4) aufgenommen. Einen wesentlich breiteren Katalog von Grundsätzen, die durchaus als axiologischer Unterbau des Gesundheitsversicherungsrechts verstanden werden können und sollten, enthält das Gesetz über die allgemeine Krankenversicherung vom 6. Februar 1997. Dessen Art. 1a statuiert, die besagte Versicherung basiere zuvörderst auf den folgenden Grundsätzen: 1. Soziale Solidarität, 2. Selbstverwaltung, 3. Selbstfinanzierung, 4. Freie Wahl des Dienstleisters und der Krankenkasse, 5. Gewährleistung eines gleichen Zugangs zu Dienstleistungen, 6. Nicht auf Gewinn bedachte Tätigkeit der Kassen, 7. Wirtschaftlichkeit und Zweckmäßigkeit der Kassentätigkeit, 8. Staatliche Gewährleistung. Hinzu kommen Grundsätze wie der Kontrahierungszwang (Zwangsversicherung, Rechtsautomatismus), die Beitragspflicht und der durch die Existenz der Krankenkassen verwirklichte Organisationspluralismus. Mit der Zeit wurde im Zuge von Gesetzesänderungen von Werten wie Pluralismus und demokratischen Verhältnissen (Selbstverwaltung ${ }^{22}$ ) unter den Versicherten abgesehen. Gewiss zeugt dies davon, dass einzelne Rechtszweige bzw. -gebiete nicht nur eigene Werte oder Werte, die trotz ihrer Ableitung von allgemeineren Werten dennoch eine selbstständige Modifizierung darstellen oder gar inhaltliche Änderungen vorweisen, aufrechterhalten, sondern auch davon, dass der Gehalt dieser Werte sowie ihr Katalog im Ergebnis von Rechtsänderungen (Reformen) recht häufig verändert werden kann und auch tatsächlich verändert wird. Dies erscheint auch kaum verwunderlich, wenn man bedenkt, dass sich im Recht nicht nur interne, sondern sehr wohl auch externe Werte wandeln können, wovon schon die Existenz des Naturrechtskonzepts mit seinem wechselhaften Inhalt zeugt.

16. Zum Schluss sollte einmal mehr betont werden, dass die vorgehenden Überlegungen keinen Anspruch auf eine vollständige Ausschöpfung des

22 Vgl. Jończyk, Prawo zabezpieczenia społecznego, Krakau 2006, S. 247. 
Themas erheben und vielmehr eine lose Ansammlung von allgemeinen Reflexionen darstellen. Geschuldet ist dies einerseits der Breite und Komplexität der damit verbundenen Problemfelder. Andererseits kann aufgrund der Eigenständigkeit der das Recht der sozialen Sicherung bzw. das Sozialrecht bildenden Ansätze, Institutionen und rechtlichen Konstruktionen bezüglich dieser Rechte nur bedingt von einem axiologischen Grundgerüst gesprochen werden. Das allgemeine Ziel der sozialen „Bedürfnissicherung" stellt keine hinreichende Grundlage dar, um von einem kohärenten Wertesystem und -katalog in der Fülle der verschiedenen Regelungen des Sozialrechts (des Rechts der sozialen Sicherung) oder auch von einem außerrechtlichen Wertekomplex, der eine in sich geschlossene Bewertung dieser einzelnen Regelungswerke erlauben würde, ausgehen zu können. 
Soziale Gerechtigkeit in der Verfassung der Republik Polen

\author{
Renata Babińska-Górecka/Herbert Szurgacz
}

\title{
I. Gerechtigkeit und soziale Gerechtigkeit
}

\section{Ausgangspunkte}

Um Gerechtigkeit werden Kriege geführt, im Namen einer wie auch immer gearteten Gerechtigkeit entflammen Revolutionen, Menschen werden verurteilt, den Einen werden ihre Güter genommen, um sie den Anderen zu geben, man gewährt Privilegien und erkennt sie ab. Menschen sehen sich bereit, vieles zu ertragen, solange ihre Last eine gerechte bleibt, und sie fühlen sich wiederum verletzt, obwohl es ihnen gar nicht schlecht geht, wenn es die Anderen ungerechterweise besser haben ${ }^{1}$. Allgemein gilt, dass Gerechtigkeit sozial relevante Situationen betrifft und man sich überall dort auf sie beruft, wo Konflikte entstehen: beim Nehmen und Geben, bei Ansprüchen und Absagen, bei der Verteilung und Umverteilung von Gütern und Pflichten. Trotz einer enormen Zahl mannigfaltiger Gerechtigkeitstheorien ist dieser Begriff noch immer nicht eindeutig bestimmt worden. Im rechts- bzw. politikwissenschaftlichen Kontext jedenfalls wird der "Gerechtigkeit" ein normativer und kein axiologischer Wert zugeschrieben. Höffe stellt dazu fest: „Wohlwollen, Mitleid und Solidarität sind jedoch weder überflüssige Einstellungen noch Haltungen, die aus Gerechtigkeitsgründen geboten sind. Während wir um das wohlwollende, solidarische oder großzügige Handeln eines anderen bitten oder darauf hoffen können, ist die gerechte Praxis etwas, das man verlangt. Die Anerkennung der Gerechtigkeit betrachten wir nicht als einen Gnadenakt, um den wir die Mitmenschen oder die »Obrigkeit« bitten und die sie uns aus Sympathie oder Mitleid gewähren. Die Verwirklichung von Gerechtigkeit wird

1 Perelman, O sprawiedliwości, Warschau 1959, S. 21, zit. nach: Ziembiński, O pojmowaniu sprawiedliwości, Lublin 1992, S. 15. 
gefordert; angesichts von Ungerechtigkeit wendet man sich nicht enttäuscht ab, sondern ist entrüstet, empört und erhebt Protest.“2

Die einzelnen Gerechtigkeitskonzepte erweisen sich jedoch als sehr vielfältig. Was sie voneinander unterscheidet, sind vor allem die zur ihren Prämissen zählenden sog. Gerechtigkeitsformeln, d.h. Kriterien, nach denen man gewisse Rechtsträger gleichbehandelt, weil sie eine gewisse Eigenschaft gemein haben, die aus dem Blickwinkel des jeweiligen Konzepts als entscheidend angesehen wird. Man unterscheidet in diesem Sinne zwischen Verteilungsgerechtigkeit (iustitia distributiva) und ausgleichender Gerechtigkeit (iustitia commutativa) als die beiden Arten der Gerechtigkeit im materiellen Sinne, also bei der Aufteilung von Vorteilen und Lasten. Daneben steht außerdem die Gerechtigkeit im formellen Sinn, die all jenes als gerecht ansehen will, was mit dem Gesetz übereinstimmt.

Nach Ziembiński ${ }^{3}$ betrifft die Verteilungsgerechtigkeit die Fragestellung, ,was der einzelne für das Allgemeinwohl leistet und was ihm dafür gerechterweise im Gegenzug gebührt“. Im Schrifttum wird zumeist zwischen den folgenden Formeln der Verteilungsgerechtigkeit differenziert: a) egalitäre Formeln - jedem das Gleiche, unabhängig von seinen besonderen Merkmalen bzw. jedem nach seinen (gerechtfertigten) Bedürfnissen sowie b) meritorische Formeln - jedem nach seiner geleisteten Arbeit (erbrachtem Aufwand), jedem nach seinen Verdiensten. Die ausgleichende Gerechtigkeit hingegen strebt nach Angemessenheit zwischen mehreren Individuen und kann z.B. in zivilrechtlich geprägten Beziehungen Anwendung finden. Verteilungsgerechtigkeit basiert, so Tkacz, in Anlehnung an Aristotele, auf dem Verhältnismäßigkeitsgrundsatz, ausgleichende Gerechtigkeit hingegen auf dem Gleichheitssatz. ${ }^{4}$ Vor einem Einstieg in die genauere Untersuchung der Rechtsprechung des Verfassungsgerichtshofs zum Verständnis des Gerechtigkeitsgrundsatzes in der polnischen Verfassung sei bereits vorweggenommen, dass die ausgleichende Gerechtigkeit

2 Die ursprünglich von Höffe, Politische Gerechtigkeit. Grundlegung einer kritischen Philosophie von Recht und Staat, Frankfurt am Main 1989 (polnische Auflage Krakau 1999), S. 56 entnommene Aussage wurde von Karp, Sprawiedliwość społeczna. Szkice ze współczesnej teorii konstytucjonalizmu i praktyki polskiego prawa ustrojowego, Krakau 2004, S. 37 angeführt.

3 Ziembinski (Fn. 1), S. 135.

4 Tkacz, Rozumienie sprawiedliwości w orzecznictwie Trybunału Konstytucyjnego, Kattowitz 2003, S. 37. 
in dieser Judikatur auch im Verhältnis zwischen dem Einzelnen und der Gemeinschaft auftritt. ${ }^{5}$

\section{Soziale Gerechtigkeit}

Der für die vorliegende Aufarbeitung bedeutsame Begriff der sozialen Gerechtigkeit findet sich in Art. 2 der polnischen Verfassung (plVerf) wieder, in dem es heißt, die Republik Polen sei ein die Grundsätze der sozialen Gerechtigkeit verwirklichender Rechtsstaat. In der Literatur wird dieser Begriff als ein Konglomerat verschiedener Gerechtigkeitsformeln im Rahmen der Verteilungsgerechtigkeit verstanden. Die Verwendung der Bezeichnung „soziale Gerechtigkeit" stellt, insbesondere nach Ansicht von Ziembiński, keine Bezugnahme auf eine bestimmte, einfache, auf einem einzigen Kriterium aufbauende Gerechtigkeitsformel dar. Stattdessen wird auf eine speziellere komplexe Formel zurückgegriffen, die in einem angemessenen Kompromiss verschiedene Forderungen in Bezug auf die Regelung zwischenmenschlicher Beziehungen und der gesellschaftlichen Ordnung berücksichtigt. An anderer Stelle kommt derselbe Autor zu dem Schluss, dass man ,zur Feststellung des tatsächlichen Inhalts einer als »soziale Gerechtigkeit« bezeichneten Formel, wenn diese für die Verteilung von gewissen Gütern angewandt wird, wohl mit einer Aufstellung aller eindimensionalen Gerechtigkeitsformen anfangen sollte, um jene Kriterien zu ermitteln, von denen man glaubt, sie sollten bei der Verteilung von Gütern berücksichtigt werden. Im nächsten Schritt ist das Gewicht jedes dieser Kriterien zu bestimmen". 6

Im Schrifttum wird zur Bedeutung des Begriffs "Gerechtigkeit“ in der Rechtsprechung des Verfassungsgerichtshofs ebenfalls die Ansicht vertreten, im Rahmen der als „soziale Gerechtigkeit“ betitelten Formel des Art. 2 plVerf sei der „sozialen“ Komponente jede Bedeutung abzusprechen. ${ }^{7}$ Das grundsätzliche Argument zur Unterstützung dieser These wurde aus der oben zitierten Meinung von Ziembiński abgeleitet. Aus dieser geht hervor, dass die genaue Bestimmung, was den „sozialen“ Charakter von Gerechtigkeit ausmachen soll, ohne eine vorherige Festlegung der

5 Siehe VerfGH v. 22.02.2000, 8/98, OTK-ZU2000 3/87.

6 Ziembiński, Sprawiedliwość społeczna jako pojęcie prawne, Warschau 1996, S. 58; ebendieser (Fn. 1), S. 135.

7 Tkacz (Fn. 4), S. 9 f. 
speziellen Grundsätze, auf denen zuerst der Begriff „Gerechtigkeit“ gründen soll, unmöglich bleibt. Dem ist jedoch hinzuzufügen, dass dieser Umstand Ziembiński nicht daran hinderte, sich mit der sozialen Gerechtigkeit zu befassen. Soziale Gerechtigkeit nimmt Bezug auf Gerechtigkeit allgemein, wenngleich es sich dabei um eine sozial institutionalisierte Gerechtigkeit handelt, die deutlich gewichtigere Angelegenheiten als ,zum Beispiel eine gerechte Benotung in einem künstlerischen Wettbewerb oder einem Boxwettkampf" betrifft. ${ }^{8}$ Die Verkennung eines bedeutsamen Bestandteils des im Wortlaut von Art. 2 plVerf verwendeten Begriffs der ,sozialen Gerechtigkeit" erscheint als eine unzulässige Vereinfachung. Dieses Vorgehen wird auch nicht durch den von Tkacz vorgebrachten Umstand gerechtfertigt, dass der Begriff der sozialen Gerechtigkeit erst im 19. Jh. auftauchte und eng mit den damaligen gesellschaftlichen Bewegungen verknüpft war, ohne dass es sich dabei um einen wissenschaftlichen Terminus handelte. Diese Meinung stellt wiederum eine Verallgemeinerung der Herkunft und Bedeutung des Begriffs ,,soziale Gerechtigkeit“ dar, der gerade im Rechtswesen eine bedeutende Rolle u.a. im Hinblick auf die Abkehr vom Rechtspositivismus spielte, indem er keinen Verfall in das andere Extrem, die Naturrechtskonzepte, zuließ. ${ }^{9}$

Auf der Grundlage des geltenden Rechts werden verschiedene Ansichten zum Verhältnis zwischen den beiden in Art. 2 plVerf verwendeten Begriffen „Rechtsstaat" und „soziale Gerechtigkeit" vertreten. Nach einigen Autoren (vor allem Morawski) liegt die Essenz des Rechtsstaats in der Verwirklichung von Politik-, Sozial- und Wirtschaftswesen in einer politisch-rechtlichen Grundordnung. Das Rechtsstaatskonzept an sich beinhaltet bereits einige wertende Regeln: Gleichheit vor dem Recht, Verbot der Diskriminierung von Minderheiten, Meinungs- und Versammlungsfreiheit, Verbot von entschädigungsloser Enteignung, Recht auf rechtliches Gehör, Unschuldsvermutung, Verbot von Entscheidungen, die zu Umweltkatastrophen führen. Die Rechtsstaatsidee stellt demnach gewisse Anforderungen an die Gerechtigkeit, wobei es sich - so Karp - einzig um elementare Werte des Gerechtigkeitsideals handelt. Der Unterschied zwischen einem theoretischen Gerechtigkeits- und dem Rechtsstaatskonzept

8 Ziembiński (Fn. 6), S. 58.

9 Giaro, Wartości w języku prawnym i w dyskursie prawniczym, in: Biblioteka Trybunału Konstytucyjnego, Zespót Prezydialny Biura Trybunału Konstytucyjnego (Hrsg.), Preambuła Konstytucji Rzeczpospolitej Polskiej, Warschau 2009, S. 13 ff.; siehe auch Karp (Fn. 2), S. 45 u.a. 
besteht darin, dass ersteres vor der Bestimmung anderer moralischer Werte nichtpolitischer Natur (z.B. gleicher Zugang zu Bildungswesen, Ämtern, Gesundheitswesen) keinen Halt macht. Soziale Gerechtigkeit wird dadurch zu einem universalen gesellschaftlichen, politischen und moralischen Ideal, welches über die bloße Benennung von wertvollen Gütern in jedem Lebensbereich hinaus auch die Rangordnung dieser Güter zu bestimmen sowie in Kollisionsfällen zwischen ihnen zu entscheiden vermag. ${ }^{10}$

\section{Rechtliche Bedeutung der sozialen Gerechtigkeit}

\section{Die Rechtsnatur der sozialen Gerechtigkeit als Verfassungsgrundsatz}

In der Präambel der Verfassung tritt der Begriff „Gerechtigkeit“ in zweierlei Hinsicht in Erscheinung: Einerseits neben der Wahrheit, Güte und Schönheit, als einer der universellen Werte, auf die sich die Begründer der Verfassung berufen, andererseits als ein Bestandteil der Grundlage, aus der die Grundrechte, die Achtung der Freiheit, das Zusammenwirken der Gewalten, der Sozialdialog und das Subsidiaritätsprinzip zur Stärkung der Rechte von Bürgern und ihrer Vereinigungen erwachsen. In Art. 2 plVerf tritt er hingegen in Verknüpfung mit dem Adjektiv „sozial“ auf. Das in dieser Vorschrift enthaltene Gebot der „Verwirklichung" sozialer Gerechtigkeit geht dabei weiter als die in der Präambel einzig in Bezug auf die Grundrechte genannte „Achtung“. Während die Grundsätze der sozialen Solidarität in der Verfassung der Volksrepublik Polen noch bei einer Vielzahl anderer Vorschriften über die Aufgaben des Staates und die von ihm zu erfüllenden Ziele (Verwirklichung sozialer Gerechtigkeit, Abschaffung der Ausbeutung des Menschen und Bekämpfung von Verstößen gegen Grundprinzipien des gesellschaftlichen Zusammenlebens) genannt worden waren, wurde den Grundsätzen der sozialen Gerechtigkeit in der Verfassung der Republik Polen während der Übergangszeit von 1989-1997 der höchste Rang unter den Vorschriften über die politische Staatsordnung zugeschrieben, obwohl die entsprechende Norm mit dem Rechtsstaatsprinzip in ein und derselben Vorschrift verortet war.

10 Karp, ebenda., S. 184. 
Dem Art. 2 der Verfassung vom 2. April 1997 lassen sich hingegen drei Grundsätze entnehmen: das Demokratie- und das Rechtsstaatsprinzip sowie die Grundsätze der sozialen Gerechtigkeit. Jedes dieser elementaren Prinzipien gilt es einzig in Zusammenhang mit und unter Berücksichtigung der beiden anderen zu erläutern. ${ }^{11}$

Die Rechtsnatur des Grundsatzes der sozialen Gerechtigkeit bleibt in der Lehre zu Verfassungsrecht und Rechtstheorie umstritten. Die meisten Autoren bescheinigen dem Grundsatz als Ganzem ebenso wie seinen einzelnen Bestandteilen einen normativen Charakter. Die in Art. 2 zur Anwendung kommenden staatsorganisatorischen Grundsätze werden als Generalklauseln verstanden, bilden also eine Art normatives Konstrukt der Rechtssprache, durch das sich der Gesetzgeber mit den Normadressaten auf die Berücksichtigung von außerrechtlichen Kriterien bei der Rechtsanwendung verständigt. Darüber hinaus erlegen sie dem besagten Normadressaten das Gebot auf, sich in gewissen Situationen auf eine bestimmte Art und Weise zu verhalten. ${ }^{12}$ Teilweise wird vertreten, den Grundsätzen der sozialen Gerechtigkeit seien ein normativer Charakter sowie eine mindestens denen der sonstigen Grundsatznormen im ersten Kapitel der Verfassung entsprechende Rechtskraft zuzuschreiben. Nach anderer Ansicht fehlt diesem Prinzip ein solcher normativer Charakter bzw. handelt es sich lediglich um einen quasi-normativen Grundsatz, der zwar mithilfe eines normschöpfenden Wortlauts ausgedrückt wurde, jedoch (genauso wie andere derartige Prinzipien) nicht die entsprechende Substanz besitzt, um ihm unmittelbar anwendbare, für den Staat verbindliche und hinreichend konkrete Normenaussagen zu entnehmen. ${ }^{13}$

Der normative Charakter der sozialen Gerechtigkeit als Verfassungsgrundsatz schließt gleichwohl nicht aus, dass die vom Sejm (der Unterkammer des polnischen Parlaments) im Wege von Gesetzen getroffenen Entscheidungen einer Prüfung durch den Verfassungsgerichtshof zugänglich sind. Der Ansicht, der Verfassungsgerichtshof könne bei der Beurteilung der Verfassungsmäßigkeit einzelner Rechtsakte eine eigene Wahl in Bezug auf die anwendbaren Formeln der sozialen Gerechtigkeit treffen,

11 Sokolewicz, Komentarz do art. 2 Konstytucji, in: Garlicki (Hrsg.), Konstytucja Rzeczypospolitej Polskiej. Komentarz, Warschau 1999, S. 10.

12 Vgl. Karp (Fn. 2), S. 171.

13 Ebenda, S. 166 und die dort angeführten Ansichten von Tuleja und Ludwikowski. 
wurde in der Lehre mit Skepsis begegnet. ${ }^{14}$ Dem hielt man vor allem entgegen, dass der Gerichtshof, sollte er die Grundsätze der sozialen Gerechtigkeit als Prüfungsmaßstab für formelle Gesetze heranziehen, eigentlich vielmehr anhand der eigenen Gerechtigkeitsvorstellungen urteilen würde. Aus diesem Grund wird in der neuesten Rechtsprechung des Verfassungsgerichtshofs betont, dass ,die Beurteilung von Maßnahmen zur Verwirklichung des Grundsatzes der sozialen Gerechtigkeit eine sichtbare Zurückhaltung der Verfassungsgerichtsbarkeit verlangt", weil der Gerichtshof nicht zur Bewertung der Zweckmäßigkeit der vom Gesetzgeber gewählten Lösungen berufen ist und die Auslegung des Gebots zur Verwirklichung sozialer Gerechtigkeit nicht ohne eine eingehende Berücksichtigung des Inhalts einzelner Verfassungsnormen erfolgen sollte. ${ }^{15}$

Auf die Frage, ob Art. 2 plVerf eine Grundlage bzw. Quelle für subjektive Rechte, insbesondere mit Anspruchscharakter, darstellen kann, geben weder die Rechtsprechung des Verfassungsgerichtshofs noch die Rechtslehre eine klare Antwort. Der Gerichtshof stellte gleichwohl fest, dass Art. 2 plVerf keine eigenständige Quelle subjektiver Rechte darstelle, weil die Regelung vielmehr objektiver Natur sei und lediglich die Eingriffsmöglichkeiten der öffentlichen Gewalt in die Sphäre der subjektiven Rechte beschränke. ${ }^{16}$ Die verfassungsrechtlichen Grundsätze der sozialen Gerechtigkeit können aber dennoch einen eigenständigen Kontrollmaßstab bilden, nämlich wenn die gegebene Rechtssache einen Eingriff in solche Elemente der Grundsätze der sozialen Gerechtigkeit betrifft, die in keiner speziellen Verfassungsnorm ihren Ausdruck fanden. ${ }^{17}$

Auf der Grundlage von Art. 2 plVerf gilt das Gebot der Verwirklichung des Grundsatzes der sozialen Gerechtigkeit bei der Rechtsetzung und -Anwendung. Dieser Grundsatz stellt, wie Ziembiński betont, keine unmittelbar geltende Rechtsnorm dar, sondern wirkt vielmehr richtungsweisend beim Gebrauch der gesetzgeberischen Kompetenz bzw. des zustehenden subjektiven Rechts. ${ }^{18}$ Eine übermäßige Vereinfachung würde seiner Ansicht nach die Gleichstellung des „Grundsatzes der sozialen Gerechtig-

14 Zieliński, Klauzule generalne w prawie pracy, Warschau 1988, S. 140; Nowacki, Rządy prawa. Dwa problemy, Katowice 1995, S. 132, zit. nach Tkacz (Fn. 4), S. 39 .

15 Vgl. VerfGH v. 22. 06.1999, K. 5/99, OTK-ZU 1995/5/100.

16 Siehe auch Sokolewicz (Fn. 11), S. 28 ff.

17 Vgl. VerfGH v. 14.06.2003, K 34/02.

18 Ziembiński (Fn. 6), S. 52. 
keit“ mit dem Begriff der „Rechtsgrundsätze“ darstellen, da letztere den Inhalt des verfassungsmäßigen Gebots der Verwirklichung sozialer Gerechtigkeit dadurch näher bestimmen, dass sie entsprechende Hinweise für die Gesetzgebung und die Rechtsanwendung aufstellen. Wie bereits betont, wird in der Lehre wie in der Rechtsprechung des Verfassungsgerichtshofs davon ausgegangen, dass die analysierten Normen eine Art Generalklausel mit Verweis auf außerrechtliche, philosophische, wirtschaftliche und, ethische Wertungen, also eine Art Rechtsgrundsatz darstellen. Diese Generalklausel fungiert auch als Mustergrundsatz zum „Verweis“ auf verschiedene Gerechtigkeitsformeln. ${ }^{19}$

$\mathrm{Zu}$ der Frage, ob von einem Grundsatz der sozialen Gerechtigkeit gesprochen werden kann, wenn der Wortlaut der Verfassung unmissverständlich von „Grundsätzen“ im Plural ausgeht, werden verschiedene Ansätze vertreten. Sokolewicz findet es gerechtfertigt, von einem allgemeinen Grundsatz auszugehen, der wiederum einen Teil des noch allgemeiner in Art. 2 plVerf ausgedrückten, aus Demokratie, Rechtsstaatlichkeit und sozialer Gerechtigkeit bestehenden Prinzipientrias darstellt. Nach Ansicht von Ziembiński hingegen erstarren die Grundsätze der sozialen Gerechtigkeit nicht zu Normen des geltenden Rechts, auch wenn man ihnen die Gestalt bestimmter Verhaltensnormen verleihen mag, weswegen auch kein Grund dafür besteht, von einem „Grundsatz der sozialen Gerechtigkeit“ auszugehen, da die Verfassung gerade auf den Plural abstellt. Der Verfassungsgerichtshof selbst bedient sich in der überwiegenden Mehrheit seiner Entscheidungen des Begriffs „Grundsatz“ im Singular, ohne jemals eine Begründung für die „Vereinfachung“ des gesetzlichen Terminus angegeben zu haben.

\section{Begriff der sozialen Gerechtigkeit in der Rechtslehre}

Die frühesten eingehenden Untersuchungen der sozialen Gerechtigkeit als Begriff entstammen den vorstehend zitierten Aufarbeitungen von Ziembiński über das Verständnis sozialer Gerechtigkeit (1992) und über die soziale Gerechtigkeit als Rechtsbegriff (1996). In der ersten Arbeit stellte Ziembiński fest, dass die Forderung nach sozialer Gerechtigkeit nicht gänzlich als inhaltsleer angesehen werden kann und in einem gewissen

19 Ebenda, S. 171. 
Umfang auch ständige Elemente beinhaltet. Der Autor kommt zu dem Schluss, dass allgemein angenommen wird, dass auf das Wohl jedes Mitglieds der Gesellschaft geachtet werden solle. Darüber hinaus sei keine allzu weitreichende Bildung von hierarchischen Schichten in der Gesellschaft erwünscht, insbesondere werde keine radikale Diskriminierung irgendeiner Kategorie von Menschen zugelassen, und allen Bürgern gegenüber sei ein Existenzminimum zu gewährleisten. Trotz einer egalitären Betonung lehnen die Verfechter der "sozialen Gerechtigkeit“ ihren Aussagen zufolge einen vereinfachten Egalitarismus zu Gunsten von meritären Formeln ab. ${ }^{20}$ In der zweiten Arbeit weist der Autor unter Berufung auf die verfassungsrechtliche Formel darauf hin, dass soziale Gerechtigkeit auf die Ordnung der Verhältnisse zwischen bestimmten gesellschaftlichen Kategorien und nicht zwischen den Individuen bzw. Einzelpersonen, die der Gruppe gegenüber auf irgendeine Weise verpflichtet sind, abstellt. Jede Bezugnahme auf soziale Gerechtigkeit setze deswegen notwendigerweise einen Rückgriff auf die Zustimmung zu einer gewissen ganzheitlich betrachteten gesellschaftlichen Ordnung voraus. ${ }^{21}$

Sokolewicz ${ }^{22}$ stützt sich in seinem Kommentar zu Art. 2 der Verfassung bei der Beschreibung der Grundsätze der sozialen Gerechtigkeit auf die Rechtsprechung des Verfassungsgerichtshofs. Seiner Ansicht nach geht das Gebot der Verwirklichung sozialer Gerechtigkeit einerseits mit der Annahme, der Staat stelle ein Allgemeinwohl dar, andererseits mit der Solidaritätspflicht anderen gegenüber einher. Die Grundsätze der sozialen Gerechtigkeit seien materiell mit der angeborenen und unveräußerlichen Menschenwürde verbunden, die eine unparteiische und gerechte Behandlung eines jeden Menschen nach denselben Maßstäben verlangt. Schließlich werde das verfassungsrechtliche Gerechtigkeitsgebot durch den Grundsatz von gleichen Rechten für alle verstärkt, der wiederum vom Gerechtigkeitsgebot dahingehend einer Korrektur unterzogen wird, dass er nur eine Gleichbehandlung von Rechtsträgern mit wesentlich gleichen Eigenschaften in einer wesentlich gleichen Rechtslage gebietet.

Banaszak $^{23}$ wies in seinem Kommentar zu Art. 2 der Verfassung darauf hin, dass die Wortwahl im Fall des Adjektives „sozial“ (im Zusammen-

20 Ziembiński (Fn. 1), S. 133.

21 Ziembiński (Fn. 6), S. 56.

22 Sokolewicz (Fn. 11), S. 58.

23 Banaszak, Konstytucja Rzeczypospolitej Polskiej. Komentarz, Warschau 2009, S. 57. 
hang mit Gerechtigkeit) bedeutet, dass der Verfassungsgrundsatz einerseits Verhältnisse zwischen verschiedenen Gruppen innerhalb der Gesellschaft, andererseits zwischen den Gruppen und dem Staat, nicht hingegen die Relation zwischen dem Staat und dem Einzelnen, betrifft. Die Vorschrift des Art. 2 plVerf bezieht sich nicht auf die subjektive Gerechtigkeitswahrnehmung, sondern vielmehr auf Gerechtigkeit als eine soziale Kategorie. Dies impliziert die Notwendigkeit, dass der Staat seine Wirtschaftspolitik am Interesse der Gesellschaft ausrichtet, und sich nicht einzig darauf beschränkt, die am wenigsten wohlhabenden Gruppen der Gesellschaft in Schutz zu nehmen. Seine Wirkung entfalte dieser Grundsatz überdies auf verfassungsrechtliche Normen zum Schutz der Rechte und Freiheiten der einzelnen Bürger und auf den Inhalt des allgemeinen Gleichheitssatzes. Die bisherige Rechtsprechung des Verfassungsgerichtshofs zu den Grundsätzen der sozialen Gerechtigkeit verallgemeinernd befürwortet der Autor die Ansicht von Domańska ${ }^{24}$, dass diese Grundsätze durch die Anwendung komplexer Gerechtigkeitsformeln im Rahmen meritärer statt egalitärer Theorien verwirklicht werden. Dabei wechseln sich die einzelnen Gerechtigkeitsregeln in Rolle und Rang stets ab und bleiben vor allem von der sozialen und wirtschaftlichen Lage, in der die Grundsätze der sozialen Gerechtigkeit verwirklicht werden sollen, abhängig.

\section{Die Grundsätze der sozialen Gerechtigkeit in der Rechtsprechung des Verfassungsgerichtshofs im Bereich des Sozialrechts}

a) Allgemeine Anmerkungen

Die Begriffe „soziale Gerechtigkeit“ wie auch „Grundsätze der sozialen Gerechtigkeit" wurden in der Rechtsprechung des Verfassungsgerichtshofs weiter konkretisiert. Man kommt an dieser Stelle nicht umhin, die Rolle der Bürgerrechtsbeauftragten in diesem Prozess hervorzuheben. In der Kompetenz des Ombudsmanns liegt u.a. die Ermittlung von Rechtsverstößen, mitunter gegen die Grundsätze der sozialen Gerechtigkeit, weswegen den Trägern dieses Amtes in zahlreichen Fällen eine Antragsberechtigung im Verfahren der konkreten Normenkontrolle von formellen Gesetzen am Maßstab der Verfassung zusteht. Die Verdienste der Bürger-

24 Domańska, Zasady sprawiedliwości społecznej we współczesnym polskim prawie konstytucyjnym, AUL. Folia Iuridica 66, Lodz 2001, S. 167. 
rechtsbeauftragten auf diesem Gebiet sind bemerkenswert. Ihrer Analyse ist, zumindest in einem bestimmten Umfang, die bereits erwähnte Arbeit von Domańska gewidmet. ${ }^{25}$

Von Anfang an bildeten Fälle aus dem Bereich des Sozialrechts einen beachtlichen Prozentsatz der vom Verfassungsgerichtshof erkannten Rechtssachen. Meistens stellten die Grundsätze der sozialen Gerechtigkeit den Kontrollmaßstab für die gerügten Rechtsnormen dar. In Sozialsachen nahm der Gerichtshof auf die Grundsätze der sozialen Gerechtigkeit meistens im Zusammenhang mit der Gleichheit vor dem Recht und dem Grundsatz der sozialen Solidarität Bezug. Ihre normative Natur ermöglichte den Grundsätzen der sozialen Gerechtigkeit (als Leitlinien) eine gestaltende Einflussnahme auf die sonstigen Staatsprinzipien, mitunter den bereits erwähnten Gleichheitssatz (s. unten).

b) Die Grundsätze der sozialen Gerechtigkeit im Sozialversicherungswesen

Eingangs gilt es daran zu erinnern, dass der Verfassungsgerichtshof bis Ende 1989 über eventuelle Verstöße von Gesetzen gegen die Grundsätze der sozialen Gerechtigkeit auf der Grundlage von Vorschriften urteilte, die einer anderen, sozialistischen Gesellschafts- und Wirtschaftsordnung entstammten. Art. 5 Pkt. 5 der vorherigen Verfassung im Wortlaut von 1976 verlautbarte: „Die Volksrepublik Polen [...] wirkt auf die Verwirklichung die Grundsätze der sozialen Gerechtigkeit, die Abschaffung der Ausbeutung von Menschen sowie die Bekämpfung von Verstößen gegen Grundprinzipien des gesellschaftlichen Zusammenlebens hin.“ Die damaligen ideologischen Prämissen zeichneten auch einige Entscheidungen des Verfassungsgerichtshofs dieser Zeit.

aa) Formeln der sozialen Gerechtigkeit

Von den verschiedenen Formeln der Verteilungsgerechtigkeit berief sich der Verfassungsgerichtshof in seiner Rechtsprechung am häufigsten auf die folgenden: Jedem nach seiner (Arbeits-)Leistung, jedem nach seinen

25 Ebenda, S. $58 \mathrm{ff}$. 
Bedürfnissen und jedem nach seinem Verdienst. Gleichzeitig gilt es festzustellen, dass der Gerichtshof jegliche Adäquanz egalitärer Formeln der Verteilungsgerechtigkeit, etwa ,jedem gleich viel“", unabhängig von ihren Alleinstellungsmerkmalen ablehnte. Egalitäre Formeln stünden nämlich im gänzlichen Widerspruch zu den grundsätzlichen Prämissen der Sozialversicherungen, mitunter ihrer Funktion, Anreize für die Aufnahme von bezahlter Beschäftigung oder anderen Anstrengungen zugunsten der Gesellschaft (etwa bevölkerungspolitischer Art) zu schaffen. In einem System von Hilfs- bzw. gehaltsunterstützenden Maßnahmen drohe dadurch sogar eine Verschwendung von Gütern entgegen der Bedürfnisse der Empfänger ${ }^{26}$ Diese Formel vermochte es nicht, Anstöße zu Anstrengungen für das Gesamtwohl zu liefern.

In einer Entscheidung vom 30. November $1988^{27}$ stellte der Gerichtshof die neuen, mit dem Gesetz vom 14. Dezember 1982 über die Rentenversorgung für Arbeitnehmer und ihre Familien eingeführten Voraussetzungen für den Erwerb einer Invalidenrentenanwartschaft u.a. aus dem Gesichtspunkt der Grundsätze der sozialen Gerechtigkeit in Frage. Die besagten Vorschriften erhöhten die Mindestbeschäftigungszeit für den Erwerb der Anwartschaft von fünf auf zehn Jahre bei Arbeitnehmern, die ihre erste Anstellung erst nach der Vollendung des 40. Lebensjahres bzw. nach Vollendung des 40. Lebensjahres eine neue Beschäftigung erst zehn Jahre nach Beendigung des vorherigen Arbeitsverhältnisses oder einer analog anzurechnenden Zeit aufgenommen haben. Gemäß der Formel ,jedem nach seinen Bedürfnissen“ befand der Gerichtshof, dass „der Gesetzgeber bei der Gestaltung der Rentenanwartschaft auf gar keinen Fall auf solche grundlegenden Bausteine wie Anreize in Gestalt von höheren Renten für entsprechend längere Beschäftigungszeiträume zurückgreifen sollte, weil in Fällen einer Unterbrechung des Beschäftigungszeitraums aufgrund eines zufälligen, für die Behinderung ursächlichen Ereignisses die Verlängerung der Beschäftigungszeit gerade in keiner Weise vom Arbeitnehmer abhängt. Die grundsätzliche Idee der Invalidenrente besteht darin, die Erfüllung sozialer Bedürfnisse solcher Menschen zu ermöglichen, die eine Erwerbsunfähigkeit bzw. eine Einschränkung ihrer Arbeitsfähigkeit aufgrund einer bleibenden oder langwierigen Beeinträchtigung der körperlichen Leistungsfähigkeit hinnehmen mussten." Der Gerichtshof führte da-

26 Vgl. Ziembiński (Fn. 6), S. 24.

27 VerfGH v. 30.11.1988, OTK 1988/1/6; fortan: K 1/88. 
her aus, dass der ansonsten anwendbare Grundsatz der Verteilung nach geleisteter Arbeit gerade bei der Regelung der Anwartschaft auf eine Invalidenrente der bedürfnisorientierten Verteilungsformel weichen muss, weswegen die Erwerbsunfähigkeitsrente als eine Leistung zur Erfüllung allein grundsätzlicher Bedürfnisse von Personen, deren Erwerbsunfähigkeit gesundheits- oder altersbedingt andauert, anzusehen sei.

Diese Ansicht wäre heutzutage aus Sicht der aktuellen Ausgestaltung der Anwartschaft auf die Arbeitsunfähigkeitsrente kaum angemessen. Die bedürfnisorientierte Verteilungsformel bildet nämlich die Grundlage für die Gestaltung des Sozialhilfesystems ${ }^{28}$ und gegebenenfalls auch der Sozialversorgung (vgl. Sozialhilfe und Familienleistungen), welche gerade unabhängig vom Beitrag des Einzelnen zur Erhaltung und Fortentwicklung der Gesellschaft durch produktive Betätigung gewährt werden. Das Konzept des Verfassungsgerichtshofs wäre vielmehr dann begründet, wenn der Sozialschutz im Falle einer Behinderung (Erwerbsunfähigkeit) im Rahmen eines arbeits- und/oder beitragsunabhängigen Versorgungssystems gewährleistet worden wäre. Die Differenzierung der Rechtslage von Versicherten (d.h. ihrer Rechte und Pflichten) sollte im Sozialversicherungswesen nach der Gerechtigkeitsformel ,jedem nach seiner Arbeit" erfolgen. Im Einklang mit diesen Formeln bleiben schließlich die aktuell geltenden Regelungen zur Berechnung der Rentenhöhe bei der Arbeitsunfähigkeitsrente, die vorbehaltlich einer relativ langen Versicherungs- und Beitragszeit, aufgrund der Anwendung eines Basissatzes, eine deutlich über die Grundversorgung hinausgehende Leistung garantieren. Der arbeitsorientierten Verteilungsformel entspräche nämlich genauso eine Ausgestaltung der Berechnungsregeln unter Beibehaltung einer entsprechenden Lohnersatzquote. ${ }^{29}$ Damit einher geht auch eine entsprechende Gestaltung der allgemeinen Regeln zur Berechnung der Versicherungszeit bei der Feststellung von Rentenanwartschaften und deren Höhe, nach denen die Länge der Unterbrechungen im Erwerbsverlauf, die Art und Weise der Beendigung von Arbeitsverhältnissen und ähnliche Faktoren ohne Bedeutung für die Berechnung der Versicherungszeit bleiben ${ }^{30}$. Dem Ansatz nach wird nämlich bei der Formel ,jedem nach seiner Arbeit" davon ausgegangen, die Verteilung von Gütern erfolge im Verhältnis zu den Gesamtleistungen

28 Jończyk, Prawo zabezpieczenia społecznego, Krakau 2006, S. 40.

29 Vgl. IAO-Übereinkommen Nr. 102 über die Mindestnormen der Sozialen Sicherheit.

30 Vgl. VerfGH v. 30.11.1988, K 1/88. 
der Interessierten. ${ }^{31}$ Daher rechtfertigt diese Formel die Gewährung von Rentenansprüchen in unterschiedlicher Höhe je nach Beitragshöhe und Versicherungszeit. ${ }^{32}$ Andererseits wird jedoch festgestellt, die Formel gehe von einer Vergleichbarkeit von Leistungen aus und ermögliche im Grundsatz auch dann Anrechnungen, wenn eine lange Reihe verschiedener Ergänzungskriterien herangezogen werde. ${ }^{33}$ Aus diesem Grund bleibt eine schlichte Verknüpfung zwischen Rentenanwartschaft und -höhe auf der einen und der Versicherungszeit sowie der Beitragshöhe auf der anderen Seite ausgeschlossen. ${ }^{34}$

Die beiden sonstigen Verteilungsformeln, nach Bedürfnis und nach Verdienst, dienen im Sozialversicherungswesen als Ergänzung und Korrektiv, beispielsweise bei der Ausdifferenzierung der Höhe solcher Renten- und sonstigen Leistungen, die aufgrund eines Arbeitsunfalls oder einer Arbeitserkrankung entstanden sind. Dabei wird die Bedürftigkeit im Sozialversicherungswesen nicht etwa individuell untersucht, sondern gestützt auf ein schematisches Gesamtbild von Bedürfnissen aus der Perspektive der Allgemeinheit der Versicherten festgelegt. Dies zeugt gleichzeitig von einer verschwindend geringen Praktikabilität der bedürfnisorientierten Gerechtigkeitsformel im Sozialversicherungswesen. Das Ansinnen dieser Formel liegt schließlich in der Berücksichtigung von Grundbedürfnissen zur Sicherung des überlebensnotwendigen Minimums, was einmal mehr der Funktion und den Grundsätzen der Sozialversicherungen zuwiderläuft.

In der Entscheidung vom 11. Februar $1992^{35}$, lehnte der Verfassungsgerichtshof unter Berufung auf die Verteilungsformel ,jedem nach geleisteter Arbeit" die Abschaffung von Branchenzulagen, d.h. Zulagen für die Arbeit unter besonderen Bedingungen (Art. 21 Abs. 4 des Gesetzes vom 17. Oktober 1991 über die Aufwertung von Alters- und sonstigen Renten, die Grundsätze ihrer Festlegung und die Änderung einiger anderer Geset$\mathrm{ze}^{36}$ ) ab. Der Gerichtshof stellte fest, dass „,iese Zulagen angesichts des aktuellen Zustands des Sozialversicherungswesens in Polen [am Anfang der 1990er-Jahre, Ergänzung der Autoren] grundsätzlich ihre Berechti-

31 Tkacz (Fn. 4), S. 107.

32 Vgl. Entscheidung des VerfGH vom 22. August 1990, K 7/90, OTK 1990/5.

33 Tkacz (Fn. 4), S. 110.

34 VerfGH v. 23.09. 1997, K 25/96, OTK ZU 1997, Nr. 3-4, 12-13.

35 VerfGH v. 11.02.1992, OTK 1992/1/7; fortan: K 14/91.

36 Poln. GBl. 1991, Nr. 104, Pos. 450; fortan „Aufwertungsgesetz“ oder „Gesetz“. 
gung besitzen und einen Ausdruck der beruflichen Differenzierung sowie des Prinzips der Verteilung im Sozialversicherungswesen entsprechend der geleisteten Arbeit darstellen."

Im vorstehenden Kontext sollte darauf hingewiesen werden, dass die Verteilung gemäß der geleisteten Arbeit - wie bereits betont - die prinzipielle Formel für die Verteilungsgerechtigkeit im Sozialversicherungsrecht darstellt. ${ }^{37}$ Dies hängt damit zusammen, dass Sozialversicherungen in Polen in ihrer Gestalt ab dem Ende des Zweiten Weltkriegs, mit Ausnahme der ehemaligen Familienversicherung (die formell ab den 1950erJahren bis 1994 existierte), die Gefahr (d.h. das soziale Risiko) des Eintritts von (im weiteren Sinne) erwerbsfähigkeitseinschränkenden Ereignissen anbelangen. Aus diesem Grund betrafen sie Personen, die ihren Unterhalt aus eigener Erwerbstätigkeit bestreiten - und sollten dies grundsätzlich auch weiterhin tun. Neben der besagten arbeitsbezogenen Formel wird jedoch in der Wissenschaft und Rechtsprechung des Verfassungsgerichtshofs $\mathrm{s}^{38}$ auch auf andere Formeln abgestellt, unter anderem die Verteilung nach Verdienst. ${ }^{39}$ Mit Blick auf den Unterschied zwischen den Formeln ,jedem nach seiner Arbeit" (seinem Beitrag, seinen Leistungen) und ,jedem nach seinem Verdienst" ist vor allem anzumerken, dass die besondere Honorierung von Arbeit unter schwierigen Bedingungen bzw. von besonderem Charakter oder von besonderen Verdiensten für den Staat oder die Gesellschaft viel eher der letztgenannten Gerechtigkeitsformel entspricht. Eine Entlohnung von Verdiensten solcher Art sollte gleichwohl keine Belastung für die Gemeinschaft der Versicherten und die von ihnen unterhaltenen Fonds mit sich bringen. $\mathrm{Zu}$ Recht wird also in der Lehre angenommen, dass „die Vergütung von besonderen Verdiensten außerhalb des Versicherungssystems stattfinden sollte, z.B. mithilfe von speziellen Versorgungsleistungen." 40

Mit der sozialversicherungsrechtlichen Gleichstellung von produktiver (Arbeits-) und reproduktiver (Erziehungs-) Tätigkeit stufte der Verfassungsgerichtshof erwerbstätige Männer einerseits und wegen der Erziehung ihrer Kinder nicht erwerbstätige Frauen andererseits als im gegebe-

37 Jończyk (Fn. 28), S. 40.

38 VerfGH v. 30.11.1988, K 1/88.

39 Ziembiński (Fn. 6), S. 20-31; Tkacz (Fn. 4), S. 99.

40 Wagner, Z problematyki równości w ubezpieczeniach społecznych, in: Skapski/ Slebzak (Hrsg.), Aksjologiczne podstawy prawa pracy i ubezpieczeń społecznych, Posen 2014, S. 239; dieselben, a.a.O., S. 559. 
nen Kontext wesentlich gleich anzusehende und rechtlich zu behandelnde Gruppen ein (vgl. Entscheidung K 1/88). Der Gerichtshof befand, dass sich die mit dem Gesetz vom 14. Dezember 1982 über die Rentenversorgung für Arbeitnehmer und ihre Familien erfolgte Erhöhung der für den Erwerb einer Invalidenrentenanwartschaft vorausgesetzten Mindestbeschäftigungszeit von fünf auf zehn Jahre bei Arbeitnehmern, die ihre erste Anstellung erst nach der Vollendung des 40. Lebensjahres bzw. nach Vollendung des 40. Lebensjahres eine neue Beschäftigung erst zehn Jahre nach Beendigung des vorherigen Arbeitsverhältnisses oder einer analog qualifizierten Zeit aufgenommen haben, besonders ungünstig auf die Lage von Frauen auswirkt, die ihre Berufstätigkeit in der Regel wegen der Erziehung ihrer Kinder unterbrechen oder erst spät aufnehmen.

Daraus lässt sich schließen, dass der Verfassungsgerichtshof die grundlegende arbeitsorientierte Gerechtigkeitsformel in dieser Entscheidung dadurch abwandelte, dass er ihren Inhalt um den Beitrag zur Entwicklung und Erziehung künftiger Generationen ergänzte. Ein solches Verständnis entspricht gleichzeitig der Verteilungsformel ,jedem nach seinen Verdiensten (Leistungen)“, die auch ohne Weiteres die Formel ,jedem nach seiner Arbeit" mit umfasst. ${ }^{41}$

bb) Die Grundsätze der sozialen Gerechtigkeit und die Gleichheit vor dem Recht

Die Rolle der Grundsätze der sozialen Gerechtigkeit im Sozialversicherungswesen untersuchte der Verfassungsgerichtshof am häufigsten im $\mathrm{Zu}-$ sammenhang mit dem verfassungsrechtlichen Gleichheitssatz und dem Diskriminierungsverbot (Art. 32 und 33 der polnischen Verfassung). Ihre gegenseitige Beziehung erweist sich als besonders komplex. Nach Ansicht einiger Verfassungsrechtler ist der Grundsatz der sozialen Gerechtigkeit fernab der Gleichheit vor dem Recht zu verorten, wenngleich er ihr als Korrektiv dienen kann. ${ }^{42}$ „Der bereinigte Grundsatz der sozialen Gerechtigkeit als im Gleichheitssatz inbegriffener Wert verliert seine adversative Kontrastwirkung gegenüber einem anderen Verfassungswert - der Freiheit - und mildert das Spannungsfeld zwischen Freiheit und Gleichheit.“

41 Vgl. ebenda.

42 Sokolewicz (Fn. 11), S. 71. 
Mit Blick auf die verfestigte Rechtsprechung des Verfassungsgerichtshofs kann davon ausgegangen werden, dass die Gleichbehandlung von wesentlich Gleichem bereits von der Definition her gerecht ist und keiner zusätzlichen Kontrolle unter dem Gesichtspunkt anderer Grundsätze sozialer Gerechtigkeit bedarf.

Zum Beispiel befand der Gerichtshof im Urteil vom 14. Juni 2004, dass die Ungleichbehandlung von Versicherten im Hinblick auf die Möglichkeit, wegen einer Arbeitstätigkeit unter gesundheitsschädlichen bzw. belastenden Bedingungen in Frührente zu gehen, je nach den Eigentumsverhältnissen ihrer Arbeitgeber willkürlich und sachfremd sei - und daher im Widerspruch zum Grundsatz der sozialen Gerechtigkeit stehe ${ }^{43}$ (Art. 32 Abs. 2 des Gesetzes vom 17. Dezember 1998 über Alters- und sonstige Rentenleistungen aus dem Sozialversicherungsfond). In ähnlicher Weise berief sich der Gerichtshof im Urteil vom 24. Mai 2012 (AZ: P 12/10) auf den Grundsatz der sozialen Gerechtigkeit. ${ }^{44}$ Thematisch äußerte sich der Gerichtshof darin zur Ablehnung der Ungleichbehandlung von zwei in Bezug auf die Krankenversicherung als relevante Eigenschaft vergleichbaren Gruppen - Arbeitnehmern und solchen selbstständig Erwerbstätigen, die vor dem Gang in die Selbstständigkeit über einen längeren Zeitraum der arbeitnehmerischen Versicherungspflicht unterlagen - bei der Bestimmung der Berechnungsgrundlage für Entgeltersatzleistungen nach Art. 48 Abs. 2 und Art. 52 des Gesetzes vom 25. Juni 1999 über Geldleistungen aus der Sozialversicherung im Krankheitsfall und bei der Mutterschaft.

Das in der Entscheidung K 14/91 aufgezeichnete Konzept für das Verhältnis zwischen Gleichheit vor dem Recht und der Verfestigung und Vertiefung sozialer Gerechtigkeit, vertrat der Verfassungsgerichtshof in seinen nachfolgenden Entscheidungen unverkennbar die Ansicht, dass die Grundsätze der sozialen Gerechtigkeit eine Durchbrechung des allgemeinen Gleichheitssatzes rechtfertigen können. Im genannten Urteil wies der Gerichtshof darauf hin, dass „sachlich begründete, im Gerechtigkeitsgrundsatz gründende soziale Präferenzen mit dem Verbot der Bevorzugung gewisser Kategorien (Gruppen) von Rechtsträgern durchaus vereinbar seien.“

43 OTK-A 2004/6/57.

44 OTK-A 2012/5/52; vgl. VerfGH v. 5.07.2010 r., P 31/09, OTK-A 2010/6/57. 
In diesem Sinne sind die Grundsätze der sozialen Gerechtigkeit als Ergänzung oder vielmehr als Korrektiv des allgemeinen Gleichheitssatzes anzusehen $^{45}$

Weil die Versicherten ausnahmslos (formell, infolge einer bewussten Entscheidung des Gesetzgebers) einer homogenen Gemeinschaft zur (wenngleich nicht identischen) Absicherung derselben sozialen Risiken angehören, die mit ihren Beiträgen einen gemeinsamen Fonds (mit)trägt, aus dem wiederum Leistungen auf der Grundlage einer schematischen Bedarfsermittlung der Gemeinschaftsmitglieder finanziert werden, kann angenommen werden, dass sie eine Gruppe gleichberechtigter Rechtsträger darstellen.

Diese Annahme führt zu dem Schluss, dass jede Differenzierung ihrer Berechtigungen unmittelbar mit einem bestimmten Ziel verbunden sowie durch andere Werte, Grundsätze oder Verfassungsnormen, allen voran die soziale Gerechtigkeit und Solidarität, zu rechtfertigen sein muss. ${ }^{46}$

Nach Ansicht des Verfassungsgerichtshofs besteht ein legitimer Zweck für die Rechtfertigung einer Ungleichbehandlung von grundsätzlich gleichgestellten Versicherten in der Rücksichtnahme auf die Verteilungsgerechtigkeit (iustitia distributiva) mit Blick auf die Umverteilungsfunktion der Sozialversicherungen.

Das Sozialversicherungsrecht als Grundsatzinstrument zur Verwirklichung der staatlichen Sozialpolitik, zu deren Zielen mitunter der Ausgleich überragender Missverhältnisse zwischen den Lebens- und Existenzbedingungen unterschiedlicher sozialer Gruppen gehört ${ }^{47}$, sollte demzufolge schlichtweg von einer Ungleichheit (Ungleichbehandlung) der Versicherten ausgehen. Im Sozialversicherungswesen sind es entsprechend angewandte Formeln der Verteilungsgerechtigkeit, gekoppelt mit dem Solidaritätsprinzip zur Rechtfertigung der Umverteilung im Rahmen einer Gemeinschaft, die einer gerechten Differenzierung der rechtlichen Lage von grundsätzlich gleichbehandelten Versicherten dienen. ${ }^{48}$

45 Wagner (Fn. 40), S. 224 und die in Fn. 34 zitierte Rspr. des VerfGH.

46 Vgl. VerfGH: v. 20.011992, K 15/91, Państwo i Prawo 1993, Heft 2, S. 100; vom 12. Dezember 1994, K 3/94, OTK 1994/2/42; vom 22. Oktober 1995, K 4/95, OTK 1995/2/11; vom 28. Mai 2002, P 10/01, OTK-A 2002/3/35.

47 Auleytner, Polityka społeczna, czyli ujarzmienie chaosu społecznego, Warschau 2002, S. 14.

48 Vgl. Wagner (Fn. 40), S. 226. Vgl. ähnliche Ansicht in: Ślebzak, ebenda., S. 260. Darauf wies der VerfGH im Urteil vom 12.07.2012, P 24/10, OTK-A 2012/7/79 hin und betonte, dass die Umverteilungsfunktion des Sozialversicherungswesens 
cc) Wesentliche Ungleichbehandlung von wesentlich Ungleichem

Im Urteil vom 25. September $2014^{49}$ betonte der Verfassungsgerichtshof, dass „das Gebot der Ungleichbehandlung von wesentlich Ungleichem eine in den Grundsätzen der sozialen Gerechtigkeit aufgehende Pflicht darstellen kann“, zumal „die Grundsätze der sozialen Gerechtigkeit einen weitergehenden und entschieden umfassenderen Inhalt als der Gleichheitssatz aufweisen.“

dd) Grundsätze der sozialen Gerechtigkeit vor dem Hintergrund der Grundsätze der Gegenseitigkeit und Verhältnismäßigkeit; soziale Gerechtigkeit und soziale Solidarität

Zum Leitgedanken des Urteils K 14/91, dass der - im Hinblick auf die soziale Solidarität und deren Gebot der Lastenverteilung auf möglichst viele Versicherte bei der Leistungserbringung gerechtfertigte - „Grundsatz der sozialen Gerechtigkeit im Sozialversicherungswesen unter Berücksichtigung seiner Umverteilungsfunktion verwirklicht wird“", kehrte der Verfassungsgerichtshof mehrmals in seiner späteren Rechtsprechung zur Prüfung der Übereinstimmung von Vorschriften des Sozialversicherungsrechts mit den Grundsätzen der sozialen Gerechtigkeit zurück.

Unter Berufung auf das Zusammenwirken von sozialer Gerechtigkeit und sozialer Solidarität ließ der Gerichtshof im Urteil vom 19. Dezember $2012^{50}$ das einzig für dieses Jahr geltende einmalige Absehen des Gesetzgebers von der Anwendung der allgemeinen Regelungen zur Anhebung der Altersrenten ${ }^{51}$, die von einer prozentualen (nach dem Preisindex ermittelten) Anhebung ausgingen, zugunsten einer Anhebung um einen starren, von der Rentenhöhe unabhängigen Betrag zu. Dieser Mechanismus (d.h. die unterschiedslose Anhebung sämtlicher Rentenleistungen um 71 zloty) war von vornherein ungeeignet, den Geldwertverlust (Kaufkraftverlust) al-

„auf einer bestimmten Verflachung des Leistungsumfangs zugunsten von Personen mit einem niedrigen und zu Lasten von Personen mit einem hohen beitragspflichtigen Einkommen beruht.“.

49 VerfGH v. 25.09.2014, SK 4/12.

50 VerfGH v. 19.12.2012, K 9/12.

51 Aus dem Gesetz vom 17. Dezember 1998 über Alters- und sonstige Rentenleistungen aus dem Sozialversicherungsfond. 
ler Rentenleistungen gleichmäßig zu kompensieren. Im Endeffekt blieb der reale Wert einzig bei Leistungen in Höhe von über 1480,00 zloty erhalten.

Diese unterschiedliche Behandlung von grundsätzlich gleichgestellten Rechtsträgern fand jedoch nach Ansicht des Gerichtshofs eine hinreichende Rechtfertigung im Grundsatz der sozialen Gerechtigkeit unter Berücksichtigung seiner Umverteilungsfunktion im Sozialversicherungswesen. ${ }^{52}$

Diesem Gedanken entsprechend bildet die Sozialsolidarität zusammen mit der Verteilungsgerechtigkeit ein Instrument zur Korrektur der Leistungsberechnung zugunsten von Personen mit einem niedrigeren Einkommen. Sie ermöglicht eine Umverteilung von Mitteln innerhalb der Gesellschaft von wohlhabenderen auf weniger wohlhabende Bürger.

Bei der Bewertung dieser Rechtsfrage ließ sich der Gerichtshof überdies von dem Gedanken leiten, dass der Grundsatz der Verhältnismäßigkeit von empfangenen Leistungen und erbrachter Arbeit (eingezahlten Beiträgen) relativ zu verstehen ist, da er hinter den Grundsätzen der sozialen Solidarität und Umverteilung der Einkünfte in der Gesellschaft zurücktritt. Der Verhältnismäßigkeitsgrundsatz im Sinne einer Gleichwertigkeit von Beiträgen und empfangenen Leistungen gilt im Sozialversicherungswesen nicht absolut, da - so der Gerichtshof in einer anderen Entscheidung - die jeweilige Leistung nicht auf der Grundlage des individuellen Risikos berechnet werde und ihre Höhe auch sonst davon unabhängig sei. ${ }^{53}$ Dies entspreche dem Grundsatz der sozialen Solidarität zur Gestaltung von Form und Inhalt der Pflichten im Rahmen der Gemeinschaft der Versicherten sowie zur Regelung der Grundsätze für das Bestehen und Funktionieren derselben (bezogen auf: die prozentuale Berechnung der Beitragshöhe anstelle einer Pauschale, das Absehen von der individuellen Risikoeinschätzung, Leistungsberechtigung in Fällen der Risikoverwirklichung). Soziale Solidarität ist gleichbedeutend mit einer ungleichen Beteiligung bei der Erhaltung des Fonds und der Nutzung dieser Mittel, da eine Symmetrie zwischen dem eigenen Beitrag und den empfangenen Leistungen Risikogemeinschaften fremd sind. ${ }^{54}$

Sozialversicherungen unterliegen demnach den Grundsätzen sozialer (Verteilungs-)Gerechtigkeit und Solidarität, während dem Gegenseitigkeitsgrundsatz allein die Funktion eines Korrektivs zur gesetzgeberischen

52 So auch: Urteil des VerfGH K 17/00, OTK ZU 2001/1/4.

53 VerfGH v. 12.07.2012 r., P 24/10.

54 Jończyk (Fn. 28), S. 38 ff. 
Freiheit bei der Bestimmung der Rechte und Pflichten der Versicherten zukommt, sodass eine vermehrte finanzielle Belastung einiger Mitglieder der Versichertengemeinschaft stets gerechtfertigt und allgemein akzeptiert bleibt. ${ }^{55}$

Eine abweichende Auslegung der Rolle der sozialen Gerechtigkeit und Solidarität nahm der Gerichtshof im Urteil vom 24. Oktober $2005^{56}$ vor, als er feststellte, dass Art. 15 Abs. 5 des Gesetzes vom 17. Dezember 1998 über Alters- und sonstige Rentenleistungen aus dem Sozialversicherungsfond über die Beschränkung der Höhe des RentenberechnungsgrundlagenIndikators (nach der sog. alten Formel für die Berechnung der Rentenhöhe) auf $250 \%$ durchaus den Vorgaben der Art. 2 und 32 plVerf entsprechen. ${ }^{57}$

Der Gerichtshof betonte zwar, für die gesetzliche Abflachung der Rentenhöhe von Besserverdienenden spreche mitunter der Grundsatz der sozialen Gerechtigkeit. Nach Ansicht des Gerichthofs ,rechtfertigt dieses Prinzip eine solche Differenzierung des Rentenanspruchs im Sozialversicherungsrecht. Sie ergibt sich aus dem im Wege der Rentenzahlung ausgedrückten Ausmaß der geleisteten Arbeit sowie der Erwerbsdauer, wobei die Umverteilungsfunktion der Sozialversicherungen als Korrektiv zu berücksichtigen ist."

Dem fügte das Gericht gleichzeitig bei, hinter der Beibehaltung dieser Einschränkung des Rentenberechnungsgrundlagen-Indikators stünden auch Solidaritätsüberlegungen. Wie jedoch aus den Beweggründen hervorging, ist damit die Solidarität zwischen den Generationen gemeint. Der Gerichtshof hob nämlich hervor, „eine etwaige Abschaffung dieser Beschränkung würde, angesichts 296.000 betroffener Anwartschaften, zu einem jährlichen Anstieg der Rentenausgaben um ca. 1,7 Mrd. zloty führen." Dies hätte gleichzeitig eine Verletzung des Grundsatzes der gemeinsamen Solidarität ,aller Versicherungspflichtiger und vom Nationalen Gesundheitsfonds finanzierte Leistungen in Anspruch nehmender Personen“ zur Folge. Das Verfassungsgericht fügte dem bei, dass ,der aktuelle Aufbau der Versicherung (und der damit einhergehende Solidaritätsgrundsatz) dazu führt, dass die eingenommenen Versicherungsbeiträge sowohl zur Absicherung künftiger Renten versicherungspflichtiger Personen als auch aktuell bezogener Leistungen verwendet werden.“

55 Vgl. Wagner (Fn. 40), S. 227.

56 VerfGH v. 24.10.20055, P 13/04.

57 OTK-A 2005/9/102. 
Nach Ansicht des Verfassungsgerichtshofs sind die in Art. 2 plVerf niedergeschriebenen Grundsätze der sozialen Gerechtigkeit als Kontrollmaßstab für die Verfassungsmäßigkeit des Sozialversicherungsrechts unbedingt unter Einhaltung der Grundsätze des Gemeinwohls (Art. 1 der polnischen Verfassung) und der Solidarität (aus der Präambel der Verfassung), die eine Betrachtung des Systems nicht lediglich aus dem Gesichtspunkt der Einzelinteressen sondern des Gemeinwohls gebieten, anzuwenden.

Überdies stellte der Gerichtshof im Urteil vom 5. Juli 2010 fest: „Im Katalog der Verfassungswerte, welche die soziale Gerechtigkeit ausmachen, sind u.a. die Schaffung von Bedingungen für eine ausgewogene und stabile wirtschaftliche Entwicklung, das Gleichgewicht des Staatshaushalts, das Recht der Bürger, ihre Vertreter zur Bestimmung von Anlage, Richtung und Prioritäten der Sozial- und Wirtschaftspolitik im demokratischen Verfahren zu wählen, zu nennen." Zum Inhalt der Grundsätze der sozialen Gerechtigkeit gehört auch eine Reihe spezieller, an den Gesetzgeber und die öffentliche Verwaltung gerichteter Rechtsgrundsätze, etwa „die soziale Minimalabsicherung, die Gewährleistung einer Grundversorgung für unfreiwillig arbeitslose Personen, aber auch der Gleichheitssatz." ${ }^{\circ 8}$

c) Die Grundsätze der sozialen Gerechtigkeit in sonstigen ausgewählten Systemen der sozialen Sicherheit

\section{aa) Verteilungsgerechtigkeit}

In der Rechtsprechung des Verfassungsgerichtshofs wird grundsätzlich anerkannt, dass die Verteilung von Mitteln in der Gesellschaft außerhalb des Versicherungswesens nach der Formel ,jedem nach seinen (gerechtfertigten) Bedürfnissen oder jedem nach seinen Verdiensten“ erfolgen sollte.

Der Einführung von Wohnungszulagen etwa lag nach Ansicht des Gerichtshofs der Grundsatz der sozialen Gerechtigkeit nach der Formel ,jedem nach seinen Bedürfnissen“ zu Grunde. ${ }^{59}$ Ähnlich verhält es sich, nach Einschätzung der Verfassungsrichter, bei der Gewährung von Sachmitteln für spezielle Zwecke im Rahmen der Sozialhilfe. ${ }^{60}$

58 P 31/09, OTK-A 2010/6/57.

59 VerfGH v. 4.02.1997 r., P 4/96, OTK-ZU 1997/1/3.

60 VerfGH v. 29.09.1993 r., K 17/92, OTK 1993, Teil II, Rn. 33. 
Im Urteil vom 21. Oktober 2014 betonte der Verfassungsgerichthof ferner, auch das Pflegeleistungssystem beruhe auf dem Grundsatz der sozialen Gerechtigkeit nach der Bedürfnisformel. ${ }^{61}$ Bei der Gewährung von Leistungen für die Pflege behinderter Personen muss der Gleichheitssatz nicht zwangsläufig auf alle formellen Mitglieder dieser Berechtigtengruppe (d.h. die in die Pflege von Behinderten eingebundenen nicht erwerbstätige Personen) durchschlagen. Die Annahme einer solchen Verteilungsformel kann eine Rechtfertigung für die Anwendung des Einkommenskriteriums als Voraussetzung für den Erwerb von Leistungen, wie z.B. eines speziellen Pflegegeldes, darstellen.

Der Verfassungsgerichtshof wies jedoch darauf hin, dass „der Gesetzgeber beim Rückgriff auf das Kriterium des Familieneinkommens auf die gesamte Vermögenslage anstatt lediglich auf das Einkommen selbst abstellen sollte. Die Anknüpfung allein an Einkünfte aus abhängiger Arbeit sei, obwohl diese die grundsätzliche Verdienstquelle darstellen, nicht ausreichend und mit Blick auf die Grundsätze der sozialen Gerechtigkeit kaum annehmbar. Überdies kann es die adäquate Einschätzung der Vermögenslage einer Familie, die sich um von der gesamten Gesellschaft finanzierte Leistungen bewirbt, wesentlich erschweren. Der Gesetzgeber sollte demnach vorsichtig mit dem Einkommenskriterium umgehen, wenn er darunter schlicht neuerworbene finanzielle Mittel verstehen will, ohne dabei auf die finanzielle Gesamtlage jener Personen zu achten, die von der Gesellschaft einen Transfer zu ihren Gunsten begehren. Eine derartige Regelung kann nämlich gegen den Gerechtigkeitsgrundsatz verstoßen." Im zitierten Urteil führte der Verfassungsgerichtshof ebenfalls an, dass die Gewährung von Leistungen für Behindertenpfleger nicht zwangsläufig zu einer Gleichbehandlung aller dieser Gruppe formell angehörenden Personen (also der in die Pflege von Behinderten eingebundenen Nichterwerbstätiger) führen muss. Die Schlussfolgerung im Urteil lässt die Annahme zu, der Verfassungsgerichtshof empfand die Gewährung des Pflegegeldes im Verhältnis zur Bedürftigkeit als die adäquate Verteilungsformel für diese Gruppe von Leistungen. Ihre Anwendung vermag es, die unterschiedliche Behandlung verschiedener Pfleger nach dem von vornherein nicht willkürlich bestimmten Bedürftigkeitskriterium zu rechtfertigen. Unter den Seniorenpflegern stellen nämlich weder bereits empfangene noch

61 VerfGH v. 21.10.2014 r., K 38/13, OTK-A 2014/9/104. 
künftige (erwartete wie aufgeschobene) Leistungen der Berechtigten eine Begründung für die Gewährung der Leistung (des Transfers) dar.

\section{bb) Ausgleichende Gerechtigkeit}

Besondere Aufmerksamkeit verdient, vor dem Hintergrund des eben Dargestellten, das Urteil des Verfassungsgerichtshofs vom 24. Juni 201362, in dem die Richter in Bezug auf die ausgleichende Gerechtigkeit explizit äußerten, dass sie für Systeme der sozialen Unterstützung brauchbarer und adäquater als die Verteilungsgerechtigkeit sei. In einer Stellungnahme zu den Voraussetzungen für den Erwerb einer Sozialrente beanstandete der Verfassungsgerichtshof das Erfordernis des Aufenthalts auf polnischem Staatsgebiet und betonte, „Verteilungsgerechtigkeit bezieht sich auf die Voraussetzungen und Verfahren für die Verteilung von Gütern, Vorteilen und Privilegien; sie gründet auf dem Kriterium der Verdienste im Sinne einer proportionalen Beteiligung an den Gütern, Vorteilen und Privilegien im Hinblick auf einen bestimmten Verdienst oder Verdienste.“ Der Gerichtshof stellte daraufhin fest, dass die Gewährung der Sozialrente und die Berechnung ihrer Höhe nicht unter Berücksichtigung des Verdienstkriteriums stattfänden, wie es etwa bei der Sozialversicherungsrente mit der Beitragszeit der Fall sei, weil hier Personen betroffen seien, die sich aus von ihnen nicht zu vertretenden Gründen (Alter und Arbeitsunfähigkeit) nicht auf dem Arbeitsmarkt zurechtfinden und sich dementsprechend kein „Verdienst" i.S. einer Erwerbsdauer erarbeiten konnten.

Nach Ansicht des Gerichtshofs erfährt hier die Verteilungsgerechtigkeit demnach ,gewisse Korrekturen, die eine Hervorhebung der ausgleichenden Gerechtigkeit rechtfertigen."

Auf die Bedeutung der Grundsätze der sozialen Gerechtigkeit - einer ausgleichenden Gerechtigkeit, wie es scheint - berief sich der Verfassungsgerichtshof für die Begründung einer Ungleichbehandlung von wesentlich Ungleichem ebenfalls im Urteil vom 13. Juni $2013^{63}$, als er die Gleichstellung der Lage von weitgehend oder eingeschränkt behinderten

62 VerfGH v. 24.06.2013, P 11/12, OTK-A 2013/5/62.

63 VerfGH v. 13.06.2013, K 17/11, OTK-A 2013/5/58, ähnlich in Bezug auf die einfältige öffentliche Finanzierung von Krankenversicherungsbeiträgen von allen Landwirten, trotz Unterschieden innerhalb dieser Gruppe-VerfGH v. 26.10. 2010, K 58/07, OTK-A 2010/8/80. 
Arbeitnehmern mit der von Nichtbehinderten bei der Normierung der Arbeitszeit beanstandete. Die Verfassungsrichter wandten ein, dass man „bei der Beurteilung der Vereinbarkeit der gerügten Vorschriften mit dem Gerechtigkeitsgrundsatz feststellen muss, dass ungleiche Rechtsträger nichtbehinderte Arbeitnehmer und solche mit einer leichten Behinderung einerseits und schwer- sowie mittelbehinderte Arbeitnehmer andererseits hinsichtlich der Arbeitszeitnormierung im Wesentlichen identisch behandelt worden sind. Gleichzeitig sind keine verfassungsrechtlichen Grundwerte ersichtlich, die einen solchen Verstoß gegen den Gerechtigkeitsgrundsatz zu rechtfertigen vermochten und denen man Vorrang vor dem Schutz der Gesundheit und der Existenz von schwerbehinderten Personen gewähren müsste.“

Der Stellungnahme des Verfassungsgerichtshofs aus dem Urteil in der Rechtssache K 38/13 ${ }^{64}$ folgend, ließe sich demnach annehmen, dass auch die Ungleichbehandlung von Betreuern von behinderten Kindern und Jugendlichen auf der einen und älteren Personen auf der anderen Seite gerechtfertigt sei. Auch hier kann die ausgleichende Gerechtigkeit eine hinreichende Begründung liefern, wenn man annimmt, dass die vom Staat erteilte Unterstützung behinderten Personen und ihren Betreuern die Bewältigung von Barrieren beim Zugang zu Gütern und Dienstleistungen ermöglicht und damit auch für die Gesellschaft - im Wege der sozialen Inklusion behinderter Personen - langfristig ein Vorteil entstehe. Innerhalb der Gruppe der Betreuer von jüngeren Personen würde die ausgleichende Gerechtigkeit hingegen eine vollständige Gleichbehandlung erfordern.

Angesichts dieser Überlegungen erweckt die Einschätzung des Verfassungsgerichtshofs aus dem Urteil in der Rechtssache K 38/13, dass ein Abstellen des Gesetzgebers auf das Kriterium des genauen Eintrittsdatums der Behinderung (bis zur Vollendung des 18. bzw. 24. Lebensjahrs) in Art. 17 Absatz 1 b des Gesetzes über Familienleistungen zu einer Ungleichbehandlung von pflegebedürftigen Personen nach Art. 32 plVerf führe, keine bedeutenden Zweifel. Diese Unterscheidung stellte nämlich keine im Hinblick auf die soziale Gerechtigkeit gebotene Differenzierung dar. Das hier angewandte Kriterium beruhte weder auf der Annahme, dass diese Unterscheidung Bedürfnissen von unterschiedlichem Umfang und Charakter gerecht werde (Verteilungsgerechtigkeit nach dem Bedürfniskriterium), noch darauf dass einzig die Personen, deren Behinderung wäh-

64 VerfGH v. 21.10.2014 r., K 38/13, OTK-A 2014/9/104. 
rend des im Art. 17 Absatz 1b des Gesetzes über Familienleistungen beschriebenen Zeitraums ihren Ursprung hat, ein gewisses unterstützungsbedürftiges Potenzial beibehalten, das eine Angleichung beim Zugang zu gesellschaftlich begehrten Gütern und Leistungen rechtfertigen würde (ausgleichende Gerechtigkeit). Zweifelsfrei deutete das vom Gesetzgeber bestimmte Kriterium - vorbehaltlich der obigen Anmerkungen - darauf hin, ihm seien das Alter von behinderten Personen und ihre fortdauernde bzw. beendete Schulzeit bei der Ausgestaltung des Systems von Pflegeleistungen, mitunter im Wege von verschiedenen Zugangsvoraussetzungen und einer unterschiedlichen Höhe von Leistungen, nicht gleichgültig. Dieses Kriterium hätte jedoch auch in Anlehnung an die ausgleichende Gerechtigkeit bestimmt werden können, ohne gleichzeitig die Formel der Verteilungsgerechtigkeit ,jedem nach seinen gerechtfertigten Bedürfnissen“ gänzlich zu missachten.

Dem geltenden Gesundheitswesen lassen sich durchaus konkrete Ausprägungen der ausgleichenden Gerechtigkeit entnehmen. Dies betrifft vor allem die allgemeine Leistungsberechtigung aller Kinder (bis zum ihrem 18. Lebensjahr) in der Gesundheitsversorgung ungeachtet der Versicherungslage ihrer Eltern und Betreuer. Die Grundlage für diese gesetzliche Bestimmung bildet die - im allgemeinen Interesse liegende - Investition in die Gesundheit und Entwicklung der jüngeren Generationen, um damit einen künftigen, zeitlich versetzten Vorteil zu sichern. Im sonstigen Umfang gelten für die Vorschriften über den Zugang zu Leistungen der Gesundheitsversorgung die Grundsätze der Verteilungsgerechtigkeit entsprechend der Formel ,jedem nach seinen Bedürfnissen“.

Zusammenfassend findet ausgleichende Gerechtigkeit dann Anwendung, wenn ein Rückgriff auf Verdienst- oder Arbeitskriterien entfällt, bestimmte rechtliche Lösungen (mit einem Schutzzweck) dennoch eine entsprechende Begründetheit vorweisen, erstens wegen der angeborenen und von Verdiensten unabhängigen Würde des Menschen und zweitens wegen des Chancenausgleichs bei Verdienstmöglichkeiten, die sich aufgrund von Arbeitsunfähigkeit oder anderen persönlichen Einschränkungen sehr unterschiedlich gestalten können.

Daher zeigte der Verfassungsgerichtshof in seiner Urteilsbegründung zur Rechtssache P 11/1265 auf, dass ,der formelle Gleichheitssatz als Gleichbehandlung von wesentlich Gleichem und Ungleichbehandlung von 
wesentlich Ungleichem allein für sich noch keine gerechte Behandlung gewährleistet. Notwendig erscheint vielmehr die Aufstellung von weiteren Voraussetzungen zur Gewährleistung einer gleichen Beteiligung an Gütern, Vorteilen und Institutionen, im weiteren Sinne - einer gleichberechtigten Teilhabe am gesellschaftlichen Leben. Der verfassungsrechtliche Gerechtigkeitsgrundsatz bietet in diesem Fall keine Rechtfertigung für Ungleichbehandlungen oder Abweichungen vom Gleichheitssatz. Im Gegenteil, er stellt geradezu eine Voraussetzung für die Gleichbehandlung im materiellen Sinne dar. Die Verfassung geht nämlich von einer gleichberechtigten Autonomie des Einzelnen und der Gleichstellung ihrer Werte mit denen von anderen Menschen aus. Die von einer gleichberechtigten Teilhabe am gesellschaftlichen Leben, mitunter beim Zugang zu Gütern, ausgehende soziale Gerechtigkeit kann erst verwirklicht werden, wenn die diesen Zugang versperrenden oder erschwerenden Barrieren abgebaut werden, etwa (1) erstens eine durch Vorurteile und diskriminierende Praktiken, z.B. in Bezug auf behinderte Personen, auftretende fehlende Anerkennung der Individuen oder Gruppen oder (2) zweitens das Fehlen von entsprechenden Mitteln auf Seiten des Individuums oder der Gruppe, die eine gleichberechtigte Teilhabe am gesellschaftlichen Leben überhaupt erst ermöglichen."

Im Vergleich zur ausgleichenden Gerechtigkeit, erfolgt die Zuweisung von Gütern bei der Verteilungsgerechtigkeit nach Arbeit (Leistungen), Verdiensten oder Bedürftigkeit. ${ }^{66}$ Demnach wird grundsätzlich von Diskrepanzen zwischen den Begünstigten und einer ungleichen Berechtigung zu den ausgeteilten Gütern ausgegangen. Ausgleichende Gerechtigkeit setzt demgegenüber keinen bereits erbrachten Beitrag voraus, stattdessen wird sie mit künftigen Handlungen (Arbeit und Beiträgen) der Berechtigten begründet. ${ }^{67}$ An dieser Stelle erzwingt jedoch das Fehlen eines vorausgehenden Beitrags als Bezugspunkt eine identische Gleichverteilung von Gütern. Ein bedeutendes Merkmal dieser Art von sozialer Gerechtigkeit ist die Erforderlichkeit und Angemessenheit der Begründung von Möglichkeiten zur Entfaltung und Nutzung des eigenen Potenzials, vor allem die Einführung von gewissen Präferenzen entsprechend den Ideen von Chancengleichheit und gleichem Zugang. Ausgleichende Gerechtigkeit wirkt demnach vorbeugend gegen einen gesellschaftlichen Ausschluss.

66 So wohl auch Tkacz (Fn. 4), S. 34 ff.

67 Dies entspricht dem Verständnis von ausgleichender Gerechtigkeit nach Ziemiński im Bereich der künftigen, zeitversetzten Gegenseitigkeit. 
Eine auf diese Art begriffene soziale - ausgleichende - Gerechtigkeit sollte die Gestaltung von Leistungssystemen zur Förderung und Unterstützung des individuellen Potenzials und zum Ausgleich verschiedener Defizite beeinflussen. Darunter fallen etwa Familienleistungen, Stipendien, die Gesundheitsvorsorge (z.B. die Impfung von Kindern und Jugendlichen) oder Leistungen für Einzelpersonen oder Gruppen, die wegen körperlichen Beeinträchtigungen Beschränkungen beim Zugang zu verschiedenen Gütern und Leistungen erfahren.

Ausgleichende Gerechtigkeit wirkt sich zugunsten der Chancen junger Menschen aus, weswegen sie Renten- und Alterspflegesysteme nur in geringerem Maße betreffen. In einem gewissen Umfang vermag sie das Recht auf Versorgungs- und Sozialversicherungsleistungen bei Lohnausfall während der Kindererziehungszeit (z.B. Mutterschaftsgeld und andere Elternleistungen, die Fortzahlung von Rentenbeiträgen durch den Staat) zu beeinflussen.

Die Angemessenheit dieser Lösungen hängt jedoch davon $a b$, ob sie erstens die generationenübergreifende Solidarität nicht beeinträchtigen, d.h. keine übermäßige Belastung für die aktuell erwerbstätige Generation darstellen, und zweitens entsprechende sozioökonomische Voraussetzungen für ihre Anwendung herrschen, die eine künftige Rückgewinnung der getätigten Kosten erwarten lassen. 


\title{
Zur sozialen Solidarität in der Gesundheitsversicherung ${ }^{1}$
}

\author{
Daniel Eryk Lach
}

\section{Einführung - Bedeutung des Grundsatzes der sozialen Solidarität für den Aufbau des Systems der Gesundheitsfürsorge}

Geradezu offensichtlich erscheint die These, dass der Grundsatz der sozialen Solidarität ein Fundament (einen Leitgedanken) für den versicherungsbasierten Ansatz zur Lösung der sozialen Absicherung darstellt. ${ }^{2}$ Aussagen dieser Art lassen sich sowohl der Literatur ${ }^{3}$ als auch der Rechtsprechung des Verfassungsgerichtshofs ${ }^{4}$ entnehmen. In Bezug auf die Gesundheitsfürsorge sieht Art. 65 des Gesetzes vom 27. August 2004 über Leistungen der aus öffentlichen Mitteln finanzierter Gesundheitsfürsorge ${ }^{5}$ (im Folgenden: LÖffGG) die Solidarität explizit als einen Leitgrundsatz für

1 Es handelt sich hierbei um eine abgeänderte und ergänzte Fassung des Vortrags von der XIX. Tagung von Lehrstühlen für Arbeits- und Sozialversicherungsrecht unter dem Titel „Axiologische Grundlagen des Arbeits- und Sozialversicherungsrechts“, Posen, 15.-17. Mai 2013, veröffentlicht in: Skapski/Ślebzak (Hrsg.), Aksjologiczne podstawy prawa pracy i ubezpieczeń społecznych, Posen 2014, S. 271-285.

2 Es ist auch die Bedeutung der Solidarität als ein allgemeines Prinzip der Unionsrechtsordnung zu bemerken. Becker betonte dazu, dass die Solidarität nicht unmittelbar zur Herleitung ungeschriebener Rechte und Pflichten dient, denn sie besitzt auch als Prinzip vorrechtlichen Charakter und bedarf immer der Konkretisierung durch gesetzliche Akte, wenn aus ihr verbindliche Folgen abgeleitet werden sollen. Das gilt gerade auch für die mit sozialen Interventionen verbundene Umverteilung, für die Solidarität ein Leitbegriff ist. Nichtsdestotrotz hängt die Legitimität der Rechtsordnung auch davon ab, dass sie unter den Bürgern Solidarität im Sinne der Sicherung der eigenen Grundlagen - auf nationaler wie auf europäischer Ebene herstellt und bewahrt. Vgl. Becker, Sozialstaatlichkeit in der Europäischen Union, in: Hatje (Hrsg.), Verfassungszustand und Verfassungsentwicklung in der Europäischen Union, EuR Beiheft. 2/2015, S. 36.

3 So Jończyk, Prawo zabezpieczenia społecznego, Krakau 2001, S. 38.

4 Vgl. VerfGH v. 11.02.1992, K 14/91, OTK 1992, H. 1, Pos. 7.

5 Konsolidierte Fassung: Poln. GB1. 2008, Nr. 164, Pos. 1027 mit späteren Änderungen. 
die Organisation der „Gesundheitsversicherung"6 vor. Dabei ist die Annahme zulässig, es handele sich nicht lediglich um einen starren, beschreibenden Grundsatz (die Bestimmung, wie gewisse Rechtsinstitute der „Gesundheitsversicherung" beschaffen sein sollen), sondern ebenfalls um einen leitenden Grundsatz i.S. einer bestimmten Verhaltensvorgabe. Der vom Gesetzgeber für Art. 65 LÖffGG gewählte Wortlaut, die Gesundheitsversicherung „,werde nach dem Grundsatz der sozialen Solidarität verwirklicht", lässt die Annahme zu, dass diesem eine besondere Rolle im Aufbau der öffentlich finanzierten Gesundheitsfürsorge zugeschrieben wurde. Somit bildet er nicht nur einen Ansatzpunkt für sozialpolitische Wertungen, sondern stellt vor allem eine materielle Begründung für eine Reihe von Normen, insbesondere zur Finanzierung des Systems, dar. ${ }^{7}$

Der Grundsatz der sozialen Solidarität bildete auch die Grundlage für Lösungen wie der beitragsfreien Mitversicherung von Familienmitgliedern, dem Absehen von einer Bindung der garantierten Leistungen an die Beitragshöhe sowie der uneingeschränkten Höhe der Beitragsbemessungs-

6 Der Begriff „Gesundheitsversicherung“ wird nachfolgend in Anführungszeichen angegeben, da das System der Gesundheitsfürsorge, entgegen seiner Bezeichnung als Versicherung, nicht nach versicherungstechnischen Grundsätzen aufgebaut ist. Der Nationale Gesundheitsfonds - weder ein Versicherer im eigentlichen Sinne des Wortes noch ein staatliches Organ - fungiert als Verwalter für öffentliche, größtenteils beitragsfinanzierte Mittel und nimmt im Wesentlichen die Aufgaben eines Treuhänders der Leistungsempfänger wahr. Er handelt nämlich im eigenen Namen (z.B. bei Vertragsschlüssen mit Leistungserbringern), gleichwohl aber auch im Interesse der Leistungsempfänger (weil sie letzten Endes die Anspruchsberechtigten aus den vertraglich gesicherten Leistungen sind). Trotz der Versicherungsstaffage und der Zahlung von „Beiträgen“ genießen die „Versicherten“ keine körperschaftlichen Rechte gegenüber dem Nationalen Gesundheitsfonds. Dieser ist zwar eine speziell für die Verwaltung und den Betrieb vom Gesundheitswesen ins Leben gerufener professioneller Treuhänder, jedoch gerade keine selbstverwaltende, zur Vertretung der Versichertengemeinschaft berufene Versicherungsinstitution. Wenngleich er im Interesse der Leistungsempfänger handelt, so tut er dies dennoch im eigenen Namen als eigenständiger Rechtsträger mit einem gesetzlich genau bestimmten Kompetenzbereich. Vertiefend: Lach, Powiernicza technika realizacji zabezpieczenia społecznego (na przykładzie ubezpieczenia zdrowotnego), Państwo i Prawo 2009, Heft 3, S. 34-47.

7 Zum begrifflichen Verständnis von Rechtsgrundsätzen vgl. Wronkowska/Zieliński/ Ziembiński, Zasady prawa. Zagadnienia podstawowe, Warschau 1974, S. 24 ff.; Wróblewski, Prawo obowiązujące a „ogólne zasady prawa“, Zeszyty Naukowe Uniwersytetu Łódzkiego 1965, Heft 42, S. 18 ff., aber auch: Opałek/Wróblewski, Zagadnienia teorii prawa, Warschau 1969, S. $92 \mathrm{ff}$. 
grundlage und dem Heranziehen aller Einkommensquellen bei ihrer Festsetzung (Grundsatz des universalen Beitrags). Gleichzeitig liefert er auch eine Begründung für die aus diesem Grundsatz resultierende Ungleichbehandlung verschiedener Gruppen von Leistungsempfängern bei der Regelung ihrer Versicherungsverhältnisse. Dies ist insbesondere für das in Art. 68 Abs. 2 der polnischen Verfassung aufgestellte Gebot der Schaffung eines Systems der Gesundheitsfürsorge von Bedeutung, das nicht nur der praktischen Umsetzung des Rechts auf Leben und dem damit verbundenen Recht auf den Schutz der eigenen Gesundheit dienen soll, sondern überdies den Bürgern unabhängig von ihrer Einkommenslage einen gleichen Zugang zu Leistungen der öffentlich finanzierten Gesundheitsfürsorge im Krankheitsfall zu gewährleisten hat.

Bevor zu weiteren Überlegungen übergegangen werden kann, gilt es zu betonen, dass der Grundsatz der sozialen Solidarität hauptsächlich die Pflichten der Leistungsempfänger, nicht hingegen ihre Rechte betrifft. Anders ausgedrückt: Durch den Grundsatz der sozialen Solidarität sind die Teilhabe an der Risikogemeinschaft und der Umfang der Verpflichtung zur Lastentragung zu betrachten. Während die Leistungsberechtigung bereits auf die bloße Teilhabe zurückzuführen ist, bleibt der Umfang der Berechtigung von der individuellen Bedürftigkeit abhängig - der besagte Grundsatz findet demnach an dieser Stelle keine Anwendung.

Ein kurzer Blick auf diese Problematik zeigt, dass die für das Privatrecht bezeichnende Gegenseitigkeit von Beitrag und Anspruch auf Leistungen gerade keine Geltung für das aktuelle Gewährleistungssystem der Gesundheitsfürsorge beansprucht. Entscheidend hierfür ist, dass die Leistungsberechtigung (die Teilhabe an der gesetzlichen Leistungsgarantie) und die Pflicht zur Zahlung von Beiträgen in keinem zwingenden Verhältnis zueinander stehen. Einen Hinweis dafür bietet Art. 67 LÖffGG. Der Gesetzgeber unterscheidet zwischen der „Erfüllung der Versicherungspflicht" (Abs. 1) durch Anmeldung und die Entrichtung der eigenen Beiträge einerseits und dem „Erwerb von Leistungsrechten im System der Gesundheitsfürsorge" andererseits, für den bereits die Erfüllung der entsprechenden Anmeldepflichten ausreichend ist (Abs. 2). Daraus lässt sich ableiten, dass auch wenn die Zahlung von Versicherungsbeiträgen im System der Gesundheitsfürsorge zu den grundlegenden Pflichten der Leistungsempfänger gehört, der Erwerb von Leistungsansprüchen dennoch ausschließlich von der Anmeldung im dafür vorgesehenen Verfahren ab- 
hängig ist. ${ }^{8}$ Offensichtlich ausgeschlossen ist aus diesem Grund die Gegenseitigkeit der besagten Leistungen - des Versicherungsbeitrags auf der einen und der staatlichen Gewährleistung auf der anderen Seite - im Sinne eines synallagmatischen Verhältnisses nach Art. 487 des polnischen Zivilgesetzbuches. Dies bedeutet, dass auch eine eventuelle Prüfung auf ihre Äquivalenz hin unterbleiben muss, weil mangels eines Gegenseitigkeitsverhältnisses (do ut des) auch kein Vergleich von Leistungen angestellt werden kann. ${ }^{9}$

Vor dem Hintergrund, dass Beiträge und Leistungen im System der Gesundheitsfürsorge dieses Grundprinzip durchbrechen, ist auf die Aussage von Sadurski hinzuweisen, der in Anlehnung an die aristotelische Unterscheidung zwischen Verteilungs- und ausgleichender Gerechtigkeit anmerkte: „Ausgleichende Gerechtigkeit verlangt eine Gleichwertigkeit der ausgetauschten Güter und Dienstleistungen, jedoch kann die Feststellung, welche Güter und Dienstleistungen den gleichen Wert besitzen, nicht ohne vorherige Einschätzungen verteilender Natur, d.h. unter Berücksichtigung der relativen Lage der am Austausch teilnehmenden Parteien im gesamten Verteilungsgefüge, erfolgen. [...] Die austauschende Gerechtigkeit erweist sich [...] als abhängig vom Urteil der Verteilungsgerechtigkeit, denn die Gleichwertigkeit der ausgetauschten Güter [...] entpuppt sich als nichts anderes, denn ihre proportionale Verteilung nach einem vorweg angenommenen Kriterium". ${ }^{10}$. Mit anderen Worten erweist sich die Behauptung, dass der Grundsatz der sozialen Solidarität die fehlende Äquivalenz von Beiträgen und Leistungen legitimiere, als eine gedankliche Abkürzung. Der Solidaritätsgrundsatz rechtfertigt nämlich einzig eine solche Ausgestaltung des Umfangs der gewährten Gesundheitsfürsorge, bei der die Beitragshöhe auf das persönliche Einkommen zurückzuführen ist, während der Umfang der gewährten Leistungen allein von der festgestellten Bedürftigkeit abhängt. Eine entsprechende Ungleichbehandlung verschiedener Personen ist unter dem Gesichtspunkt der Verteilungsgerechtigkeit gerechtfertigt. Deshalb sind die Pflicht des Versicherten und die gesetzliche Gewährleistung in dem Sinne gleichwertig, dass jedem Berechtigten ohne

8 Vgl. Lach, Nabycie prawa do świadczeń opieki zdrowotnej, Praca i Zabezpieczenie Społeczne 2010, Heft 11, S. 2-9.

9 Vgl. umfassender Lach, Zasada równego dostępu do świadczeń opieki zdrowotnej, Warschau 2011, S. 319 f.

10 Sadurski, Teoria sprawiedliwości. Podstawowe zagadnienia, Warschau 1988, S. $71 \mathrm{f}$. 
Rücksicht auf die individuelle Belastung des Einzelnen durch die Beitragspflicht (bzw. die Befreiung von ebendieser) derselbe Umfang und Standard von Leistungen angeboten wird.

Die Rolle und Bedeutung des Grundsatzes der sozialen Solidarität für den Aufbau des Systems der Gesundheitsfürsorge vor Augen lohnt ein Rückblick auf - einem ausführlicheren Beitrag über die Begründung der unterschiedlichen Ausgestaltung der rechtlichen Lage von (einzelnen Gruppen von) Versicherten entnommenen ${ }^{11}$ - Aussagen zum Inhalt dieses Prinzips und seiner Tragweite bei der Schaffung und Bewertung von rechtlichen Maßnahmen im Bereich des Aufbaus, der Organisation und der Finanzierung des Systems der Gesundheitsfürsorge.

\section{Der Grundsatz der sozialen Solidarität in der Literatur und Rechtsprechung}

\section{Die philosophischen Grundlagen des Solidaritätsgedankens}

Bei der Definition des Grundsatzes der sozialen Solidarität lohnt zunächst ein Blick auf die Solidarität als eine Idee, die zur letzten Jahrhundertwende Einzug in die Sozialwissenschaften hielt. Ihr Ausgangspunkt war die Vision von einer Gesellschaft als ein selbstständiges, gerade auf der Solidarität seiner Mitglieder gegründetes Wesen. Durkheim empfand die soziale Solidarität als moralische Erscheinung, die sich nach außen hin durch Recht manifestierte. ${ }^{12}$ In Anlehnung an Durkheims Gedanken betonte Duguit, dass die Solidarität als soziale Interdependenz aus zwei Teilen bestehe: Der Deckungsgleichheit menschlicher Bedürfnisse von Mitgliedern derselben sozialen Gruppe einerseits sowie der Unterscheidung ihrer Bedürfnisse und Fähigkeiten andererseits. Im Zusammenhang mit diesen Bestandteilen lässt sich auch von einer „Solidarität durch Affinität“ (Men-

11 Lach (Fn. 8), S. 111-124.

12 Für eine umfassendere Darstellung der Ideen von Durkheim vgl. Olszewski, Historia doktryn politycznych i prawnych, Warschau 1982, S. 327; aber auch: Oniszczuk, Filozofia i teoria prawa, Warschau 2008, S. 910 f. Vgl. darüber hinaus: Mik, Solidarność w prawie Unii Europejskiej. Podstawowe problemy teoretyczne, in: Mik (Hrsg.), Solidarność jako zasada działania Unii Europejskiej, Thorn 2009, S. 33 f. und Czarnota, Prawo a współczesne odmiany solidaryzmu społecznego, in: Labno (Hrsg.), Idea solidaryzmu we współczesnej filozofii prawa i polityki, Warschau 2012, S. $60 \mathrm{ff}$. 
schen tun sich zusammen, um gemeinsame Bedürfnisse zu erfüllen) oder einer „Solidarität durch Arbeitsteilung“ (Menschen tun sich zusammen, um füreinander Dienstleistungen zu erfüllen und dabei gleichzeitig verschiedenartige Bedürfnisse zu erfüllen) sprechen. Duguit erblickte die Rechtfertigung für das Bestehen des Rechtsstaates gerade in der letztgenannten „Solidarität durch Arbeitsteilung“. ${ }^{13}$ Die „Solidarität durch Affinität" und die Gründung von Bedarfsgemeinschaften dort, wo sich Menschen mit der Erfüllung von Bedürfnissen nicht anders zu helfen wissen, sind hingegen als das Fundament und die Begründung der sozialen Absicherung im Wege einer versicherungstechnischen und treuhänderischen Lösung mitsamt dem tragenden Konzept der (zwingenden) Risikogemeinschaft anzusehen. ${ }^{14}$

Im 20. Jahrhundert entstand als Reaktion auf totalitäre Ideologien und den Zweiten Weltkrieg das Konzept des integralen Humanismus, der mit der Hervorhebung der Menschenwürde im gesellschaftlichen Leben und ihrem Vorrang gegenüber der Gesellschaft den Grundstein für die Lehre vom sozialen Personalismus legte. ${ }^{15}$ Dies bildete den Ausgangspunkt für die Beschlüsse des II. Vatikanischen Konzils und der begleitenden Enzykliken, in denen ein Vorrang privater Initiative betont wurde, während staatliche Eingriffe - entsprechend dem Subsidiaritätsprinzip - einzig zum Zwecke der Befürwortung, Förderung, Koordinierung, Unterstützung und Ergänzung erwünscht seien - so z.B. die Enzyklika Mater et magistra (1961). Der Begriff der Solidarität hielt schließlich in späteren Enzykliken Einzug. Die Enzyklika Laborem exercens (1981) sprach die Solidarität in ihrer defensiven Bedeutung an, in Bezug auf den Konflikt zwischen Arbeit und Kapital. Sie wurde darin als eine gemeinsame billige Reaktion auf die Degradierung des Menschen zum Arbeitssubjekt umschrieben. Ein abweichender Solidaritätsbegriff wurde in der Enzyklika Sollicitudo rei socialis (1987) formuliert. Dort beschrieb man Solidarität als „einen festen und be-

13 Vgl. Duguit, Kierunki rozwoju prawa cywilnego na początku XIX wieku, in: Czarnota/Justyński (Hrsg.), Wybór tekstów źródłowych z historii doktryn politycznoprawnych, B. 2, Thorn 1988, S. 196, aber auch: Mik, ebenda, S. 34 und Olszewski, ebenda, S. $422 \mathrm{ff}$.

14 Anders stellt sich die Situation in der Grundversorgung dar, bei der die Bürgergemeinschaft alle Bürger (Bewohner) umfasst und die Zuständigkeit für die Gewährleistung der sozialen Sicherheit (wenn auch im eingeschränkten Umfang) bei der öffentlichen Hand liegt.

15 Vgl. Auleytner, Polityka społeczna, czyli ujarzmianie chaosu socjalnego, Warschau 2002, S. $198 \mathrm{f}$. 
ständigen Willen, sich für das Gemeinwohl, also das Wohlbefinden aller und eines jeden, einzusetzen“, und schrieb ihr, anders als in der Enzyklika Laborem exercens, eine positive Bedeutung als „Engagement“ zu. ${ }^{16}$

Nicht ohne Bedeutung ist dabei, dass die Hervorhebung der Würde einer Person im gesellschaftlichen Zusammenleben, ähnlich wie der Vorrang der Würde des Einzelnen vor der Gesellschaft, nicht zwangsläufig in einem Spannungsverhältnis zum, mit den Ideen von Gerechtigkeit und Solidarität verwandten, Grundsatz „Vorrang des Gemeinwohls“ stehen müssen. Der soziale Personalismus betont nämlich die Würde und Bedeutung eines Einzelnen gegenüber totalitärer Unterdrückung. In einer demokratischen Grundordnung hingegen sollte der Individualismus nicht in Egoismus umschlagen. Daraus lässt sich schließen, dass eine Grundvoraussetzung für die Entstehung einer Solidargemeinschaft (z.B. einer Risikogemeinschaft) in dem Bewusstsein zu erblicken ist, welche Ziele mit ihr verfolgt werden und welche Bedeutung sie für ihre Mitglieder hat. Dies gilt sogar dann, wenn eine Zwangsmitgliedschaft besteht. Ein auf diese Art und Weise begriffenes Bewusstsein sollte überdies den Einzelnen von Missbrauchsversuchen abhalten und die Mitglieder der Gemeinschaft zur Befolgung gewisser Regeln (Erfüllung von aus der Solidarität resultierenden Pflichten) wie zur Anerkennung der vorrangigen Stellung des Allgemeininteresses (des Gemeinwohlgrundsatzes) bewegen.

\section{Aussagen in der polnischen Lehre}

Von den kanonischen Studien der polnischen Lehre im Bereich der sozialen Absicherung ist an erster Stelle die Feststellung von Szubert zu nennen, der aufzeigte, dass ,zu den Alleinstellungsmerkmalen der Sozialversicherung die Verteilung der Beitragslast auf eine weite Gesamtheit von Verpflichteten gehört“. In diesem Kontext gebrauchte er jedoch nie den Begriff „Grundsatz der sozialen Solidarität“. ${ }^{17}$ Der Verfassungsgerichtshof stellte in Anlehnung daran in seiner Entscheidung vom 11. Februar 1992 lakonisch fest, dass der Grundsatz der sozialen Solidarität, der die Verteilung der Beitragslasten auf eine weite Gesamtheit von Sozialversi-

16 Ebenda, S. 198-203.

17 Szubert, Ubezpieczenie społeczne. Zarys systemu, Warschau 1987, S. 62 f. 
cherten gebietet, eine Rechtfertigung für die umverteilende Funktion von Versicherungen darstellt. ${ }^{18}$

Zieliński hingegen behandelte die Problematik der Solidarität im Zusammenhang mit dem Subsidiaritätsgrundsatz und dem Personalismus, welche als Bestandteile der katholischen und evangelischen Sozialphilosophie seiner Ansicht nach die ideelle Grundlage für den Sozialstaat bilden. Demnach stellt der Solidaritätsgrundsatz im Hinblick auf Sozialversicherungen eine „mithilfe eines von allen Versicherten gemeinsam getragenen Fonds erfolgte Konkretisierung der Idee der sozialen Selbsthilfe bei der Unterstützung bedürftiger Personen" dar. ${ }^{19}$ Zieliński berief sich darüber hinaus auf den Grundsatz der Solidarität unter Versicherten, die er mit der Gegenseitigkeitsidee gleichsetzt: Die Versicherungslast wird gemäß der Formel „einer für alle, alle für einen“ durch die Gemeinschaft der Versicherten getragen. Dabei darf der Grundsatz der Gegenseitigkeit (der Solidarität unter Versicherten) aber nicht mit dem schuldrechtlichen Gegenseitigkeitsprinzip (Leistungssynallagma) verwechselt werden, da dieses den Sozialversicherungen fremd ist. ${ }^{20}$

Auch Piotrowski betont die Bedeutung des Solidaritätsgrundsatzes für die Risikogemeinschaft, in der es zu einer Verteilung der Verantwortung unter allen Versicherten kommt. Er stellt fest, dass das Wesen der Risikogesellschaft in dem Bedürfnis besteht, die durch Zufallsereignisse entstandenen Vermögensbedürfnisse auf eine Vielzahl von Personen zu verteilen, die auf ähnliche Weise von einem nicht absehbaren Risiko betroffen sind. ${ }^{21}$

Eine ähnliche Ansicht vertritt auch Jończyk, der darauf hinweist, dass in der Literatur ,in Bezug auf Risikogemeinschaften im rechtlichen Sinne selten die Rede von Solidarität ist, obwohl diese jeglichen Formen der sozialen Absicherung zugrunde liegt".22 Besonders hervorzuheben ist folgende Aussage dieses Autors: „Die Solidaritätsthematik betrifft Pflichten, Lasten, individuelle Beiträge, gemeinsame Anstrengungen, nicht hingegen die Verteilung von Geld- und Sachleistungen“, denn „die Solidarität einer

18 VerfGH v. 11.02.1992, K 14/91, OTK 1992, H. 1, Pos. 7.

19 Zieliński, Ubezpieczenia społeczne pracowników. Zarys systemu prawnego część ogólna, Warschau - Krakau 1994, S. 20.

20 Vgl. ebenda, S. $17 \mathrm{ff}$. sowie $130 \mathrm{f}$.

21 Vgl. Piotrowski, Zabezpieczenie społeczne. Problematyka i metody, Warschau 1966, S. 173.

22 Jończyk (Fn. 3), S. 38. 
Risikogemeinschaft drückt sich durch die Finanzierung (mittels individueller Beiträge) der sozialen Absicherung aus und sollte nicht mit dem Ausgleich von finanziellen Lasten im Rahmen von Risiko- bzw. Solidaritätsgemeinschaften verwechselt werden". ${ }^{23}$ Aus diesem Grund merkte Jończyk an, dass ,im Kontext der Aufteilung von Leistungen vielmehr von Gerechtigkeit als von Solidarität die Rede ist" ${ }^{24}$ In Bezug auf den Inhalt des Solidaritätsgrundsatzes stellte der Autor fest, die Schaffung einer Risikogemeinschaft (auch in Bezug auf das Risiko, nicht gesund zu sein) beruhe auf der Prämisse, es seien von ihr Rechtsträger umfasst, die - wenngleich in verschiedenem Maße - imstande und bereit sind, die Kosten des Schutzes gegen die Folgen des Eintretens eines bestimmten Risikos zu tragen. Gerade im Hinblick auf Systeme sozialer Sicherheit insgesamt und Systeme der Gesundheitsfürsorge im Besonderen beziehen sich die genannten Unterschiede nicht lediglich auf die Fähigkeit, das System mitzufinanzieren, sondern genauso auf die „Risikoanfälligkeit“ i.S. der individuellen Wahrscheinlichkeit des Eintretens eines Zufallsereignisses, welche als Grundlage für den rechtlichen Begriff des sozialen Risikos dient. Ebenso wenig besteht ein ,symmetrisches Verhältnis zwischen dem eigenen Beitrag und den empfangenen Leistungen“, vielmehr spiegelt diese Asymmetrie das wahre Wesen der Solidarität wider: „Obgleich sich alle am System beteiligen, wenn auch oftmals in ungleichem Maße sowie in längeren oder kürzeren Mitgliedszeiträumen, so empfangen doch einzig die Personen eine Entschädigung, die tatsächlich einen Schaden erlitten haben“. ${ }^{25}$ Aus diesem Grund - und ferner zur Verhinderung von „Egoismus und Spekulation“ - muss die Schaffung einer Risikogemeinschaft obligatorisch sein, da diese eine „Garantie für die Solidarität und Tragfähigkeit der Sozialversicherungen" darstellt. ${ }^{26}$ Unmittelbar zum System der Gesundheitsfürsorge sprach sich Jończyk wie folgt aus: „Im Vergleich mit der Zeit der Volksrepublik Polen ist es sogar zu einer Vertiefung des Solidaritätsgrundsatzes gekommen, was sich beispielsweise in einer deutlich größeren Finanzierungsvielfalt im Bereich der Gesundheitsrisiken zeigt [...]. Angesichts der auseinandergehenden Einkommensschere in der Bevölkerung (die ihren Hauptverdienst mit Arbeitslöhnen bestreitet) ist zwangsläufig eine wachsende Diskrepanz zwischen Beitragszahlungen

23 Ebenda.

24 Ebenda.

25 Ebenda.

26 Ebenda, S. 39. 
und empfangenen Leistungen zu erwarten" ${ }^{27}$ Dies verleitete den Autor zu einer klaren Stellungnahme: „Es handelt sich somit um eine gesetzlich auferlegte Solidarität, die im Lichte der Staatsorganisation der III. Republik keine hinreichende ethische, soziale und wirtschaftliche Rechtfertigung findet". .28

\section{Der Solidaritätsgrundsatz und sozialer Solidarismus in der Rechtsprechung des Verfassungsgerichtshofs und des Obersten Gerichts}

An dieser Stelle soll nun die Rechtsprechung des Verfassungsgerichtshofs zum Solidaritätsgrundsatz näher beleuchtet werden. Im bereits zitierten Urteil vom 11. Februar $1992^{29}$ befand der Gerichtshof, dass „eine Begründung [...] für die Umverteilungsfunktion der Sozialversicherungen im Grundsatz der sozialen Solidarität liegt, der eine Verteilung der Beitragslast auf die Allgemeinheit der Versicherungspflichtigen verlangt“. Ferner hob der Verfassungsgerichtshof im Urteil vom 7. Januar 200430, Az. K 14/03 ${ }^{31}$, den finanziellen Aspekt des Solidaritätsgrundsatzes hervor und stellte fest: „Der Zugang zu öffentlich finanzierten Leistungen muss für alle Bürger unabhängig von ihrer finanziellen Lage gleichermaßen möglich sein. Die von der untersuchten Vorschrift normierte Gleichheit beim Zugang zu Leistungen der Gesundheitsfürsorge stellt eine Fortbildung des allgemeinen Gleichheitssatzes aus Art. 32 der Verfassung sowie dem Konzept der sozialen Solidarität dar. Die Voraussetzungen für die Nutzung der Leistungen der Gesundheitsfürsorge richten sich nämlich unabhängig von der Beteiligung des einzelnen Bürgers nach der Aufbringung der öffentlichen Mittel zur Finanzierung dieser Leistungen“.

Ähnlich formulierte das Oberste Gericht den Solidaritätsgrundsatz im Urteil vom 9. Juni $2005^{32}$, indem es feststellte, dass ,die Organe der öf-

27 Ebenda, S. 309.

28 Ebenda. Vgl. auch: Jończyk, Transformacja ubezpieczeń społecznych i ochrony zdrowia, in: Szurgacz (Hrsg.), Konstytucyjne problemy prawa pracy i zabezpieczenia społecznego. Referaty na XV Zjazd Katedr i Zakładów Prawa Pracy i Ubezpieczeń Społecznych, Wrocław 1-2 czerwca 2005 r., Breslau 2005, S. 120 f.

29 VerfGH v. 11.02.1992, K 14/91, OTK 1992, H. 1, Pos. 7.

30 VerfGH v. 07.02.2004, K14/03.

31 Poln. GBl. 2004, Nr. 5, Pos. 37.

32 Oberstes Gericht v. 09.06.2005, III CK 626/04 = OSNC 2006, Nr. 5, Pos. 89. 
fentlichen Gewalt zur Erhaltung eines öffentlich finanzierten Systems der Gesundheitsfürsorge verpflichtet worden sind, das den Grundsätzen der allgemeinen Zugangsgleichheit und der Solidarität in Gestalt der Verwendung der gleichen medizinisch angemessenen Verfahren gegenüber Bedürftigen ungeachtet deren Beteiligung an der Gestaltung der Einnahmen des Systems Folge leistet".

Vor diesem Hintergrund ist anzumerken, dass Untersuchungen der Rechtsprechungspraxis im Schrifttum ergaben, dass die „Termini ,Solidarität ${ }^{\circ}[\ldots]$ und ,Solidarismus' synonym verwendet werden und die jeweilige Begriffswahl mehr auf stilistischen denn auf sachlichen Überlegungen beruht" ${ }^{33}$ In der Literatur wurde sogar die Ansicht vertreten, dass „oftmals der geltende Sprachgebrauch über die Unterscheidung zwischen den Begriffen ,Solidarität" und ,Solidarismus' und ihre Austauschbarkeit bestimmt. Vom sprachlichen Brauchtum hängt demzufolge unsere Entscheidung ab, wie wir uns bei der Anwendung der Begriffe Solidarismus und Solidarität entscheiden und ob von einem solidaristischen oder solidarischen Staat in Rede ist. Unter diesen Umständen sind jegliche Versuche, die genauen Unterschiede zwischen den beiden Begriffen herzauszuarbeiten, zum Scheitern verurteilt. Deshalb bestehen auch keine Hindernisse, beide Begriffe synonym zu verwenden". 34 Dieser Annahme kann kaum widersprochen werden.

Das Problem der korrekten Terminologie bei der Behandlung der theoretischen Grundlagen und des Aufbaus von Techniken zur Verwirklichung der Idee von einer sozialen Absicherung wurde bereits früher in Bezug auf die Rechtsprechung des Obersten Gerichts diskutiert. ${ }^{35}$ Zwischen dem Grundsatz der sozialen Solidarität und dem sozialen Solidarismus besteht ein wesentlicher Unterschied. Gemäß der Definition im „Wörterbuch der polnischen Sprache" bezeichnet man als Solidarismus eine Mitte des 19. Jh. entstandene sozialpolitische Denkrichtung, die von einer natürlichen Interessengemeinschaft ausgeht, welche sich aus verschiedenen Gruppen

33 Vgl. Bielska-Brodziak/Bogucka, Solidarność jako termin prawny i jego funkcjonowanie w praktyce orzeczniczej, in: Labno (Hrsg.), Idea solidaryzmu we współczesnej filozofii prawa i polityki, Warschau 2012, S. 208 ff.

34 Vertiefend zu den Termini „Solidarismus” und „Solidarität” vgl. Tkacz/Wentkowska, O naturze teoretyczno-prawnej i uwikłaniach pojęcia „solidaryzm”, in: Labno (Hrsg.), Idea solidaryzmu we współczesnej filozofii prawa i polityki, Warschau 2012, S. 107 ff.

35 Vgl. Lach, Glosse zum Beschluss des Obersten Gerichts v. 27. 04.2005, II UZP 2/05, GSP Prz. Orz. 2006, Nr. 2, S. 163 ff. 
von Bürgern im Staat unabhängig von finanziellen und sozialen Unterschieden zusammensetzt. Der Grundsatz der sozialen Solidarität betrifft hingegen allein die Mitglieder der Gemeinschaft aller Versicherten - einer Risikogemeinschaft - und nicht die Gesamtheit der Bürger (woran auch die allgemeine Natur der „Gesundheitsversicherung“ nichts zu ändern vermag). Jończyk führte dazu nüchtern an: „Die Solidarität einer Risikogemeinschaft ist von einem Gruppencharakter geprägt [...]. Es handelt sich bei ihr um keine gesamtmenschliche, globale [...], nationale Solidarität."36

Der zutreffenden Bemerkung von Ślebzak ${ }^{37}$ über das Sozialversicherungswesen, dass in einer Gemeinschaft von Solidarität sowohl in den Beziehungen zwischen den Versicherten untereinander, als auch zwischen ihnen und den Leistungsempfängern ${ }^{38}$, den Versicherten und den Beitragszahlern (im Kontext der Zuweisung von Beiträgen), den Leistungsempfängern untereinander und, schließlich, den Leistungsempfängern und dem Staat ausgegangen werden könne, ist anzufügen, dass in Bezug auf die "Gesundheitsversicherung" einzig von der Solidarität zwischen Versicherten gesprochen werden kann. Dies geht mit der Tatsache einher, dass nur sie alleine die Risikogemeinschaft bilden. Patienten, die Leistungen empfangen, gehören ihr insofern an, als dass sie auch nach Beginn der Durchführung einer konkreten Leistung weiterhin in den Genuss der gesetzlichen Garantie kommen. Angesichts der Belastung durch die Beitragspflicht - die nebenbei bemerkt als mit der Einkommensteuer strikt verbundene, einzig Versicherungspflichtigen, in der Praxis vor allem Erwerbstätigen auferlegte quasi-Zwecksteuer zur Erhaltung der Gesundheitsfürsorge angesehen werden kann - sowie der Finanzautonomie der Gesundheitsfürsorge spielt die Solidarität im Falle der „Gesundheitsversicherung“ in den anderen, oben genannten Verhältnissen keine Rolle. Dies ist darauf zurückzuführen, dass im Rahmen dieses Systems eine als ,zwischenpersönlicher Ausgleichstransfer" bezeichnete Umverteilung stattfindet. Leistungen zugunsten der einen werden danach aus Beiträgen der anderen finanziert und mithilfe des Grundsatzes der sozialen Solidarität gerechtfertigt. Eine

36 Jończyk, Ubezpieczenie zdrowotne, Praca i Zabezpieczenie Społeczne 2003, S. 4.

37 Vgl. Ślebzak, Zasada solidarności w ubezpieczeniu emerytalnym, in: Kubot/ Kuczyński (Hrsg.), Z zagadnień prawa pracy i prawa socjalnego. Księga Jubileuszowa z okazji 70-tych urodzin Profesora Herberta Szurgacza, Breslau 2011, S. 540 .

38 Unter Berücksichtigung der gesetzlichen Terminologie (Art. 2 LÖffGG) ist von Patienten, die Leistungen in Anspruch nehmen, die Rede. 
andere, umfassendere, auf die nationale oder staatsbürgerliche Gemeinschaft abstellende Auslegung des Grundsatzes der sozialen Solidarität, findet keine Legitimation im Aufbau des Systems der Gesundheitsfürsorge.

In Bezug auf die axiologischen Grundlagen der Sozialversicherung und die einzelnen Techniken zur Verwirklichung dieser Idee sollte auf den Begriff der sozialen Solidarität i.S. einer vorausgesetzten Verbundenheit der Mitglieder in Zwangsverbänden zur gegenseitigen Absicherung von Leistungsansprüchen im Falle des Eintritts von sozialen Risiken zurückgegriffen werden. Dieser Grundsatz besitzt einen eigenen, bestimmten Inhalt (vgl. III.) und kann in keiner Weise mit der politischen Doktrin des Solidarismus gleichgesetzt werden, die sich auf eine weitere Gemeinschaft sowie sozialpolitische Aspekte bezieht.

\section{Aussagen aus der deutschen Doktrin}

Über das Sozialrecht und seine axiologischen Grundlagen wurden in der deutschen Rechtslehre zahlreiche Aussagen gemacht. Die Problematik des in Deutschland als Solidarprinzip bezeichneten Erfassungsgrundsatzes behandelt unter anderem Volkmann ${ }^{39}$, der vor allem die kooperative, auf die Verhältnisse zwischen Rechtsubjekten bezogene Dimension der Solidarität betont. Diese tritt vor allem in den Pflichten zur Berücksichtigung des Entfaltungsspielraums des Gegenübers, der Kooperations- und der Einstandspflicht ${ }^{40}$ in Erscheinung und konstatiert eine Verantwortung der Rechtsträger. Der Autor stellt deshalb die These der Solidarität als Grundpflicht auf. ${ }^{41}$ Über den Sozialstaat schrieb Volkmann: „Der Sozialstaat erscheint im Lichte der Solidarität nicht mehr als bürokratisch-institutioneller Komplex, mit dem eine mit wichtigeren Dingen beschäftigte Gesellschaft ihre Sozialfälle entsorgt und ihre hilfsbedürftigen Mitglieder zu passiven Klienten zurichtet, sondern als Derivat einer sämtliche Mitglieder umspannenden Verantwortungsgemeinschaft". ${ }^{42}$ Als Ausfluss der Solidarität werden demnach nicht nur soziale Rechte verstärkt, sondern auch das Gefühl, dass jeder Bürger ein „Solidaritätsschuldner“ ist, da „der Sozial-

39 Vgl. Volkmann, Solidarität - Programm und Prinzip der Verfassung, Tübingen 1998.

40 Der Pflicht zur Beteiligung an den Kosten der Solidargemeinschaft.

41 Vgl. Volkmann (Fn. 39), S. $378 \mathrm{f}$.

42 Ebenda, S. 395. 
staat selbst nur das Mittel ist, dessen sich die Bürger bedienen, um ihre Solidarität zu organisieren". ${ }^{43}$ Volkmann stellt fest, dass das Solidarprinzip in diesem Zusammenhang eine Legitimation zum Eingriff in die Rechtslage des Einzelnen und zur Auferlegung sowie Differenzierung von Lasten wie z.B. die Verknüpfung der Beitragshöhe mit dem persönlichen Einkommen liefert. ${ }^{44}$

Becker $^{45}$ bemerkte zutreffend, dass der Begriff „Solidarität“ zunächst nur unspezifisch das Füreinander-Einstehen-Müssen bezeichnet und als Rechtsbegriff der gesetzlichen Ausformung bedarf. Durch diese werden aus möglichen moralischen Verpflichtungen vor allem konkrete Zahlungsverpflichtungen. Weiterhin schrieb er: „Solidarität wird im Sozialrecht weniger durch die Schaffung von Leistungssystemen selbst als vielmehr durch die Anordnung eines finanziellen Ausgleichs innerhalb von Systemen hergestellt. Insofern spielt es eine wesentliche Rolle, welche Personen in welche Systeme einbezogen und wie die zu erbringenden Sozialleistungen finanziert werden." Bezugnehmend auf das Prinzip der Eigenverantwortung als Kehrseite der Solidarität betonte Becker den kollektiven Charakter des letztgenannten Grundsatzes.

Ferner kann auf die Arbeit von Ruland mit einer nahezu schlagwortartigen Darstellung des Solidaritätsbegriffs, mitunter in Bezug auf die Vorschriften des Sozialversicherungsrechts, hingewiesen werden. Der Autor merkte vor allem an, dass Solidarität gleichbedeutend mit einer „Entindividualisierung" von Risiken ist ${ }^{46}$, was jedoch nicht auf einen Verzicht auf die Eigenverantwortlichkeit von Leistungsempfängern im Rahmen solidarischer Systeme hinauslaufen kann, da Solidarität gleichzeitig Pflichten mit sich bringt wie die Loyalitätspflicht gegenüber der Risikogemeinschaft. Aus diesem Grund verletzt seine Pflichten, wer ohne einen entsprechenden Bedarf auf Leistungen der Gesundheitsfürsorge zurückgreift bzw.

43 Ebenda, S. 396. Auch andere Autoren haben angemerkt, dass das Sozialstaatsprinzip ebenfalls vom Gesichtspunkt der Belastung von Bürgern, der sich auch als Solidarprinzip bezeichnen lässt, erfasst werden kann. Vgl. Bley/Kreikebohm/Marschner, Sozialrecht, Neuwied 2007, S. 27.

44 Vgl. Volkmann (Fn. 39), S. 400.

45 Vgl. Becker, Sozialrecht und Sozialrechtswissenschaft, ZÖR 2010, S. 616 f.

46 Zacher schreibt in diesem Zusammenhang von der Kollektivierung individueller Risiken. Vgl. Zacher, Individuelle und soziale Sicherung gegen die Notfälle des Lebens in der sozialen Marktwirtschaft, Berlin 1973, S. 142. 
selbst ein Ereignis schuldhaft herbeiführt, das Leistungsansprüche auslöst. ${ }^{47}$ Dabei ist der Anmerkung von Gitter beizupflichten, dass „ohne Eigenverantwortung Solidarität anonym und missbräuchlich“ wird, „Eigenverantwortung ohne Solidarität egoistisch ist" . ${ }^{48}$

Das Solidarprinzip als ,axiologische Grundlage des Sozialrechts“ bezeichnend ${ }^{49}$, trug Faude hingegen vor, dass es sich um ein Konzept gemeinsamer Verantwortung für das Schicksal eines jeden Einzelnen im Gegensatz zum individualistischen Konzept des Privatrechts handele. Danach sei sie auf verschiedenen Organisationsebenen realisierbar, woraufhin er die staatliche Ebene mit Beispielen wie Sozialhilfe, Unterstützungsleistungen und soziale Entschädigung sowie die Ebene der einzelnen Systeme sozialer Absicherung (darunter auch der Gesundheitsfürsorge) hervorhob. Ähnlich wie Ruland, wies auch Faude auf die aus dem Solidarprinzip abgeleitete Notwendigkeit des "solidarischen Verhaltens" hin und stellte die verschiedenen Dimensionen ihrer Bewertung vor: 1) das Verhalten des Rechtsträgers (böswilliges Verhalten verdient keine Solidarität), 2) den Zweck, aus dem die solidarische Risikogemeinschaft entstanden ist (z.B. die Einschränkung der Risikodefinition auf typische Folgen und Ursachen eines gegebenen Zufallsereignisses durch den Ausschluss einer Garantie in Fällen einer Eigenverschuldung bei seiner Herbeiführung) und 3) garantierte Leistungen (bewertet wird die Art und Weise der Inanspruchnahme der Leistung sowie die Kooperation des Leistungsempfängers)..$^{50}$

Im deutschen Schrifttum wird das Solidarprinzip zumeist im Verhältnis mit den Grundsätzen der Gegenseitigkeit und Gleichwertigkeit von gezahlten Beiträgen und empfangenen Leistungen angeführt, die zwar die Grundlage für Versicherungen im Privatrecht bilden, in der „Gesundheitsversicherung" aber - wie bereits festgestellt - grundsätzlich ausgeschlos-

47 Vgl. Ruland, Solidarität, NJW 2002, S. 3518 f;; aber auch: Borchert, Die Rolle der Patienten und Versicherten im neustrukturierten GKV-System, in: Heinze/Schmitt (Hrsg.), Festschrift für Wolfgang Gitter zum 65. Geburtstag am 30. Mai 1995, Wiesbaden 1995, S. 133-144.

48 Gitter, Strukturen der Reform der gesetzlichen Krankenversicherung, Die soziale Gerichtsbarkeit 1991, S. 86.

49 So ähnlich: Heinig, Der Sozialstaat im Dienst der Freiheit, Tübingen 2008, S. 121-133.

50 Vgl. Faude, Selbstverantwortung und Solidarverantwortung im Sozialrecht. Strukturen und Funktionen der sozialrechtlichen Relevanz des Selbstverschuldens des Leitungsberechtigten, Bonn 1983, S. 33 f. und 36 ff. 
sen sind. In diesem Zusammenhang kann auf die Meinung von Kirchhof ${ }^{51}$ verwiesen werden, der bei der Ermittlung des Inhalts des Solidarprinzips auf vier grundlegende, eine äquivalente Gestaltung des Verhältnisses von Beitragszahlungspflicht und Leistungsberechtigung aus einer Sozialversicherung ausschließende Formen der Umverteilung abstellte. Erstens - den intertemporalen Ausgleich, bei dem es zu einer zeitlichen Verschiebung zwischen der Entrichtung von Beiträgen und dem Erhalt von Leistungen kommt, wobei diese Verschiebung weiterhin denselben Rechtsträger betrifft (beispielsweise im Falle von kapitalanlagenfinanzierten Rentenversicherungen), zweitens - den generationenübergreifenden Ausgleich (z.B. durch Umverteilung finanzierte Renten), und drittens - den institutionsübergreifenden Ausgleich in Bezug auf Verschiebungen zwischen den Haushalten unterschiedlicher Institutionen der sozialen Absicherung (beispielsweise den bei einer Mehrzahl von Gesundheitsversicherungsträgern notwendige Mechanismus zur Vorbeugung der Risikowahl). ${ }^{52}$ Am bedeutendsten für die Funktionsfähigkeit eines Systems der Gesundheitsfürsorge erscheint jedoch - wie bereits erwähnt - die vierte Form der Umverteilung, der sog. personenübergreifende Ausgleich, nach welchem die Leistungen des einen durch Beiträge der anderen finanziert werden. ${ }^{53}$ Kirchhof führte des Weiteren aus, dass die vom Solidarprinzip legitimierte Umverteilung nachreguliert werden kann, und zwar durch Vorschriften über Beiträge (im Wege der Einforderung der finanziellen Mitverantwortung von anderen Trägern als den Versicherten, etwa den Versicherern oder dem Staat - durch Zuschüsse) sowie Leistungen (die auch anderen Trägern als den Versicherten, wie etwa ihren Familienmitgliedern, zugesprochen werden bzw. aus gesetzlich auferlegten außerversicherungsrechtlichen Aufgaben der öffentlichen Hand resultieren können, wie z.B. die Mitversicherung von Arbeitslosen, Empfängern von Sozialhilfe usw.). ${ }^{54} \mathrm{Im}$ Ergebnis einer Untersuchung der deutschen Sozialversicherungssysteme stellte Kirchhof fest, dass soziale Elemente gerade in der Gesundheitsversiche-

51 Vgl. Kirchhof, Das Solidarprinzip im Sozialversicherungsbeitrag, in: Schulin (Hrsg.), Sozialfinanzverfassung: 5. Sozialrechtslehrertagung, Wiesbaden 1992, S. $65 \mathrm{ff}$.

52 Daneben bleibt zu bedenken, dass ähnliche Mechanismen auch im Gesetz vom 6. Februar 1997 über die allgemeine Krankenversicherungspflicht vorgesehen waren. Entsprechend Art. 135 Abs. 1 beteiligten sich die Krankenkassen am finanziellen Ausgleich von einkommens- und kostenbedingten Unterschieden.

53 Vgl. Kirchhof (Fn. 51), S. $65 \mathrm{ff}$.

54 Vgl. ebenda, S. $67 \mathrm{ff}$. 
rung deutlich stärker als in anderen Bereichen zur Geltung kommen. Er betonte, die Beitragshöhe hänge stets vom Einkommen des Versicherten $a b$, weshalb - trotz des Abstellens der Versicherungsgarantie auf eine Sachleistungszusage für medizinische Bedarfsfälle anstelle eines pauschalen Ausgleichs vom Verdienstausfall - eine Differenzierung der Rechtslage der Versicherten je nach ihren Vermögensverhältnissen stattfindet, was ein Indiz für die Anwendung des Solidarprinzips darstellt. ${ }^{55}$ Schließlich wies er ferner auf die Mitversicherung von Familienmitgliedern hin. ${ }^{56}$

\section{Zusammenfassung - Inhalt des Grundsatzes der sozialen Solidarität in der ,Gesundheitsversicherung “}

Bei dem Versuch, den Grundsatz der sozialen Solidarität im „Gesundheitsversicherungswesen" mit Blick auf die polnische Lehre und Rechtsprechung des Verfassungsgerichtshofs und des Obersten Gerichts einerseits und das deutsche Schrifttum andererseits zu definieren, muss vor allem auf die unterschiedlichen Akzente bezüglich der Bedeutung und Funktion des Solidaritätsprinzips abgestellt werden. Dies wirkt sich ohnehin auf die Bewertung der Funktionalität eines Systems und seine außerrechtliche Wahrnehmung in der Öffentlichkeit aus. In der Begründung des Urteils vom 7. Januar $2004^{57}$ stellte der Verfassungsgerichtshof fest, dass aus der Solidarität „ein gleicher Zugang zu Leistungen der Gesundheitsversorgung" hervorgeht, während die Inanspruchnahme von Leistungen der Gesundheitsversorgung ,unabhängig von der Beteiligung einzelner Mitglieder der Bürgergemeinschaft an der Finanzierung durch öffentliche

55 Vgl. ebenda, S. 75. Diesen Gesichtspunkt als Ausdruck von Solidarität zwischen dem einzelnen Versicherten und anderen Mitgliedern der Versichertengemeinschaft (Risikogemeinschaft) betonte auch Ost, in: Ost/Mohr/Estelmann (Hrsg.), Grundzüge des Sozialrechts, München 1998, S. 15 f.

56 Vgl. Kirchhof (Fn. 51), S. 75. Auch Haverkate sah - in Bezug auf die Gesundheits- bzw. Krankenversicherung - die unentgeltliche Mitversicherung von Familienmitgliedern als das bedeutendste Beispiel (neben der unterschiedlichen Beitragshöhe trotz identischer gesetzlicher Garantien) für die Verwirklichung des Solidarprinzips als Grundgedanken des gesamten deutschen Sozialversicherungswesens. Vgl. Haverkate, Gleichheitsprobleme an den Nahtstellen der Sozialleistungssysteme - Am Beispiel der Alterssicherung, in: Beyerlin/Bothe/Hofmann/Petersmann (Hrsg.), Recht zwischen Umbruch und Bewahrung, Völkerrecht, Europarecht, Staatsrecht, Festschrift für Rudolf Bernhardt, Berlin 1995, S. 394.

57 VerfGH v. 07.01.2004, K 14/03. 
Mittel“" möglich sein muss. Ohne diesen Thesen grundsätzlich zu widersprechen sollte angemerkt werden, dass dieses Verständnis von Solidarität vor allem den Erwerb von Leistungsberechtigungen durch weniger wohlhabende Bürger auf Kosten der Vermögenden rechtfertigt.

Analog bemerkte man im polnischen Schrifttum, dass „der Grundsatz der sozialen Solidarität (des sozialen Solidarismus) i.S. der „Gesundheitsversicherung" auf einer spezifischen Anonymität des aus Beiträgen finanzierten Fonds beruht. Grundsätzlich haben die Beitragszahler keine Kenntnis davon, wessen Leistungen aus den von ihnen eingezahlten Mitteln finanziert werden. Ungeachtet der Höhe des von ihnen gezahlten Beitrags kommt ihnen dieselbe Leistungsberechtigung zu. Demzufolge erwirbt keiner der Versicherten größere Anrechte beim Zugang zu Versicherungsleistungen allein weil seine Beiträge höher ausfallen als die der anderen". 58

Demgegenüber wird das Solidarprinzip im deutschen Recht gänzlich anders (und zutreffender) als im polnischen Recht ausgelegt. Aus dem Solidarprinzip werden vor allem Pflichten für die Mitglieder der Versichertengemeinschaft abgeleitet: Die Zwangsteilnahme, die Pflicht zur Zahlung von Beiträgen - trotz fehlender Gegenseitigkeit von Beitragshöhe und erhaltenen Leistungen - und die Pflicht, sich solidarisch zu verhalten. Dieser für Leistungsempfänger verpflichtend wirkende und auf Verantwortlichkeit und einer bewussten Haltung beruhende Aspekt des Solidaritätsgrundsatzes verdient, so scheint es, eine deutlich stärkere Betonung sowohl in der Rechtsprechung als auch der Lehre. Seine Ausklammerung oder gar Nichtberücksichtigung führt zu einer fehlenden Identifikation der Leistungsempfängern mit dem System, was zu Versuchen führt, sich der Beitragspflicht um jeden Preis zu entziehen (u.a. durch einen Rückzug in die Grauzone oder die Auslagerung der unternehmerischen Tätigkeit ins Ausland) oder die garantierten Leistungen zu missbrauchen.

In Anspielung auf die angeführte Aussage von Jończyk sollte einmal mehr unterstrichen werden, dass ,die Thematik der Solidarität vor allem

58 Nowak-Kubiak/Łukasik, Ustawa o świadczeniach opieki zdrowotnej finansowanych ze środków publicznych, Kommentar zu Art. 65, Warschau 2006, S. 126-128. Am Rande sei angemerkt, dass mit Ausnahme der kapitalanlagenfinanzierten Alterssicherung jeder andere Versicherungsfonds in dem Sinne anonym bleibt, als dass ein Beitrag (seine Höhe) nicht an bestimmte versicherte Personen gebunden ist. Das Fehlen einer Verbindung zwischen Leistungsumfang und Beitragshöhe hingegen hat mit der Anonymität eines solchen Fonds nichts zu tun vielmehr handelt es sich dabei um die Quintessenz des Grundsatzes der sozialen Solidarität. 
Pflichten, Lasten, individuelle Beiträge und gemeinsame Anstrengungen betrifft und nicht die Verteilung von Geld- und Sachleistungen“, während „im Hinblick auf die Verteilung von Leistungen vielmehr auf Gerechtigkeit denn auf Solidarität abgestellt wird“".59 Anders ausgedrückt kann der Gerechtigkeitsgrundsatz bei der Suche nach einer axiologischen Begründung für die unterschiedliche rechtliche Behandlung von Leistungsempfängern (das Differenzierungskriterium sollte aus der angenommenen Werteordnung hervorgehen) - im Zusammenhang mit dem Grundsatz des gleichen Zugangs zu Leistungen der öffentlich finanzierten Gesundheitsversorgung - sehr wohl eine Unterscheidung bei der Gewährung von Rechtspositionen rechtfertigen, während der Grundsatz der sozialen Solidarität vielmehr die Differenzierung der Pflichten von Teilnehmern dieses Systems betrifft.

Vor dem Hintergrund der angeführten Aussagen aus dem polnischen und deutschen Schrifttum sowie unter Berücksichtigung der Rechtsprechung des Verfassungsgerichtshofs lässt sich zusammenfassend festhalten, dass die aus den gegebenen Interdependenzen hervorgehende Übernahme von gewissen Lasten und Pflichten durch eine Gemeinschaft, welche zu einem sozialen Ausgleich führen, den Inhalt des Grundsatzes der sozialen Solidarität ausmacht. Der Solidaritätsgedanke geht nämlich von einer „Vergemeinschaftung“ (,Entindividualisierung“) von Risiken und nicht von einem jeweiligen individuellen Risiko oder Bedürfnis (personenübergreifender Ausgleich) aus. Die „Vergemeinschaftung“ manifestiert sich vor allem in der Zahlung von einkommensabhängigen Beiträgen. Die Solidarität unter Mitgliedern einer Gemeinschaft i.S. ihrer gegenseitigen Verbundenheit entspricht dabei einem Vorrang des Allgemeinwohls gegenüber dem Wohl des Einzelnen. Das Allgemeinwohl sowie Handlungen zu dessen Gunsten sind sowohl Ziel als auch Folge des Bestehens einer Solidargemeinschaft. Daher folgt aus dem Grundsatz der sozialen Solidarität u.a. eine Loyalitätspflicht gegenüber den anderen Mitgliedern der Gemeinschaft in Gestalt der Pflicht zur aktiven Minimierung der Wahrscheinlichkeit eines Risikoeintritts und der potentiellen Folgen einerseits sowie der angemessenen Nutzung der garantierten Leistungen und der Notwendigkeit des Zusammenwirkens und Berücksichtigung der Interessen anderer Mitglieder, etwa durch die Gewährleistung gleicher Garantien bei ungleichen Belastungen andererseits.

59 Ebenda, S. 127. 
Bei der Ermittlung einer verfassungsrechtlichen Grundlage für die gesetzlich bestimmten Lösungen zur Verwirklichung des Grundsatzes der sozialen Solidarität kann auf Art. 68 Abs. 2 der polnischen Verfassung hingewiesen werden. Der dort statuierte Grundsatz des gleichen Zugangs zu Leistungen der Gesundheitsfürsorge betrifft nämlich in erster Linie die Vermögensunterschiede der Bürger. Unabhängig von dem eigenen Beitrag (dessen Höhe nach der Versicherungsgrundlage und dem erzielten Einkommen, jedoch nicht nach der Zahl der mitversicherten Familienmitglieder oder dem individuellen Risikopotenzial von Gesundheitsbeeinträchtigungen beim Versicherten und seinen Mitversicherten berechnet wird) sollte jeder Bürger im gleichen Maße (d.h. ohne Unterscheidung in Bezug auf die Reichweite und Voraussetzungen dieser Fürsorge) auf die im Rahmen des Systems der Gesundheitsfürsorge garantierten, öffentlich finanzierten Leistungen zurückgreifen können.

Dennoch sollte einmal mehr bedacht werden, dass sich der Grundsatz der sozialen Solidarität im Wesentlichen auf die Pflichten und weniger auf die Berechtigungen der Versicherten bezieht. Anhand dieses Prinzips lassen sich die Beteiligung an der Risikogemeinschaft und der Grad ihrer Finanzierungspflicht ausmachen, während das Recht auf Leistungen auf der bloßen Mitgliedschaft im System beruht und ihr Umfang von der individuellen Bedürftigkeit abhängt. Die Teilnahme an der Risikogemeinschaft kann demnach in einem solidarisch geprägten Leistungssystem zu keinem Verzicht des Versicherten auf Eigenverantwortung führen, da Solidarität mitunter, wenn nicht vor allem, eine an Verantwortung und bewusste Eigenhaltung anknüpfende Einstandspflicht fordert - insbesondere die Pflicht zur Sorge um die eigene Gesundheit.

Nur am Rande sei angemerkt, wie problematisch sich die Frage einer eventuellen Sanktionierung von Verstößen gegen solche Pflichten darstellt. Dies liegt zum einen an den beschränkten Ermittlungsmöglichkeiten (vor allem in Bezug auf die Feststellung, ob ein Ereignis tatsächlich zufällig eingetreten ist, d.h. inwiefern sich das Eigenverhalten des Leistungsempfängers auf den Eintritt des Gesundheitsrisikos bzw. die Behandlungsdauer und -effektivität ausgewirkt hat), aber vor allem auch an den vorhandenen rechtlichen Mitteln, über die der Versicherungsträger (der Nationale Gesundheitsfonds) verfügt. Wie bereits an anderer Stelle angemerkt ${ }^{60}$, kann ein eventuelles Verschulden des Versicherten nicht dazu 
führen, dass ihm der Erwerb von Leistungsrechten im System der Gesundheitsfürsorge abgesprochen wird, da es sich hierbei nicht etwa um eine individualisierte Fürsorge für den Fall einer konkreten Gesundheitsbeeinträchtigung handelt, sondern allgemein um die Aufnahme in ein System der Gesundheitsfürsorge und die Erteilung einer generellen Garantie einer solchen Fürsorge in einem zeitlichen und sachlichen Umfang, der sich nach den Umständen des Einzelfalls bestimmen lässt. Aus diesem Grund kann vielmehr davon ausgegangen werden, dass die Feststellung eines Verschuldens auf Seiten des Versicherten zum Verlust oder zur Einschränkung seiner Berechtigung zur Einforderung öffentlich finanzierter Leistungen im System der Gesundheitsfürsorge führt. Dieser Rechtsverlust kann jedoch nicht dahingehend verstanden werden, dass die Erteilung dringender Leistungen einer gegebenenfalls notwendigen Gesundheitsfürsorge schlicht versagt wird. Die hier vorgeschlagene Sanktionierung eines vom Versicherten selbstverschuldeten Gesundheitsverlusts würde stattdessen auf die Verpflichtung einer solchen Person zur selbstständigen Tragung der Kosten - in vollem Umfang oder anteilig - der ihr erteilten Leistungen hinauslaufen. Mit anderen Worten erhielte der Behandlungsbedürftige die notwendige Fürsorge nach den allgemeinen Grundsätzen (Besuch beim Hausarzt, etwaige Untersuchungen, Überweisungen an Fachärzte usw., bzw. Leistungen der Notfallmedizin), jedoch stünde dem Versicherer im Falle der Feststellung einer vorsätzlichen Herbeiführung oder Mitverursachung der Gesundheitsschädigung und der Verneinung eines Zufallsereignisses im Nachhinein ein Regressanspruch zu. ${ }^{61}$

61 Vorbehaltlich der kontroversen Natur dieser These sollte angemerkt werden, dass der Nationale Gesundheitsfonds jetzt schon über Möglichkeiten verfügt, Regressforderungen gegen Verursacher von Situationen, die eine Notwendigkeit der Erteilung medizinischer Leistungen an Versicherte nach sich zogen, nachzugehen, da gem. Art. 116 Abs. 1 Pkt. 6 LÖffGG zu den Einnahmen des Fonds u.a. aus Regressansprüchen gewonnene Mittel zählen. Eingehend zur Problematik vgl. Lach, Roszczenia regresowe przysługujące NFZ, Praca i Zabezpieczenie Społeczne 2005, Heft 8, S. 20-25. 


\title{
Grundsatz des gleichen Zuganges zu den Leistungen der Gesundheitsfürsorge
}

\author{
Daniel Eryk Lach
}

\section{Der verfassungsrechtliche Grundsatz als Programmnorm}

Der Grundsatz des gleichen Zuganges zu den Leistungen der Gesundheitsfürsorge ist das Fundament (die Leitidee) des polnischen Systems der Gesundheitsfürsorge. Er ist in Art. 68 Abs. 2 der polnischen Verfassung (pV) verankert, demzufolge die öffentliche Gewalt den Staatsangehörigen, unabhängig von deren materiellen Lage, gleichen Zugang zur Gesundheitsfürsorge, die aus öffentlichen Mitteln finanziert wird, zusichert. Bedingungen und Umfang der Leistungen regelt das Gesetz.

Bei der Auslegung der Vorschrift des Art. 68 Abs. $2 \mathrm{pV}$ ist vor allem die Tatsache zu berücksichtigen, dass die sozialen Rechte und Freiheiten, welche mit den Richtungen und Zielen der von der öffentlichen Gewalt geführten Sozialpolitik verbunden sind, besonderen Rechtscharakter haben. Wie Garlicki anmerkte, muss die Verfassung in Bezug auf die Verhältnisse zwischen Staat und Bürger die Normen nicht so präzise bestimmen, dass diese ohne Hilfe von weiteren Normen oder Auslegungsinstrumenten niedrigerer Ordnung angewendet werden könnten. Dies folgt aus der Tatsache, dass das Grundgesetz in der Sprache von Werten, Grundsätzen und Ideen geschrieben ist und keine konkret formulierten Rechtsnormen enthält. ${ }^{1}$

Im Lichte der Aussagen der Verfassungsrechtliteratur scheint es richtig, anzunehmen, dass Art. 68 Abs. 2 pV Programmcharakter hat, d.h. dass die Vorschrift ihre Adressaten durch die Vorgabe der gewünschten Ziele bindet, aber keine konkreten und notwendigen Ausführungsschritte bestimmt. Sie bezieht sich auf ein allgemeines gesellschaftliches Wissen ihrer Adressaten, das seinerseits eine empirische Grundlage besitzt. Die in solchen

1 Vgl. Garlicki, Normatywna wartość ustawy zasadniczej (Normative Wert des Grundgesetzes), in: Wyrzykowski (Hrsg.), Konstytucyjne podstawy systemu prawa (Verfassungsrechtliche Grundsätze des Rechtssystems), Warschau 2001, S. 19. 
Normen vorgegebenen Ziele haben einen verbindlichen Charakter in dem Sinne, dass sie so verwirklicht werden müssen, dass die verpflichteten Subjekte zumindest von der Sorge um Beibehaltung des erreichten Status quo befreit würden. ${ }^{2}$

Im Kontext des Programmcharakters des Art. 68 Abs. 2 pV lassen sich - bezugnehmend auf die Literatur - auch folgende Argumente hervorheben: 1. Die Vorschrift enthält eindeutige Vorgaben für das Gesetz zur Bestimmung des Inhalts der Berechtigung (Art und Umfang von Leistungen $)^{3}$. 2. Die Vorschrift bezieht sich auf die Ziele des Normgebers und nicht des Normadressaten, sie ge- oder verbietet dem Adressaten, d.h. der

2 Vgl. Sarnecki, Normy programowe w Konstytucji i odpowiadające im wolności obywatelskie (Programnormen in der Verfassung und die den entsprechenden Bürgerfreiheiten), in: Garlicki/Szmyt (Hrsg.), Sześć lat Konstytucji Rzeczypospolitej Polskiej. Doświadczenia i inspiracje (Sechs Jahre der Verfassung von Republik Polen. Erfahrungen und Inspirationen), Warschau 2003, S. 252 ff. Auch in der deutschen Literatur wird angeführt, dass bei Programmnormen ,dem Gesetzgeber eine bestimmte Richtung für seine Aktivität zwecks Annäherung an bestimmte Sachziele vorgeschrieben wird”. „Bei den Programmen geht es [...] um eine in die Zeit hinein wirkende, sich kontinuierlich erprobende Linie". Vgl. Lerche, Das Bundesverfassungsgericht und die Verfassungsdirektiven, AöR 1965, S. 347, zu den „nicht erfüllten Gesetzgebungsaufträgen“".

3 Vgl. Sarnecki (Fn. 2), S. 254; Garlicki merkte hierin an, dass - weil die Verfassung als anwendbares Recht gedacht wurde - bei der Formulierung von Sozialrechten mehrere Klauseln eingeführt worden sind, welche die „Zulässigkeit der Bestimmung von Begrenzungen in Bezug auf einzelne Rechte und Freiheiten" vorsehen. In diesem Lichte ist die Vorschrift des Art. 68 Abs. 2 Satz 2 der Verfassung zu verstehen, wonach Bedingungen und Umfang der Leistungen das Gesetz regelt. Garlicki deutete darauf hin, dass die sehr allgemeine Formulierung von Sozialrechten und die Übergabe der Kompetenz, deren Inhalt und Umfang zu bestimmen, an den Gesetzgeber, ein bewusster Akt der Verfassungsautoren war, da sie Bürgeransprüche befürchteten, welche das Gleichgewicht der öffentlichen Finanzen stören könnten (vgl. Garlicki, Wolności i prawa jednostki w Konstytucji Rzeczypospolitej Polskiej z 1997 roku. Bilans pięciu lat (Freiheiten und Rechte der Einheit in der Verfassung der Republik Polens vom 1997. Bilanz von 5 Jahren), in: Jerzmański (Hrsg.), Pięć lat Konstytucji Rzeczypospolitej Polskiej. Materiały z konferencji na Zamku Królewskim w Warszawie, 17 października 2002 (Fünf Jahre der Verfassung der Republik Polens. Materialien von der Konferenz am Königsschloss in Warschau, 17. Oktober 2002), Warschau 2002, S. 61 und 68 f. In diesem Lichte ist auch auf die Aussage von Jellinek hinzuweisen, wonach „Die Begründung eines subjektiven Rechts [...] in der Regel nicht [...] durch Rechtsätze, welche Prinzipien für [die] Erlassung künftiger oder Auslegung bestehender Gesetze enthalten" stattfindet. Vgl. Jellinek, System der subjektiven öffentlichen Rechte, Tübingen 1905, S. $71 \mathrm{f}$. 
öffentlichen Gewalt, also unmittelbar kein Handeln zur Erreichung des Ziels. ${ }^{4}$ 3. Das Ziel ist nicht als empirisch identifizierbarer Stand der Dinge bestimmt - zum ersten, weil in Art. 68 Abs. 2 pV Wertaussagen verwendet werden (der „gleiche“ Zugang) 5 , und zum zweiten, weil die Pflicht der Sicherung des gleichen Zuganges als „regulative Idee“ zu verstehen ist, die nie vollkommen verwirklicht werden kann. ${ }^{6}$ Wie Zacher bereits bemerkte: "Mehr Gleichheit in der Sicherheit bedeutet zugleich neue Ungleichheit."

Bei der Bestimmung des Rechtscharakters des Art. 68 Abs. 2 pV als Programmnorm ist auch die Aussage von Banaszak hervorzuheben, der feststellte, dass in dieser Vorschrift das Ziel des Handelns der öffentlichen Gewalt deutlich bestimmt wurde, wobei die Norm nicht Programm-, sondern Gewährleistungscharakter hat. Die öffentliche Gewalt ist verpflichtet, die entsprechenden Institutionen zu schaffen, welche der Vorbeugung von Krankheiten, und im Falle des Auftretens von Krankheiten deren Behandlung dienen werden. ${ }^{8}$ Den normativen Charakter dieser Pflicht bestätigend konstruierte Banaszak anstelle einer Programmnorm die Gewährleistungsnorm.

4 Vgl. Gizbert-Studnicki/Grabowski, Normy programowe w Konstytucji Programmnormen in der Verfassung in: Trzciński (Hrsg.), Charakter i struktura norm Konstytucji (Charakter und Struktur der Verfassungsnormen), Warschau 1997, S. 98. Die Feststellung, welches Handeln von bestimmten Subjekten (un-)zulässig ist, damit das in der Programmnorm definierte Ziel erreicht werden kann, ist möglich. Es geschieht allerdings nur im Wege von juristischen Schlussfolgerungen (effet utile, effet nécessaire), welche sich auf das empirische Wissen der Kausalzusammenhänge beziehen, was über den Gesetzestext hinausgeht.

5 Wobei bei der Bewertung der Gleichheit des Zugangs die Grundsätze der (sozialen) Gerechtigkeit und Solidarität berücksichtigt werden müssen.

6 Vgl. Gizbert-Studnicki/Grabowski (Fn. 4), S. 99 f.

7 Vgl. Zacher, Abhandlungen zum Sozialrecht, Heidelberg 1993, S. 34.

8 Vgl. Banaszak, Konstytucja Rzeczypospolitej Polskiej. Komentarz, (Verfassung der Republik Polens. Kommentar) Warschau 2009, Kommentar zu Art. 68 Rn. 4. 
Es scheint die These berechtigt zu sein, dass dieses Konzept sich auf die Idee des Gewährleistungsstaats ${ }^{9}$ (the enabling state ${ }^{10}$ ) bezieht. Auf deren Grundlage wird auch die Technik ${ }^{11}$ der treuhänderischen Verwaltung als eine Art der Verwirklichung der Idee der sozialen Sicherung in Bezug auf die Gesundheitsfürsorge vorgesehen. Der Nationale Gesundheitsfonds als Organisator des polnischen Systems der Gesundheitsfürsorge ist im Lichte seiner Aufgaben und seines Rechtscharakters weder ein Sozialversicherungsträger noch ein Organ der Leistungsverwaltung. Im Grunde genommen handelt er wie ein treuhänderischer Verwalter ${ }^{12}$, der in eigenem Namen, aber für die Leistungsberechtigten, die Verträge für die Erbringung der Leistungen der Gesundheitsfürsorge aushandelt, abschließt und abrechnet. Damit erfüllt der Fonds die öffentlichen Aufgaben aus dem Bereich der sozialen Sicherheit, die ihm durch den Gesetzgeber auferlegt worden sind. Bezugnehmend auf die Aussagen der polnischen Literatur ${ }^{13}$

9 Mehr dazu: Franzius, Der „Gewährleistungsstaat“ - ein neues Leitbild für den sich wandelnden Staat?, Der Staat 42 (2003), S. 493-517; ders., Gewährleistung im Recht. Grundlagen eines europäischen Regelungsmodells öffentlicher Dienstleistungen, Tübingen 2009, S. 24 ff., 39; Luthe, Der aktivierende Sozialstaat im Recht, Nachrichtendienst Deutscher Verein 2003, Nr 5, S. 167; Kurzke-Maasmeier, Aktivierende Soziale Arbeit im reformierten Sozialstaat, in: Kurzke-Maasmeier/ Mandry/Oberer (Hrsg.), Baustelle Sozialstaat! Sozialethische Sondierungen in unübersichtlichem Gelände, Münster 2006, S. 111-128.

10 Vgl. Jończyk, Trudna modernizacja opieki zdrowotnej w Niemczech i w Zjednoczonym Królestwie (UK) (Schwierige Modernisierung der Gesundheitsfürsorge in Deutschland und in der Vereinigten Königreich), PiZS 2006, Nr 6, S. 6.

11 In der polnischen Literatur gilt als herrschende Meinung (die an die deutsche Rechtstheorie von vor 30. Jahren anknüpft), dass die Idee der sozialen Sicherheit mit diversen „Methoden“ oder „Techniken“ verwirklicht werden kann: Fürsorge (z.B. Sozialhilfe), Versicherung (z.B. Gesetzliche Krankenversicherung) und Versorgung (z.B. staatlicher Gesundheitsdienst). Vgl. z.B. Schulin, Techniken und Instrumente der sozialen Sicherung, in: v. Maydell/Hohnerlein (Hrsg.), Die Umgestaltung der Systeme sozialer Sicherheit in den Staaten Mittel- und Osteuropas, Fragen und Lösungsansätze, Berlin 1993, S. 174; ebenso Kaczyński, Pojęcie zabezpieczenia społecznego i kryterium rozróżniania jego technik (Der Begriff der sozialen Sicherheit und Kriterium für die Unterscheidung ihre Techniken), PiZS 1986, Heft 5-6, S. 20-31.

12 Dazu eingehender: Lach: Powiernicza technika realizacji zabezpieczenia społecznego (na przykładzie ubezpieczenia zdrowotnego) (Treuhänderische Technik der Verwirklichung der sozialen Sicherheit (am Beispiel der Krankenversicherung), „Państwo i Prawo” 2009, Heft 3, S. 34-47.

13 Vgl. Biernat, Prywatyzacja zadań publicznych. Problematyka prawna (Privatisierung von öffentlichen Aufgaben. Rechtsproblematik), Warschau - Krakau 1994. 
ist darin die Privatisierung öffentlicher Aufgaben als Instrument des Gewährleistungsstaates zu sehen. ${ }^{14}$ Der Staat leistet nicht alleine (mittels der Leistungsverwaltung), sondern organisiert den rechtlichen Rahmen des Systems und bestimmt die Aufgaben nichtstaatlicher Rechtssubjekte, welche dann die öffentlichen Aufgaben für die öffentliche Gewalt vornehmen und ausführen. ${ }^{15}$

Des Weiteren stellte Banaszak fest, dass aus der in Art. 68 Abs. 2 der Verfassung verankerten Pflicht der öffentlichen Gewalt keine subjektiven Rechte ableitbar sind. ${ }^{16}$ Auch nach Jończyk begründet Art. 68 Abs. 2 pV keine Ansprüche von Versicherten, sondern enthält im Grunde lediglich ein Verbot der Differenzierung von Bürgern nach dem Kriterium der materiellen Lage. ${ }^{17}$

Diese Ansicht vertrat auch (unmittelbar auf Art. 68 Abs. 3 pV bezogen $^{18}$ ) der polnische Verfassungsgerichtshof (Trybunał Konstytucyjny, TK). Im Urteil vom 22. Juli $2008^{19}$ hielt er fest, dass aufgrund dieser Vorschrift die Programmnorm konstruiert werden kann, sie aber keine Rechte bestimmt, welche dem Bürger unmittelbar zustehen und - als „Vorschrift in der Gestalt eines Staatspolitikgrundsatzes und nicht eines Bürgerrechts“ - weder individuelle Anspruchsgrundlage, noch Quelle von verfassungsrechtlichen subjektiven Rechten sein kann. ${ }^{20}$ Der Gerichtshof deutete da-

14 Vgl. Lach, Prawny paradygmat opieki zdrowotnej a stosunek, ubezpieczenia zdrowotnego" i jego charakter prawny (Das Rechtsparadigma der Gesundheitfürsorge und das Verhältnis der „Krankenversicherung” und seinen Rechtscharakter), in: $Z$. Kubot, T. Kuczyński (Hrsg.), Współczesne zagadnienia prawa pracy i prawa socjalnego. Księga Jubileuszowa z okazji 70-tych urodzin Profesora Herberta Szurgacza (Gegenwärtige Fragen des Arbeits- und Sozialrechts. Jubiläumsbuch zum 70. Geburtstag von Professor Herbert Szurgacz), Breslau 2011, S. 451-463.

15 Vgl. Lach, Powierzanie realizacji zadań publicznych z zakresu zabezpieczenia społecznego podmiotom niepublicznym, (Anvertrauen der Verwirklichung von öffentlichen Aufgaben aus dem Bereich der sozialen Sicherung den nichtöffentlichen Subjekten), „Państwo i Prawo” 2015, Heft 2, S. 35-57.

16 Vgl. Banaszak (Fn. 8), Kommentar zu Art. 68, Rn. 10.

17 Vgl. Jończyk, Glosse zum Urteil des Obersten Gerichts (Sąd Najwyższy - SN) v. 12.02.2004 r., II UK 243/03, OSP 2004, Heft 10, S. 130.

18 Wonach die öffentliche Gewalt verpflichtet ist, den besonderen Schutz der Kinder, Schwangeren, Behinderten und Älteren zu sichern.

19 VerfGH v. 22.07.2008, K 24/07.

20 Vgl. auch TK v. 12.11.2003 r., Ts 11/03, OTK-B 2003, Nr 4, Pos. 226. Es ist aber zu beachten, dass der Gerichtshof in früheren Judikaten eine andere Meinung vertreten hat. In Oberstes Gericht v. 23.03.1999, K 2/98 stellte der Gerichtshof fest, dass von Art. 68 Abs. 1 der Verfassung (Jeder hat das Recht auf Gesundheits- 
bei darauf hin, dass dieser Gedankengang an die Erwägungen von Verfassungsautoren anknüpft. ${ }^{21}$

Zusammenfassend kann gesagt werden, dass aus der Vorschrift des Art. 68 Abs. 2 (in Verbindung mit Abs. 3) pV die Pflicht der öffentlichen Gewalt folgt, ein System der Gesundheitsfürsorge aufzubauen, welches einerseits das Gleichheitsprinzip in Bezug auf den Zugang zu den Leistungen der Gesundheitsfürsorge verwirklicht, andererseits ausgewählten Subjekten besondere Vorsorge sichert. Die Konstruktion des Art. 68 Abs. 2 $\mathrm{pV}$ und dessen Trennung in zwei Sätze - wovon der erste die Pflicht der öffentlichen Gewalt statuiert, den gleichen Zugang zu den Leistungen der Gesundheitsfürsorge zu sichern, und der zweite es dem Gesetzgeber gebietet, die Bedingungen und den Umfang der Leistungen in dem entsprechenden Gesetz zu regeln - erlaubt den Schluss, dass man aufgrund des Art. 68 Abs. 2 pV kein Recht auf den gleichen Zugang zu den Leistungen der Gesundheitsfürsorge, die aus den öffentlichen Mitteln finanziert wird, als öffentliches subjektives Recht konstruieren darf. Die ausgeführte Rechtsnorm hat dazu auch die innere Struktur eines Prinzips ${ }^{22}$, d.h. sie hat den Charakter einer Optimierungsnorm, in welcher der ideale Zustand, der so weit wie möglicherreicht werden soll, beschrieben ist. Das rechtsanwendende Organ ist somit an ein bestimmtes normatives Ideal gebunden. Eine solche Norm gebietet die Verwirklichung des gleichen Zuganges zu den Leistungen im maximalen Grad, wobei die rechtlichen und tatsächlichen Möglichkeiten der Verwirklichung berücksichtigt werden müssen, also mit dem Vorbehalt der Zulassung einer bestimmten Differenzierung.

schutz) „das subjektive Recht des Einzelnen auf den Gesundheitsschutz und das objektive Gebot für die öffentliche Gewalt, die Handlungen vorzunehmen, welche für den entsprechenden Schutz und die Verwirklichung dieses Rechtes notwendig sind, abzuleiten ist." Diese Meinung wurde später in TS v. 10.01.2001, Ts 72/00, OTK 2001, Nr 1, Pos. 12 bestätigt. Sie folgt aber den anderen Inhalt und Charakter von Abs. 1 und Abs. 2 des Art 68 der Verfassung.

21 Vgl. Eckhardt, Prawo do ochrony zdrowia. Zagadnienia wybrane (Recht auf Gesundheitsschutz. Ausgewählte Fragen), Prawa Człowieka 2006, Nr. 10, S. 67 f.

22 Vgl. Alexy, Rechtsregeln und Rechtsprinzipien, Archiv für Rechts- und Sozialphilosophie 25 (1985), S. 13-29; ders.: Theorie der Grundrechte, Baden-Baden 1985; ders.: Zum Begriff des Rechtsprinzips, Rechtstheorie 1 (1979), S. 63 ff.; GizbertStudnicki, Zasady i reguły prawne (Rechtsregeln und Rechtsprinzipien), „Państwo i Prawo" 1988, Heft 3, S. 17; Gizbert-Studnicki/Grabowski (Fn. 4), S. 101 ff.; Lerche: Das Bundesverfassungsgericht und die Verfassungsdirektiven. Zu den ,nicht erfüllten Gesetzgebungsaufträgen", AöR 90 (1965) S. 347; Sarnecki (Fn. 2), S. 252-254. 
Aus der so verstandenen Pflicht der öffentlichen Gewalt kann man dann als Reflex ein subjektives Rechts ableiten. Dieser Reflex verbietet es, die Rechte so auszugestalten, dass daraus eine ungerechtfertigte Differenzierung des Zuganges zu den Leistungen der Gesundheitsfürsorge folgt, was vor allem die Einführung von ungerechtfertigten Finanzsperren beim $\mathrm{Zu}$ gang zu den Leistungen betrifft. Im Übrigen schützt Art. 68 Abs. 2 pV einen inhaltlichen Kern (core). Als Kern (Minimum) kann dann die Pflicht der öffentlichen Gewalt, das Gesundheitsfürsorgesystem zu schaffen, angesehen werden. Dabei gilt: Das System muss aus öffentlichen Mitteln finanziert sein (d.h. es muss ein öffentlich-rechtlicher Mechanismus für die Ansammlung und die Ausgabe von Mitteln geschaffen werden). Zudem muss der gleiche Zugang zu den Leistungen der Gesundheitsfürsorge für alle Staatsangehörigen (tatsächlich für alle Berechtigten) gesichert sein, d.h. Quantität und Qualität (Standard) der Leistungen und die Grundsätze der Erbringung können nicht von der materiellen Lage oder dem Grad der finanziellen Teilnahme (Beitragsleistungen) eines Berechtigten abhängig sein, wenn auch die Kostenteilnahme typisiert und unterschiedlich sein darf - Ausschluss der Risikoselektion. Es ist damit auch eine solche Ausgestaltung verboten, welche den Zugang zu den Leistungen der Gesundheitsfürsorge, in Bezug auf die materielle Lage der berechtigten Bürger unbegründet differenzieren würde, was vor allem die Einführung von ungerechtfertigten Finanzschwellen betrifft.

\section{Die Umsetzung der Programmnorm}

1. Sicherung des gleichen Zugangs zu den Leistungen der Gesundheitsfürsorge als verfassungsrechtliche Pflicht der öffentlichen Gewalt

In Art. 68 Abs. 2 pV wurde „die Sicherung des gleichen Zugangs zu den Leistungen der Gesundheitsfürsorge" als Aufgabe der öffentlichen Gewalt formuliert. Der Begriff „Sicherung“ ist hier anders als „,soziale Sicherung“ zu verstehen. Hier geht es eher um „das Sichern“ oder - bezugnehmend auf die schon erwähnte Idee vom Gewährleistungsstaat - „die Gewährleistung“. Die Vorschrift knüpft nämlich an den seit einiger Zeit zu beobachtenden Prozess der Übergabe (oder des Anvertrauens) von öffentlichen Aufgaben (oder deren Verwirklichung) aus dem Bereich der sozialen Sicherung (oder sogar der Sozialpolitik) an nichtöffentliche Subjekte an. Zur 
Durchführung wird dabei kein öffentlich-rechtliches, sondern das privatrechtliche Instrumentarium verwendet.

Diese Form der Privatisierung wurde bereits in der Literatur diskutiert. Szurgacz gab zu bedenken, dass sich ein Rückzug des Staates in Bezug auf die Erbringung von Sozialleistungen und den Einsatz von nichtöffentlichen Subjekten in diesem Gebiet beobachten lässt. ${ }^{23}$ Dieses Phänomen wurde vom zitierten Autor gerade mit dem Konzept des Gewährleistungsstaates, welcher als „dritter Weg zwischen dem klassischem Interventionsund dem Wohlstandstaat" bezeichnet worden ist, erklärt. ${ }^{24}$ Die in der deutschen Literatur ${ }^{25}$ ausgearbeitete Definition des Gewährleistungsstaates präzisiert, dass „der Gewährleistungsstaat der Staat ist, der an seiner konkreten Gemeinwohlverantwortung festhält, aber die Instrumente zur eigenhändigen, also unmittelbaren Aufgabenerfüllung aufgegeben hat. Er führt den prinzipiellen sozialgestalterischen Anspruch des wohlfahrtsorientierten Erfüllungsstaates in dem Sinne fort, dass er auf bestimmte positive gesellschaftliche Verhältnisse und Zustände zielt und sich weiterhin in der Letztverantwortung hierfür sieht.“

In diesem Zusammenhang ist auch die Privatisierung von öffentlichen Aufgaben aufzuführen, durch die ein Staat (die öffentlichen Gewalt) von einem selbstständigen Leistungserbringer zu einem Garanten für die Aus-

23 Jończyk wies dabei auf die Unterscheidung zwischen dem klassischen privatrechtlichen „Hartvertrag“ (hard contracting) und dem neuen „Weichvertrag“" (soft contracting) hin, wobei es bei dem letzten Konstrukt vor allem um die Anknüpfung der festen Kooperation zwischen Parteien geht, um dem gemeinsamen Ziel der Parteien zu folgen. Soft contracting bezieht sich dann vor allem auf die Situationen, in denen das öffentliche Subjekt als Disponent von öffentlichen Mitteln dominiert. Vgl. Jończyk, Glosse zum Urteil des Obersten Gerichts (Sąd Najwyższy SN) v. 10.12.2004 r., III CK 134/04, OSP Nr 6/2005, S. 333; Treutner, Kooperativer Rechtsstaat. Das Beispiel Sozialverwaltung, Baden-Baden 1998.

24 Szurgacz, Zagadnienie przekazywania przez państwo zadań w zakresie zabezpieczenia społecznego podmiotom niepublicznym (Die Frage der Übergabe vom Staat den Aufgaben aus dem Bereich der sozialen Sicherung durch den Staat an den nichtöffentlichen Subjekten) in: Szurgacz (Hrsg.), Konstytucyjne problemy prawa pracy i zabezpieczenia społecznego. Referaty na XV Zjazd Katedr i Zakładów Prawa Pracy i Ubezpieczeń Społecznych, Wrocław 1-2 czerwca 2005 r.(Verfassungsprobleme des Arbeits- und Sozialsicherungsrechtes. Referaten für die 15. Tagung von Lehrstühlen und Anstalten des Arbeits- und Sozialversicherungsrechtes, Wrocław 1-2.06.2005), Breslau 2005, S. 125-142.

25 Vgl. Franzius (Fn. 9), S. 494; ders., Die Europäische Dimension des Gewährleistungsstaates, Der Staat 2006 (45), S. 547. 
führung der öffentlichen Aufgaben wird ${ }^{26}$, wobei diese „Garantie“ (richtig: Gewährleistung) vor allem durch den Aufbau der Rechtsregulation geleistet ist. ${ }^{27}$ Von großer Bedeutung sind auch die pragmatischen Fragen, da die nichtöffentlichen Subjekte oft effektiver arbeiten als die öffentlichen Einrichtungen. ${ }^{28}$

Wenn es um den Sinn des Gewährleistungsstaates und die daraus folgenden Aufgaben/ Pflichten der öffentlichen Gewalt geht, ist festzustellen, dass diese Gewährleistung nicht nur die Haftung für nichtöffentliche Subjekte wegen der fehlerhaften Ausübung der ihnen übertragenen Aufgaben nach sich zieht, sondern auch die entsprechenden Präventionsmaßnahmen umfasst. ${ }^{29}$ Der aktivierende Staat ${ }^{30}$ darf selbst nicht passiv bleiben. Dies ist insbesondere darauf zurückzuführen, dass es hier um öffentliche Aufgaben geht, die für die gesamte Gesellschaft von großer Bedeutung sind.

In diesem Kontext sollte auch die der öffentlichen Gewalt auferlegte Pflicht der „Sicherung von gleichem Zugang zu den Leistungen der Gesundheitsfürsorge" verstanden werden. Es geht um mehr als nur die Regulierung von Rechtsverhältnissen zwischen Akteuren des Systems der Gesundheitsfürsorge, was die in Art 68 Abs. 2 Satz 2 pV bestimmte Aufgabe des Gesetzgebers ist. Die „Sicherung“ als Gewährleistung umfasst vielmehr auch die Pflicht der Exekutive, die Kontroll- und Aufsichtstätigkeit gegenüber dem Nationalen Gesundheitsfonds (NFZ) und den Leistungserbringern (sowohl individuellen Vertretern von medizinischen Berufen, welche die wirtschaftliche Tätigkeit selbständig als Freiberufler oder in der Gruppe als Partnergesellschaft ausüben, als auch juristischen Personen

26 Vgl. Biernat (Fn. 13), S. 7 ff. In der deutschen Literatur wurde dazu, ausgehend von der Idee geteilter Verantwortung, die Gewährleistung als Gegenbegriff zur Erfüllung bestimmt. Wo dem Staat eine Gewährleistungsverantwortung zugewiesen sei, schließe dies die Übernahme von Erfüllungsverantwortung aus, vgl. Ruge, Die Gewährleistungsverantwortung des Staates und der Regulatory State, Berlin 2004, S. 180.

27 Vgl. Franzius (Fn. 9), S. 499, 510-515.

28 Szurgacz (Fn. 24), S. $132 \mathrm{f}$.

29 Vgl. Franzius (Fn. 9), S. 496 ff., 504 ff.; ders., Gewährleistungsrecht als Erscheinungsform des Verwaltungsrechts, Zeitschrift für öffentliche und gemeinwirtschaftliche Unternehmen, ZögU 2008, S. 372 ff.

30 Luthe, Der aktivierende Sozialstaat im Recht, Nachrichtendienst Deutscher Verein 2003, Nr. 5, S. 167-177; Kurzke-Maasmeier, Aktivierende Soziale Arbeit im reformierten Sozialstaat, in: Kurzke-Maasmeier/Mandry/Oberer (Hrsg.), Baustelle Sozialstaat! Sozialethische Sondierungen in unübersichtlichem Gelände, Münster 2006, S. 111-128. 
jeder Art die gesetzesgemäß die medizinische Tätigkeit ausüben) auszuüben. Die Aufsicht über das Funktionieren des Systems ist dabei dynamisch zu verstehen, d.h. nicht nur mit Blick auf die Erfüllung der gesetzlichen Anforderungen, sondern im Kontext der Umsetzung des Grundsatzes des gleichen Zugangs. Diese Dynamik begründet u.a. die Notwendigkeit einer regelmäßigen Evaluierung der geltenden Rechtsregelungen und der Übereinstimmung der Wirkungen ihrer Anwendung, mit dem Ziel, kontinuierlich die erforderlichen Anpassungen vornehmen zu können, um das System zu optimieren. ${ }^{31}$ Es ist zu bedenken, dass die in Art. 68 Abs. 2 pV verankerte Pflicht der öffentlichen Gewalt nicht nur als gesetzgeberische Kompetenz zu verstehen ist. Hierin ist das Ziel des Gesetzgebers definiert, welches als Optimierungsgebot die Richtung der gesetzgeberischen Aktivität bestimmt. Da als Ziel die Sicherung des gleichen Zugangs festgelegt wurde, ist bei der Bewertung der Verwirklichung dieser Vorgabe die Problematik des Gleichheitsgrundsatzes im Sozialrecht zu betrachten. Zum einen geht es hier um die Frage der gerechtfertigten Differenzierung zwischen der Rechtslage von bestimmten Subjekten bzw. Personengruppen in Bezug auf den Zugang zu den Leistungen der Gesundheitsfürsorge (hiermit sind sowohl der Zugang zum System, die Eintrittsbedingungen, z.B. Beitragssatz, als auch der Zugang innerhalb des Systems, d.h. die Inanspruchnahmebedingungen, z.B. Eigenanteil an den Kosten der Leistungen der Gesundheitsfürsorge, gemeint). Zum anderen folgt daraus die Pflicht der ständigen und kontinuierlichen Weiterentwicklung der praktizierten Lösungen, um die derzeitigen und künftigen Ungleichheiten zu überwinden, denn noch immer gilt: „Mehr Gleichheit in der Sicherheit bedeutet zugleich neue Ungleichheit". 32

Die postulierte Gleichheit des Zuganges bezieht sich laut Art. 68 Abs. 2 $\mathrm{pV}$ auf die materielle Lage von Bürgern. In diesem Sinne verdient das Urteil des polnischen Verfassungsgerichthofes vom 7. Januar $2004^{33}$ Beachtung, in dem festgestellt wurde, dass es in Art. 68 Abs. 2 pV, ,um den gleichen Zugang für alle Bürger unabhängig von deren materieller Lage geht“", da „die Grundsätze der Inanspruchnahme von Leistungen der Gesundheitsfürsorge vom Grad der Teilnahme der einzelnen Mitglieder der Gemeinschaft an den öffentlichen Mitteln, die die Finanzierungsquelle dieser

31 Vgl. Lach, Organisation, Akteure und Rechtsverhältnisse im polnischen System der Gesundheitsfürsorge, ZIAS 2016, Heft 2, S. 289-301.

32 Vgl. Zacher (Fn. 7), S. 34.

33 VerfGH v. 07.01.2004, K 14/03. 
Leistungen darstellen, unabhängig sind.“ Der Gesetzgeber muss das System so organisieren, dass weder der Zugang zum System (Systemeinbeziehung und Beginn der Garantiephase) noch der Zugang zu den Leistungen der Gesundheitsfürsorge (bei Beginn der Realisationsphase beim Eintritt des Sozialrisikos) von der materiellen Lage, insbesondere von dem Finanzierungsgrad, abhängig ist. Wie Jończyk anführte, liegt der Sinn der Pflicht des Gesetzgebers aus Art. 68 Abs. 2 pV darin, angesichts „,der momentan bestehenden beträchtlichen sozialen Unterschiede in Polen die Gefahr der Risikoselektion in der Gesundheitsfürsorge zu minimieren. “34 Es ist dabei zu betonen, dass die Gleichheit des Zuganges nicht unmittelbar, sondern durch das Versicherungsverhältnis (Verhältnis zwischen dem Versicherten und dem Nationalen Gesundheitsfonds) und das Organisationsverhältnis (Verhältnis zwischen den Leistungserbringern und dem Nationalen Gesundheitsfonds) realisiert werden soll. ${ }^{35}$

Des Weiteren lässt sich festhalten, dass aufgrund des Inhalts und des Rechtscharakters von Art. 68 Abs. 2 pV (Programmnorm mit der Struktur des Optimierungsgebotes) das in dieser Vorschrift definierte Ziel Gleichheit des Zuganges - optimal verwirklicht werden soll. Die Maximierung von Leistungen darf hingegen nicht als von der Verfassung angestrebtes Ziel verstanden werden. Priorität hat die Unabhängigkeit des $\mathrm{Zu}-$ ganges zu den Leistungen der Gesundheitsfürsorge von der materiellen Lage der Bürger. Daraus folgt, dass sowohl die Konstruktion des Systems (Systemeinbeziehung- und Finanzierungsbedingungen) als auch der Garantieumfang (Quantität und Qualität von Leistungen) Instrumente des sozialen Ausgleiches sein sollen. ${ }^{36}$

34 Jończyk, Ochrona zdrowia (Gesundheitschutz), PiP 2007, Heft. 2, S. 6.

35 Vgl. Jończyk, Stosunek opieki zdrowotnej (Gesundheitsfürsorgeverhältnis), PiZS, Nr. 3/2007, S. 5.

36 Vgl. Lach, Komercjalizacja SPZOZ-ów a obowiązki władzy publicznej w zakresie zapewnienia równego dostępu do świadczeń opieki zdrowotnej, część 1 (Kommerzialisierung von „selbständigen öffentlichen Gesundheitsfürsorgeanstalten“ und die Pflichten der öffentlichen Gewalt im Bereich der Sicherung des gleichen Zugangs zu den Leistungen der Gesundheitsfürsorge, Teil 1), PiZS 2012, Heft 9, S. 2-8. 


\section{Sicherung des gleichen Zugangs und Rechtfertigung einer Differenzierung}

Wie schon in der Literatur ${ }^{37}$ dargestellt, muss man bei der Analyse des Grundsatzes des gleichen Zugangs zu den Leistungen der Gesundheitsfürsorge berücksichtigen, dass dieser Grundsatz die Sozialrechtsregulierung betrifft, welche die Verwirklichung von sozialpolitischen Zielen bezweckt und sich deswegen auf eine eigene Axiologie stützt. Da das Sozialrecht Chancengleichheit und die Nivellierung übermäßiger Ungleichheiten in der Lebenssituation verschiedener Personengruppen anstrebt, müssen seine Normen von Anfang an die Ungleichheit in Bezug auf die anerkannten Rechte oder auferlegten Lasten, die Differenzierungen also, berücksichtigen. Dabei muss im Einklang mit der polnischen Lehre und Rechtsprechung des polnischen Verfassungsgerichtes die Bewertung, inwieweit die Vorschriften, die das System der Gesundheitsfürsorge konstituieren und regulieren, die Grundsätze des gleichen Zugangs und der gleichen Betrachtung verwirklichen, zweistufig vorgenommen werden. Zunächst sind die Verteilungskriterien zu beurteilen, die zur Differenzierung hinsichtlich der Rechtsstellung bestimmter Subjektgruppen herangezogen wurden. Diese sollten objektiv, relevant, verhältnismäßig und ausreichend begründet sein. Anschließend wird die in der Norm angewandte Verteilung von Rechten und Pflichten auf die zuvor bestimmten Personengruppen dahingehend untersucht, inwieweit sie bestehende Unterschiede berücksichtigt und damit gerecht ist.

Für die Feststellung, ob die Typisierung ausgewählter Subjektgruppen und die Differenzierung hinsichtlich ihrer Rechtsstellung „,gerecht“ ist, ist die Begründetheit des angenommenen Differenzierungskriteriums zu überprüfen. Diese soll aus dem angenommenen Wertesystem sowie den Verfassungsgrundsätzen oder -normen folgen. Als erstes muss in diesem Kontext der (soziale) Solidaritätsgrundsatz herangezogen werden, der die Basis und das Leitprinzip des Versicherungssystems als eine von mehreren Methoden der Verwirklichung der Idee der sozialen Sicherung dar-

37 Vgl. Lach, Zasada równego dostępu do świadczeń opieki zdrowotnej (Grundsatz des gleichen Zugangs zu den Leistungen der Gesundheitsfürsorge), Warschau 2011, S. 81 ff.;ders. Die Verteilungsgerechtigkeit in der Gesundheitsfürsorge, in: Classen/Eukańko/Richter (Hrsg.), Diskriminierung aufgrund der Gesundheit in alternden Gesellschaften. Deutschland und Polen vor neuen Herausforderungen, Berlin 2015, S. 281-292. 
stellt. Der Solidaritätsgrundsatz betrifft vor allem die Pflichten der Systemteilnehmer (sowie Benefiziare) und nicht deren Rechte. ${ }^{38}$ Daraus folgt, dass man die Teilnahme an der Risikogemeinschaft und die Höhe des Beitrags zu ihrer Finanzierung im Lichte der Solidarität bewerten kann. Das Recht auf Leistungen folgt bereits aus der Systemteilnahme selbst. Sein Umfang richtet sich nach dem individuellen Gesundheitszustand (Bedarf). Der Solidaritätsgrundsatz braucht hier nicht angewendet zu werden. Der Inhalt des Grundsatzes der sozialen Solidarität (Solidarprinzip) ist der, dass die aus den bestehenden Interdependenzen folgende Übernahme von bestimmten Lasten und Pflichten durch die Gemeinschaft einen sozialen Ausgleich innerhalb der Gemeinschaft herbeiführt. Die Idee der sozialen Solidarität ist also die Vergemeinschaftung („Entindividualisierung“) des Risikos. ${ }^{39}$ Dies wird vor allem in der Konstruktion des Beitrages ersichtlich ist, der ausschließlich von der Einkommenshöhe und nicht von dem Risiko oder Bedarf des Einzelnen abhängt (interpersonaler Ausgleich). ${ }^{40}$

An anderer Stelle thematisiere ich das Verhältnis zwischen Gleichheitsund Gerechtigkeitsgrundsatz. ${ }^{41}$ Ich komme zu dem Schluss, dass die Gleichheitsregel in der Tat nur eine der Gerechtigkeitsregeln ist, da sowohl die gleiche (identische - jedem das Gleiche oder gleich viel) als auch ungleiche (differenzierte) Verteilung gerecht sein kann. ${ }^{42}$ Es ist jedoch zu bedenken, dass im Falle der legislativen Aktivitäten der öffentlichen Ge-

38 Vgl. Lach, O solidarności społecznej w „,ubezpieczeniu zdrowotnym” (Von der sozialen Solidarität in der „Krankenversicherung), in: Skapski/Ślebzak (Hrsg.), Aksjologiczne podstawy prawa pracy i ubezpieczeń społecznych (Axiologische Grundsätze des Arbeits- und Sozialversicherungsrechtes), Posen 2014, S. 271-285.

39 Die Vergemeinschaftung („Entindividualisierung“) des Risikos unterscheidet die soziale Versicherung von den privatrechtlichen Versicherungen, bei welchen die Höhe der Beiträge grundsätzlich von dem individuellen Risiko des Versicherten abhängt.

40 Vgl. Kirchhof, Das Solidarprinzip im Sozialversicherungsbeitrag, in: Schulin (Hrsg.), Sozialfinanzverfassung: 5. Sozialrechtslehrertagung 6. bis 8. März 1991 in Göttingen, Wiesbaden 1992, S. 65 ff.

41 Vgl. Lach, Die Verteilungsgerechtigkeit in der Gesundheitsfürsorge, in: Classen/ Łukańko/Richter (Hrsg.), Diskriminierung aufgrund der Gesundheit in alternden Gesellschaften. Deutschland und Polen vor neuen Herausforderungen, Berlin 2015, S. 281-292.

42 Vgl. Nowacki, Sprawiedliwość a równość w orzecznictwie Trybunału Konstytucyjnego (Die Gerechtigkeit und die Gleichheit in der Rechtsprechung des Verfassungsgerichtes), in: Kudej (Hrsg.), W kręgu zagadnień konstytucyjnych. Profesorowi Eugeniuszowi Zwierzchowskiemu w darze (Im Kreis der Verfassungsfragen. Festgabe für Professor Eugene Zwierzchowski), Kattowitz 1999, S. 83-103. 
walt, vor allem im Sozialrecht, kaum eine Situation vorstellbar ist, in der eine einheitliche Entscheidung über die Verteilung von Gütern, Rechten oder Pflichten möglich wäre. Schließlich folgt jede Gesellschaftspolitik der unbestrittenen These von der bestehenden Diversität der Lebens- und Daseinskonditionen der verschiedenen sozialen Gruppen. Wenn eines der Grundziele der Gesellschaftspolitik die Nivellierung von übermäßigen Disproportionen in diesem Bereich sein soll, dann muss eine diesem Ziel dienende Regelung von einer Ungleichheit in Bezug auf die zuerkannten Rechte oder auferlegten Lasten ausgehen. Erst im Lichte dieser Annahme kann man die bestehende Regelung im Hinblick auf die angewandten Verteilungskriterien, anhand derer (zwischen den Subjekten) differenziert wurde, bewerten. Dabei ist zu prüfen, ob sie objektiv, relevant, verhältnismäßig und gerecht, d. h. geeignet, ist, um feststellen zu können, ob die Verteilung von Rechten und Pflichten zwischen den so bestimmten Personengruppen gleich, also in dem Sinne gerecht ist, dass die bestehenden Unterschiede berücksichtigt wurden.

Aus der Anerkennung der Verteilungsgerechtigkeit als begründetem und relevantem Ziel des Rechts folgt die Frage, ob es einen Konflikt zwischen dem vom Rechtssystem verwirklichten Gerechtigkeitsgrundsatz und dem Grundsatz der Gleichheit vor dem Gesetz geben kann. Jede Forderung nach einer differenzierten Behandlung, die aus der materiellen Gerechtigkeit abzuleiten sein kann (z.B. Sonderpflege für gesellschaftlich benachteiligte Gruppen oder Bevorzugung von ausgewählten Subjektgruppen, ausgedrückt in Sonderleistungsberechtigungen [Leistungen außerhalb des Katalogs, außerhalb der Reihe, ohne Zuzahlung u.a.]), scheint der Gleichheit vor dem Gesetz zu widersprechen. In diesem Kontext ist jenen Literaturaussagen beizupflichten, denen zur Folge der Begriff der Gleichheit vor dem Gesetz keinen autonomen, von anderen Werturteilen unabhängigen, Inhalt hat und der Grundsatz der Gleichheit vor dem Gesetz inhaltlich sekundär gegenüber den Grundsätzen der materiellen Gerechtigkeit ist und daher nicht deren Zulässigkeitskriterium sein kann. ${ }^{43}$

Dies heißt also auch, dass wenn der Gleichheitsgrundsatz keinen absoluten Charakter hat, die Differenzierung nach der jeweiligen Rechtssituation zulässig ist, sofern sie nicht - mangels hinreichender Begründung -

43 Vgl. Sadurski, Teoria sprawiedliwości. Podstawowe zagadnienia, (Die Theorie der Gerechtigkeit, Grundfragen), Warschau 1988, S. 87 f.; ähnlich: Nowacki (Fn. 42), S. 95, 103. 
eine Diskriminierung oder unzulässige Bevorzugung darstellt. ${ }^{44}$ Mit anderen Worten hat die Gleichheit im Recht materiellen und nicht formellen Charakter, sie betrifft die Begründetheit der Wahl des Differenzierungskriteriums, welche aus dem angenommenen Wertsystem folgt. ${ }^{45}$ Auch das Verfassungsgericht war der Auffassung, dass die Differenzierung im Recht zulässig ist, soweit sie gerechtfertigt ist. ${ }^{46}$

\section{Verwirklichung des Grundsatzes des gleichen Zugangs zu den Leistungen der Gesundheitsfürsorge}

Die Analyse der Gleichheit des Zuganges zu den Leistungen der Gesundheitsfürsorge betrifft also die Frage, ob Differenzierungen aufgrund der unterschiedlichen Rechtssituationen bestimmter leistungsberechtigter Gruppen im Lichte des Gerechtigkeitsgrundsatzes (in verschiedenen Aspekten durch das Solidarprinzip korrigiert) begründet sind, nicht aber den tatsächlichen (räumlichen, technischen u.a.) Zugang. Dabei soll der Zugang zu den Leistungen der Gesundheitsfürsorge als die Möglichkeit der Nutzung der im System garantierten Gesundheitsfürsorge(-leistungen) verstanden werden, was sowohl den Zugang zum System, als auch den Zugang zu der Gesundheitsfürsorge (bzw. den -leistungen) für die Systemteilnehmer umfasst. Der Gegenstand des Zugangs (und der Finanzierung) ist die Gesundheitsfürsorge, deren Umfang in jedem Fall individuell angepasst wird, wobei die erforderlichen medizinischen Dienst- und Sachleistungen von der Fachbewertung des medizinischen Personals abhängig sind. Die Bewertung von bestehenden sozialrechtlichen Regelungen soll,

44 Vgl. Garlicki, Zasada równości i zakaz dyskryminacji w orzecznictwie Trybunału Konstytucyjnego (Gleichheitsgrundsatz und Diskriminierungsverbot in der Rechtsprechung des Verfassungsgerichthofes), in: Oliwa-Radzikowska (Hrsg.), Obywatel - jego wolności i prawa. Zbiór studiów przygotowanych z okazji 10-lecia urzędu Rzecznika Praw Obywatelskich (Bürger - seine Freiheiten und Rechte. Sammlung von Studien vorbereitet zum 10. Jubiläum des Ombudsman-Amtes), Lodz 1998, S. 66.

45 Vgl. Sadurski, Równość wobec prawa (Gleichheit im Recht), PiP 1978, Nr. 8-9, S. 58 f. und die dort zitierte Literatur; auch: Sadurski (Fn. 43), S. 98 f.

46 Vgl. VerfGH v. 26.09.1989, K 3/89, OTK 1989, Nr. 1, Pos. 5; v. 08.05.1990, K 1/90, OTK 1990, Nr. 1, Pos. 2; v. 22.08.1990, K 7/90, OTK 1990, Nr. 1, Pos. 5; v. 28.05.1991, K 1/91, OTK 1991, Nr. 1, Pos. 4; v. 07.01.1992, K 8/91, OTK 1992, Nr. 1, Pos. 5 i v. 28.11.1995, K 17/95, OTK 1995, Nr. 3, Pos. 18. 
soweit es deren Vereinbarkeit mit dem Grundsatz des gleichen Zugangs betrifft, einen abstrakt-rechtlichen und keinen konkreten Charakter haben. Bewertungsgegenstand ist die den Zugang betreffende rechtliche Regelung und nicht der Zugang als solcher in seiner räumlichen und technischen Bedeutung, der sich auf die individuelle Situation eines konkreten Leistungsempfängers bezieht. Es ist selbstverständlich und kann nicht im Lichte des Gleichheitssatzes bewertet werden, dass die Bewohner größerer Städte besseren (leichteren) Zugang zu den, vor allem stationären oder fachärztlichen, Gesundheitsfürsorgeleistungen haben, als die Versicherten aus ländlichen Regionen.

Soweit es die subjektive Seite der Verwirklichung des Grundsatzes des gleichen Zugangs zu den Leistungen der Gesundheitsfürsorge betrifft, ist anzunehmen, dass - angesichts des breiten, aber doch begrenzten Katalogs von zum Systembeitritt verpflichteten Subjekten - deren Erfüllung drei Instrumente dienen. Der Zugang zum System ist damit auch für die nicht versicherungsverpflichteten Personen gesichert. Es geht hier um die freiwillige Versicherung, die aber wegen der Höhe der Beitragsgrundlage und des Zusatzbeitrags grundsätzlich auf die wohlhabenderen Personen (wenn auch ohne Einkommen, z.B. Rentner) begrenzt ist. In diesem Sinne findet die freiwillige Versicherung kaum praktische Anwendung. Zu dem Kreis der Leistungsberechtigten wurden auch Personen ohne Versicherungstitel, die die polnische Staatsangehörigkeit besitzen und ihren Wohnsitz im Gebiet von Polen haben, gezählt, deren Einkünfte die von Art. 8 des Gesetzes über die Sozialhilfe genannten Grenzen nicht überschreiten und gleichzeitig die in Art. 7 dieses Gesetzes genannten Voraussetzungen für die Erteilung von Sozialhilfe erfüllen. Die genannten Personen sind nicht in der Lage, ihre schwierige Lebenssituation mit Hilfe ihrer eigenen Ressourcen zu überwinden. Mit der Einbeziehung auch der ärmsten Bürger, für die keine Beitragspflicht besteht, folgt der Gesetzgeber dem Gebot, die Leistungen der Gesundheitsfürsorge für alle Bürger, unabhängig von deren materiellen Lage, gleich zugänglich zu machen. Im Unterschied zu den Versicherten werden die Leistungen für diese Berechtigten nicht aus Mitteln des Fonds, sondern aus der Staatskasse finanziert. Zum dritten sind auch Personen ohne Versicherungstitel, die ihren Wohnsitz im Gebiet von Polen haben und nicht älter als 18 Jahre oder schwanger sind, leistungsberechtigt., Dies gilt auch während der Geburt bzw. dem Wochenbett. Auch hier gilt natürlich keine Beitragspflicht. Zusammenfassend kann gesagt werden, dass Leistungsberechtigte in der Tat alle Bürger sind - um die Vorgabe des Art. 68 Abs. 2 der Verfassung zu erfüllen. 
Es ist auch zu erwähnen, dass das Gesetz Sonderberechtigungen für bestimmte Subjekte vorsieht. Diese Frage wurde bereits im Schrifttum diskutiert ${ }^{47}$, daher soll hier lediglich festgestellt werden, dass weder die Bestimmung dieser Subjekte noch deren Bevorzugung hinsichtlich der Rechte auf Einwände im Hinblick auf den Grundsatz des gleichen Zugangs zu den Leistungen der Gesundheitsfürsorge stößt und die Regelungen somit als gerecht(fertigt) bezeichnet werden können. Fraglich sind aber die Art, wie diese Leistungen finanziert werden, sowie die Belastung der Gemeinschaft der Leistungsberechtigten mit den daraus folgenden Kosten. Dies gilt umso mehr, als es bei den Bevorzugten meistens um ein Recht auf Leistungen geht, das an die Idee der sozialen Entschädigung anknüpft (Leistungen für die Kriegsversehrten u.a.).

Soweit es die objektive Seite der Verwirklichung des Grundsatzes des gleichen Zugangs zu den Leistungen der Gesundheitsfürsorge angeht, muss zuerst zwischen dem Recht des Leistungsberechtigten auf die weit verstandene Gesundheitsfürsorge, welche aus öffentlichen Mitteln finanziert sein soll, und dem Recht auf bestimmte Leistungen der Gesundheitsfürsorge differenziert werden. Die abstrakte Definition der Gesundheitsfürsorge ist, im Interesse des Nationalen Gesundheitsfonds (wegen seiner Organisationspflichten) und der Leistungserbringer (im Hinblick auf das Entgelt), in den von diesen Parteien abgeschlossenen „Verträgen über die Erbringung der Leistungen der Gesundheitsfürsorge" konkretisiert. Diese Verträge dürfen aber natürlich nicht den Umfang der Ansprüche der Leistungsberechtigten auf die Leistungen der Gesundheitsfürsorge bestimmen - dies folgt aus dem Gesetz. Der Katalog von garantierten Leistungen, in dem nicht nur die einzelnen Leistungen, sondern auch die Konditionen für deren Erfüllung und Finanzierung bestimmt sind, dient sowohl der eindeutigen Feststellung des Umfangs von Leistungen, welche im System finanziert und im Rahmen der gesetzlichen Garantie erfüllt werden, als auch der Vereinheitlichung der oben erwähnten Verträge. Damit sollen territoriale Unterschiede des Leistungsumfangs sowie der -konditionen ausgeschlossen werden. Bezugnehmend auf die finanziellen Begrenzungen und das Bedürfnis, das Verhalten der Leistungsberechtigten und -erbringer zu steuern, sehen die Verträge, für bestimmte Leistungen auch (Anzahl- oder Betrags-) Grenzen vor. Der Zugang zu diesen Leistungen muss reglementiert werden, dies erfolgt durch die Verwendung von Wartelisten. Dadurch

47 Vgl. Lach (Fn. 41), S. 281-292. 
werden allerdings die Rechte der Leistungsberechtigten (Umfang der gesetzlichen Garantie) begrenzt bzw. die Leistungsberechtigten werden unterschiedlich behandelt. Die Möglichkeit, bestimmte Leistungen in Anspruch zu nehmen, wird zeitlich verschoben, d.h. die Leistungsberechtigten müssen auf einen freien Termin warten. Begründet wird dies mit dem Gemeinwohlprinzip: Die Knappheit der Finanzmittel, die dem Nationalen Gesundheitsfonds zur Verfügung stehen, rechtfertigt die Limitierung der Möglichkeit der Leistungsinanspruchnahme, da das Interesse aller Leistungsberechtigten, eine bestimmte Leistung unter Garantie erhalten zu können, gegenüber dem Interesse eines einzelnen Patienten, diese Leistung unverzüglich (auf Anfrage) in Anspruch nehmen zu können, überwiegt. Damit wird auch an die Systemgrundlagen angeknüpft - denn dieses bezieht sich auf die Rechte der Leistungsberechtigten (im rechtlichem Sinne) und nicht der Patienten (im faktischem Sinne).

Hinsichtlich finanzieller Aspekte des Grundsatzes des gleichen $\mathrm{Zu}$ gangs zu den Leistungen der Gesundheitsfürsorge ist zwischen der Frage der Beitragsfinanzierung der Systemgarantie (nebst Einschluss in der Versichertengruppe Subjekten, die keine Einkünfte erreichen und keine Beiträge bezahlen) und der Problematik des Selbstanteiles in der Verwirklichungsphase zu unterscheiden. Bei der Regelung der öffentlichen Abgabe sui generis, im Gesetz Beitrag genannt, wird zwischen verschiedenen Subjektgruppen erheblich und unverhältnismäßig differenziert. Das Fehlen einer Beitragsbemessungsgrenze führt zusätzlich zu der Differenzierung zwischen einzelnen Personen innerhalb der jeweiligen Gruppe. Eine solche Differenzierung lässt sich nicht mit dem Grundsatz der sozialen Solidarität rechtfertigen. Die Einbeziehung von Personen, die selbst kein Einkommen haben und deren Beitrag von der Staatskasse finanziert wird (wobei dies umstritten ist), in das Versicherungssystem könnte mit den Grundsätzen der sozialen Gerechtigkeit (Art. 2 pV) begründet werden. Problematisch ist die Belastung von Patienten mit den (Teil-)Kosten, die bei der Inanspruchnahme bestimmter Sach- und Begleitleistungen auferlegt werden, wenn es um individualisierte Leistungen geht. Die individuelle materielle Lage wird dabei nicht berücksichtigt, was zur Verfassungswidrigkeit dieser Regelung führen könnte. In diesem Zusammenhang ist auf das Gemeinwohlprinzip hinzuweisen, welches den Vorrang der Interessen der Versichertengemeinschaft gegenüber den Interessen des einzelnen Patienten zum Ausdruck bringt. Besondere Bedeutung kommt dabei den Vorschriften des neuen Arzneimittelkostenrückerstattungsgesetzes zu, in denen die materielle Lage der Versicherten in höherem Maße Beach- 
tung findet als in der früheren Regelung. Die Rückerstattungsstufen hängen nicht mehr von medizinischen Kriterien (Art der Arzneimittel Grund-, Ergänzungs- oder sonstige Mittel), sondern von finanziellen Kriterien (Kosten der Therapie etc.) ab. Damit wird das Gebot des Art. 68 Abs. $2 \mathrm{pV}$ beachtet und in einem volleren Maß zur Verwirklichung gebracht. ${ }^{48}$

\section{Fazit}

1. Art. 68 Abs. 2 der Verfassung hat den Charakter einer Optimierungsnorm im Sinne der möglichst umfassenden Verwirklichung eines idealen Zustands. Die das Recht anwendenden Organe sind daher an ein bestimmtes normatives Ziel gebunden und sollen eine umfassende Verwirklichung des gleichen Zugangs zu den Leistungen unter Beachtung der rechtlichen und tatsächlichen Möglichkeiten gewährleisten. In diesem Rahmen und unter bestimmten Voraussetzungen ist eine Differenzierung zulässig.

2. Daraus wiederum folgt die Pflicht der öffentlichen Gewalt, die bestehende Rechtsregelung zu überwachen und die bestehenden Lösungen kontinuierlich an die tatsächliche Situation anzupassen, um die derzeitigen und zukünftigen Ungleichheitszustände in Bezug auf den $\mathrm{Zu}-$ gang zu den Leistungen der Gesundheitsfürsorge zu beseitigen oder zumindest zu begrenzen.

3. Kern des Grundsatzes des gleichen Zugangs ist dann ein an die öffentliche Gewalt gerichtetes Gebot, ein von öffentlichen Mitteln finanziertes System der Gesundheitsfürsorge aufzubauen. Dieses System soll als wichtigste Vorgabe die Gleichheit des Zugangs ermöglichen. Gleichzeitig muss aber, wegen des Inhalts des Art. 68 Abs. 3 der Verfassung, die Bevorzugung bestimmter Subjekte vorgesehen sein.

4. Der Zugang zu den Leistungen der Gesundheitsfürsorge soll als die Möglichkeit der Nutzung der in dem System garantierten Gesundheitsfürsorge(-leistungen) verstanden werden, was sowohl den Zugang

48 Vgl. Lach, Refundacja leków a równy dostęp do świadczeń opieki zdrowotnej (Arzneimittelkostenrückerstattung und der gleiche Zugang zu der Leistungen der Gesundheitsfürsorge), „Ruch Prawniczy, Ekonomiczny i Socjologiczny” 2014, Heft 1, S. 119-131. 
zum System, als auch den Zugang zu der Gesundheitsfürsorge (bzw. deren Leistungen) für die Systemteilnehmer umfasst.

5. Gegenstand des Zugangs (und der Finanzierung) ist die Gesundheitsfürsorge, deren Bereich in jedem Fall individuell angepasst wird. Die erforderlichen medizinischen Dienst-, Sach- und Begleitleistungen werden in Abhängigkeit von den Fachbewertungen des medizinischen Personals bestimmt.

6. Gleichheit des Zugangs heißt, dass in Bezug auf die Leistungen der Gesundheitsfürsorge weder Quantität (Art und Umfang) noch Qualität (Standard) oder die Voraussetzungen der Gewährung von der materiellen Lage oder dem Grad der finanziellen Partizipation des Leistungsberechtigten (die unterschiedlich sein können) abhängig gemacht werden dürfen.

7. Es ist also verboten, die Rechtsregulation so zu gestalten, dass beim Zugang in ungerechtfertigter Weise aufgrund der materiellen Lage der Bürger differenziert wird. Dies bezieht sich insbesondere auf die Einführung ungerechtfertigter Finanzschranken.

8. Eine Betrachtung des Sozialrechts ergibt, dass die Gesellschaftspolitik einen Chancenausgleich und die Beseitigung übermäßiger Unterschiede in der Lebenssituation verschiedener Personengruppen bezweckt. Daraus folgt, dass einer diesem Ziel dienenden Rechtsregelung von Anfang an die Annahme einer Ungleichheit in Bezug auf die anerkannten Rechte oder die auferlegten Lasten zugrunde liegen muss. Erst im Lichte dieser Annahme kann man die bestehende Regelung bezüglich der angewandten Verteilungskriterien dahingehend bewerten, ob sie objektiv, relevant, verhältnismäßig und gerecht ist. Anschließend kann festgestellt werden, ob die Verteilung von Rechten und Pflichten zwischen den so bestimmten Personengruppen gleich und damit in dem Sinne ist, dass die bestehenden Unterschiede berücksichtigt werden.

9. Unter Berücksichtigung der besonderen Axiologie des Sozialrechtes kann man sagen, dass die Zulässigkeit der Differenzierung sowie der angewendeten Differenzierungskriterien nicht nur mit dem Gerechtigkeits- oder Gemeinwohl-, sondern auch mit dem Solidaritätsgrundsatz begründet werden kann.

10. Bei dem Aufbau von Systemen der sozialen Sicherung sollte der Gesetzgeber nicht nur gewisse axiologische Annahmen berücksichtigen und verfassungsrechtlich bestimmte Ziele verfolgen, sondern auch die rechtlichen und tatsächlichen Möglichkeiten beachten. Deshalb steht 
ihm bei der Wahl bestimmter Lösungen bzw. bei der Schaffung neuer Institutionen ein erheblicher Spielraum zu.

11. Bei einer rechtlichen Beurteilung im Lichte der Programmnormen der Verfassung sind nur solche Regelungen zu beanstanden, die klar und eindeutig im Widerspruch $\mathrm{zu}$ den in diese Programmnormen zum Ausdruck gebrachten Zielen stehen. Wenn die bestehenden Lösungen bedenklich sind, aber das Handeln des Gesetzgebers nicht als willkürlich bezeichnet werden kann, dürfen nur de lege ferenda-Postulate formuliert werden. Die Entscheidungen sind hingegen dem Gesetzgeber mit der durch Wahlen zum Ausdruck gebrachten Legitimation des Souveräns zu überlassen.

12. Die derzeitigen rechtlichen Regelungen bezüglich der finanziellen Belastungen der einzelnen Subjekte (bzw. deren Gruppen) können als umstritten bezeichnet werden. Es ist daher eine Änderung der bestehenden Regelung zu fordern. Dennoch liegt in ihr keine ,unbestreitbare und offensichtliche" Verfassungsverletzung. 
Grundriss des polnischen Systems der öffentlichen

Gesundheitsfürsorge

Daniel Eryk Lach

I. Das System der Gesundheitsfürsorge als Institution des

Gesundheitsschutzes

\section{Gesundheitsschutz}

Der Gesundheitsschutz umfasst die Gesamtheit aller Aufgaben der öffentlichen Gewalt zur Verwirklichung der Vorgaben aus Art. 68 plVerf (,Jeder hat das Recht auf den Schutz der Gesundheit") im Rahmen der staatlichen Sozialpolitik, aber auch aus Art. 30 („,Die Würde des Menschen ist ihm angeboren und unveräußerlich. Sie bildet die Quelle der Freiheiten und Rechte des Menschen und des Staatsbürgers. Sie ist unverletzlich, ihre Beachtung und ihr Schutz ist Verpflichtung der öffentlichen Gewalt") und Art. 38 plVerf („Die Republik Polen gewährleistet jedem Menschen rechtlichen Schutz des Lebens"). Nach Ansicht des Verfassungsgerichtshofs (VerfGH) ,geht der Gesundheitsschutz strikt mit dem Schutz des Lebens einher, genauso wie das Recht auf Leben mit der Menschenwürde. Das Recht auf Gesundheitsschutz besteht vor allem im Recht auf die Erhaltung und den Schutz von Leben im Falle einer Gefährdung"1. Aus diesem Grund stellen die Art. 68 Abs. 1 i. V. m. Art. 30 und 38 plVerf die axiologische Grundlage für die gemeinsame Eingliederung der Straftaten gegen diese beiden geschützten Rechtsgüter dar (vgl. Kapitel XIX des polnischen Strafgesetzbuchs mit dem Titel „Straftaten gegen das Leben und die Gesundheit").

Auch wenn man sich auf einen bloßen Versuch beschränkt, den Begriff „Gesundheitsschutz" als Gegenstand von Maßnahmen der Sozialpolitik definieren zu wollen, wird man feststellen müssen, dass er einen weiten Anwendungsbereich aufweist. Er umfasst nämlich im Grunde genommen

1 Vgl. VerfGH v. 07.01.2004, K 14/03; ebenso Surówka, Glosse zum Urteil des VerfGH v. 07.01.2004, K 14/03, Przegląd Sejmowy 2004, Nr. 6, S. 172 ff. 
die Gesamtheit staatlichen Handelns, im allgemeinen wie im individuellen Interesse, bezogen auf die öffentliche Gesundheit (u.a. Gesellschaftskrankheiten, Impfungen, sanitäre und epidemiologische Belange, Blutspenden, Transpathologie), die Ausübung medizinischer Berufe, die Regelung des Marktes für Gesundheitsdienstleistungen und der Dienstleister selbst und sogar zur Umwelt sowie zur körperlichen Aktivität der Bürger. ${ }^{2}$

Eine derart breit gefächerte Umschreibung des Gesundheitsschutzes als Gegenstand rechtlicher Regelungen geht auf Art. 68 plVerf zurück. Insgesamt betrifft dieser Artikel die Gesamtheit der unter dem Oberbegriff „Gesundheitsschutz" zusammengefassten Aufgaben der öffentlichen Gewalt, wobei die Absätze 2-5 eine Ergänzung zu Abs. 1 darstellen, der das Menschenrecht auf Gesundheitsschutz statuiert und dabei auf dessen einzelne Aspekte eingeht. Absatz 2 (,Den Staatsangehörigen, unabhängig von deren materiellen Lage, sichert die öffentliche Gewalt gleichen Zutritt zur Gesundheitsfürsorge, die aus den öffentlichen Mitteln finanziert wird. Bedingungen und Umfang der Leistungen regelt das Gesetz.") betrifft die Pflicht zur Begründung eines Systems der Gesundheitsfürsorge unter Verwirklichung des Grundsatzes des gleichen Zugangs zu garantierten Leistungen, während Absatz 3 („Die öffentliche Gewalt ist verpflichtet, den besonderen Schutz der Kinder, Schwangeren, Behinderten und Älteren zu sichern"), der in der individuellen und vertragsleistungsbezogenen Gesundheitsfürsorge zu verorten ist, die Notwendigkeit der Gewährleistung einer besonderen Gesundheitsfürsorge für die dort genannten Gruppen von Rechtssubjekten betont - damit stellt er nicht nur eine Leitlinie für die Begründer dieses Systems auf, sondern bestimmt gleichzeitig die Gruppen von Rechtssubjekten, die aufgrund ihrer persönlichen Lage oder ihres Alters eine besondere Fürsorge von Seiten der öffentlichen Gewalt erfahren sollen. $\mathrm{Zu}$ verstehen ist darunter wohl nicht nur eine Maßnahme zur Verwirklichung der Familienpolitik, sondern auch zur Gewährleistung von Chancengleichheit sowie der Bekämpfung von sozialem Ausschluss durch den Schutz der Schwächsten und Bedürftigen. Abs. 3 stellt dabei keinen eigenständigen Programmsatz auf, der in einem Konkurrenzverhältnis zu

2 Vgl. Poździoch, Prawo zdrowia publicznego. Zarys problematyki, Krakau 2004, S. 28 f.; Sieńko, Prawo ochrony zdrowia, Warschau 2006, S. 18; Dercz/Izdebski, Organizacja ochrony zdrowia w Rzeczypospolitej Polskiej w świetle obowiązującego ustawodawstwa, Warschau - Posen 2001, S. 11. 
jenem, der aus Abs. 2 folgt, stehen würde ${ }^{3}$, sondern ergänzt und präzisiert diesen lediglich. Die Verfassung der Republik Polen verpflichtet nämlich die öffentliche Gewalt zur Begründung eines Systems der Gesundheitsfürsorge, das den Bürgern einen gleichen (im Grunde also ausdifferenzierten) Zugang zu Leistungen gewährt und dabei Kindern, Schwangeren, Behinderten und älteren Personen eine besondere Gesundheitsfürsorge garantiert. Abs. 4 („Die öffentliche Gewalt ist verpflichtet, ansteckende Krankheiten zu bekämpfen und den negativen Auswirkungen der Umweltverschmutzung auf die Gesundheit vorzubeugen.") bezieht sich hingegen ausdrücklich auf die öffentliche Gesundheit, ohne weitere Fragestellungen der Organisation und Finanzierung des Systems der Gesundheitsfürsorge zu regeln. Einen gänzlich abstrakten Charakter besitzt schließlich die in Abs. 5 statuierte Pflicht der öffentlichen Gewalt zur Unterstützung der sportlichen Betätigung, insbesondere bei Kindern und Jugendlichen - ihre Verortung in Art. 68 plVerf macht deutlich, dass diese Problematik als Eckpfeiler der Prophylaxe eine bedeutende Funktion für den Gesundheitszustand jedes Einzelnen und der Gesellschaft als Ganzes erfüllen soll. Unter diesem Gesichtspunkt stellt Abs. 1 letzten Endes eine Klammer für die sonstigen Absätze dieses Artikels dar, indem er sie auf einen gemeinsamen Nenner - Ziel und Zweck der aufgezählten Vorschriften - bringt, nämlich den Gesundheitsschutz. ${ }^{4}$

3 Vgl. Trzciński, Konstytucyjne prawo do zdrowia na tle Art. 35 Karty Podstawowych Praw Unii Europejskiej, in: Garlicki/Szmyt (Hrsg.), Sześć lat Konstytucji Rzeczypospolitej Polskiej. Doświadczenia i inspiracje, Warschau 2003, S. 302-305; Gizbert-Studnicki/Grabowski, Normy programowe w Konstytucji, in: Trzciński (Hrsg.), Charakter i Struktura norm Konstytucji, Warschau 1997, S. 111-112.

4 Der Verfassungsgerichtshof ist der Ansicht, dass Art. 68 Abs. 1 der polnischen Verfassung ein subjektives Recht des Einzelnen begründet. Trzciński sieht hingegen zwei mögliche Varianten für die Auslegung dieser Vorschrift: Entweder als selbstständige Grundlage für die Ableitung eines subjektiven Rechts oder, „nach den Grundsätzen der systematischen Auslegung”, als zusammengehörig mit den sonstigen Absätzen von Art. 68 der polnischen Verfassung, die ,den Inhalt von Abs. 1 zwar ergänzen, ohne ihn jedoch vollständig auszufüllen” (vgl. Trzciński, (Fn. 3), S. 302). Winczorek stellt demgegenüber fest, im Wortlaut des Art. 68 plVerf seien Bestimmungen doppelter Natur zu finden. Einerseits sollen sie subjektive Rechte zugunsten bestimmter Personen begründen, konkret zugunsten jedermanns (Abs. 1), polnischer Staatsangehöriger (Abs. 2) sowie Kinder, Schwangerer, behinderter Personen und älterer Menschen (Abs.3). Andererseits enthalte die Vorschrift (in Abs. 2-5) ebenfalls einen entsprechenden Auftrag für die öffentlichen Gewalt (vgl. Winczorek, Komentarz do Konstytucji Rzeczypospolitej Polskiej vom 2. April 
In der Literatur ${ }^{5}$ wird angemerkt, die Ziele des Gesundheitsschutzes ließen sich einteilen in solche mit Bezug zur gesundheitlichen Verfassung der gesamten Gesellschaft (die Gesundheit der Bevölkerung als kollektive Kategorie) und jene betreffend konkret gefährdete oder erkrankte Personen (Gefahr für Menschen durch künftige, ungewisse, ungünstige und willensunabhängige Ereignisse). Konsequenterweise gestalten sich die Aufgaben (Funktionen) des Gesundheitsschutzes wie folgt: Verbesserung der Gesundheit (allgemeine Prophylaxe), Vorbeugung vor Krankheiten (Spezialprophylaxe), Behandlung zur Vorbeugung der Krankheitsentwicklung, Behandlung zur Eindämmung von Krankheitsfolgen, Rehabilitation, ärztlich-soziale Betreuung von geistig Schwerbehinderten und Palliativpflege.

Die den Gesundheitsschutz betreffenden Aufgaben der öffentlichen Gewalt werden in zahlreichen Gesetzesakten, mitunter zur Auferlegung von Rechtspflichten bestimmten Rechtssubjekten gegenüber, weiter präzisiert. In ihrer Gänze lassen Sie sich, wenn man auf ihren Regelungsgegenstand als Kriterium abstellt, in einem separaten Rechtszweig zusammenfassen: dem Gesundheitsschutzrecht. Definieren lässt sich dieses, unter Berücksichtigung der Aussagen im Schrifttum, als ,ein komplexer Rechtszweig zur Regulierung jeglicher der öffentlichen wie der privaten Sphäre zugehöriger Rechtsverhältnisse und -Ereignisse mit Folgen, die sich auswirken auf: 1) Die Erfüllung von Aufgaben durch den Staat und die territoriale Selbstverwaltung im Bereich der Gewährleistung der gesundheitlichen Sicherheit der Bürger, 2) das Funktionieren des Marktes für Leistungen der Gesundheitsfürsorge, 3) das Betreiben einer Tätigkeit auf dem Markt für Gesundheitsleistungen, 4) die Organisation von Institutionen und Einrichtungen des Gesundheitsschutzes sowie 5) die zivil- und strafrechtliche Verantwortung bezüglich aller Formen von Aktivitäten auf dem medizinischen Markt"6.

1997, Warschau 2000, S. 91). Vgl. Lach, Zasada równego dostępu do świadczeń opieki zdrowotnej, Warschau 2011, S. 23-34, $140 \mathrm{ff}$.

5 Vgl. Szurgacz, Ochrona zdrowia a opieka społeczna, in: Jończyk (Hrsg.), Opieka zdrowotna. Materiały V Kolokwium Ubezpieczenia Społecznego, Breslau 1989, S. 22 f.; Jończyk, Ochrona zdrowia, Państwo i Prawo 2007, Heft 2, S. 3 ff., 12.

6 Vgl. Sieńko, (Fn. 2), S. 18. 


\section{Gesundheitsfürsorge}

Die Gesundheitsfürsorge stellt einen Gegenstand gesetzlicher Regelung dar und wird aus öffentlichen Mitteln finanziert. Der Begriff an sich soll integrierend wirken und für die Summe aller Gesundheits-, Begleit- und Sachleistungen stehen, die der Leistungsempfänger zum Zeitpunkt des Eintritts des Risikos eines Gesundheitsmangels erwarten kann. ${ }^{7}$ Sie wird gegenüber dem individualisierten Leistungsempfänger im System in einer konkretisierten Situation erbracht, die infolge der Verwirklichung des Risikos eines Gesundheitsmangels entstanden ist. Das gesamte System der Gesundheitsfürsorge - ungeachtet seiner organisatorischen und finanziellen Grundprinzipien sowie der rechtlichen Ausgestaltung - verfolgt als

7 Das Risiko eines Gesundheitsmangels ist ein soziales Risiko, dessen Eintritt zu Leistungen der aus öffentlichen Mitteln finanzierten Gesundheitsfürsorge berechtigt. Jończyk nahm angesichts der Tatsache, dass Gegenstand des Systems der Gesundheitsfürsorge mittlerweile nicht mehr lediglich die Ermöglichung der Nutzung von Gesundheitsleistungen im Wege der Übernahme ihrer Kosten, sondern auch die Gewährleistung des Gesundheitsschutzes einschließlich Heilbehandlungen, der Prophylaxe, Rehabilitation, und Pflege- bzw. ärztlicher Leistungen praktisch allen Bürgern gegenüber ist, an, es sei nicht länger von einem Erkrankungsrisiko, sondern vielmehr von einem „Risiko eines Gesundheitsmangels” i S. einer „Ermangelung dessen, was nach der Definition der WHO als Gesundheit angesehen wird" zu sprechen, Jończyk, Prawo zabezpieczenia społecznego, Zakamycze 2001, S. 306 f. Das Risiko eines Gesundheitsmangels ist ein Rechtsbegriff zur näheren (wenn auch weiterhin sehr weiten) Bestimmung, welche Ereignisse, in deren Folge ein Verlust von Gesundheit eintritt (gemeint ist ein realer Verlust biologischer Natur sowie - in Anlehnung an den Gesundheitsbegriff der WHO - Ereignisse, die sich gleichermaßen auf die körperliche wie auf die seelische Verfassung beziehen) zu einer Aktualisierung und Konkretisierung des Rechts auf aus öffentlichen Mitteln finanzierte Leistungen der Gesundheitsfürsorge, auf die der Berechtigte seit der Entstehung des Versicherungsverhältnisses einen Anspruch hat, führen. Das System der Gesundheitsfürsorge schützt weder vor dem Risiko eines Gesundheitsmangels (abgesehen von sachlich und persönlich eingeschränkten Maßnahmen der Prophylaxe und Werbung für einen gesunden Lebensstil - wobei auch solche Maßnahmen keine Abschaffung von Krankheiten beanspruchen) noch vor den Folgen seines Eintritts in dem Sinne des Ausgleichs von Schäden, die infolge eines Gesundheitsverlusts entstanden sind (was wiederum zum Leistungsgegenstand der persönlich deutlich stärker eingeschränkten Krankenversicherung zählt). Dem Risiko eines Gesundheitsverlusts kommt die Bedeutung zu, dass es der Bewertung der vom Leistungsempfänger vorgetragenen Fälle des Eintritts eines Gesundheitsverlusts aus dem Blickwinkel der Pflichten des Organisators und der Leistungsempfänger dient. 
Zielsetzungen die Verwaltung von Finanzmitteln und die Organisation der Erbringung von garantierten Leistungen an die Berechtigten. ${ }^{8}$

Der Begriff „Gesundheitsfürsorge“ versetzt die Leistungsempfänger in eine zentrale Lage - in die Mitte des Geschehens - und richtet an die Leistungserbringer wie auch an den Organisator des Systems das Gebot, alles zu tun, um für den Leistungsempfänger im Falle der Verwirklichung des Risikos eines Gesundheitsmangels zu „sorgen“. In der Literatur wird zu Recht angeführt, dadurch werde „der rechtliche Aspekt der Leistungen ausgedrückt - der Patient fordert Gesundheitsfürsorge an sich, nicht hingegen die eine oder andere medizinische Behandlung" ${ }^{\text {"9 }}$. Die gesamte Tätigkeit des Leistungserbringers (unter dem Gesichtspunkt der Gesundheitsfürsorge), d.h. alle ihm auferlegten Pflichten, dienen im Grunde genommen der Leistung von Gesundheitsfürsorge. Eine Konkretisierung dieser Fürsorge kann erst in Bezug auf einen individualisierten Fall erfolgen, jedoch läuft sie auch dann nicht auf eine bloße Erteilung von gesundheitlichen Leistungen hinaus, sondern umfasst auch Begleit- (z.B. die Gewährleistung einer dem Gesundheitszustand gerecht werdenden Verpflegung im Krankenhaus) und Sachleistungen (vgl. nachstehend III.2.).

Dies bedeutet, dass der Begriff der Gesundheitsfürsorge im weitesten Sinne nicht im Wege einer abstrakten, grundsätzlichen Konkretisierung von Leistungen, die dem Leistungsempfänger im Falle des Eintritts des konkreten Risikos eines Gesundheitsmangels erteilt werden sollten, definiert werden kann. Möglich wird dies erst dann, wenn sich das gegebene Risiko in Bezug auf den konkreten Leistungsempfänger bereits verwirklicht hat. Erst dann kann ein qualifiziertes medizinisches Personal eine Diagnose stellen und auf ihrer Grundlage, unter Berücksichtigung der persönlichen Eigenschaften des konkreten Patienten (allgemeiner Gesundheitszustand, Erkrankungsgeschichte, Zugehörigkeit zu Risikogruppen, Alter usw.), eine entsprechende Behandlung i.S.e. Durchführung aller aus Sicht der Heilkunst notwendigen Maßnahmen verordnen, die sowohl gesundheitliche Leistungen als auch behandlungsrelevante Medikamente,

8 Vgl. Lach, Koszyk świadczeń gwarantowanych w systemie opieki zdrowotnej, Praca i Zabezpieczenie Społeczne 2009, Nr. 12, S. 3 ff.

9 Vgl. Jończyk, Stosunek opieki zdrowotnej, Praca i Zabezpieczenie Społeczne, Nr. 3/2007, S. 4. Der zitierte Autor merkte dabei an, dass die „Erfüllung einer Leistung auch dann erfolgt, wenn der Leistungserbringer aus gerechtfertigtem Grund die Durchführung der einen oder anderen Behandlung ablehnt.”. 
medizinische Produkte und Hilfsmittel sowie Begleitleistungen umfassen. ${ }^{10}$

3. Die Gesundheitsversicherung und ihre Rechtnatur vor dem Hintergrund des rechtlichen Paradigmas des Systems der Gesundheitsfürsorge

Der Begriff der „Gesundheitsversicherung“ steht für die gesetzliche Bezeichnung des in Polen geltenden Systems der Gesundheitsfürsorge. Eines Systems der Organisation und Finanzierung von gesetzlich garantierten Leistungen der Gesundheitsfürsorge für den Fall des Eintritts eines bestimmten sozialen Risikos: Dem Risiko eines Gesundheitsmangels. Es handelt sich um das Rechtsinstitut zur Verwirklichung des Gedankens der sozialen Absicherung im Bereich der Gesundheitsfürsorge.

Bei der Beleuchtung des Gesundheitsversicherungssystems ist zunächst auf die Problematik seiner Rechtsnatur einzugehen. Der Name selbst legt nahe, dass es sich um einen versicherungstechnischen Ansatz zur Umsetzung der sozialen Absicherung handelt, jedoch findet diese vom Gesetzgeber angewandte Terminologie keine Bestätigung im Inhalt der rechtlichen Konstruktionen aus dem Gesetz vom 27. August 2004 über aus öffentlichen Mitteln finanzierte Leistungen der Gesundheitsfürsorge (im Weiteren: ÖffLG).

Stellt man auf die in der Sozialrechtslehre verwendeten Kriterien zur Unterscheidung der einzelnen Techniken der sozialen Absicherung ab, ergibt sich, dass das System der "Gesundheitsversicherung“ im Nationalen Gesundheitsfonds (poln. NFZ) mit Sicherheit kein Versicherungssystem nach traditionellem Verständnis darstellt. Unter Verweis auf den allgemeinen Geltungsanspruch (vgl. unten V.1.) und die Rechtsnatur der Gesundheitsversicherungsbeiträge (vgl. unten V.1.) sind vor allem Rolle und Aufgaben des NFZ hervorzuheben. Der Fonds stellt eine staatliche Organisationseinheit dar, ohne dabei die Anforderungen an selbstverwaltende Versicherungsinstitutionen zu erfüllen. Er ist selbst in keiner Weise zu Leistungen an Versicherte verpflichtet, da er einzig als Verwalter von aus Versicherungsbeiträgen stammenden Mitteln sowie als Organisator des Systems agiert - letzteres indem er die notwendigen Verträge über die Erteilung

10 Vgl. Lach (Fn. 8). 
von Leistungen der Gesundheitsfürsorge schließt. Demnach erfüllt er nicht die Rolle, die Versicherern, unabhängig von deren Namen, beim versicherungstechnischen Ansatz zukommt. ${ }^{11}$ Die allgemeine "Gesundheitsversicherung“ fungiert ferner nicht als Versorgungssystem des Gesundheitswesens, der NFZ ist auch kein Organ der öffentlichen Gewalt, denn er besitzt eine eigene Rechtspersönlichkeit und erfüllt klar präzisierte Aufgaben. ${ }^{12}$ Der Gesetzgeber verpflichtet die öffentliche Gewalt bei der Bestimmung der Aufgaben im Bereich der Gewährleistung des gleichen Zugangs zu

11 Diese Rolle erfüllen ebenso wenig die Krankenkassen (weder in der körperschaftlich-vertretungs- noch in der selbstverwaltungsbasierten Variante der Organisation der „Gesundheitsversicherung“) wie der NFZ (in der „,nationalen” Variante) - Bezeichnungen der Varianten nach Jończyk, Ubezpieczenie zdrowotne, Praca i Zabezpieczenie Społeczne, Nr. 4/2003, S. 3. Das System der Gesundheitsfürsorge konsequent als Versicherung bezeichnend, betont Jończyk gleichermaßen, dass die Ansicht über die Gesundheitsversicherung als eine Unterart der Sozialversicherung ,veraltet” sei und dass weder die Kasse noch der NFZ zu individuellen Sachleistungen gegenüber dem Versicherten/Patienten verpflichtet seien - Vgl. Jończyk, Glosa do uchwały Sądu Najwyższego z 24 stycznia 2007 r., III UZP 4/06, OSP 2008/4/316, S. 318; ders., Charakter stosunków ubezpieczenia zdrowotnego, in: VI Ogólnopolskie Forum Prawniczo-Medyczne - „Aktualne problemy prawa medycznego". Materiały konferencyjne, Warschau 2003, S. 17.

12 Strus war der Ansicht, dass der NFZ zweifelsfrei öffentliche Aufgaben erfülle, vor allem einschließlich der Pflicht zur Organisation des Systems der Gesundheitsfürsorge. Er sei aber dennoch kein Träger der öffentlichen Gewalt und erfülle demzufolge seine gesetzlichen Pflichten einzig mit privatrechtlichen Instrumenten, ohne dass ihm dabei hoheitliche Berechtigungen gegenüber den Leistungsempfängern zukämen, vgl. Strus, Rola i odpowiedzialność cywilna Narodowego Funduszu Zdrowia w stosunku do ubezpieczenia zdrowotnego, Przegląd Sądowy, Nr. 9/2005, S. 40 ff. Sehr knapp, aber dennoch bezeichnend, nahm auch Jończyk zu dieser Frage Stellung, indem er zu Art. 68 Abs. 2 der polnischen Verfassung schrieb: „Die Krankenkasse bzw. der NFZ gehören nicht der öffentlichen Gewalt an“, Glosa do wyroku SN v. 12.02.2004, II UK 243/03, OSP 2004/10/130. Aus der Rechtsprechung des Obersten Gerichts ist an dieser Stelle auf den Beschluss v. 17.11.2000, III KKO 4/00, OSNAPiUS 2001/14/473 hinzuweisen, in dem das Gericht noch in Bezug auf die unter dem Gesetz vom 6. Februar 1997 über die allgemeine Versicherungspflicht funktionierenden Krankenkassenbefand, dass diese ,zur Umsetzung des Gesundheitsversicherungswesens berufene Institutionen der Gesundheitsversicherung seien und in dieser Kapazität der Krankenkassenleiter u.a. dazu verpflichtet sei, als Bescheide bezeichnete Entscheidungen in allen im Gesetz und der Satzung der Krankenkasse genannten Angelegenheiten herauszugeben. Nichtsdestotrotz kommt diesen Entscheidungen nicht der Charakter eines Verwaltungsaktes zu, da weder die Krankenkassen noch ihre Organe zu Organen der öffentlichen Gewalt zählen”. 
Leistungen der Gesundheitsfürsorge auf keine Weise gegenüber den Bürgern/Versicherten zur Erfüllung, Organisation oder Finanzierung von Leistungen der Gesundheitsfürsorge.

Angesichts der gesetzlich bestimmten Funktionen und Aufgaben des Nationalen Gesundheitsfonds scheint demnach der Begriff „Versicherer“ wohl nicht zuzutreffen, zumal keine Leistungsverpflichtung gegenüber den Leistungsempfängern besteht. ${ }^{13}$ Die Formulierung „Zahler“, die eine passive, vor allem auf die Begleichung von durch die Leistungserbringer gestellten Rechnungen hinauslaufende, Rolle des Fonds nahezulegen scheint, ist vielmehr Ausdruck der Erwartungen von ebendiesen und steht in einem Missverhältnis zu den organisatorischen Aufgaben des NFZ. ${ }^{14}$ Das Gesetz bestimmt nämlich, dass der NFZ finanzielle, vor allem aus Beiträgen stammende, Mittel verwaltet. Im Hinblick auf Mittel aus Gesundheitsversicherungsbeiträgen handelt er im eigenen Namen für die Versicherten und sonstige Personen mit einer Leistungsberechtigung aus den einschlägigen unionsrechtlichen Koordinierungsvorschriften. Im weiteren Verlauf bestimmt das Gesetz fallgruppenartig Näheres zur allgemeinen Pflicht der Verwaltung von Mitteln im eigenen Namen für die Versicherten und weist dabei insbesondere auf die Durchführung von Ausschreibungen, Verhandlungen und das Abschließen von Verträgen über die Erteilung von Leistungen der Gesundheitsfürsorge wie auch die Überwachung ihrer Einhaltung und Abrechnung hin. Dies bedeutet, dass der NFZ, ohne ein Versicherer im eigentlichen Sinne oder ein Organ der öffentlichen Gewalt zu sein, als Verwalter der vor allem aus Beiträgen stammenden Mittel im Grunde genommen als Treuhänder für die Leistungs-

13 Vgl. Oberstes Gericht v. 13.05.2005, I CK 691/04: „Im polnischen Modell der Gesundheitsversicherung ist der NFZ kein Leistungserbringer (auch nicht im Sinne eines Potenzials zur Erteilung von Gesundheitsleistungen). In diesem Bereich greift er auf zivilrechtliche Instrumente zurück, d.h. auf Verträge über die Erbringung von Gesundheitsleistungen, die er mit den Leistungserbringern abschließt".

14 Vgl. Sieben-Richter-Beschluss des Obersten Gerichts v. 24.01.2007, III UZP 4/06, OSNP 2007/15-16/226 mit der Betonung darauf, dass der NFZ Aufgaben im Bereich der Gesundheitsversicherungen einschließlich der Bestimmung von $\mathrm{Zu}-$ gangsregeln zu Gesundheitsleistungen wahrnimmt, während Anstalten der Gesundheitsfürsorge Rechtssubjekte sind, mit deren Hilfe die Zweigstellen des NFZ die ihnen gesetzlich auferlegten Pflichten erfüllen. Vgl. auch Oberste Gericht v. 9.02.2005, III CK 345/04, nicht veröffentl. 
empfänger agiert. ${ }^{15}$ Diese These vom treuhänderischen Handeln wird weiterhin dadurch untermauert, dass der Fonds (z.B. bei der Schließung von Verträgen mit Leistungserbringern) im eigenen Namen, jedoch für die Leistungsempfänger (da ihnen auf dieser Grundlage das Recht zur Einforderung der vertraglich vereinbarten Leistungen zukommt, vgl. unten III.3.) auftritt. Der NFZ ist demnach ein professioneller Treuhänder, geschaffen zur Verwaltung und Organisation des Systems der Gesundheitsfürsorge („Gesundheitsversicherung“), und keine selbstverwaltende Versicherungsinstitution, die das Interesse einer Versichertengemeinschaft vertritt. Er handelt für die Berechtigten, wenngleich im eigenen Namen und als organisatorisch eigenständiger Träger mit einem klar aufgezeichneten Kompetenzbereich. ${ }^{16}$

Unter Berücksichtigung des Gesamtverhältnisses zwischen den am System Beteiligten, deren Rechte und Pflichten auf eine spezifische Art und Weise verflochten sind, ist der in der Lehre geäußerten Ansicht beizupflichten, dass „die Theorie des Gesundheitsschutzes anhand des schuldrechtlichen Modells zu konstruieren ist, genauer gesagt als Kombination verschiedenartiger Schuldverhältnisse zwischen dem Versicherten und dem NFZ (Versicherungsverhältnis), dem NFZ und dem Leistungserbringer (Organisations- und Finanzierungsverhältnis) und zwischen Leistungserbringer und -empfänger (Gesundheitsfürsorgeverhältnis)“17. Dieses Paradigma betont nicht nur die Koexistenz der drei Rechtssubjekte, sondern bestimmt auch die Verhältnisse zwischen ihnen als solche des Schuldrechts indem es zeigt, dass die einzelnen Beteiligten einander gegenüber berechtigt sowie verpflichtet sind und dass das „Gesundheitsver-

15 Zur Treuhand: Kędzierska-Cieślak, Powiernictwo, Państwo i Prawo, 1977, Heft 8-9, S. 44-54; Dybowski, Zasada jedności własności państwowej a stosunek powiernictwa, Państwo i Prawo, 1984, Heft 10, S. 17-33; Stec, Powiernictwo w prawie polskim na tle porównawczym, Kraków 2005.

16 Vgl. Lach, Powiernicza technika realizacji zabezpieczenia społecznego (na przykładzie ubezpieczenia zdrowotnego), Państwo i Prawo 2009, Heft 3, S. 34-47.

17 Vgl. Jończyk, Transformacja ubezpieczeń społecznych i ochrony zdrowia, in: Szurgacz (Hrsg.), Konstytucyjne problemy prawa pracy i zabezpieczenia społecznego, Breslau 2005, S. 113; ebendieser, Czwarta wersja powszechnego ubezpieczenia zdrowotnego, Praca i Zabezpieczenie Społeczne, Nr. 11/2004, S. 3 f.; ebendieser, Stosunek opieki zdrowotnej, Praca i Zabezpieczenie Społeczne, Nr. 3/2007, S. 3. Derselben Ansicht wohl auch Strus mit der Feststellung: „Das Gesundheitsversicherungsverhältnis ist schuld- sowie öffentlichrechtlicher Natur” (Fn. 12), S. 48. 
sicherungsverhältnis" von einem besonderen Charakter geprägt ist, weil es die Einzelverhältnisse zwischen den drei Parteien miteinander verflicht. Die Grundlage für diese Verbindung bildet hingegen der ganzheitliche und funktionale Ansatz in Bezug auf das Paradigma der aus öffentlichen Mitteln finanzierten Gesundheitsfürsorge, welcher sich mitunter aus der Axiologie der Idee der sozialen Absicherung ergibt. ${ }^{18}$

Mit Blick auf die funktionale Verbindung aller Rechtssubjekte und der Verhältnisse zwischen ihnen soll auch darauf hingewiesen werden, dass der Leistungserbringer gegenüber dem Leistungsempfänger im System der Gesundheitsvorsorge seine eigenen Pflichten und nicht die Aufgaben des Organisators erfüllt. Zu den Aufgaben des NFZ gehört nämlich nicht die Leistung der Gesundheitsfürsorge, sondern die Betreibung eines Systems zur „Sicherung“ solcher Leistungen. ${ }^{19}$ Daraus resultiert die bereits genannte Kooperationspflicht von Organisator und Leistungserbringern, die sich nicht lediglich auf die Aushandlung von Tarifen für die einzelnen, die Gesamtleistung der Gesundheitsfürsorge ausmachenden Behandlungen beschränken kann. Vielmehr dient diese Kooperation der Verwirklichung des Rechts von Berechtigten auf eine aus öffentlichen Mitteln finanzierte Gesundheitsfürsorge.

Nach alledem ist die These gerechtfertigt, dass es sich im Falle des Systems der Gesundheitsfürsorge um eine einzelne, komplexe Rechtsbeziehung mit der komplizierten Rechtsnatur eines sozialen Absicherungsverhältnisses unter Beteiligung von drei Rechtssubjekten handelt. In einer grafischen Darstellung in Dreiecksform wäre an der oberen Spitze der Leistungsempfänger als Berechtigter in diesem System anzubringen. Die Grundlage dieses Dreiecks würden hingegen die Verhältnisse zwischen dem Organisator des Systems und den Leistungserbringern bilden, deren Kooperation eine Inanspruchnahme von ,aus öffentlichen Mitteln finanzierten Leistungen der Gesundheitsfürsorge" durch den Berechtigten erst ermöglicht. Die Rechtsverhältnisse zwischen den einzelnen Beteiligten sind funktional eng miteinander verknüpft und verstrickt, weswegen ihre unabhängige Untersuchung nur unter Berücksichtigung der Form und Funktionsweise des gesamten Systems möglich ist. Dieser Vorbehalt be-

18 Vgl. Lach, Prawny paradygmat opieki zdrowotnej a stosunek, ubezpieczenia zdrowotnego" i jego charakter prawny, in: Kubot/Kuczyński (Hrsg.) Z zagadnień prawa pracy i prawa socjalnego. Księga jubileuszowa Profesora Herberta Szurgacza, Breslau 2011, S. 451-463.

19 Vgl. Oberstes Gerichts v. 28.05.2002, III UZP 3/02, OSNAPiUS 2002.23.575. 
trifft jedoch vor allem das Verhältnis zwischen den Leistungserbringern und dem Organisator, das häufig einzig unter dem Gesichtspunkt geschlossener Verträge und der Reduzierung des NFZ auf die Rolle des Zahlers für erbrachte Leistungen betrachtet wird, während das eigentliche Ziel, die Organisation des Gesundheitsfürsorgesystems, außer Acht gelassen wird. Zu beachten ist nämlich, dass dieses System grundsätzlich aus der Summe der geschlossenen Verträge besteht, weswegen es auf eine umfassende Art und Weise unter Berücksichtigung seiner Komplexität zu verstehen und zu analysieren ist. Anders als bei dem Modell der Sozialversicherung handelt es sich hierbei um etwas mehr als lediglich die Summe von drei Rechtsverhältnissen zwischen drei verschiedenen Rechtssubjekten, unter denen die Leistungserbringer einzig die Pflichten des Versicherers im Rahmen des Konstrukts der Verträge über Leistungen zugunsten Dritter erbringen. ${ }^{20}$ Während ein Versicherer seine Pflichten selbstständig erfüllen kann - indem er die Kosten der Heilbehandlung rückerstattet (nach dem reimbursement-Untermodell) oder eigenes medizinisches Personal verpflichtet (nach dem managed care-Untermodell) - ist ein Treuhänder, Organisator und Finanzverwalter auf eine Zusammenarbeit mit Leistungserbringern angewiesen, um das Funktionieren des Systems zu gewährleisten.

Im Lichte dieser Überlegungen ist die Behauptung gerechtfertigt, dass das polnische System der Gesundheitsfürsorge eine spezielle rechtliche Natur innehat, die aus der Interaktion von drei miteinander verflochtenen Rechtssubjekte und den spezifischen Rechtsverhältnissen zwischen ihnen hervorgeht und sich weder den traditionell verstandenen Unterordnungsverhältnissen des Verwaltungsrechts noch den klassischen zivilrechtlichen Verhältnissen zuordnen lässt. Im Falle der Verhältnisse zwischen dem Fonds und den Leistungserbringern liegt eine zivilrechtliche Vertragsbindung nahe, allerdings unter Berücksichtigung der besonderen Natur des Marktes für medizinische Dienstleistungen (hohe Regelungsdichte, beträchtliche Einschränkungen des freien Wettbewerbs, Monopolstellung des Fonds, oftmals weitgehende Spezialisierung von Leistungserbringern, Absprachen und Kartelle von Arzneimittel-, Ausrüstungs- und Geräteherstellern) und der gesetzlichen Einschränkungen in Bezug auf Vertragsschlüsse bzw. der weitgehenden Eingriffe in die freie Vertragsgestaltung. Die gegenseitigen Verbindungen zwischen dem Fonds und den Leistungs-

20 Vgl. Strus (Fn. 12), S. 53 f. 
empfängern sind hingegen, aufgrund der Allgemeinheit des Systems, dem Teilnahmezwang, der verwaltungsrechtlichen Vollstreckung und Bemessung von Beiträgen sowie dem Verfahren zum Leistungsschutz deutlich eher verwaltungsrechtlichen Verhältnissen nachempfunden, wenngleich sie von aus Treuhandverhältnissen entnommenen Elementen mit eindeutig zivilrechtlicher Herkunft durchdrungen sind, die diesen Verhältnissen eine spezielle Rechtsnatur verleihen - jene eines sozialen Absicherungsverhältnisses. Der NFZ ist ein zugunsten der Berechtigten handelnder Treuhänder und kein Träger der öffentlichen Gewalt, was ihm sonst gegebenenfalls das Recht zur einseitigen Gestaltung der Rechtslage der Leistungsempfänger verleihen würde. Als Verwalter/Organisator agiert der Treuhänder hingegen im Rahmen von gesetzlich bestimmten Leitlinien und unter Aufsicht der öffentlichen Gewalt, die ihm Aufgaben erteilt und die für deren Erfüllung vorgesehenen Mittel zur Verfügung stellt - Mittel, auf deren Verwendung die Leistungsempfänger einen Anspruch haben. So gesehen erfüllt der Fonds den Berechtigten gegenüber im Grunde genommen die Rolle eines Dieners. Die Verbindung zwischen Leistungsempfänger und -erbringer, ist von ebenso komplizierter Natur. Die Leistungspflicht ergibt sich für den Erbringer aus einem grundsätzlich zivilrechtlichen Vertrag zwischen ihm und dem Fonds, nichtsdestotrotz ist auch gesetzlichen Vorschriften eine Reihe von Rechten und Pflichten der Parteien, etwa die besonderen Pflichten des Leistungserbringers bei der Führung einer Anstalt der Gesundheitsfürsorge, zu entnehmen, was hingegen zur Schlussfolgerung führt, dass eine genaue Beschreibung von diesem Verhältnis erst unter Anwendung der besonderen Konstruktion des sozialen Absicherungsverhältnisses, das sowohl Elemente des öffentlichen als auch des Privatrechts aufweist, möglich ist. ${ }^{21}$

\section{Akteure}

\section{Leistungsberechtigter 22 und Patient}

Nach dem LÖffG ist Leistungsberechtigter eine Person, der ein Recht auf aus den öffentlichen Mitteln finanzierte Leistungen der Gesundheitsfürsor-

21 Vgl. Lach, (Fn. 18), S. 451-463.

22 Vgl. Lach, Organisation, Akteure und Rechtsverhältnisse im polnischen System der Gesundheitsfürsorge, ZIAS Nr. 2/2016, S. 289 ff. 
ge zukommt. Die entsprechende Regelung bezieht sich nicht nur auf polnische Staatsangehörige, sondern auch auf Staatsangehörige der EU- oder EFTA-Staaten und sonstige Ausländer, die sich rechtmäßig auf dem Gebiet Polens oder der EU oder der EFTA aufhalten.

Als Leistungsberechtigte gelten zunächst die Versicherten. Versicherungspflichtig sind Personen, die irgendein legales Einkommen erlangen Quelle und Höhe dieses Einkommens sind dabei irrelevant (es sind etwa keine Versicherungsfreiheit und auch keine Beitragsbemessungsgrenze vorgesehen). Das Gesetz kennt einen sehr breiten Katalog von Pflichtversicherten, der Angestellte aller Art, Bauern, Beamte, Angehörige der „Uniformdienste“ (Militär, Polizei, Feuerwehr, Grenzschutz, Zöllner u.ä.) sowie selbstständig Erwerbstätige u.a. umfasst. Man muss aber auch die Vergabe des Versichertenstatus an solche Rechtssubjekte erwähnen, die keine Einkünfte erreichen und keine Beiträge bezahlen. ${ }^{23}$

Wer in den Katalog der Pflichtversicherung nicht aufgenommen ist, kann sich freiwillig versichern, wobei seine Rechte (auf Quantität und Qualität der Leistungen der Gesundheitsfürsorge) grundsätzlich gleich denen der Pflichtversicherten sind. Wegen der Höhe der Beitragsgrundlage und der Zusatzgebühren ist die freiwillige Versicherung aber grundsätzlich auf die wohlhabenderen Personen (jedoch ohne Einkommen - z.B. Rentier) begrenzt. Deshalb findet das Institut der freiwilligen Versicherung kaum praktische Anwendung. ${ }^{24}$

Sowohl in der Pflicht- als auch in der freiwilligen Versicherung sind Familienmitglieder, die selber über keinen Versicherungstitel verfügen, ohne zusätzliche Beiträge mitversichert.

$\mathrm{Zu}$ dem Kreis der Leistungsberechtigten gehören nach dem Gesetz auch Personen, die keinen Versicherungstitel haben, die polnische Staatsangehörigkeit besitzen und ihren Wohnsitz im Gebiet von Polen haben, deren Einkünfte die Kriterien von Art. 8 des Gesetzes über die Sozialhilfe nicht überschreiten und die gleichzeitig die in Art. 7 dieses Gesetzes genannten Voraussetzungen für die Erteilung von Sozialhilfe erfüllen; zudem dürfen diese Personen nicht in der Lage sein, ihre schwierige Lebenssituation auf

23 Vgl. Lach, Zasada powszechności ubezpieczenia zdrowotnego a założenia aksjologiczne ubezpieczeń społecznych, Państwo i Prawo 2006, Heft 7, S. 52-64.

24 Ausführlicher dazu: Lach, Dobrowolne ubezpieczenie zdrowotne na tle rozwiązań przyjętych w systemach wybranych państw (Freiwillige Krankenversicherung vor dem Hintergrund der in den Systemen der ausgewählten Länder vorgesehenen Lösungen), Ruch Prawniczy, Ekonomiczny i Socjologiczny 2002, Heft 4, S. 93-108. 
der Grundlage ihrer eigenen Ressourcen zu überwinden. Mit dem Einschluss der ärmsten Bürger (ohne Beitragspflicht) folgt der Gesetzgeber dem Gebot, die Leistungen der Gesundheitsfürsorge für alle Bürger, unabhängig von deren materieller Lage, gleichermaßen zugänglich zu machen. Im Unterschied zu den Versicherten werden die Leistungen für diese Berechtigten nicht aus den Mitteln des Fonds, sondern aus der Staatskasse finanziert. ${ }^{25}$

Bezugnehmend auf die Vorschrift des Art. 68 Abs. 3 plVerf, wonach die öffentliche Gewalt verpflichtet ist, den besonderen Schutz der Kinder, Schwangeren, Behinderten und Älteren zu sichern, sind auch Personen leistungsberechtigt, die zwar keinen Versicherungstitel, aber ihren Wohnsitz auf dem Gebiet von Polen haben und gleichzeitig nicht älter als 18 Jahre bzw. schwanger, in der Entbindung oder im Wochenbett sind. Hier gilt natürlich ebenfalls keine Beitragspflicht.

Zusammenfassend kann gesagt werden, dass in der Tat alle Bürger leistungsberechtigt sind - um die verfassungsrechtliche Vorgabe des Art. 68 Abs. 2 plVerf zu erfüllen.

Alle Leistungsempfänger haben, nach gesetzlich bestimmten Regeln, ein Recht auf Leistungen der Gesundheitsfürsorge zur Wahrung der Gesundheit, Vorbeugung von Krankheiten und Verletzungen, Früherkennung von Krankheiten, Heilung, Pflege sowie Vorbeugung und Einschränkung von Behinderungen, wobei allen Berechtigten derselbe Katalog von garantierten Leistungen in vollem Umfang gebührt (Art. 15 ÖffLG, vgl. unten III.2.).

Patient ist hingegen, wer die Erteilung von gesundheitlichen Leistungen beantragt oder Gesundheitsleistungen von einem solche Leistungen erteilenden (d.h. eine Heiltätigkeit betreibenden) Rechtssubjekt oder einer Person, die einen medizinischen Beruf ausübt, empfängt.

Vor dem Hintergrund der im Gesetz über die Rechte von Patienten statuierten Definition dieses Begriffs lohnt auch ein Blick auf die Richtlinie 2011/24/EU des europäischen Parlaments und des Rates vom 9. März

25 Ausführlicher dazu: Lach, Finansowanie świadczeń opieki zdrowotnej dla osób nieubezpieczonych (Finanzierung der Leistungen der Gesundheitsfürsorge für die Nichtversicherten), Praca i Zabezpieczenie Społeczne 2014, Heft 5, S. 2-8; vgl. auch Zieleniecki, Problemy zakresu podmiotowego prawa do świadczeń zdrowotnych finansowanych ze środków publicznych, Gdańskie Studia Prawnicze 2007, Nr. 2, S. 503-517; Sidorko, Bezpłatne leczenie osób nieubezpieczonych, Studia Prawnicze 2009, Nr. 10, S. 19-24. 
2011 über die Ausübung der Patientenrechte in der grenzüberschreitenden Gesundheitsversorgung: Patient ist danach jede natürliche Person, die Gesundheitsdienstleistungen in einem Mitgliedstaat in Anspruch nehmen möchte oder in Anspruch nimmt.

Aus beiden Definitionen geht hervor, dass der Patientenbegriff jeden Nutzer von Gesundheitsleistungen, und zwar nicht zwangsläufig im Rahmen des Systems der Gesundheitsvorsorge, mit einschließt. Patient kann man demnach unabhängig davon werden, ob man Leistungsempfänger ist, z.B. durch die Inanspruchnahme von privaten Gesundheitsleistungen. Mit anderen Worten gilt es, den Begriff des Leistungsempfängers im rechtlichen Sinne, also einer leistungsberechtigten (d.h. zur Finanzierung von Leistungen aus öffentlichen Mitteln berechtigten) Person von dem des Leistungsempfängers im medizinischen Sinne (d.h. des Patienten - einer Leistungen in Anspruch nehmenden Person) voneinander zu trennen.

\section{Leistungserbringer ${ }^{26}$ und das Recht, den Leistungserbringer zu wählen}

Leistungserbringer ist jedes Subjekt, das eine medizinische Tätigkeit ausübt. Vor allem sind hier natürliche Personen zu nennen, die entsprechende Kompetenzen haben und nach den gesetzlichen Vorschriften zur Berufsausübung berechtigt sind, Leistungen der Gesundheitsfürsorge im Rahmen der geführten Praxis zu erbringen, sei es selbstständig als Freiberufler oder in der Gruppe als Partnerschaftsgesellschaft. Zum zweiten fallen darunter juristische Personen jeder Art. Wie bereits erwähnt, wurden nach dem Abbau des Gesundheitsdienstes die Leistungen von Anstalten der Gesundheitsfürsorge mit einem sehr komplizierten Rechtscharakter erbracht, wobei zu diesen Anstalten nicht nur Krankenhäuser, sondern auch Arztpraxen zählten. Die öffentlichen, vom Landkreis geführten und mitfinanzierten Krankenhäuser verschuldeten sich immer wieder, weil sie, statt sich an Vertragslimits zu halten, „nach Bedarf“ leisteten. Daher hat der Gesetzgeber beschlossen, dass sie, was im ambulanten Bereich schon längst der Regelfall ist, rechtlich selbstständig werden sollen, damit eventuelle Schulden nicht zulasten der territorialen Selbstverwaltungsorgane gehen. Nach einem weiteren Gesetz aus dem Jahr 2011 dürfen mithin keine neuen Anstalten mehr geschaffen werden, während den existierenden Anstalten mit

26 Vgl. Lach (Fn. 22), S. 295. 
verschiedenen Mitteln nahegelegt wurde, die Umwandlung in eine Gesellschaft des Handelsrechts anzustreben ${ }^{27}$, wobei mittlerweile eine Rückkehr zum früheren Rechtstand geplant ist. Weiterhin ist Leistungserbringer jedes Subjekt, das die Versorgung mit medizinischen Produkten gewährt.

Ein Leistungserbringer ist Vertragspartner des Nationalen Gesundheitsfonds und Partei des Vertrages für die Erbringung der Leistungen der Gesundheitsfürsorge. Es ist dabei zu betonen, dass diese Verträge mit einzelnen Leistungserbringern abgeschlossen werden. Es existiert kein öffentlicher Verband von Ärzten oder irgendeine sonstige Vertretung der Leistungserbringer, die gegenüber dem Fonds tätig wird, was natürlich die Position des Letzteren stärkt. ${ }^{28}$

An dieser Stelle sollte überdies darauf hingewiesen werden, dass dem Leistungsempfänger das Recht zur Wahl des Leistungserbringers unter all jenen zusteht, die einen entsprechenden Vertrag mit dem NFZ abgeschlossen haben. Die für den Gesundheitsdienst bezeichnende lokale Zuordnung unter Anwendung einer wohnortbezogenen Einschränkung des Zugangs zum Leistungserbringer wurde im aktuellen System durch das Recht auf die freie Wahl des Leistungserbringers ersetzt. Dieses stellt nunmehr ein Grundprinzip im Aufbau des Gesundheitsversicherungswesens (Art. 65 Pkt. 2 ÖffLG) dar.

Im Rahmen des Rechts auf die freie Wahl eines Leistungserbringers kann der Leistungsempfänger zwischen solchen Erbringern von Leistungen im Bereich der gesundheitlichen Grundfürsorge wählen, die einen Vertrag über die Erteilung von Leistungen der Gesundheitsfürsorge geschlossen haben, wobei mit der Wahl des Leistungserbringers gleichzeitig die Wahl des Arztes, der Krankenschwester bzw. Hebamme der gesundheitlichen Grundfürsorge erfolgt. Das Wahlrecht des Leistungsempfängers

27 Vgl. Lach, Komercjalizacja SPZOZ-ów a obowiązki władzy publicznej w zakresie zapewnienia równego dostępu do świadczeń opieki zdrowotnej, Teil 1 - Praca i Zabezpieczenie Społeczne 2012, Heft 9, S. 2-8; ders., Komercjalizacja SPZOZ-ów a obowiązki władzy publicznej w zakresie zapewnienia równego dostępu do świadczeń opieki zdrowotnej, Teil 2 - Praca i Zabezpieczenie Społeczne 2012, Heft 10, S. 2-8.

28 Näheres dazu: Lach: Stosunki prawne między instytucją ubezpieczenia zdrowotnego a świadczeniodawcami w Niemczech i w Polsce (Rechtsverhältnisse zwischen Krankenversicherungsträgern und Leistungserbringern in Deutschland und Polen), Ruch Prawniczy Ekonomiczny i Socjologiczny 2005, Heft 4, S. 167-181; ders., Kontraktowanie świadczeń zdrowotnych (Kontrahierung von Gesundheitsfürsorgeleistungen), Prawo i Medycyna 2006, Heft 3, S. 5-21. 
kann nicht mehr als dreimal im Kalenderjahr unentgeltlich ausgeübt werden, während jede weitere Änderung unter Zahlung eines Entgelts i. H. v. 80 zloty möglich ist. Eine Befreiung von der Entgeltpflicht erfolgt bei einem Wechsel des ständigen Wohnortes oder wenn der gewählte Erbringer bzw. der ortsansässige Arzt/ die ortsansässige Ärztin, Krankenschwester oder Hebamme der gesundheitlichen Grundfürsorge aufhören, Leistungen der Gesundheitsfürsorge anzubieten oder aus anderen, vom Leistungserbringer zu vertretenden Gründen (Art. 28 ÖffLG).

Der Leistungsempfänger hat zudem ein Recht auf die Wahl eines Leistungserbringers für ambulante Sonderleistungen, eines Krankenhauses wie auch eines Zahnarztes, soweit mit diesen ein Vertrag über die Erbringung von Leistungen der Gesundheitsfürsorge besteht. In Bezug auf diese Erbringer erfolgt die Wahl durch die Inanspruchnahme der Leistungen, die der Erbringer im Voraus mit dem NFZ vertraglich vereinbart hat.

Dieses Wahlrecht wird eingeschränkt bzw. ausgeschaltet bei Inhabern sog. bewaffneter Ämter außerhalb der Streitkräfte, Soldaten im periodischen Wehrdienst, Funktionären des Grenzschutzes im Kandidatendienst sowie Personen, die eine Freiheitsstrafe verbüßen (vgl. Art. 28-31 ÖffLG).

\section{Der Nationale Gesundheitsfonds}

Der Nationale Gesundheitsfonds ist eine staatliche Organisationseinheit mit eigener Rechtspersönlichkeit, Organisator des Systems der Gesundheitsversicherung (des Gesundheitsfürsorgesystems) und treuhänderischer Verwalter der aus den Beiträgen der Gesundheitsversicherung stammenden Mittel.

Der NFZ besteht aus einer Zentrale mit Sitz in Warschau und den der staatlichen territorialen Aufteilung entsprechenden Wojewodschaftszweigstellen des Fonds. In der Zentrale und in den Zweigstellen wurden spezielle Abteilungen für „Uniformdienste" gegründet. Betrieben wird der Fonds auf der Grundlage des Gesetzes und seiner Satzung, die ihm vom Premierminister im Wege einer Verordnung verliehen wurde und die insbesondere die Organisationsstrukturen des Fonds, einschließlich seiner Zentrale und der Wojewodschaftszweigstellen sowie deren Sitze bestimmt und dabei auf die zügige Durchführung der Aufgaben des Fonds Rücksicht nimmt.

Hinsichtlich der Aufgaben des NFZ weist das Gesetz vor allem auf die Verwaltung der aus Beiträgen der Gesundheitsversicherung stammenden finanziellen Mittel hin und stellt klar, dass der Fonds in dieser Sache im 
eigenen Namen für die Versicherten sowie für Personen handelt, die auf der Grundlage von Vorschriften zur Koordinierung ebenfalls leistungsberechtigt sind. Das Betätigungsfeld des Fonds umfasst vor allem: Die Bestimmung von Qualität und Zugänglichkeit sowie die Kostenanalyse in Bezug auf Leistungen der Gesundheitsfürsorge in einem für den korrekten Abschluss von Verträgen über die Erteilung von Leistungen der Gesundheitsfürsorge unerlässlichen Umfang; die Durchführung der Ausschreibungen von Angeboten und Verhandlungen, das Abschließen von Verträgen über die Erteilung von Leistungen der Gesundheitsfürsorge sowie die Überwachung ihrer Durchführung und Abrechnung; die Finanzierung von Leistungen der Gesundheitsfürsorge für die im Gesetz genannten Personen (vor allem in Bezug auf gesellschaftliche Krankheiten); die Finanzierung von Leistungen der Gesundheitsfürsorge für Leistungsempfänger, die nicht versichert sind und gleichzeitig das Einkommenskriterium des Art. 8 des Sozialhilfegesetzes vom 12. März 2004 erfüllen, wenn im jeweiligen Fall nicht die in Art. 12 dieses Gesetzes genannten Umstände festgestellt worden sind; die Finanzierung medizinischer Rettungshandlungen gegenüber Leistungsempfängern; die Finanzierung von mit Zustimmung des Fondsleiters im Ausland durchgeführten Leistungen der Gesundheitsfürsorge; die Umsetzung, Durchführung, Finanzierung, Überwachung, Beaufsichtigung und Kontrolle von Gesundheitsprogrammen; die Durchführung des gesetzlichen Auftrags einschließlich der vom Minister für Gesundheit finanzierten Aufgaben, insbesondere die Umsetzung von Gesundheitsprogrammen; die Überwachung von ärztlichen Verschreibungen; das öffentliche Werben für eine gesunde Lebensführung; das Führen des Zentralen Versichertenregisters; das Führen einer Verlagstätigkeit zum Zwecke der Öffentlichkeitsarbeit und Information im Bereich des Gesundheitsschutzes; die Errechnung von im Erstattungsgesetz geregelten Beträgen; die Überwachung und Koordinierung des Gebrauchs von Sonderberechtigungen durch Soldaten und Veteranen, Kriegs- und Militärinvaliden sowie Kombattanten.

$\mathrm{Zu}$ den Aufgaben des Fonds gehört ebenso die Abrechnung mit den einschlägigen bzw. wohnortszuständigen Institutionen der EU- bzw. EFTA Mitgliedstaaten des im Entscheidungsbereich des Ministers für Gesundheit verbleibenden Teils der Kosten von staatlich finanzierten Leistungen der Gesundheitsfürsorge sowie der Kosten medizinischer Rettungshandlungen von Rettungsdiensten gemäß dem Gesetz vom 8. September 2006 über das staatliche Rettungsdienstwesen, mit Ausnahme der Kosten von Ret- 
tungshandlungen durch Flugrettungsdienste gegenüber Personen, die nach den Vorschriften über die Koordinierung leistungsberechtigt sind.

Kraft Gesetzes erfüllt der Fonds die Rollen der zuständigen staatlichen Institution, der Institution am Wohnort, der Institution am Aufenthaltsort und der Verbindungsinstitution im Bereich von gesundheitlichen Sachleistungen i.S.d. Vorschriften über die Koordinierung, und führt in der FondsZentrale den in der Verordnung (EG) Nr. 987/2009 des Europäischen Parlaments und des Rates vom 16. September 2009 zur Festlegung der Modalitäten für die Durchführung der Verordnung (EG) Nr. 883/2004 über die Koordinierung der Systeme der sozialen Sicherheit bestimmten Kontakt zum Datenaustausch im Rahmen des Systems zum elektronischen Austausch von Informationen über die soziale Sicherheit im Bereich gesundheitlicher Sachleistungen.

Es gilt dabei zu betonen, dass der Fonds nicht Eigentümer von Rechtssubjekten sein, d.h. nicht selbst Heiltätigkeiten i.S.d. Vorschriften über Heiltätigkeiten durchführen darf, um Situationen zu vermeiden, in denen der Organisator des Systems gleichzeitig als Leistungserbringer fungiert. Einer transparenten Trennung von Kompetenzen dienen auch die Vorschriften sowohl über Organwalter und Mitglieder der Organe des NFZ (zu denen der Rat des Fonds, der Fondsleiter, die Räte sowie die Direktoren der Wojewodschaftszweigstellen zählen) als auch über die Mitarbeiter des NFZ, die es den genannten Personen verbieten, gleichzeitig die folgenden Rollen zu erfüllen: Leistungserbringer, der einen Vertrag auf Erteilung von Leistungen der Gesundheitsfürsorge unterschrieben hat oder sich darauf bewirbt; Eigentümer, Angestellter oder mitwirkender Partner eines Leistungserbringers, der einen Vertrag auf Erteilung von Leistungen der Gesundheitsfürsorge unterschrieben hat oder sich darum bemüht; Organmitglied oder Angestellter eines Gründer-Rechtssubjekts i.S.d. Vorschriften über Heiltätigkeiten; Organmitglied oder Angestellter einer Einheit der kommunalen Selbstverwaltung; Organmitglied einer Versicherungsanstalt, die eine Versicherungstätigkeit auf der Grundlage des Gesetzes vom 22. Mai 2003 über Versicherungstätigkeiten ausübt, Aktien- oder Anteilsinhaber einer eine Heiltätigkeit betreibenden Handelsgesellschaft; Anteilseigener von mehr als $10 \%$ des Stammkapitals von Handelsgesellschaften; Abgeordnete des Sejm, des Europaparlaments oder des Senats. Mitarbeiter des NFZ dürfen darüber hinaus weder im Rat des Fonds noch in den Räten der Wojewodschaftszweigstellen des Fonds sitzen und nicht ohne Zustimmung des Fondsleiters von einem anderen Arbeitgeber beschäftigt werden oder einer eigenen wirtschaftlichen Tätigkeit nachgehen. 
Im Hinblick auf die Organe des NFZ kommen dem Rat des Fonds Überwachungs-, Gestaltungs- und Begutachtungskompetenzen zu, während die Geschäftsführung und Vertretung des Fonds nach außen hin dem Fondsleiter obliegt. Seine Berechtigungen wurden in einem offenen Katalog niedergeschrieben und umfassen vor allem die Führung der Finanzwirtschaft des Fonds. Weiterhin ist auf die gesetzlich bestimmte Kompetenzvermutung zu seinen Gunsten hinzuweisen - seine Zuständigkeit als Organ umfasst alle Angelegenheiten, die nicht explizit in den Aufgabenbereich des Rats des Fonds, der Räte der Wojewodschaftszweigstellen bzw. deren Direktoren fallen. Die Räte der Wojewodschaftszweigstellen verfügen hingegen über Begutachtungs- und Überwachungskompetenzen. Bedeutsame Aufgaben nehmen die Direktoren der Zweigstellen wahr, die nämlich nicht lediglich die jeweiligen Wojewodschaftszweigstellen leiten und in deren Aufgabenbereich nach außen hin vertreten, sondern vor allem effektiv und sicher die Finanzmittel ihrer jeweiligen Zweigstelle verwalten; Finanz- und Arbeitspläne für ihre Zweigstellen umsetzen, indem sie die Verfahren zum Abschluss von Verträgen über die Erteilung von Leistungen der Gesundheitsfürsorge einschließlich hochspezialisierter Leistungen durchführen; Verträge über die Erteilung von Leistungen der Gesundheitsfürsorge einschließlich hochspezialisierter Leistungen, über Arzneimittelprogramme nach den Bestimmungen des Erstattungsgesetzes sowie über die Umsetzung von Gesundheitsprogrammen schließen und abrechnen; die Erfüllung von Verträgen über die Erteilung von Leistungen der Gesundheitsvorsorge kontrollieren und überwachen sowie Kontrollen von Leistungserbringern und Apotheken durchführen; die Zweckmäßigkeit der im Rahmen von Verträgen erteilten Leistungen der Gesundheitsfürsorge überwachen; entsprechend den Vorschriften des Arbeitsgesetzbuches die Rolle des Arbeitgebers gegenüber den Angestellten der Wojewodschaftszweigstellen des Fonds erfüllen; individuelle Bescheide in Sachen Gesundheitsversicherung erteilen; Verfahren zum Abschluss von Verträgen mit den Disponenten medizinischer Rettungseinheiten über die Leistung von medizinischen Rettungshandlungen durchführen und die Verträge im Nachhinein auf der Grundlage des Gesetzes vom 8. September 2006 über das staatliche Rettungswesen abschließen, abrechnen und ihre Umsetzung kontrollieren; Verträge über die freiwillige Gesundheitsversicherung abschließen und letztlich Verträge über die Umsetzung von Arzneimittelverschreibungen und Verträge zur Berechtigung von Ärzten, Zahnärzten und Truppenärzten zur Verschreibung von erstattungsfähigen Arzneimitteln schließen, kontrollieren, überwachen und abrechnen. 
Seine Finanzwirtschaft führt der Fonds nach gesetzlichen Vorgaben. $\mathrm{Zu}$ seinem Einkommen gehören vor allem Mittel aus Beiträgen der Gesundheitsversicherung, aber auch Zinsen für nicht fristgerecht eingezahlte Beiträge; Schenkungen und Vermächtnisse; vom Staatshaushalt überwiesene Mittel für die Verwirklichung von gesetzlich festgeschriebenen Aufgaben; staatliche Beihilfen, mitunter zweckgebundene Zuwendungen für die Finanzierung von Leistungen an Soldaten und Veteranen und nichtversicherte Leistungsempfänger; aus Regressforderungen erlangte Mittel; Einnahmen aus Geldanlagen und im Erstattungsgesetz vorgesehene Beträge.

Das Gesetz sieht überdies die Möglichkeit der Aufnahme von Krediten und Darlehen vor, wenngleich unter Vorbehalt einer Einwilligung von Seiten der Minister für öffentliche Finanzen und für Gesundheit. Die Höhe der im gegebenen Jahr zurückzuzahlenden Kredit- bzw. Darlehensrate darf die Höhe der im Finanzplan für dieses Jahr vorgesehenen allgemeinen Reserve (i. H. v. $1 \%$ der geplanten zustehenden Einnahmen aus Beiträgen der Gesundheitsversicherung) nicht überschreiten, wobei sich dies nicht auf aus dem Staatshaushalt überwiesene Mittel bezieht.

$\mathrm{Zu}$ den Kosten des Fonds zählen hingegen: Kosten für Leistungen der Gesundheitsfürsorge an die Versicherten und sonstige nach den Vorschriften über die Koordinierung leistungsberechtigte Personen; nach dem Erstattungsgesetz bestimmte Kosten der Erstattung; Kosten von Leistungen an Soldaten und Veteranen sowie von gesetzlich festgeschriebenen Aufgaben; überdies Betriebskosten des Fonds, insbesondere die Amortisation, Kosten der Unterhaltung von Immobilien, Lohn- und verwandte Kosten, Diäten und Reisekostenerstattungen. Ferner hinzuweisen ist auf: Kosten der Erhebung und Buchung von Beiträgen der Gesundheitsversicherung (eine Aufgabe der Staatlichen Sozialversicherungsanstalt ZUS); Kosten der Auszahlung von Schadensersatz und andere Kosten auf der Grundlage von speziellen Vorschriften. Die finanziellen Mittel des Fonds können natürlich ebenfalls zur Abbezahlung von Krediten und Darlehen verwendet werden.

Der Fondsleiter bereitet alljährlich für den Fonds einen Finanzplan mit bilanzierten Einnahmen und Ausgaben vor. Die Ausgeglichenheit des Finanzplans ist bezeichnend für die Finanzautonomie des Gesundheitsversicherungswesens. Im Finanzplan bestimmt der Fondsleiter u.a. die Höhe der geplanten Kosten der einzelnen Wojewodschaftszweigstellen. Die für die Deckung der Kosten der Finanzierung von Leistungen der Gesundheitsvorsorge an die Versicherten durch die Wojewodschaftszweigstellen vorgesehen Mittel werden an die Zweigstellen unter Berücksichtigung der 
folgenden Faktoren verteilt: die Zahl der in der Zweigstelle des Fonds registrierten Versicherten; bestimmte nach Alter und Geschlecht ermittelte Gruppen von Versicherten sowie bestimmte Gruppen von Leistungen der Gesundheitsfürsorge (einschließlich hochspezialisierter Leistungen) sowie das entsprechende Erkrankungsrisiko für die gegebenen Versichertengruppen im Bereich der konkreten Gruppen von Leistungen der Gesundheitsfürsorge, im Vergleich zu der jeweiligen Bezugsgruppe. Wichtig ist dabei die Vorgabe, dass die geplanten Kosten der Finanzierung von Leistungen der Gesundheitsfürsorge durch die jeweilige Wojewodschaftszweigstelle nicht geringer ausfallen dürfen als die analogen Kosten derselben Zweigstelle, die im Finanzplan des Vorjahres vorgesehen waren. Das Verfahren und die Kriterien für die Verteilung von Mitteln für die Finanzierung von Leistungen der Gesundheitsfürsorge an Versicherte zwischen Zentrale und Wojewodschaftszweigstellen werden vom Minister für Gesundheit im Wege einer Verordnung bestimmt.

Zusammenfassend sei gesagt, dass der Fonds in Bezug auf Mittel aus Beiträgen der Gesundheitsversicherung im eigenen Namen für die Versicherten und sonstige auf der Grundlage von Vorschriften über die Koordinierung leistungsberechtigte Personen handelt und demnach als Verwalter öffentlicher Mittel, die vor allem aus Beiträgen stammen, in der Rolle des Treuhänders für die Leistungsempfänger agiert. Der NFZ ist ein professioneller Treuhänder, der ins Leben gerufen wurde, um die Verwaltung und Organisation des Systems der Gesundheitsfürsorge (,der Gesundheitsversicherung") zu verwirklichen. Er handelt für die Empfänger, wenngleich im eigenen Namen, als organisatorisch eigenständiges Subjekt mit einem deutlich umrissenen Kompetenzbereich. Zu den Aufgaben des NFZ gehört keinesfalls die Leistung der Gesundheitsfürsorge, sondern die Organisation eines Systems ihrer „Gewährleistung“. 29

\section{Leistungen}

\section{Leistung der Gesundheitsfürsorge}

Der Begriff der Leistung der Gesundheitsfürsorge ist gesetzlich definiert als ,gesundheitliche Leistung, gesundheitliche Sachleistung bzw. Begleit-

29 Vgl. Lach, Powierzanie realizacji zadań publicznych z zakresu zabezpieczenia społecznego podmiotom niepublicznym, Państwo i Prawo 2015, Heft 2, S. 35-57. 
leistung“. Unter Berücksichtigung der integrativen Bedeutung des Begriffs "Gesundheitsfürsorge" gilt es darauf hinzuweisen, dass der Terminus „Leistung der Gesundheitsfürsorge“ in zweierlei Hinsicht verstanden werden kann.

Erstens kann mit Blick auf das Verhältnis zwischen dem Titel des Gesetzes vom 27. August 2004 über ,aus öffentlichen Mitteln finanzierte Leistungen der Gesundheitsfürsorge" und Art. 68 Abs. 2 S. 1 plVerf über das Recht auf gleichen Zugang zu ,aus öffentlichen Mitteln finanzierten Leistungen der Gesundheitsfürsorge" davon ausgegangen werden, dass dieser Begriff als Gegenstand der Finanzierung aus öffentlichen Mitteln und demnach nicht objektiv (d.h. als Pflicht eines Schuldners), sondern als Handlungsbegriff zu verstehen ist. Den Gegenstand der im System erteilten Garantie bildet nämlich nicht etwa der Zugang zu ,(irgend-) einer“ Fürsorge i.S.d. des Systems der Gesundheitsfürsorge, sondern zu den Leistungen der Fürsorge (Leistungen - im Plural - für eine Vielzahl von Leistungsempfängern). Aus Sicht der Leistungsempfänger leistet der Erbringer nämlich Fürsorge als Ganzes und nicht etwa jene Einzelleistungen, die diese Fürsorge ausmachen. Im System der Gesundheitsfürsorge geht es um die Finanzierung einer Leistung, die Erfüllung, Gewährung und Erteilung von Fürsorge i.S. einer bestimmten Verhaltensweise des Leistungserbringers zugunsten des Leistungsempfängers, den Gesamtvorgang der „Fürsorge“ für den Empfänger, und nicht um die Summe der einzelnen „Leistungen“ i.S.v. gesondert betrachteten, aus der Sicht der benötigten Qualifikationen sehr vielfältigen medizinischen Verfahren (manche Handlungen können von einer Krankenschwester, andere wiederum müssen unbedingt von einem Arzt, meistens allein von einem Facharzt durchgeführt werden) sowie der Abrechnungen mit dem NFZ („Preislisten“ für Leistungen). ${ }^{30}$

Vom Standpunkt des Verhältnisses zwischen Leistungserbringer und NFZ aus sollte jedoch, insbesondere im Kontext der organisatorischen Aufgaben des Fonds, vielmehr eine objektive Betrachtung des Begriffs „Leistung der Gesundheitsfürsorge“ stattfinden. Mit Rücksicht auf die Bedürfnisse der Prozeduren zum Vertragsschluss, zur Abrechnung und Kontrolle von Verträgen sowie zur Aufsicht über die Erfüllung der gesetzlichen und vertraglichen Pflichten durch die Leistungserbringer erscheint demgegenüber die Annahme einer technischen Betrachtung des Begriffes

30 Vgl. Lach, Zasada (Fn. 4), S. 145-148. 
„Leistungen der Gesundheitsfürsorge“ - als bestimmte medizinische Prozeduren ergänzt um Sach- und Begleitleistungen - notwendig.

Dabei ist zu betonen, dass Bestimmungen von Verträgen, an die der Organisator des Systems und die Leistungserbringer gebunden sind, allein auf ihre Bedürfnisse hin den Inhalt der Leistungen konkretisieren, deren Summe die den Empfängern gesetzlich garantierte Gesundheitsfürsorge ausmacht. Diese Konkretisierung besteht vor allem darin, dass der Inhalt gegebener Gesundheitsleistungen konkret bestimmt (sowie regelmäßig auch limitiert) und deren Preis ermittelt wird. ${ }^{31}$ Durch diesen Vorgang kann gleichwohl nicht der Umfang des den Leistungsempfängern zustehenden Rechts auf Gesundheitsfürsorge definiert werden (vgl. unten III. 3.).

In diesem Kontext ist folglich die Vorschrift des Art. 15 ÖffLG anzuführen. In Absatz 1 wurde insgesamt festgestellt, dass Leistungsempfänger nach gesetzlich festgelegten Regeln ein Recht auf Leistungen der Gesundheitsfürsorge zum Zwecke der Wahrung der Gesundheit, Vorbeugung von Krankheiten und Verletzungen, Früherkennung von Krankheiten, Heilung, Pflege sowie Vorbeugung und Beschränkung von Behinderungen haben. Damit wurde betont, das Ziel der Gesundheitsfürsorge bestehe nicht allein in der „Behebung von Schäden“ - dem Zurückversetzen in den vorherigen gesundheitlichen Zustand durch die Heilung von Krankheiten - sondern ebenfalls in der Verhinderung von deren Entstehung. Art. 15 Abs. 1 ÖffLG ist nicht allein auf die Heilung oder Pflege beschränkt. Daneben nennt die Vorschrift Ziele von prophylaktischer, vorbeugender und diagnostischer Natur. Bestimmte Leistungen werden dem-

31 Vgl. VerfGH v. 28.02. 2005, P 7/03, in einer Rechtssache zur Vereinbarkeit der Vorschriften des Gesetzes über die allgemeine Gesundheitsversicherung zur vertraglichen Sicherung von Leistungen und vertraglichen Bestimmung von Betragsund Mengenbeschränkungen mit Art. 68 Abs. 2 der polnischen Verfassung. Der Gerichtshof stellte fest, dass die besagten Vorschriften des Gesetzes nicht verfassungswidrig seien, da solche Verträge über die Verteilung von Leistungen der Gesundheitsfürsorge durch die in ihnen enthaltenen Bestimmungen insbesondere der Art und des Umfangs der zu erteilenden Leistungen der Gesundheitsfürsorge einzig die essentialia negotii der Vertrages beschreiben. Derweil gilt: „Die Ausformulierung von Bedingungen und Umfang der Erteilung gewisser Leistungen in einem bestimmten Vertrag stellt [...] - im Grunde genommen - einzig eine fallbezogene Präzisierung gesetzlicher Normen im Hinblick auf das gegebene Rechtsverhältnis dar und setzt daher lediglich eine abstrakte gesetzliche Bestimmung in Bezug auf eine konkrete Situation zwischen Teilnehmern am Rechtsverkehr um”. 
nach im Rahmen des Systems nicht lediglich vor dem Eintritt eines $\mathrm{Zu}$ fallsereignisses in Gestalt einer Gesundheitsminderung, sondern auch gerade deswegen garantiert, um es gar nicht erst dazu kommen zu lassen. Vor diesem Hintergrund ist auf Absatz 2 hinzuweisen, gemäß dem Empfänger zu Leistungen aus den folgenden Bereichen berechtigt sind: 1) gesundheitliche Grundfürsorge; 2) ambulante Spezialfürsorge; 3) Krankenhausbehandlungen; 4) psychiatrische Fürsorge und Behandlung von Suchtkrankheiten; 5) Rehabilitation; 6) Pflege- und Fürsorgeleistungen im Rahmen einer langfristigen Pflegeversorgung; 7) zahnärztliche Behandlungen; 8) Kurbehandlungen; 9) Versorgung mit und Wartung von im Erstattungsgesetz genannten medizinischen Erzeugnissen auf Auftrag einer berechtigten Person; 10) medizinische Rettungsbehandlungen; 11) Palliativfürsorge und Betreuung im Hospiz; 12) hochspezialisierte Leistungen; 13) Gesundheitsprogramme; 14) Arzneimittel, Lebensmittel, die für eine besondere Ernährung bestimmt sind, medizinische Erzeugnisse, die gleichzeitig apotheken- und verschreibungspflichtig sind; 15) Arzneimittelprogramme nach dem Erstattungsgesetz; 16) Chemotherapeutika nach dem Erstattungsgesetz; 17) auf dem Gebiet der Republik Polen nicht zum Verkehr zugelassene Arzneimittel, die nach den Voraussetzungen und im Rahmen des Verfahrens nach Art. 4 des Pharmagesetzes vom 6. September 2001 unter der Voraussetzung aus dem Ausland eingefahren werden, dass in Bezug auf die gegebenen Arzneimittel Bescheide über die Erstattung ihrer Kosten nach dem Erstattungsgesetz ergangen sind; 18) aus dem Ausland nach den Voraussetzungen und im Rahmen des Verfahrens nach Art. 29a des Gesetzes vom 25. August 2006 über Lebensmittelsicherheit und sichere Ernährung eingeführter Lebensmittel, die für eine besondere Ernährung bestimmt sind, unter der Voraussetzung, dass in Bezug auf die bezeichneten Lebensmittel Bescheide über die Erstattung ihrer Kosten nach dem Erstattungsgesetz ergangen sind.

Zum Umfang der in Art. 15 genannten Leistungen der Gesundheitsfürsorge gilt es gleichwohl anzumerken, dass der Katalog in Art. 15 Abs. 2 ÖffLG, der die allgemeine Erklärung aus Art. 15 Abs. 1 ÖffLG fortentwickelt und präzisiert, keine genaue Definition des garantierten Leistungspakets enthält, weil eine Leistung der Gesundheitsfürsorge erst dann ein solches Prädikat erhalten kann, wenn sie die in Titel II Kapitel 1a des Gesetzes beschriebene Prozedur erfolgreich durchläuft. Gemäß Art. 31b ÖffLG ist für die Qualifikation von Leistungen der Gesundheitsfürsorge als garantierte Leistungen im nach Art. 15 Abs. 2 Pkt. 1-8 und 10-13 geregelten Bereich der Minister für Gesundheit zuständig. Hierfür hat dieser jedoch 
zunächst eine Empfehlung des Vorsitzenden der Agentur für die Bewertung von Medizinischen Technologien einzuholen, wobei die in Art. 31a ÖffLG bestimmten Kriterien zu berücksichtigen sind. Die Qualifikation der Leitungen nach Art. 15 Abs. 2 Pkt. 9, 14-16 und 17-18 als garantierte Leistungen erfolgt ebenfalls durch den Minister für Gesundheit, allerdings nach den Kriterien aus dem Erstattungsgesetz. ${ }^{32}$

Obwohl das Gesetz über Leistungen der Gesundheitsfürsorge dies nicht ausdrücklich bestimmt, sollte der begriffliche Umfang von Leistungen der Gesundheitsfürsorge um weitere Elemente ergänzt werden, die aus den Vorschriften des Gesetzes vom 15. April 2011 über Heiltätigkeiten hervorgehen. Zwar bestimmt dieses Gesetz, dass eine Heiltätigkeit in der Erteilung von gesundheitlichen Leistungen (ausgenommen unbegründete gesundheitliche Sach- und Begleitleistungen), besteht, jedoch dürfen eine Reihe von Pflichten, die dieses Gesetz den Erbringern von Heiltätigkeiten auferlegt und die die Leistungsempfänger zumindest mittelbar begünstigen, nicht außer Acht gelassen werden. Dies betrifft insbesondere folgende Pflichten: die öffentliche Bekanntgabe von Informationen über den Umfang und die Art von erteilten Gesundheitsleistungen; der Besitz geeigneter Räumlichkeiten und Geräte, welche den Anforderungen der ausgeübten Heiltätigkeit und dem Umfang der erteilten Gesundheitsleistungen gerecht werden, die Erbringung von Gesundheitsleistungen durch ausschließlich medizinisch geschulte und die in speziellen Vorschriften geregelten gesundheitlichen Anforderungen erfüllende Personen; der Abschluss einer Haftpflichtversicherung für Schäden, welche infolge der Erteilung von Gesundheitsleistungen oder der rechtswidrigen Unterlassung ihrer Erteilung sowie aufgrund medizinischer Ereignisse entstehen. Weiterhin gilt es auf jene Pflichten hinzuweisen, die den Patientenrechten aus dem Gesetz vom 6. November 2008 über Patientenrechte und den Patientenrechtsbeauftragten entnommen werden können. D.h. die Pflicht zur Leistung entsprechend den aktuellen Anforderungen der Heilkunst sowie die Anwendung eines transparenten, objektiven, auf medizinischen Kriterien basierenden Verfahrens zur Festlegung der Reihenfolge der Gewährung des Zugangs zu den eigenen Leistungen; die Pflicht zur Wahrung der gebotenen Sorgfalt bei der Erteilung von Gesundheitsleistungen unter Einhaltung der Bedingungen, die sich aus den fachlichen und sanitären Vorgaben spezieller Vorschriften ergeben; die Pflicht zur Erteilung von Infor-

32 Näheres zu dieser Problematik vgl. unten III.2. 
mationen über den eigenen Gesundheitszustand, Patientenrechte sowie Art und Umfang der erteilten Gesundheitsleistungen, mitunter auch über von diesem Rechtssubjekt umgesetzte, aus öffentlichen Mitteln finanzierte prophylaktische Gesundheitsprogramme; die Pflicht zur Anzeige einer unerwünschten Wirkung eines medizinischen Produkts gegenüber dem medizinischen Personal, dem Vorsitzenden des Amtes für die Registrierung von Heilprodukten, Medizinischen Erzeugnissen und biovernichtenden Produkten oder gegenüber dem für die Einführung des Heilprodukts auf den Markt gemäß dem Pharmagesetz vom 6. September 2001 verantwortlichen Rechtssubjekt; die Geheimhaltungspflicht des medizinischen und behandelnden Personals in Bezug auf patientenbezogene Informationen, welche sie in Folge ihrer Berufsausübung erlangen; die Pflicht zur Erteilung einer Zustimmung oder Absage zur Gewährung von Gesundheitsleistungen; die Pflicht, die Intimsphäre und Würde des Patienten zu respektieren, insbesondere während der Erbringung von Gesundheitsleistungen, wobei das Recht auf die Respektierung der Menschenwürde das Recht auf würdevolles Sterben in Frieden, das Recht auf Einblick in die medizinische Dokumentation zum eigenen Gesundheitszustand und zu den gewährten Gesundheitsleistungen umfasst (zur Verwirklichung dieses Rechts ist der Erbringer von Gesundheitsleistungen verpflichtet, eine medizinische Dokumentation nach gesetzlichen Regeln zu führen, aufzuheben und bereitzustellen und die Sicherheit der gesammelten Daten zu gewährleisten). Des Weiteren fällt hierunter das Recht auf Einlegung eines Widerspruchs gegen ärztliche Gutachten bzw. Befunde, sofern diese einen Einfluss auf gesetzlich festgelegte Rechte und Pflichten des Patienten haben sollten und zuletzt das Recht auf Seelsorge sowie das Recht auf die Verwahrung von Wertsachen umfasst.

Die Aufgaben von Rechtssubjekten, die Leistungen der Gesundheitsfürsorge im Rahmen des Systems der „Gesundheitsversicherung“ erbringen, beschränken sich nämlich nicht nur auf Prophylaxe, Heilung, gutachterliche Tätigkeiten und die Versorgung mit Heil- und Hilfsmitteln. Auf den Leistungserbringern lastet eine ganze Reihe von verwaltungsrechtlichen Pflichten (fachspezifische und sanitäre Anforderungen an Räumlichkeiten und Geräte, die Pflicht zur Führung einer medizinischen Dokumentation, durch Patientenrechte bedingte Pflichten), die zusammen mit den Gesundheits-, Sach- und Begleitleistungen die Gesamtheit der Leistungen der Gesundheitsfürsorge ausmachen. 


\section{Die garantierte Leistung und die Qualifizierung von Leistungen als garantiert}

Eine garantierte Leistung ist eine Leistung der Gesundheitsfürsorge, die nach gesetzlichen Regeln und im gesetzlichen Umfang aus öffentlichen Mitteln finanziert bzw. mitfinanziert wird.

Die Gesetze (über aus öffentlichen Mitteln finanzierte Leistungen der Gesundheitsfürsorge und über die Erstattung der Kosten von Arzneimitteln, Lebensmitteln, die für eine besondere Ernährung bestimmt sind, und medizinischen Erzeugnissen) sowie deren Durchführungsverordnungen bestimmen eine „Teilentgeltlichkeit“ in Bezug auf Kurbehandlungen und die Nutzung von Krankentransporten und legen die Grundsätze der Finanzierung bzw. Erstattung der Kosten von einem Arzneimittel, einem Lebensmittel, das für eine besondere Ernährung bestimmt ist, oder einem medizinischen Erzeugnis fest (vgl. unten V.2.). Mit anderen Worten bezieht sich die gesetzliche Garantie vielmehr auf die Gewährleistung des Zugangs zur Gesundheitsfürsorge oder zu bestimmten Arzneimitteln usw., als auf ihre Finanzierung, wobei jedoch betont werden sollte, dass die Mitfinanzierung von erhaltenen Leistungen gesetzlich vorgesehen sein muss.

In diesem Kontext ist anzumerken, dass die Legaldefinition von garantierten Leistungen durchaus eine Mitfinanzierung aus öffentlichen Mitteln zulässt, was bedeutet, dass die Leistungsempfänger einen Teil der Kosten selbst zu tragen haben. Die Eigenbeteiligung der Empfänger des Systems an den Kosten der erhaltenen Fürsorge wird, ähnlich der Reglementierung von Leistungen und den damit einhergehenden Wartelisten (vgl. unten III. 4.), in Gesundheitsfürsorgesystemen verschiedener Länder praktiziert. Problematisch ist jedoch die Bewertung einer solchen Mitfinanzierung vor dem Hintergrund des verfassungsrechtlichen Grundsatzes des gleichen $\mathrm{Zu}-$ gangs zu aus öffentlichen Mitteln finanzierten Leistungen der Gesundheitsfürsorge (Art. 68 Abs. 2 plVerf). In der Literatur wird zu Recht angenommen, dass die Vorschrift des Art. 68 Abs. 2 plVerf ein Verbot der Ungleichbehandlung von Bürgern wegen ihrer finanziellen Lage enthält und demnach ein Verbot der Einführung finanzieller Barrieren beim Zugang zu Leistungen, der Eigenbeteiligung an ihren Kosten, Praxis- und Verschreibungsgebühren usw., statuiert. ${ }^{33}$ Es lässt sich die These aufstellen,

33 Vgl. Jończyk, Glosse zum Urteil des Obersten Gerichts v. 12.02.2004, II UK 243/03, OSP 2004, Heft 10, S. 130 ff. Ähnlich auch VerfGH v. 22.06.2008, K $24 / 07$. 
dass der Grundsatz des gleichen Zugangs zu Leistungen der Gesundheitsfürsorge eine Schranke für die Anwendung aller nicht auf medizinischen Kriterien beruhenden Barrieren aufstellt, anstatt lediglich einen Zugang zu Gesundheitsleistungen unabhängig von dem Wohlstand des jeweiligen Empfängers zu fordern. In der Literatur des Verfassungsrechts wurde in Bezug auf das Institut der Wartelisten vertreten, dass alle etwaigen Zuzahlungen zum Zwecke der „Beschleunigung“ der Inanspruchnahme limitierter Leistungen im Rahmen des aus öffentlichen Mitteln finanzierten Systems als verfassungswidrig anzusehen sind. ${ }^{34}$ Im Hinblick auf die Definition der garantierten Leistung sollte demnach angemerkt werden, dass jede „Mitfinanzierung“ als ein Verstoß gegen den Grundsatz der Gleichheit beim Zugang zu ihr bewertet werden kann. Wenn die Berechtigten im System dazu verpflichtet sind, die Kosten von garantierten Leistungen zum Teil selbst zu tragen, bedeutet dies zwangsläufig, dass die gesetzliche Garantie hinter der Fähigkeit der Leistungsempfänger zur Eigenfinanzierung zurücktritt. ${ }^{35}$

Die Grundlage der Qualifikation einer Leistung der Gesundheitsfürsorge als garantierte Leistung, bildet ihre Bewertung in den Bereichen gesundheitliche Grundfürsorge, ambulante Spezialfürsorge, Krankenhausbehandlungen, psychiatrische Fürsorge und Behandlung von Suchtkrankheiten, Rehabilitation, Pflege- und Fürsorgeleistungen im Rahmen einer langfristigen Pflegeversorgung, zahnärztliche Behandlungen, Kurbehandlungen, medizinische Rettungsbehandlungen, Palliativfürsorge und Betreuung im Hospiz, hochspezialisierte Leistungen, Gesundheitsprogramme unter Berücksichtigung einer Reihe von Kriterien.

Das Gesetz weist zunächst auf die Eigenschaft der gesundheitssteigernden Wirkung zugunsten der Bürger unter Berücksichtigung der folgenden Faktoren hin: Gesundheitliche Prioritäten gemäß der Verordnung des Gesundheitsministers (dazu gehören: Die Verringerung der Erkrankungs- und Frühsterberate bei kardiovaskulären Krankheiten einschließlich Herzinfarkten und Schlaganfällen, bösartigen Krebserkrankungen, chronischen Atemwegserkrankungen); die Minderung der Folgen von Unfallverletzungen, insbesondere durch eine effektive Rehabilitation von Geschädigten; die Vorbeugung, Behandlung und Rehabilitation bei seelischen Erkran-

34 Vgl. Winczorek, Komentarz do Konstytucji Rzeczypospolitej Polskiej z 2 kwietnia 1997 r., Warschau 2000, S. 92.

35 Vgl. Lach, Koszyk świadczeń gwarantowanych w systemie opieki zdrowotnej, Praca i Zabezpieczenie Społeczne 2009, Heft 12, S. 2-10. 
kungen; die Verringerung von Früherkrankungen und Einschränkung der nachteiligen Folgen von chronischen Erkrankungen des Knochen- und Gelenksystems; die Steigerung der Effektivität bei der Vorbeugung von Infektionskrankheiten und Infektionen; die Einschränkung von gesundheitsschädlichen Folgen von Alkohol-, Rauschmittel- und Rauchtabakkonsum; die Vorbeugung vor Adipositas und Diabetes; die Einschränkung der Folgen von gesundheitsschädlichen Einflüssen im Arbeits- und Wohnumfeld; die Steigerung von Qualität und Effektivität der Gesundheitsfürsorge für Mütter, Neugeborene und Kinder bis zur Vollendung des 3. Lebensjahres; die Vorbeugung vor den häufigsten gesundheitlichen Problemen und Störungen der körperlichen und psychosozialen Entwicklung von schul- und bildungspflichtigen Kindern und Jugendlichen, ggf. bis zur Vollendung ihrer Schulbildung in der Mittelstufe; die Entwicklung von langfristiger Betreuung unter besonderer Berücksichtigung der Kompensation von Mobilitätsverlust und die Verbesserung der Qualität und Effektivität der geriatrischen Betreuung von Patienten im hohen Alter sowie nach aktueller medizinischer Kenntnis bestimmte Indikatoren für die Erscheinungs-, Erkrankungs- und Sterbehäufigkeit. Zweitens verlangt das Gesetz die Berücksichtigung der Folgen einer Erkrankung bzw. eines gesundheitlichen Zustands, insbesondere wenn diese zum frühen Tod, der Unfähigkeit zum selbstständigen Bestreiten seiner Existenz i.S. der Vorschriften über Renten des Sozialversicherungsfonds, Arbeitsunfähigkeit i.S. der Vorschriften über Renten des Sozialversicherungsfonds, chronischem Leid oder einer chronischen Erkrankung und der Minderung der Lebensqualität führen. ${ }^{36}$ Das dritte Kriterium bildet die Bedeutung der zu bewertenden Leistungen für die Gesundheit der Bürger unter Berücksichtigung ihrer Notwendigkeit: Leben zu retten und die vollständige Gesundheit wiederzuerlangen, Leben zu retten und eine Besserung der Gesundheit zu erlangen, einen frühen Tod zu vermeiden sowie die Lebensqualität zu steigern. Nicht ohne Bedeutung ist auch die Notwendigkeit, die klinische Effektivität und Sicherheit von Leistungen und das Verhältnis zwischen der erreichten Ver-

36 An dieser Stelle stellt sich die Frage, ob es nicht im Interesse der Finanzen des Versicherungswesens zu Konstellationen kommen kann, in denen Leistungen, die typischerweise an Personen mit der Aussicht auf eine Rückkehr auf den Arbeitsmarkt gerichtet sind, auf Kosten anderer Leistungen bzw. Gruppen von Leistungsempfängern der Vorzug gewährt wird, was wiederum sehr fragwürdig im Hinblick auf den Grundsatz des gleichen Zugangs und der Gleichbehandlung (Art. 65 ÖffLG) erscheint. Vgl. Lach, (Fn. 35), S. 8. 
besserung der Gesundheit und dem damit verbundenen gesundheitlichen Risiko zu berücksichtigen. Von Bedeutung bleibt zudem das ausdrückliche gesetzliche Gebot, bei dieser Bewertung auch das Verhältnis der Kosten $\mathrm{zu}$ den erlangten gesundheitlichen Resultaten sowie die finanziellen Folgen für das System des Gesundheitsschutzes, mitunter für die Gesamtheit der Personen, die zur Finanzierung von Leistungen der Gesundheitsvorsorge verpflichtet sind, zu berücksichtigen.

Was hingegen garantierte Leistungen im Bereich der Versorgung mit den im Erstattungsgesetz genannten medizinischen Erzeugnissen bzw. deren Wartung im Auftrag einer berechtigten Person anbelangt, so sind ihre klinische und praktische Effektivität, die Sicherheit ihrer Anwendung, das Verhältnis des erlangten Gesundheitsvorteils zu den Anwendungsrisiken sowie die finanziellen Folgen für das zur Finanzierung der Leistung verpflichtete Rechtssubjekt als Bewertungskriterien zu berücksichtigen. Für Arzneimittel, Lebensmittel, die für eine besondere Ernährung bestimmt sind und medizinische Erzeugnisse, die gleichzeitig apotheken- und verschreibungspflichtig sind sowie für Arzneimittelprogramme und Chemotherapeutika sind nach dem Erstattungsgesetz ferner folgende Kriterien heranzuziehen: Stellungnahmen der Wirtschaftskommission; Empfehlungen des Vorsitzenden der Agentur für die Bewertung von Medizinischen Technologien; der klinische Zustand, wie er aus dem Erstattungsantrag ersichtlich ist; das Verhältnis der getragenen zu den bisher erstatteten Kosten für Arzneimittel; die durch Lebensmittel, die für eine besondere Ernährung bestimmt sind, und medizinische Erzeugnisse erlangten gesundheitlichen Resultate im Vergleich zu den beantragten; die Konkurrenzfähigkeit ihrer Preise; das Bestehen alternativer medizinischer Technologien sowie deren klinische Effektivität und Anwendungssicherheit; gesundheitliche Prioritäten und der finanzielle Schwellenwert für die Steigerung der Lebenserwartung um ein weiteres Jahr, bereinigt um die Einbußen von Lebensqualität, welche grundsätzlich anhand des dreifachen Bruttoinlandsprodukts pro Kopf gemäß dem Gesetz vom 26. Oktober 2000 über die Art der Bemessung des jährlichen Bruttoinlandsprodukts bemessen wird (bei Unmöglichkeit der Feststellung dieses Wertes genügt ein Rückgriff auf die Kosten der Steigerung der Lebenserwartung um ein weiteres Jahr). Im Falle von auf dem Gebiet der Republik Polen nicht im Verkehr zugelassenen Arzneimitteln und Lebensmitteln, die für eine besondere Ernährung bestimmt sind, gilt Folgendes: Arzneimittel, die nach den Voraussetzungen und im Rahmen des Verfahrens nach Art. 4 des Pharmagesetzes vom 6. September 2001 aus dem Ausland eingeführt werden, bedürfen eines 
Bescheides über die Erstattung ihrer Kosten nach dem Erstattungsgesetz. Gleiches gilt für aus dem Ausland nach den Voraussetzungen und im Rahmen des Verfahrens nach Art. 29a des Gesetzes vom 25. August 2006 über Lebensmittelsicherheit und sichere Ernährung eingeführte Lebensmittel, die für eine besondere Ernährung bestimmt sind. Bezüglich beider gebietet das Gesetz ausschließlich die Berücksichtigung des klinischen Zustands aus dem Erstattungsantrag, ihre klinische und praktische Effektivität, die Sicherheit ihrer Anwendung, das Verhältnis des erlangten Gesundheitsvorteils zu den Anwendungsrisiken, die Konkurrenzfähigkeit ihrer Preise und die finanziellen Folgen für das zur Finanzierung der Leistung verpflichtete Rechtssubjekt und den Leistungsempfänger sowie das Bestehen alternativer medizinischer Technologien i.S. des Gesetzes über Leistungen und deren klinische Effektivität und Anwendungssicherheit als Bewertungskriterien.

Der Gesundheitsminister qualifiziert Leistungen der Gesundheitsfürsorge als garantierte Leistungen, nachdem er eine entsprechende Empfehlung des Vorsitzenden der Agentur für die Bewertung von Medizinischen Technologien eingeholt hat. Die Agentur ist eine staatliche Organisationseinheit mit eigener Rechtspersönlichkeit, die vor allem zur Erfüllung von Aufgaben im Bereich der Bewertung von Leistungen der Gesundheitsfürsorge berufen worden ist. Dazu zählen: Die Erteilung von Empfehlungen in Sachen der Qualifikation von Leistungen der Gesundheitsfürsorge als garantierte Leistungen; die Bestimmung und Änderung des Umfangs oder der Art der Finanzierung von garantierten Leistungen sowie die Entfernung einer gegebenen Leistung der Gesundheitsfürsorge aus dem Register der garantierten Leistungen; die Erstellung von Berichten bezüglich der Bewertung von Leistungen der Gesundheitsfürsorge; die Erstellung von Bestätigungsanalysen; das Aufarbeiten, Verifizieren, Sammeln, und zur Verfügung stellen von Informationen über die Methodik der Bewertung von medizinischen Technologien und in der Republik Polen sowie anderen Ländern geschaffene medizinische Technologien sowie deren Veröffentlichung; die Beurteilung von Gesundheitsprogrammen.

Der Minister beauftragt den Vorsitzenden der Agentur zur Vorbereitung einer Empfehlung über die Qualifizierung einer konkreten Leistung als garantierte Leistung mitsamt der Bestimmung des Finanzierungsumfangs als Betrag oder Prozentsatz oder der Bestimmung der Art seiner Finanzierung. Dieser Auftrag enthält eine Beschreibung der Leistung der Gesundheitsfürsorge und eine Darstellung der Krankheit sowie des Gesundheitszustandes, nach dem sich die Leistung richtet, sowie eine Schilderung 
ihres Einflusses auf die Besserung der Gesundheit der Bürger. Unverzüglich nach dem Eingang des Auftrags fordert der Vorsitzende der Agentur Stellungnahmen von Seiten staatlicher Berater aus dem entsprechenden Bereich der Medizin und des Fondsleiters an. Als nächstes erteilt der Vorsitzende der Agentur unter Berücksichtigung der Stellungnahme des Rates für Transparenz (der eine meinungsbildende und beratende Funktion erfüllt) und der oben dargestellten Kriterien seine Empfehlung. Er spricht sich darin entweder für die Qualifizierung der gegebenen Leistung der Gesundheitsfürsorge als garantierte Leistung mit der Bestimmung des Umfangs oder Art seiner Finanzierung oder für die Unbegründetheit der Qualifizierung der gegebenen Leistung der Gesundheitsfürsorge als garantierte Leistung aus. Der Vorsitzende übergibt seine Empfehlung unverzüglich dem Minister für Gesundheit.

Es ist darauf hinzuweisen, dass die Empfehlung für den Minister nicht verbindlich ist und ihre Einholung lediglich ein obligatorisches Element des Verfahrens zur Qualifizierung einer Leistung der Gesundheitsfürsorge als garantierte Leistung darstellt. Nach ihrem Eingang veröffentlicht der Minister für Gesundheit im Wege einer Verordnung die Verzeichnisse von garantierten Leistungen, welche Bestimmungen enthalten über Umfang oder Art der Finanzierung der jeweiligen garantierten Leistung (unter Berücksichtigung der Empfehlung und der oben dargestellten Kriterien) und die Bedingungen der Umsetzung der jeweiligen garantierten Leistung, mitunter in Bezug auf das medizinische Personal und die medizinische Ausrüstung, wobei stets Rücksicht auf die Notwendigkeit der Gewährleistung einer hohen Qualität der Leistungen der Gesundheitsfürsorge und einer entsprechenden Sicherung dieser Leistungen zu nehmen ist.

Der Minister für Gesundheit kann ferner eine gegebene Leistung der Gesundheitsfürsorge vom Verzeichnis garantierter Leistungen streichen oder den Umfang bzw. die Art ihrer Finanzierung oder die Bedingungen der Durchführung einer garantierten Leistung von Amts wegen oder auf Antrag ändern, wobei auf die oben dargestellten Kriterien abzustellen ist. Das Entfernen einer bestehenden Leistung der Gesundheitsfürsorge aus dem Verzeichnis garantierter Leistungen bzw. die Änderung des Umfangs oder der Art ihrer Finanzierung erfolgt nach Einholung einer Empfehlung des Vorsitzenden der Agentur. Die folgenden Personen und Stellen können sich mit entsprechenden Anträgen an den Minister für Gesundheit wenden: Die staatlichen Berater aus dem betroffenen Bereich der Medizin; Vereine, die ihrer Satzung nach landesweit agierende wissenschaftliche 
Gesellschaften sind; der Fondsleiter; sowie Vereine und Stiftungen, deren Satzungsziele den Schutz von Patientenrechten umfassen.

\section{Die Problematik des Erwerbs und der Verwirklichung des Rechts auf Leistungen der Gesundheitsfürsorge}

Die Problematik des Erwerbs von Rechten auf Leistungen der Gesundheitsfürsorge ist deswegen kompliziert, weil im System zwei Rechtssubjekte als Verpflichtete gegenüber dem Leistungsempfänger auftreten, wobei jeder von ihnen zu einer anderen bestimmten Leistung verpflichtet ist. Der Organisator des Systems ist nicht zu Leistungen der Gesundheitsfürsorge verpflichtet, weswegen auch die Leistungserbringer in dieser Hinsicht nicht als seine „Subauftragnehmer“ betrachtet werden können. Deren Pflichten ergeben sich aus mit dem NFZ geschlossenen Verträgen und werden gleichzeitig durch diese inhaltlich beschränkt. Der Organisator des Systems ist hingegen zu Leistungen für die Berechtigten in Gestalt der Gewährleistung der Gesundheitsfürsorge, d.h. der Möglichkeit, auf Leistungen der Gesundheitsfürsorge zurückzugreifen, wenn ein Risiko des Gesundheitsmangels eingetreten ist, verpflichtet. Dies bedeutet, dass er die Finanzierung des Systems und dessen einwandfreies Funktionieren gewährleisten muss. Dazu dient das Verfahren zum Abschluss von Verträgen mit Leistungserbringern über die Erteilung von Leistungen der Gesundheitsfürsorge an die Berechtigten im System. Die Summe der geschlossenen Verträge bildet das System, in dessen Rahmen den Berechtigten ein Recht auf aus öffentlichen Mitteln finanzierte garantierte Leistungen der Gesundheitsfürsorge zusteht. Die Pflichten des Organisators gegenüber den Leistungsempfängern stellen den Inhalt des zwischen den beiden Subjekten bestehenden Rechtsverhältnisses, das in der Literatur als „Verhältnis der Gesundheitsversicherung ${ }^{\text {“37 }}$ bezeichnet wird, dar.

Unterschieden werden sollte demnach zwischen der sog. Garantiephase, in der ein Berechtigter im System (noch) nicht auf Leistungen der Gesundheitsfürsorge zurückgreift, aber die Aufgabe des Organisators gleichwohl in der Verschaffung einer solchen Möglichkeit besteht, und der Verwirklichungsphase, in der die Gefahr des Gesundheitsmangels, die bis dahin po-

37 Vgl. z.B. Jończyk, Charakter stosunków ubezpieczenia zdrowotnego, in: VI Ogólnopolskie Forum Prawniczo-Medyczne „Aktualne problemy prawa medycznego", Materiały Konferencyjne, Warschau 2003, S. 11-23. 
tenziell und undefiniert geblieben war, in ein konkretes Krankheitsbild umschlägt, was den Leistungsempfänger zum Rückgriff auf Leistungen der Gesundheitsfürsorge berechtigt. ${ }^{38}$ Besonders bedeutsam bleibt dabei, dass im Fall des Eintritts der Verwirklichungsphase nicht mehr vom Verhältnis zwischen dem Berechtigten und dem Organisator des Systems, sondern zwischen Leistungsempfänger und Leistungserbringer die Rede ist. Es entsteht in diesem Moment ein Verhältnis der Gesundheitsfürsorge, dessen Gegenstand die Erteilung der, aus der Sicht des individuellen Gesundheitszustands des Empfängers und seiner Bedürfnisse, unerlässlichen Gesundheitsfürsorge an den Leistungsempfänger ist. ${ }^{39}$ Den Inhalt der Be-

38 Dabei besteht der Zweck von garantierten Leistungen der Gesundheitsfürsorge nicht lediglich im Heilen und Pflegen, sondern u.a. auch in der Früherkennung von Krankheiten. Der Begriff der Heilung umfasst darüber hinaus - aus offensichtlichen, funktionalen Überlegungen heraus - die Diagnose des Krankheitsbildes und die Bestimmung der Heilbehandlung und -mittel. Die besondere Natur des Risikos eines Gesundheitsmangels führt dazu, dass aus der ex ante-Sicht nicht feststellbar ist, ob dieses Risiko bei einem bestimmten Patienten tatsächlich eintritt und wenn ja mit welcher Intensität und in welcher Gestalt. Deshalb lässt sich ebenso wenig präzise bestimmen, welche Gesundheits-, Sach-, und Begleitleistungen sich im gegebenen Fall als notwendig erweisen, um dem Leistungsempfänger eine entsprechende Pflege zu gewährleisten. Eine solche nähere Bestimmung wird erst nach dem Eintritt des besagten Risikos aufgrund einer ärztlichen Einschätzung möglich, bei der über die Aufstellung einer Diagnose hinaus die Wahl einer Behandlungsmethode und folglich die Verschreibung von Arzneimitteln oder Heilmaßnahmen erfolgt. Dies ändert jedoch nichts an der Tatsache, dass bei der Verwirklichung des Rechts auf Leistungen der Gesundheitsfürsorge der subjektiven Einschätzung des eigenen Zustandes und Befindens durch den Leistungsberechtigten eine grundlegende Bedeutung zukommt, auch wenn ihm, objektiv betrachtet, nichts fehlt. Es gilt nämlich im Blick zu behalten, dass sich die Definition von Gesundheit nach der WHO auf das „,vollständige körperliche und seelische Wohlergehen” bezieht.

39 Wichtig ist es, in diesem Zusammenhang zu betonen, dass beide Phasen in dem Sinne ineinander übergehen können und dass der Eintritt der Verwirklichungsphase keinen Einfluss auf das Bestehen der Garantiephase hat. Mit anderen Worten befreit die Nutzung von Leistungen der Gesundheitsfürsorge den Organisator nicht von der weiteren Gewährleistung. Es gilt nämlich darauf zu achten, dass der Eintritt des Risikos eines Gesundheitsmangels und das damit einhergehende Erhalten von bestimmten Leistungen keinesfalls dem Eintritt eines weiteren, unterschiedlichen Risikos eines Gesundheitsmangels im Wege steht. Dies kann etwa dann der Fall sein, wenn im Zusammenhang mit auftretenden Beschwerden durchgeführte Untersuchungen zeigen, dass der Leistungsempfänger an einer weiteren Krankheit leidet, von der er ursprünglich keine Kenntnis hatte. Es kann ferner vorkommen, dass vom Leistungserbringer zum Zweck der Behandlung eines gemeldeten Risikos unternommene Handlungen zur Entstehung eines weiteren Krankheitsbildes 
rechtigung machen aus öffentlichen Mitteln finanzierte Leistungen der Gesundheitsfürsorge aus, was eine Mitwirkungspflicht auf Seiten des Leistungserbringers und des Organisators des Systems begründet. Diese Kooperation besteht unterdessen vor allem in der Schaffung und Finanzierung des Systems der Gesundheitsvorsorge, weswegen der Organisator eine garantierte Leistung der Gesundheitsfürsorge in der Garantiephase gewährleistet, während der Leistungserbringer im Nachhinein die unerlässliche Fürsorge in der Verwirklichungsphase erbringen kann. ${ }^{40}$

Der Zeitpunkt des Erwerbs eines Rechts auf garantierte Gesundheitsfürsorge (und des Beginns der Garantiephase) ist die Einschließung in den Kreis „der Leistungsempfänger“. Gemäß Art. 2 ÖffLG betrifft dies solche Personen, denen eine Gesundheitspflichtversicherung ,auferlegt“ wurde. Es soll dabei darauf hingewiesen werden, dass die Aufnahme in die Pflichtversicherung ein Rechtsereignis darstellt, welches einerseits in der Feststellung des Bestehens eines Versicherungstitels (,der Einschlägigkeit der Versicherungspflicht"), andererseits in der Durchführung bestimmter Registrierungs- und Identifizierungshandlungen (Art. 67 Abs. 2 und 3 ÖffLG), und im Falle der freiwilligen Versicherung in der Antragstellung und einem Vertragsschluss, besteht. ${ }^{41}$

Die Zeit zwischen dem Beitritt zum System und der Erfüllung der Formalitäten einerseits und der tatsächlichen Nutzung von garantierten Leistungen im Rahmen des Systems andererseits darf nicht mit einer Anwartschaft verwechselt werden. Diese betrifft nämlich kein Erwarten im faktischen Sinne - also keinen Zeitablauf, sondern die rechtliche Erwartung.

beitragen, etwa durch ärztliche Behandlungsfehler, wegen einer Lebensmittelvergiftung oder während eines Krankenhausaufenthalts usw.

40 Lediglich am Rande sei bemerkt, dass eine Beurteilung der vom Organisator erteilten Garantie erst in der Verwirklichungsphase möglich wird. Berechtigt ist die Ansicht, dass eine etwaige zu dem Zeitpunkt festgestellte, aber bereits in der Garantiephase bestehende Nachlässigkeit die Grundlage für individuelle Ansprüche von Seiten Berechtigter im System gegen den Organisator sein kann. Diese Frage war Gegenstand einer Entscheidung des Obersten Gerichts v. 28.05.2002, III UZP $3 / 02$, OSNAPiUS 2002/23/575, was im vorliegenden Kotext in einem weiteren Beitrag näher vorstellt wird. Vgl. Lach, Prawna problematyka zwrotu kosztów świadczeń nabytych poza systemem opieki zdrowotnej finansowanej ze środków publicznych (na tle orzecznictwa Sądu Najwyższego, sądów administracyjnych i ETS), Ślebzak (Hrsg.), Studia i analizy Sądu Najwyższego, Band 5, Warschau 2011, S. 344-383.

41 Vgl. Lach, Nabycie prawa do świadczeń opieki zdrowotnej, Praca i Zabezpieczenie Społeczne 2010, Heft 11, S. 2-9. 
Darunter ist die Erfüllung von nacheinander entstehenden Voraussetzungen zu verstehen, wobei das Recht erst bei Erfüllung aller Voraussetzungen entsteht - es handelt sich hierbei nämlich um einen zeitlich aufgeteilten Prozess des Rechtserwerbs. Im System der Gesundheitsfürsorge erwirbt der Berechtigte derweil das Recht auf Fürsorgeleistungen, wenngleich noch in keiner präzisierten Gestalt, im Moment der Aufnahme in die Versicherung, wobei der Zeitablauf während der Dauer des Versicherungsverhältnisses keinen Einfluss auf den Inhalt und die Reichweite der erworbenen Rechte entfaltet.

Bei der Analyse der Problematik des Erwerbs des Rechts auf Leistungen der Gesundheitsfürsorge sollte gleichzeitig die Frage des Verhältnisses zwischen diesem Rechtserwerb, der Durchführung der Meldetätigkeiten und der Entrichtung anfallender Beiträge gestellt werden. Auf den ersten Blick mag es scheinen, als komme der Beitragspflicht vorrangig eine Bedeutung sowohl als Preis für die vom Organisator des Systems erteilte Garantie als auch als eine den Fonds mittragende und der Finanzierung des Systems der Gesundheitsfürsorge dienende Leistung zu. Dieser Ansicht folgt ein Teil der Literatur mit der Begründung, dass „für die Erfüllung der Versicherungspflicht die gleichzeitige Erfüllung von zwei Voraussetzungen notwendig ist, d.h. die Anmeldung der versicherungspflichtigen Person beim Fonds durch sie selbst oder eine andere gesetzlich bestimmte Person (Art. 74-76) und die Zahlung von Beiträgen gemäß den gesetzlichen Fristen und Verfahren. Erst die Durchführung dieser Tätigkeiten erlaubt einer versicherungspflichtigen Person den Erwerb eines Rechts auf Leistungen der Gesundheitsfürsorge". ${ }^{42}$ Diese These scheint gleichwohl abwegig. Bei der Ermittlung der Bedeutung des Wortlauts der Absätze 1 und 2 des Art. 67 ÖffLG muss nämlich zwischen „der Erfüllung der Versicherungspflicht“ (Abs. 1) mit der Anmeldung und Zahlung von Beiträgen als ihren Voraussetzungen auf der einen Seite und, auf der anderen, dem „Erwerb des Rechts auf Leistungen der Gesundheitsfürsorge“, deren einzige Voraussetzung hingegen die Erfüllung der Anmeldeformalitäten ist (Abs. 2), getrennt werden. Dies hat zur Folge, dass obgleich die Entrichtung von Versicherungsbeiträgen durchaus eine der wichtigsten Pflichten der Berechtigten im System ist, der Erwerb eines Rechts auf

42 Nowak-Kubiak/Eukasik, Ustawa o świadczeniach opieki zdrowotnej finansowanych ze środków publicznych, Warschau 2006, Kommentar zu Art. 67, S. 133. 
Leistungen der Gesundheitsfürsorge dennoch einzig von der Durchführung bestimmter Anmeldetätigkeiten abhängig ist.

Am Rande bemerkt wird die Ansicht, nach der der Erwerb eines Rechts auf Leistungen im Rahmen des Systems der Gesundheitsfürsorge unabhängig von der Zahlung von Beiträgen erfolgt, stark auf die Doktrin des Sozialrechts und die axiologischen Grundlagen der Idee der sozialen Absicherung gestützt. ${ }^{43}$

In Bezug auf die Verwirklichungsphase sollte demgegenüber darauf hingewiesen werden, dass es in einem System der Gesundheitsfürsorge, in dem zur Gewährung von Sachleistungen externe, nicht zum Organisator des Systems gehörende Leistungserbringer herangezogen werden, durchaus zu einer Situation kommen kann, in der ein Leistungsempfänger die Gewährung einer gebotenen Leistung fordert, der Leistungserbringer jedoch mangels entsprechender vertraglicher Vereinbarung mit dem NFZ oder wegen der Ausschöpfung des vertraglich ausgehandelten Limits diese Leistung nicht erbringen wird.

Die Unmöglichkeit Leistungen zu erlangen kann sowohl im objektiven Sinne, als Ergebnis rechtlich vorgesehener Ausschlüsse/Einschränkungen bestimmter Leistungen infolge der Verletzung von organisatorischen Pflichten durch den NFZ, als auch im subjektiven Sinne verstanden werden, wenn der Empfänger die Erteilung einer Leistung unter Missachtung der Wartelisten (vgl. unten III.4.) oder der geltenden Verfahren bzw. eine über die vertraglichen Limits oder den garantierten Standard hinausgehende Leistung fordert.

Das rechtliche Instrument, auf das ein Leistungsempfänger zurückgreifen kann, wenn er eine Fürsorge fordert, die der gewählte Leistungserbringer aus Gründen der fehlenden vertraglichen Vereinbarung über die gegebene Leistung oder die Überschreitung des vertraglich vereinbarten Limits nicht erteilen kann, ist der Antrag an das entsprechende Organ des NFZ auf Erteilung eines Bescheids nach Art. 109 ÖffLG über die „Feststellung des Leistungsrechts“ i.S. einer Bestätigung, dass nicht nur die gegebene Leistung der Garantie unterliegt (demnach „im positiven Leistungspaket" inbegriffen ist), sondern dass sich diese auch verwirklichen lässt. Die Formulierung „Feststellung des Leistungsrechts“ i.S.v. Art. 109 ÖffLG bedeutet, dass die Organe des NFZ den Umfang der im Rahmen

43 Vgl. Kolasiński, Zasady nabywania i zachowania uprawnień z ubezpieczeń społecznych, Praca i Zabezpieczenie Społeczne, Nr. 2/1989, S. 12. 
der Gesundheitsfürsorge zu erteilenden Leistungen mithilfe von deklaratorischen Entscheidungen präzisieren, deren materiellrechtliche Grundlage den Vorschriften des Gesetzes zu entnehmen ist. Die in Art. 109 Abs. 1 ÖffLG vorgesehene Kompetenz des Direktors der Wojewodschaftszweigstelle des Fonds zur Entscheidung in Sachen der Feststellung von Leistungsrechten geht mit der Pflicht zur Konkretisierung des allgemeinen Rechts auf Leistungen der Gesundheitsfürsorge (auf Ersuchen des Leistungsempfängers) einher, z.B. durch den Verweis auf (einen oder mehrere) Leistungserbringer, welche die geforderte Leistung (gebotene Fürsorge) entsprechend einem Vertrag mit dem NFZ auf Kosten des Fonds erbringen können. Die Vorschrift des Art. 109 ÖffLG allein stellt eine Kompetenzgrundlage zur Erteilung von Bescheiden durch die Organe des NFZ in Sachen Aufnahme in die Versicherung und Feststellung von Leistungsrechten dar. Sie ist hingegen keine materiellrechtliche Grundlage zur Entscheidung über die Erstattung der Kosten des Erwerbs von Leistungen. ${ }^{44}$

Auch im Falle der Nutzung von Leistungen außerhalb des Systems ohne die Zustimmung des Organisators auf der Grundlage der Koordinierungsvorschriften ${ }^{45}$, sollte ein Antrag des Leistungsempfängers auf Erstattung der getragenen Kosten im Rahmen des Verfahrens nach Art. 109 ÖffLG erörtert werden. Die „Feststellung des Leistungsrechts“ umfasst in einem solchen Fall eine Untersuchung und Entscheidung durch das Organ des NFZ darüber, ob im gegebenen Fall die Voraussetzungen aus Art. 20 Abs. 2 der Verordnung 883/2004 erfüllt sind. ${ }^{46}$ Ihre Erfüllung begründet

44 Auf die umfangreiche Rechtsprechung der Verwaltungsgerichte zu verschiedenen Aspekten der Anwendung von Art. 109 ÖffLG wird näher eingegangen in Lach (Fn. 40), S. 354-361, 369-381.

45 Verordnungen des Europäischen Parlaments und des Rates (EG): Nr. 883/2004 vom 29. April 2004 zur Koordinierung der Systeme der sozialen Sicherheit, Nr. 987/2009 vom 16. September 2009 zur Festlegung der Modalitäten für die Durchführung der Verordnung (EG) Nr. 883/2004 über die Koordinierung der Systeme der sozialen Sicherheit sowie Nr. 1231/2010 vom 24. November 2010 zur Ausdehnung der Verordnung (EG) Nr. 883/2004 und der Verordnung (EG) Nr. 987/2009 auf Drittstaatsangehörige, die ausschließlich aufgrund ihrer Staatsangehörigkeit nicht bereits unter diese Verordnungen fallen.

46 Vgl. Lach, Spełnianie świadczeń zdrowotnych na terytorium UE - kolejki a ,turystyka zdrowotna" w świetle orzecznictwa ETS, Praca i Zabezpieczenie Społeczne, Nr. 5/2007, S. 9 ff.; sowie die dort aufgeführten Urteile des EuGH; ders. Problematyka dostępu do świadczeń opieki zdrowotnej na terytorium UE w świetle orzecznictwa ETS in: Świątkowski (Hrsg.), Ochrona praw człowieka w świetle przepisów prawa pracy i zabezpieczenia społecznego. Referaty i wystąpienia zgłoszo- 
auf der Grundlage von Art. 25 Abs. 1 ÖffLG i. V. m. Art. 20 Abs. 2 der Verordnung 883/2004 sowohl den Antrag als auch den Anspruch eines Leistungsempfängers auf Erstattung der getragenen Kosten (diese Vorschriften bilden die materiellrechtliche Grundlage für die Erstattung der vom Leistungsempfänger getragenen Kosten).

Wenn hingegen der Leistungsempfänger auf Leistungen zurückgreift, die zwar außerhalb des Systems der aus öffentlichen Mitteln finanzierten Gesundheitsfürsorge, jedoch weiterhin von innerstaatlichen Leistungserbringern erbracht wurden, so ist, unabhängig davon, ob dies Umständen geschuldet ist, für die der Leistungserbringer einzustehen hat oder die Gründe für die Unmöglichkeit der Erlangung einer solchen Leistung im Rahmen des Systems vielmehr objektiver Natur sind, ein Antrag auf Erstattung der getragenen Kosten nach Art. 109 ÖffLG wegen Fehlens einer materiellrechtlichen Grundlage für eine solche Erstattung als unbegründet abzulehnen.

Falls die Erlangung einer gegebenen Leistung im Rahmen des Systems wegen einer Unterlassung auf Seiten des NFZ unmöglich bleibt oder wenn die Leistung alleine unter Voraussetzungen erbracht werden kann, die tatsächlich in die gesetzliche Gesundheitsfürsorgegarantie eingreifen, kann der Leistungsempfänger diese am freien Markt der medizinischen Dienstleistungen erwerben und sich im Nachhinein mit einem Schadensersatzanspruch auf der Grundlage von Art. 471 des polnischen Zivilgesetzbuches (ZGB) an den NFZ wenden. Die Vorschrift besagt, dass der Schuldner zur Behebung des Schadens, der aus einer nicht oder nicht wie geschuldet erbrachten Leistung resultiert, verpflichtet ist, es sei denn, der Schuldner hat die Pflichtverletzung nicht zu vertreten. In der Literatur wurde vertreten, dass die Haftung des Schuldners gemäß Art. 471 ff. ZGB, wenngleich sie traditionell auch als vertragliche Haftung bezeichnet wird, vom polnischen Gesetzgeber zweifelsfrei zur Anwendung auf alle schuldrechtlichen Verhältnisse, nicht nur jene aus Verträgen, vorgesehen ist. ${ }^{47}$

ne na XVII Zjazd Katedr/Zakładów Prawa Pracy i Zabezpieczenia Społecznego, Kraków 7-9 Maja 2009, Krakau 2009, S. 339-346; ders., Glosa do wyroku ETS (wielka izba) z 16 Maja 2006, C-372/04, Gdańskie Studia Prawnicze - Przegląd Orzecznictwa Nr. 4/2006, S. 183-194; ders. Nowe przepisy dot. koordynacji systemów opieki zdrowotnej w UE in, Niedbała (Hrsg.), Księga pamiątkowa w piątą rocznicę śmierci Profesora Andrzeja Kijowskiego, Warschau 2010, S. 117-130.

47 Flaga-Gieruszyńska, Glosa do wyroku Sądu Najwyższego vom 26. Juni 2001, III CZP 30/01, Rejent Nr. 6/2002, S. 132; vgl. auch Pełka, Podstawy prawne i zakres odpowiedzialności cywilnej Kas Chorych, Prawo i Medycyna, Nr. 6-7/2000, 
Auf der Grundlage von Art. 109 ÖffLG kann hingegen die Erteilung einer individuellen Zustimmung für die Finanzierung von Leistungen, die erst künftig von einem Leistungserbringer, der mit dem NFZ keinen entsprechenden Vertrag abgeschlossen hat, erbracht werden sollen, beantragt werden. Dies betrifft insbesondere die Situationen, in denen überhaupt kein Leistungserbringer Verträge für die Erteilung einer konkreten Leistung (bzw. Leistungen der Gesundheitsfürsorge in einem bestimmten Bereich) geschlossen hat. Eine solche Zustimmung kann sowohl die Aufnahme einer Behandlung beim Leistungserbringer im In- wie auch im Ausland (ebenfalls auf der Grundlage der Vorschriften zur Koordinierung) betreffen.

\section{Wartelisten}

Wartelisten sind ein Rechtsinstitut des Systems der Gesundheitsfürsorge zur Reglementierung des Zugangs zu garantierten Leistungen. ${ }^{48}$ Listen von Personen, die auf die Erteilung bestimmter Leistungen der Gesundheitsfürsorge warten, sind eine Folgeerscheinung der Bestimmung von Betrags- oder Mengenbeschränkungen in Verträgen über die Erteilung von Leistungen der Gesundheitsfürsorge, so dass einerseits die Pflicht der Leistungserbringer eingeschränkt und andererseits dem NFZ die gesetzlich vorgeschriebene Bilanzierung der Einnahmen aus dem System mit den Ausgaben des Fonds ermöglicht wird. ${ }^{49}$ In einem Vertrag über die Erteilung von Leistungen der Gesundheitsfürsorge wird nämlich unter anderem der Gesamtumfang der Verpflichtung des Fonds gegenüber dem Leistungserbringer bestimmt (vgl. unten IV.). ${ }^{50}$

S. 31-47; Nestorowicz, Odpowiedzialność cywilna za ograniczenie dostępności do leczenia i nieuzyskanie świadczenia zdrowotnego w nowym systemie opieki zdrowotnej, Prawo i Medycyna, Nr. 6-7/2000, S. 5 ff.; Lach, (Fn. 40), S. 376 ff.

48 Vgl. Oberstes Gericht v. 10.05.2006, III CSK 53/05.

49 Gemäß Art. 132 Abs. 5 ÖffLG kann die Summe sämtlicher Verpflichtungen des NFZ aus Verträgen mit Leistungserbringern die Höhe der dafür im Finanzplan des Fonds vorgesehenen Ausgaben nicht überschreiten, vgl. oben II.4.

50 In einer Reihe von Entscheidungen befand das Oberste Gericht, dass die Bestimmung sowohl von Betrags- als auch Mengenbeschränkungen in Verträgen (außer der Definierung von Maximalbeträgen) zulässig und verbindlich ist, vgl. z.B. Oberstes Gericht v. 7. 08. 2003, IV CKN 393/01, LEX Nr. 279804.; v. 05.11.2003, IV CK 189/02, LEX Nr. 164009.; v. 28.01.2004, IV CK 434/02, LEX Nr. 148646; 
Bei den Grundleistungen der Gesundheitsfürsorge bestimmt sich die Reihenfolge ihrer Erteilung nach den Anmeldungen. Die selbstständige Registrierung der Patienten besitzt dabei lediglich einen Ordnungscharakter, was mit dem pauschalierten (pro-Kopf-basierten) Finanzierungsmechanismus der gesundheitlichen Grundfürsorge zusammenhängt.

Hinsichtlich Leistungen der Gesundheitsfürsorge in Krankenhäusern und spezialisierten Leistungen in ambulanter Fürsorge, zu denen die entsprechenden Verträge über ihre Erteilung im Wege einer Ausschreibung oder Verhandlung geschlossen werden und die Forderung der Leistungserbringer gegenüber dem Fonds betrags- oder mengenmäßig bestimmen, sieht das Gesetz ebenfalls eine Erteilung durch den unter Vertrag genommenen Leistungserbringer nach der Reihenfolge der Anmeldung zum gegebenen Tag und Stunde, zu denen sie erteilt worden sind, vor. Ein solcher Leistungserbringer legt nicht nur die Reihenfolge fest, in der die Leistungen der Gesundheitsfürsorge entsprechend den Anmeldungen von Seiten der Leistungsempfänger erbracht werden, sondern benachrichtigt den Empfänger auch schriftlich über den Termin der Erteilung der Leistung sowie die Gründe für die Wahl von ebendiesem Termin und trägt bestimmte Daten des Leistungsempfängers in die eigenhändig geführte Warteliste zur konkreten Leistung ein. Die Durchführung der genannten Handlungen durch den Leistungserbringer ist gleichbedeutend mit seiner Verpflichtung zur Erteilung der gegebenen Leistung der Gesundheitsfürsorge.

Das Gesetz verpflichtet zur Führung von Wartelisten und der Respektierung des Grundsatzes des gerechten, gleichen, diskriminierungsfreien und transparenten Zugangs zu Leistungen der Gesundheitsfürsorge sowie gemäß den medizinischen Kriterien der Verordnung des Gesundheitsministers über medizinische Kriterien für Leistungserbringer bei der Platzierung von Leistungsempfängern auf Wartelisten für die Erteilung von Leistungen der Gesundheitsfürsorge (dies sind: der Gesundheitszustand des Leistungsempfängers; voraussichtlicher weiterer Krankheitsverlauf; Parallelerkrankungen mit Einfluss auf die Erkrankung, wegen der die Leistung erteilt wird, sowie die Gefahr, dass sich eine Behinderung ergeben, verfes-

v. 17.09.2004, V CK 58/04, LEX Nr. 194081; v. 15.10.2004, II CK 54/04, LEX Nr. 137581; v. 15.12.2004, IV CK 361/04; v. 10.03.2005, I CK 578/04, LEX Nr. 301791; v. 15.12.2005, II CSK 21/05; v. 25.05.2006, II CK 343/05, LEX Nr. 200917; v. 14.06. 2006, II CSK 68/06. Näheres dazu: Vgl. Lach, Problem odpłatności za ponadlimitowe świadczenia zdrowotne in: Ślebzak/Wróbel (Hrsg.), Studia i analizy Sądu Najwyższego, Band 2, Warschau 2008, S. 201-226. 
tigen oder verschlimmern kann). Der Leistungsempfänger bestimmt über die Reihenfolge der Patientenaufnahme und gewährleistet die redliche Führung der Wartelisten. Im Falle einer Veränderung des Gesundheitszustands des Leistungsempfängers mit Hinweis auf das Bedürfnis einer früheren Erteilung der Leistung, als zum ursprünglich bestimmten Termin, setzt der Leistungsempfänger den Erbringer über die Tatsachen in Kenntnis, woraufhin dieser, sofern dies aus medizinischen Kriterien hervorgeht, den Termin zur Erteilung der Leistung entsprechend korrigiert und den Leistungsempfänger darüber unverzüglich informiert. Im Falle des Eintritts von Umständen, die zum Zeitpunkt der Bestimmung des Termins zur Erteilung der Leistung der Gesundheitsfürsorge nicht hätten vorhergesehen werden können, die jedoch die Einhaltung des in die Warteliste eingetragenen Termins unmöglich machen, informiert der Leistungserbringer den Leistungsempfänger auf jedem ihm zur Verfügung stehenden Weg über die Änderung des Termins aufgrund von Verschiebungen in der Reihenfolge der Erbringung der Leistungen und die zugrunde liegende Ursache. Dies betrifft naturgemäß auch Verschiebungen auf einen früheren Termin.

Zu diesem Zweck sieht das Gesetz vor, dass Wartelisten für die Erteilung von Leistungen einer regelmäßigen, mindestens monatlichen Bewertung unterzogen werden. Im Fall von Krankenhäusern wird die Bewertung von einer speziell vom Leistungserbringer berufenen Gruppe zur Bewertung von Aufnahmen durchgeführt, bei speziellen Leistungen in ambulanter Fürsorge übernimmt dies der Leiter des Leistungserbringers, in den sonstigen Fällen hingegen der Leistungserbringer im Allgemeinen. Die Bewertung von Listen richtet sich nach den folgenden Kriterien: Redlichkeit der Dokumentierung, Wartezeiten für die Erteilung von Leistungen, Begründungen und Gründe für die Änderung von Terminen für die Erteilung der Leistungen. Diese Grundsätze gelten auch für Leistungserbringer hochspezialisierter Leistungen.

Überdies sind Leistungserbringer von Leistungen der Gesundheitsfürsorge in Krankenhäusern und spezialisierten Leistungen in der ambulanten Fürsorge zur monatlichen Übermittlung von Informationen an die örtlich zuständige Wojewodschaftszweigstelle des Fonds am Ort der Erteilung der Leistung bezüglich der Wartelisten verpflichtet. Informationen über die von den einzelnen Leistungserbringern geführten Wartelisten, die Zahl der wartenden Personen und die durchschnittliche Wartezeit für die Erteilung der einzelnen Leistungen der Gesundheitsfürsorge sowie über die Möglichkeit der Erteilung von Leistungen durch andere entsprechend un- 
ter Vertrag genommene Leistungserbringer veröffentlicht die für den Ort der Erteilung der Leistung zuständige Wojewodschaftszweigstelle des NFZ auf ihrer Internetseite, die mindestens einmal im Monat zu aktualisieren ist. Die Zweigstelle ist ferner dazu verpflichtet, Leistungsempfänger auf deren Ersuchen hin über die Möglichkeit der Erteilung von Leistungen der Gesundheitsfürsorge bezüglich anderer unter Vertrag genommene Leistungserbringer sowie die durchschnittliche Wartezeit für konkrete Leistungen der Gesundheitsfürsorge zu informieren. Auf der Grundlage der erhaltenen Daten bildet der Fonds überdies ein zentrales Register für Informationen über die Zahl der auf die Erteilung von Leistungen der Gesundheitsfürsorge wartenden Personen und die durchschnittliche Wartezeit in den einzelnen Wojewodschaftszweigen des Fonds.

Sowohl Leistungserbringer, die Leistungen der Gesundheitsfürsorge in Krankenhäusern als auch solche, die spezialisierte Leistungen der ambulanten Fürsorge wie auch hochspezialisierte Leistungen erbringen, sind dazu verpflichtet, auf elektronischem Wege die Buchung eines Arzttermins anzubieten, die Möglichkeit der Verfolgung der eigenen Position auf der Warteliste zu gewährleisten und das Erhalten von Benachrichtigungen über Termine für die Erteilung von Leistungen zu ermöglichen. Zu diesem Zweck übermitteln sie die Daten der Wartelisten an das im Gesetz vom 28. April 2011 über das Informationssystem zum Gesundheitsschutz erwähnte gleichnamige System.

Wenn es um die Pflichten der Leistungsempfänger geht, bestimmt das Gesetz, dass in den Fällen, in denen es dem Leistungsempfänger nicht möglich sein sollte persönlich beim Leistungserbringer zum in der Warteliste registrierten Termin zu erscheinen oder der Empfänger auf die Leistung der Gesundheitsfürsorge verzichtet hat, dieser es dem Leistungserbringer unverzüglich mitzuteilen hat. Verständlicherweise kann sich ein Leistungsempfänger zur Anmeldung für eine Leistung der Gesundheitsfürsorge auf der Grundlage einer ärztlichen Überweisung lediglich auf die Warteliste eines Leistungserbringers eintragen lassen.

Es ist darauf hinzuweisen, dass alle in die Liste eingetragenen Personen ein Recht auf im System garantierte Leistungen der Gesundheitsfürsorge haben und das einzige Kriterium für die Konkretisierung der zu leistenden Fürsorge ihre persönliche Bedürftigkeit darstellt. Die Liste dient lediglich der Feststellung der Reihenfolge, in welcher die reglementierten Leistungen erbracht werden sollen, weswegen sie nicht den Umfang der garantierten Fürsorge, sondern lediglich den Moment ihrer Erteilung betrifft. Dies bedeutet, dass der Abschluss von Verträgen zur Bestimmung von verbind- 
lichen Einschränkungen und Limits für Leistungserbringer, die in der Notwendigkeit der Führung von Wartelisten für die Erteilung gegebener Leistungen münden und durch die eingeschränkte Zugänglichkeit und Knappheit der verwalteten finanziellen Mittel gerechtfertigt sind, sehr wohl vom Wortlaut des Art. 68 Abs. 2 S. 2 plVerf gedeckt ist, gemäß dem der Umfang und die Erteilung der Leistungen gesetzlich zu bestimmen sind. Das Gesetz über aus öffentlichen Mitteln finanzierte Leistungen der Gesundheitsfürsorge sieht eine Pflicht zum Abschluss von Verträgen mit derartigen Einschränkungen vor, wenn es auch andererseits das Gebot der „Bilanzierung des Finanzplans des Fonds im Bereich der Einnahmen und Ausgaben“ aufstellt. Daraufhin gilt es festzustellen, dass die auf diese Art und Weise entstehenden Einschränkungen (Wartelisten, limitierte Leistungen usw.), so beschwerlich sie für die Leistungsempfänger auch sein mögen, einen unvermeidbaren Bestandteil des Systems ausmachen. ${ }^{51}$ Ihre Begründung liegt im Grundsatz des Allgemeinwohls, welcher derart zu verstehen ist, dass die dem NFZ zur Verfügung stehenden eingeschränkten finanziellen Mittel eine Limitierung des Zugangs zur garantierten Gesundheitsfürsorge zulassen, weil das Interesse aller Leistungsempfänger in Gestalt der Anerkennung bestimmter Leistungen der Fürsorge als garantiert (was oftmals mit der Einschränkung des Zugangs zu ihnen einhergeht) das Interesse des konkreten Leistungsempfängers (Patienten) überwiegt.

Wichtig ist dabei zu betonen, dass die vorgestellten Grundsätze bezüglich der Wartelisten nicht auf Leistungen der Gesundheitsfürsorge im Bereich der Transplantation, die in Bezug auf Personen, die entsprechend den Vorschriften über die Entnahme und Verpflanzung von Zellen, Gewebe und Organen in die nationale Warteliste für Transplantationen von Zellen, Gewebe und Organen, eingetragen sind, sowie auf berechtigte Soldaten oder geschädigte Mitarbeiter des Militärs bzw. Veteranen anwendbar sind. Diese Personen kommen außer der Reihe in den Genuss von Leistungen der Gesundheitsfürsorge im Bereich der Behandlung von Verletzun-

51 Eine Nebenfolge von Wartelisten sind Fälle von risikobasiertem Wahlverhalten die Verlängerung einer Wartezeit beschleunigt die Entscheidung eines Patienten über das Zurückgreifen auf private, also systemexterne, Gesundheitsfürsorge. In der englischen Literatur wird darauf hingewiesen, dass die längsten Warteschlangen in Großbritannien bei den Anbietern der lukrativsten medizinischen Fachgebiete entstehen, die von denselben Ärzten wie die staatlichen Anstalten des National Health Service und deren Privatpraxen bedient werden. Vgl. Jończyk, Ochrona zdrowia, Państwo i Prawo 2007, Heft 2, S. 7. 
gen und Krankheiten, die sie während der Durchführung von Aufgaben außer Landes erlitten haben. Das Recht auf den Erhalt von Leistungen der Gesundheitsfürsorge außerhalb der Warteliste gebührt schließlich ferner Leistungsempfängern mit dem Titel „Verdienter Ehrenblutspender“ bzw. „Verdienter Transplantatspender" sowie Kriegs- und Militärinvaliden und Kombattanten. ${ }^{52}$

Es gilt dabei ebenfalls darauf hinzuweisen, dass in begründeten Fällen die Tatsache einer zu langen Wartezeit auf die Erteilung einer bestimmten Leistung der Gesundheitsfürsorge eine hinreichende Voraussetzung für die Forderung zur Finanzierung der Erbringung dieser Leistung im EU-Ausland auf Kosten des nationalen Versicherers auf der Grundlage der Vorschriften über die Koordinierung (aus der Verordnung 883/2004 - vgl. oben III.3.) darstellt.

\section{Leistungen der Gesundheitsfürsorge an bedürftige Personen unter den Voraussetzungen des sog. gesetzlichen Zwangs}

In Anlehnung an die bereits erwähnten Verfassungsgrundsätze der Menschenwürde sowie des Schutzes des Lebens und der Gesundheit (Art. 30, 38 und 68 plVerf) führte der Gesetzgeber die Pflicht zur Erteilung entsprechender Leistungen der Gesundheitsfürsorge an Bedürftige in gesetzlich geregelten Notfällen ein. Die Erfüllung dieser Pflichten wurde Leistungserbringern auferlegt, mitunter im Rahmen des Systems der Gesundheitsfürsorge, wenngleich sich der Kreis der Berechtigten - was offensichtlich scheint - nicht allein auf die Berechtigten im System beschränkt. Gemäß der großen Reichweite des Rechts auf Gesundheitsschutz aus Art. 68 Abs. 1 plVerf sind alle Menschen zu entsprechenden Leistungen berechtigt, was für bestimmte praktische Probleme, vor allem im Bereich der Tragung der Kosten, der auf dieser Grundlage erteilten Leistungen, sorgt.

Gemäß Art. 15 des Gesetzes über Heiltätigkeiten kann ein medizinischer Dienstleister die Erteilung einer Gesundheitsleistung an eine Person, die diese wegen einer Gefahr für Gesundheit und Leben akut benötigt,

52 Vertiefend zu besonderen Berechtigungen auf Leistungen der Gesundheitsfürsorge sowie ihrer Rechtfertigung vgl. Lach, Die Verteilungsgerechtigkeit in der Gesundheitsfürsorge in: Classen/Lukańko/Richter (Hrsg.), Diskriminierung aufgrund der Gesundheit in alternden Gesellschaften. Deutschland und Polen vor neuen Herausforderungen, Berlin 2015, S. 281-292. 
nicht verweigern. Diese Vorschrift betrifft sowohl öffentliche als auch nicht-öffentliche medizinische Dienstleister. ${ }^{53}$ Dem lässt sich hinzufügen, dass es ohne Bedeutung bleibt, ob der Dienstleister mit dem NFZ einen Vertrag über die Erteilung von Leistungen der Gesundheitsfürsorge abgeschlossen hat oder in welchem Umfang er seine Heiltätigkeit betreibt. Die in der besagten Vorschrift aufgestellte Pflicht hat einen generellen Charakter - jede Person ist zur sofortigen Hilfe berechtigt, wenn ihre Gesundheit oder ihr Leben gefährdet sind. Wenngleich die Vorschrift dies nicht ausdrücklich bestimmt, lässt sich aufgrund einer funktionalen Untersuchung sowie aus der Rechtsprechung bezüglich ihrer Auslegung feststellen, dass die Anwendung von Art. 15 des Gesetzes über Heiltätigkeiten nicht nur von der Voraussetzung des Auftretens einer Gefahr für Gesundheit oder Leben abhängt, sondern auch davon, ob diese Gefahr für die Gesundheit akut ist (so dass Leistungen sofort erbracht werden müssen). Bei der Anwendung dieser Vorschrift gilt es zuerst festzustellen, ob das Risiko des Gesundheitsverlusts bei dieser Person akut und unvorhergesehen eingetreten ist, und erst wenn diese Voraussetzung bejaht wird, gilt es zu überprüfen, ob die Person wegen einer Gefahr für ihre Gesundheit und ihr Leben einer sofortigen Erbringung von Leistungen bedarf. ${ }^{54}$ Die Voraussetzung

53 Vgl. Dercz/Rek, Ustawa o zakładach opieki zdrowotnej. Komentarz, Warschau 2007, Kommentar zu Art. 7, S. 51-55.

54 Aus diesem Grund kann der These, ,zu den Grundelementen des Notzustandes gehören: Das Risiko von Tod oder einer schweren Körperverletzung bzw. Gesundheitsschädigung" (vgl. Śliwka, Prawo pacjenta do świadczenia opieki w stanie nagłym, Prawo i Medycyna 2008, Nr. 2, S. 61) nicht zugestimmt werden. Die akute Natur eines Ereignisses und die damit verbundenen Folgen in Gestalt der Gefahr für Leben und Gesundheit stellen zwei voneinander unabhängige Voraussetzungen dar und erst ihr gemeinsames Auftreten eröffnet den Anwendungsbereich der besagten Vorschrift. An dieser Stelle lässt sich das Beispiel der Legaldefinition eines Arbeitsunfall anbringen, der ein gleichzeitiges Auftreten von vier Merkmalen erfordert: eines äußeren Umstands, einer akuten Natur, der gesetzlich bestimmten Folgen und eines Zusammenhangs mit der Arbeit. Anders ausgedrückt: Es kommen lediglich solche Situationen in Betracht, in denen eine akute Gefahr der Gesundheitsminderung auftritt, deren Verwirklichung eine reale Gefahr für das Leben und die Gesundheit mit sich bringt. Ein bloßer akuter Vorfall ist noch nicht ausreichend (z.B. eine geringfügige Wunde), notwendig ist vielmehr ein qualifizierter Erfolg (z.B. eine solche Wunde bei einer Person mit einer Bluterkrankheit). Sehr wohl vorstellbar sind nämlich akute Situationen, die jedoch weder das Leben noch die Gesundheit gefährden, ebenso wie diese Güter gefährdende Situationen, die nicht akut in Erscheinung getreten, sondern einer seit längerem anhaltenden Krankheit geschuldet sind und sich daher ohne Weiteres vorhersehen ließen. Vgl. 
„akut” wird im Gesetz über Leistungen der Gesundheitsfürsorge definiert. In Art. 5 Pkt. 33 wird ein akuter Zustand über einen Verweis auf Art. 3 Pkt. 8 des Gesetzes vom 8. September 2006 über den Staatlichen Medizinischen Rettungsdienst definiert. Demnach gilt als Zustand der akuten Gefahr für die Gesundheit jeder Zustand der begonnenen oder kurz vor dem Eintritt stehenden Verschlechterung der Gesundheit, dessen unmittelbare Folge eine ernsthafte Beschädigung der Körperfunktionen oder des Körpers oder der Tod sein kann, die eine sofortige Aufnahme medizinischer Rettungshandlungen und einer Behandlung erfordert. Ein solches Verständnis von Art. 15 des Gesetzes über Heilungstätigkeiten schränkt die Möglichkeit seines Missbrauchs durch Leistungserbringer zur Umgehung der vertraglich beschlossenen Leistungslimits, die für den NFZ vom Standpunkt seiner organisatorischen Aufgaben und der Verwaltung der Mittel im System aus gesehen von grundlegender Bedeutung sind, ein. ${ }^{55}$

Eine davon abweichende Problematik stellt die Erteilung von Leistungen zur Ersetzung der Arbeit von insuffizienten Organen an chronisch Kranke dar, die durchaus das Merkmal von unerlässlichen und lebensrettenden Leistungen erfüllen. Dazu wird im Schrifttum zutreffend angemerkt, dass die Anwendung der Vorschriften über den sog. gesetzlichen Zwang beschränkt sei auf ,Situationen mit einem sofortigen Bedürfnis der Erteilung medizinischer Hilfe im Falle einer Gefahr für Leben und Gesundheit eines Menschen oder in anderen akuten Fällen. Diese Voraussetzungen werden grundsätzlich nicht von einer Behandlung erfüllt, die zwar unerlässlich ist, jedoch zu im Voraus geplanten, mit dem Patienten abgestimmten Terminen erbracht wird, wenn die Erteilung einer Leistung durch ebendiesen Medizindienstleister (Arzt), der bereits das vertraglich mit dem NFZ bestimmte Leistungslimit erschöpft hat, gerade aus keinem anderen Grund notwendig ist" ${ }^{\text {"56 }}$. Diese Ansicht findet Unterstützung in der Rechtsprechung des Obersten Gerichts, das in seinem Urteil vom

Lach, Glosse zum Urteil des Appellationsgerichts in Posen v. 28.09.2006, Posen 2006, S. $167 \mathrm{ff}$.

55 Vgl. Lach, Problem odpłatności (Fn. 50), S. 210 ff., sowie Lach, Glosse zum Urteil des Appellationsgerichts in Poznan v. 28.09. 2006, Posen 2006, S. 167 ff.; vgl. ferner: Janiszewska, Ponadlimitowe świadczenia zdrowotne udzielane w schorzeniach przewlekłych (uwagi na tle orzecznictwa Sądu Najwyższego), Prawo i Medycyna 2008, Nr. 1, S. 26 ff.

56 Janiszewska, Ponadlimitowe S. 39 f.; vgl. auch: Lach, Glosse zum Urteil des Appellationsgerichts in Poznan vom 28.09.2006, Posen 2006, S. 169 ff. 
4. Januar $2007^{57}$, feststellte, dass gesundheitliche Leistungen in den Vorschriften zum sog. gesetzlichen Zwang grundsätzlich akute und unerwartete Zustände umfassen, die sich nicht voraussehen ließen (z.B. Patienten mit einem Schlaganfall, Herzinfarkt, verletzte Unfallteilnehmer). Es handele sich dabei also nicht um Behandlungen, die zwar das Leben retten, jedoch an chronisch Kranke, die einer regelmäßigen medizinischen Behandlung bedürfen (z.B. einer Hämodialyse), erteilt werden. ${ }^{58}$

Hinzuweisen ist ferner auf Art. 19 Abs. 1 ÖffLG, nach dem in akuten Situationen Leistungen der Gesundheitsfürsorge dem Leistungsempfänger unverzüglich zu erteilen sind. Trotz des Wortlauts dieser Vorschrift ist anzunehmen, dass auch einem Nichtleistungsempfänger im Falle eines Bedürfnisses nach sofortiger Hilfe offensichtlich dieselbe Leistung gegenüber Personen von der sog. Warteschlange (sowohl in Bezug auf Wartelisten für limitierte Leistungen als auch die derzeitige Reihenfolge der Anmeldung) vorrangig zu gewähren ist, mitunter aus dem Grund, dass in akuten Fällen die Feststellung, ob einer solchen Person der Status eines Leistungsempfängers zukommt, oftmals unmöglich ist.

Eine weitere Vorschrift, die eine Pflicht in diesem Bereich statuiert, ist Art. 30 des Gesetzes vom 5. Dezember 1996 über die Berufe des Arztes und des Zahnarztes, nach welchem der Arzt zur Erteilung ärztlicher Hilfe in jedem Fall verpflichtet ist, in dem eine Verzögerung zur einer Gefahr für das Leben, einer schweren Körperverletzung oder Gesundheitsschädigung führen kann sowie in anderen akuten Fällen. Die Vorschrift ist an Ärzte gerichtet und stellt eine gesetzliche Erweiterung der Pflicht aus dem hippokratischen Eid dar. Ähnlich wie im Falle von Art. 15 des Gesetzes über Heiltätigkeiten spielt es keine Rolle, ob der jeweilige Arzt ein vom NFZ über die Erteilung von Leistungen der Gesundheitsfürsorge unter Vertrag genommener Leistungserbringer bzw. Angestellter eines solchen ist, genauso wenig wie eventuelle vertraglich vereinbarte Limits oder das Bestehen von Wartelisten.

Die Frage der Finanzierung von Leistungen an die Empfänger unter sog. gesetzlichem Zwang stellt sich hingegen relativ unkompliziert dar. Die Rechtsprechung des Obersten Gerichts in dieser Sache, wenngleich anfänglich uneinheitlich ${ }^{59}$, stellt sich heute einhellig dar und die verfestig-

57 Oberstes Gericht v. 04.01.2007, V CSK 396/06.

58 Vgl. Kulesza, Glosse zum Urteil SN v. 04.01.2007, V CSK 396/06, Prawo i Medycyna 2008, Nr. 4, S. 119-129.

59 Vgl. Lach, Problem odpłatności (Fn.50), S. 211-217. 
te Ansicht geht dahin, die Kosten der an Versicherte erteilten Leistungen unter dem sog. gesetzlichen Zwang gemäß Art. 56 plZGB ${ }^{60}$ zu den Folgen des zwischen dem Leistungserbringer und dem NFZ geschlossenen Vertrages zu zählen und diese Kosten dem NFZ als Verwalter der öffentlichen Mittel, aus denen diese Ausgaben beglichen werden sollten, aufzuerlegen. Der Leistungserbringer muss gleichwohl zwingend nachweisen, dass im gegebenen Fall eine die genannten gesetzlichen Voraussetzungen erfüllende Notwendigkeit der Erteilung bestimmter Leistungen bestand. ${ }^{61}$ Auch Leistungserbringer, die keine Verträge über die Erteilung von Leistungen der Gesundheitsfürsorge mit dem NFZ geschlossen hatten, haben ein Recht auf Entlohnung für eine einem Leistungsempfänger in einer Notsituation erteilte Leistung der Gesundheitsfürsorge (vgl. Art. 19 Abs. 4 ÖffLG).

Wenn demnach eine Situation des sog. gesetzlichen Zwangs aufkommt, ist der NFZ zur Deckung der Kosten der den Versicherten in Notfällen erteilten Leistungen verpflichtet - auch dann, wenn diese Leistungen nicht vertraglich bestimmt waren, worunter auch ein völliges Fehlen von Verträgen zwischen dem Fonds und dem Träger zu verstehen ist.

Gleichzeitig bleibt zweifelhaft, ob der NFZ auch zur Abdeckung der Kosten von Leistungen an Nichtempfänger verpflichtet ist. Der Gesetzgeber sicherte allen Bedürftigen in akuten Situationen die Möglichkeit die

60 Ein Rechtsgeschäft entfaltet nicht nur die mit ihm angestrebten, sondern auch gesetzlich bestimmte sowie gewohnheitsrechtlich anerkannte und aus den Grundsätzen des sozialen Zusammenlebens abgeleitete Folgen.

61 Vgl. etwa Oberstes Gericht v. 05.08.2004, III CK 365/03, LEX Nr. 276211; v. 15.12.2004, IV CK 361/04, LEX Nr. 258677; v. 10.05.2006, III CSK 53/05, LEX Nr. 258669, v. 13.10.2006, III CSK 123/06. Wichtig ist jedoch an dieser Stelle anzumerken, dass Jończyk diese Ansicht in seiner Glosse zum Urteil des Obersten Gerichts v. 13.07.2005, I CK 18/05 kritisierte. Er stellte fest, dass ein Vertrag über die Erteilung von Leistungen der Gesundheitsfürsorge durch gesetzliche Vorschriften geregelt sei, die als lex specialis den Vorschriften des Zivilgesetzbuches vorgehen und systematisch nicht von untergeordneter Bedeutung gegenüber den Vorschriften des Gesetzes über Anstalten der Gesundheitsfürsorge sind. Jończyk betonte auch, dass das Konzept der Finanzierung von Leistungen durch den NFZ über die vertraglich bestimmten Limits hinaus auf der Grundlage von Vorschriften über den sog. gesetzlichen Zwang keine hinreichende rechtliche Begründetheit vorweist, vgl. Jończyk, Glosse zum Urteil SN v. 13.07.2005, I CK 18/05, OSP 2006, Heft 6, S. 70 ff.; vgl. ferner Daszkiewicz/Daszkiewicz, Podstawy prawne roszczeń o zapłatę za świadczenia medyczne w stanach nagłych, Państwo i Prawo 2006, Heft 1, S. 30-39. 
Erteilung von Hilfe zu, indem er medizinische Dienstleister und Ärzte bezüglich der entsprechenden Gesundheitsfürsorge in die Pflicht genommen hat. Dabei traf er keine konkreten Entscheidungen hinsichtlich der Frage ihrer Finanzierung, was bedeutet, dass die allgemeinen Regeln Anwendung finden: für Berechtigte im System, also Empfänger von aus öffentlichen Mitteln finanzierten Leistungen der Gesundheitsfürsorge, zahlt deren Organisator und Mittelverwalter, während alle anderen Personen die Kosten der erhaltenen Leistungen selbst zu tragen haben und etwaige Ansprüche von Seiten jener Rechtssubjekte, die Leistungen unter den Bedingungen des sog. gesetzlichen Zwangs erbracht haben, an sie gerichtet werden sollten. ${ }^{62}$

\section{Das Abschließen von Verträgen über die Erteilung von Leistungen der Gesundheitsfürsorge}

Das Abschließen von Verträgen über die Erteilung von Leistungen der Gesundheitsfürsorge ist eine Prozedur, in deren Rahmen der NFZ einen Leistungserbringer wählt und mit ihm einen Vertrag über die Erteilung von Leistungen der Gesundheitsfürsorge schließt. ${ }^{63}$

Ein Vertrag über die Erteilung von Leistungen der Gesundheitsfürsorge, der zwischen dem Leistungserbringer und dem Direktor der Wojewodschaftszweigstelle des Fonds geschlossen wird, bildet die Grundlage für die Erteilung von aus den Mitteln des Fonds finanzierten Leistungen der Gesundheitsfürsorge. Ein solcher Vertrag kann ausschließlich mit einem Leistungserbringer geschlossen werden, der nach gesetzlichen Regeln zur Erteilung von Leistungen der Gesundheitsfürsorge ausgewählt worden ist. Insbesondere können Verträge über die Erteilung von Leistungen der Gesundheitsfürsorge nicht mit Ärzten, Krankenschwestern, Hebammen oder anderen Vertretern medizinischer Berufe und ebenso wenig mit Psycholo-

62 Es ist jedoch darauf hinzuweisen, dass das Oberste Gericht die Ansicht vertreten hat, dass in akuten Notfallsituationen eine Übernahme der Kosten für Leistungen an Nichtleistungsempfänger durch den Fonds zu erfolgen hat: Oberstes Gericht, v. 08.08.2007, I CSK 125/07; ähnlich: Nestorowicz: Glosse zum Urteil SN v. 08.08. 2007, I CSK 125/07, Prawo i Medycyna 2008, Nr. 4, S. 113-118; anders: Jończyk: Glosse zum Urteil SN v. 08.08.2007, I CSK 125/07, OSP 2008, H. 7-8, S. 72; vgl. ferner ders.: Glosse zum Urteil SN v. 13.07.2005, I CK 18/05, S. 70 ff. sowie Lach (Fn. 4), S. 186-190.

63 Näheres dazu: Lach, Kontraktowanie (Fn. 28), S. 5-21. 
gen geschlossen werden, wenn sie solche Leistungen für einen Leistungserbringer durchführen, der einen Vertrag über die Erbringung von Leistungen der Gesundheitsfürsorge mit dem Fonds geschlossen hat. Dies ändert jedoch nichts an der Tatsache, dass Leistungserbringer zur Erteilung von Leistungen Subauftragnehmer beauftragen können, solange der jeweilige Vertrag über die Erteilung von Leistungen der Gesundheitsfürsorge eine solche Möglichkeit vorsieht und dies im Rahmen dieser Bestimmungen geschieht.

Ein Vertrag über die Erteilung von Leistungen der Gesundheitsfürsorge bestimmt vor allem: Art und Umfang der erteilten Leistungen der Gesundheitsfürsorge; die Bedingungen der Erteilung solcher Leistungen; die Praxis des Rückgriffs auf Instrumente der Risikoverteilung, von denen in Art. 11 Abs. 5 des Erstattungsgesetzes die Rede ist und die das gegebene Arzneimittel oder Lebensmittel, das für eine besondere Ernährung bestimmt ist, betreffen; das Verzeichnis der Subauftragnehmer und alle an sie gestellten Anforderungen (mit Ausnahme der technischen und sanitären Anforderungen), wie sie in speziellen Vorschriften bestimmt sind; die Abrechnungsregeln zwischen Fonds und Leistungserbringern; die Regeln zur Entscheidung über Streitfälle; eine Klausel über die Kündigung des Vertrages, die mit einer mindestens 3-monatigen Frist erfolgen darf, es sei denn die Parteien vereinbaren etwas anderes; eine Klausel über Vertragsstrafen im Falle der frist- oder vertragswidrigen Kündigung sowie, am wichtigsten: Die Höhe der Forderung des Leistungserbringers gegenüber dem Fonds.

In Sachen des Verfahrens zum Abschluss von Verträgen bestimmt das Gesetz eindeutig einen Ausschluss der Anwendung von Vorschriften des Vergaberechts. Das Gesetz sieht drei unterschiedliche Verfahrensarten zum Abschluss von Verträgen über die Erteilung von Leistungen der Gesundheitsfürsorge vor: Ausschreibungen, Vertragsverhandlungen und den Abschluss von Verträgen zu vom Fondsleiter bestimmten Bedingungen. Es ist dabei anzumerken, dass es grundsätzlich keinen Kontrahierungszwang gibt, wobei natürlich im Auge behalten werden muss, dass der Fonds seine Pflichten zu erfüllen hat und hinsichtlich der Leistungserbringer der Umstand zu berücksichtigen ist, dass der private Markt der Gesundheitsleistungen einen sehr begrenzten Umfang hat und manche Anbieter ohne öffentliche Mittel nicht auskommen würden. ${ }^{64}$ 
Im Hinblick auf die Ausschreibung gilt es vor allem, die Transparenz des Verfahrens hervorzuheben, die mit der Veröffentlichung der Aufforderung unter Angabe von insbesondere dem Wert und dem Gegenstand des Auftrags einhergeht. Verfahren zum Abschluss von Verträgen über die Erteilung von Leistungen der Gesundheitsfürsorge führt der vom Direktor der Wojewodschaftszweigstelle des Fonds bestellte Ausschuss durch. Die Ausschreibung besteht aus einem öffentlichen und einem nichtöffentlichen Teil. Im öffentlichen Teil bestätigt der Ausschuss in Anwesenheit der Bietenden die Richtigkeit der Verkündung der Ausschreibung und die Anzahl der vorgelegten Angebote und führt die sonstigen Formalitäten durch. Im nichtöffentlichen Teil der Ausschreibung kann der Ausschuss ein oder mehrere Angebote wählen, die eine Kontinuität und Komplexität der erteilten Leistungen der Gesundheitsfürsorge sowie die ihre Zugänglichkeit gewährleisten und das günstigste Preis-Leistungs-Verhältnis in Bezug auf den Angebotsgegenstand vorweisen, oder auch gar kein Angebot wählen, wenn keines der vorliegenden Angebote auf eine angemessene Erteilung der ausgeschriebenen Leistungen der Gesundheitsvorsorge schließen lässt. Weil letztgenannte Möglichkeit vor allem Situationen betreffen wird, in denen die Angebote unvereinbar mit den im Finanzplan für die bestimmten Leistungen vorgesehenen Mitteln bleiben, bestimmt das Gesetz, dass der Ausschuss im nichtöffentlichen Teil der Ausschreibung mit den Bietenden über die Zahl der zur Erteilung vorgesehenen Leistungen der Gesundheitsfürsorge oder den Preis für ihre Erteilung nachverhandelt. Die Kommission ist dabei verpflichtet, diese Gespräche mit mindestens zwei der ursprünglich bietenden Parteien durchzuführen, sofern überhaupt mehr als ein einziges Angebot eingegangen ist.

Unter dem Begriff Verhandlungen versteht man hingegen ein Verfahren zum Abschluss von Verträgen über die Erteilung von Leistungen der Gesundheitsfürsorge, bei dem das Verfahren über die Bestimmung von Preisen und die Anzahl der Leistungen sowie die Bedingungen ihrer Erteilung mit einer so großen Anzahl von Leistungserbringern ausgehandelt wird, dass die Auswahl des günstigsten Angebots oder der größten Zahl der Angebote sowie eine gescheite Durchführung der Verhandlungen gewährleistet ist, wobei nicht weniger als drei Bieter beteiligt werden sollten. Etwas anderes gilt nur, wenn wegen des speziellen Charakters der gesuchten Leistungen der Gesundheitsfürsorge oder ihrer eingeschränkten Zugänglichkeit eine kleinere Zahl von Bietern überhaupt imstande ist, die Leistungen zu erbringen. Der Abschluss von Verträgen über die Erteilung von Leistungen der Gesundheitsfürsorge ergeht nach diesem Verfahren einzig 
in einem der drei gesetzlich vorgesehenen Fälle: Erstens: Das davor durchgeführte Ausschreibungsverfahren scheiterte wegen Nichtigkeit und die einzelnen Voraussetzungen des Verfahrens zum Vertragsschluss entsprechen genau denen der Ausschreibung; zweitens: es besteht ein unvorhergesehenes dringendes Bedürfnis zum Abschluss von Verträgen über die Erteilung von Leistungen der Gesundheitsfürsorge oder drittens: die Zahl der Leistungserbringer, welche imstande wären, die vertraglich geforderten Leistungen zu erbringen, ist beschränkt auf nicht mehr als fünf. Wegen der Natur dieser Umstände sieht das Gesetz vor, dass der Fonds zum Zwecke der Durchführung von Verhandlungen nach der Veröffentlichung einer entsprechenden Verkündung einzelne Einladungen an die konkreten Leistungserbringer richtet, wobei jedoch im Falle, dass eine eingehend stattgefundene Ausschreibung für nichtig erklärt worden ist, zu den Verhandlungen einzig die Leistungserbringer einzuladen sind, deren Angebote in der nichtigen Ausschreibung nicht abgelehnt worden sind. Ähnlich der Organisation der Ausschreibungen werden auch Verhandlungen in einen öffentlichen und einen nichtöffentlichen Abschnitt geteilt.

In Bezug auf beide Verfahren sieht das Gesetz dieselben Bewertungskriterien für Angebote vor: Kontinuität, Komplexität, Zugänglichkeit, Qualität von erteilten Leistungen, qualifiziertes Personal, Ausstattung mit Geräten und medizinischer Apparatur, interne und externe Bewertungen, die mit einem Qualitätszertifikat oder einer Akkreditierung bestätigt werden können, Preis und Anzahl der angebotenen Leistungen der Gesundheitsfürsorge sowie Kostenkalkulationen. Die Kriterien für die Bewertung von Angeboten und die an die Bieter gestellten Anforderungen sind öffentlich und müssen im Verlauf der Verhandlungen unverändert bleiben.

Auf Verträge über die Erteilung von Leistungen der Gesundheitsfürsorge sind die Vorschriften des Zivilgesetzbuchs anwendbar, wobei das Gesetz an gewissen Stellen spezielle Regelungen enthält. So kann ein Vertrag über die Erteilung von Leistungen der Gesundheitsfürsorge für nichtig erklärt werden, wenn er mit einem Bieter geschlossen worden ist, dessen Angebot aus im Gesetz genannten Gründen abgelehnt worden ist oder der Vertrag auf der Grundlage eines Verfahrens geschlossen wurde, dass im Nachhinein für nichtig erklärt worden ist. Der Vertrag ist überdies in dem Teil nichtig, der über den Gegenstand des Verfahrens zu seinem Abschluss hinausgeht. Es gilt das Schriftformerfordernis unter Androhung der Nichtigkeit. Des Weiteren ist für die Übertragung von Rechten und Pflichten aus dem Vertrag auf einen Dritten, wenn der Vertrag über die Erteilung von Leistungen der Gesundheitsvorsorge nichts anderes vor- 
sieht, das schriftliche Einverständnis des Direktors der Wojewodschaftszweigstelle des Fonds erforderlich. Ein Vertrag über die Erteilung von Leistungen der Gesundheitsvorsorge kann nicht auf eine unbestimmte Zeit geschlossen werden. Darüber hinaus kann eine Geltung für mehr als drei Jahre nicht ohne Einverständnis des Fondsleiters vereinbart werden. Gleichwohl bestimmt das Gesetz, dass die Vertragsdauer dann verlängert werden kann, wenn das Risiko einer fehlenden Absicherung der fortlaufenden Erteilung von Leistungen der Gesundheitsfürsorge besteht, aber auch in diesem Fall um höchstens sechs Monate. Wenn hingegen keine Absicherung der fortlaufenden Erteilung von Leistungen der Gesundheitsfürsorge möglich ist, obwohl die Leistungen im gegebenen Bereich von einem Leistungserbringer auf einem konkreten Gebiet durchgeführt worden sind, kann der Direktor der Wojewodschaftszweigstelle des Fonds einen Vertrag über die Erteilung von Leistungen der Gesundheitsfürsorge, der mit einem Leistungserbringer für denselben Bereich auf einem benachbarten Gebiet geschlossen worden ist, ändern. Auch in diesem Fall ist keine Verlängerung um mehr als 6 Monate möglich. In beiden Fällen erfordert die Vertragsänderung die Einholung einer Zustimmung von Seiten des Fondsleiters. Der Direktor der Wojewodschaftszweigstelle des Fonds ist zu einer unverzüglichen Durchführung eines Verfahrens über den Abschluss eines Vertrages über die Erbringung von Leistungen der Gesundheitsfürsorge im Bereich von bisher vertraglich bestimmten Leistungen verpflichtet, wenn die Geltungsfrist eines solchen Vertrages verlängert worden ist, soweit ein solches Verfahren nicht bereits eingeleitet oder beendet wurde.

Ferner ist anzumerken, dass in Fällen, in denen ein Vertrag über die Erteilung von Leistungen der Gesundheitsfürsorge mit einer über einjährigen Frist geschlossen wird, sich ein Leistungserbringer für die gesamte Vertragslaufzeit nicht für den Abschluss neuer Verträge über die Erteilung von solchen Leistungen in demselben Bereich und dasselbe Rechtssubjekt betreffend bewerben darf.

Bei der Änderung von Verträgen finden die Vorschriften über das Vertragsschlussverfahren in Bezug auf Leistungen der Gesundheitsfürsorge keine Anwendung. Um jedoch Änderungen vorzubeugen, die dem Sinn der gesamten Vertragsschlussprozedur widersprechen, bestimmt das Gesetz, das Änderungen von bereits geschlossenen Verträgen nichtig sind, wenn sie Vertragsbedingungen betreffen, die bei der Wahl des Vertragspartners einer Bewertung unterlagen, es sei denn, die Notwendigkeit der 
Durchführung solcher Änderungen geht aus Umständen hervor, die sich zum Zeitpunkt des Vertragsschlusses nicht vorhersehen ließen.

Neben der Ausschreibung einerseits und Verhandlungen andererseits sieht das Gesetz ein weiteres Vertragsschlussverfahren vor, welches sich jedoch ausschließlich auf Verträge über die Erbringung von Leistungen der gesundheitlichen Grundfürsorge bezieht, wenngleich mit einigen Ausnahmen: Der Gesundheitsfürsorge während der Nacht und an Feiertagen; der Durchführung von Tätigkeiten im Bereich der Belieferung mit medizinischen Erzeugnissen im Auftrag einer berechtigten Person sowie für Verträge über die Herausgabe von erstattungsfähigen rezeptpflichtigen Arzneimitteln, Lebensmitteln, die für eine besondere Ernährung bestimmt sind, und medizinischen Erzeugnissen durch Apotheken (Verträgen über das Einlösen ärztlicher Verschreibungen) und für Verträge mit einer Bevollmächtigung zu erstattungsfähigen Verschreibungen. Verträge über die Einlösung von Rezepten und die Erteilung von Berechtigungen werden zu Bedingungen geschlossen, die das Erstattungsgesetz präzisiert, während im Bereich der gesundheitlichen Grundfürsorge und der Belieferung mit medizinischen Erzeugnissen Verträge mit jedem Leistungserbringer geschlossen werden, der die vom Leiter aufgestellten Bedingungen erfüllt. Der Direktor einer Woiwodschaftszweigstelle des Fonds veröffentlicht Informationen über die Bedingungen, die für einen Vertragsschluss erfüllt werden müssen ${ }^{65}$ auf der Website der gegebenen Zweigstelle und an ihrem Sitz.

Die einzelnen Verträge sind dann eindeutig ${ }^{66}$ privatrechtliche Schuldverträge, wobei natürlich bestimmte Besonderheiten des Marktes der Gesundheitsleistungen zu berücksichtigen sind. Vor allem ist der Wettbewerb in der Praxis stark begrenzt. Der Markt ist sehr geregelt, etwa durch öffentlich-rechtliche Normen betreffend beispielsweise die Ausführung der medizinischen Tätigkeit, Ausübung der medizinischen Berufe u.a. Der Nationale Gesundheitsfonds genießt die Position eines Monopolisten, gleichzeitig sind aber bestimmte Leistungserbringer hochqualifiziert und derart spezialisiert, dass sie zumindest als "Quasi-Monopolisten“ bezeichnet werden können

65 Zur Prozedur der Bestimmung, ,allgemeiner Vertragsbedingungen bei Verträgen über die Erteilung von Leistungen der Gesundheitsfürsorge" vgl. Lach (Fn. 4), S. 254-258.

66 Vgl. z.B. Oberstes Gericht v. 13.05.2005, I CK 691/04. 
Angesichts der Vielzahl und Vielfältigkeit von Verträgen zwischen dem NFZ und den einzelnen Leistungserbringern dient der Katalog der garantierten Leistungen der landesweiten Vereinheitlichung des Umfangs und der Bedingungen der vertraglichen Leistungen, welche im Rahmen des Systems garantierte Gesundheitsfürsorge ausmachen. Lokale Umstände, wie sie aus staatlichen Analysen (Art. 6-11 ÖffLG) ${ }^{67}$ von Gesundheitsbedürfnissen und vom Gesundheitszustand der Bürger hervorgehen, werden natürlich einen Einfluss auf den Umfang und die Vertragsbedingungen haben, insbesondere bezüglich der Betrags- und Mengenbeschränkungen in den einzelnen Verträgen. Die Spezifik des Marktes für medizinische Dienstleistungen wirkt sich hingegen auf das Preisniveau aus. Nichtsdestotrotz ergibt sich der Umfang von Leistungen der Gesundheitsfürsorge aus Verordnungen, die den Katalog der garantierten Leistungen definieren. Eine solche Lösung dient dazu, die Gefahr des Auftretens regional bedingter Unterschiede im Umfang der garantierten Fürsorge auszuschließen und im Ergebnis den Grundsatz des gleichen Zugangs zu Leistungen der Gesundheitsfürsorge in ihrem gegenständlichen Bereich zu gewährleisten. ${ }^{68}$

\section{Finanzierung von Leistungen der Gesundheitsfürsorge}

\section{Gesundheitsversicherungsbeiträge und ihre Rechtsnatur}

Ein Beitrag der Gesundheitsversicherung ist eine Geldleistung zulasten der Versicherten im System der Gesundheitsfürsorge, die in den vom NFZ verwalteten Fonds zur Finanzierung von garantierten Leistungen fließt.

Die Höhe des Gesundheitsversicherungsbeitrags beträgt grundsätzlich $9 \%$ der Bemessungsgrundlage, wenngleich einige Ausnahmen bestehen (z.B. für Landwirte ${ }^{69}$ ). Wenn der Versicherte sein Einkommen aus mehr als einem Versicherungstitel erzielt bzw. wenn im Rahmen eines Titels mehrere Einkommensquellen bestehen, wird der Beitrag für die Gesundheitsversicherung aus jedem dieser Titel einzeln entrichtet. Man kann in

67 Vgl. Lach, Władza publiczna a system opieki zdrowotnej in: Hajn/Skupień, (Hrsg.),Przyszłość prawa pracy. Liber Amicorum. W pięćdziesięciolecie pracy naukowej Profesora Michała Seweryńskiego, Lodz 2015, S. 775-787.

68 Vgl. Lach (Fn. 4), S. 258.

69 Vgl. VerfGH v. 26.10.2010, K 58/07. 
diesem Sinne von einem allgemeinen Beitrag als Grundsatz sprechen - er belastet alle Einkünfte aus sämtlichen Grundlagen für Pflichtversicherungsverhältnisse. Trotzdem wird der Beitrag im Falle eines Zusammenlaufens mehrerer Versicherungstitel nur dann aus der Staatskasse bezahlt $^{70}$, wenn überhaupt kein anderer Versicherungstitel besteht. Der Versicherte ist dann dazu verpflichtet, den Beitragszahler über die Entrichtung seiner Beiträge aus anderen Versicherungstiteln zu benachrichtigen. Zudem wird im Falle eines Zusammenlaufens von verschiedenen Versicherungstiteln, bei denen die Staatskasse jedes Mal für die Beiträge aufzukommen hätte, lediglich der Beitrag aus dem Titel bezahlt, welcher als erstes entstanden ist. Wenn beide Titel zur selben Zeit entstanden sind, werden die Beiträge aus dem ersten angemeldeten Titel vom Staat übernommen.

Sonderregeln betreffen insbesondere die Befreiung bestimmter Gruppen von der Beitragspflicht, z.B. sind Selbstständige mit unterhalb dem Mindestlohn liegenden monatlichen Rentenbezügen oder einer mittleren bzw.

70 Die Entrichtung von Beiträgen aus dem Staatshaushalt betrifft allein gesetzlich bestimmte Ausnahmesituationen (Art. 86 ÖffLG), wobei die Beiträge entweder unmittelbar aus dem Staatsaushalt oder durch gesetzlich bestimmte Zahler überwiesen werden, die zu diesem Zweck entsprechend hohe Zuschüsse aus dem Staatshaushalt erhalten (z.B. der Kirchenfonds und Einheiten der territorialen Selbstverwaltung). Vgl. Baka/Machulak/Pietraszewska-Macheta/Sidorko, Ustawa o świadczeniach opieki zdrowotnej finansowanych ze środków publicznych. Komentarz, ABC, Warschau 2010, Kommentar zu Art. 86 pkt 1-4. Es stellt sich demnach die Frage, ob die Gewährleistung ,eines gleichen Zugangs zu aus öffentlichen Mitteln finanzierten Leistungen der Gesundheitsfürsorge" durch die öffentliche Gewalt gegenüber bestimmten Rechtssubjekten im Wege ihrer Einschließung in die Risikogemeinschaft unter gleichzeitigem Ausschluss der Beitragspflicht (aus Gründen eines nicht ausreichenden Einkommens) mit dem aus Art. 68 Abs. 2 der polnischen Verfassung abgeleiteten Grundsatz vereinbar ist. Im Zusammenhang mit den Sozialversicherungen wies B. Wagner auf dieses Problem hin und merkte an, dass vom Gesichtspunkt der Gleichheit der Versicherten Zweifel darüber entstehen können, ob die Entrichtung von Beiträgen aus dem Staatshaushalt für bestimmte Versicherte nicht mittelbar - durch das Steuersystem - zur Umlegung dieser Last auf Versicherte, die ihre Beiträge aus eigenen Mitteln zahlen, bedeutet. Vgl. Wagner, Równość w ubezpieczeniach społecznych in: Wagner (Hrsg.), Prawo pracy u progu XXI wieku. Stare problemy i wyzwania współczesności. Materiały z XIII Ogólnopolskiego Zjazdu Katedr i Zakładów Prawa Pracy, Białystok 21-22. September 2001, Białystok 2001, S. 72; sowie Wagner, Zasada równego traktowania w ubezpieczeniu chorobowym in: Wagner/Malaka (Hrsg.), Ubezpieczenia chorobowe, Bad Iwonicz 2010, S. 16 ff. 
schweren Behinderung, deren (nichtlandwirtschaftliche) Tätigkeit oder deren Zusammenarbeit mit Unternehmern die Entstehung eines Versicherungstitels begründet, von der Beitragspflicht befreit, wenn ihre zusätzlichen Einkünfte aus der Tätigkeit bzw. Zusammenarbeit monatlich $50 \%$ der Höhe der Mindestaltersrente nicht überschreiten oder wenn diese Personen ihre Einkommensteuer in Form einer Steuerkarte entrichten. Ferner schränkt das Gesetz die Höhe des zu zahlenden Beitrags dann ein, wenn die Versicherungspflicht eine mittel- oder schwerbehinderte Person betrifft, die ihr Einkommen ausschließlich aus einer (nichtlandwirtschaftlichen) selbstständigen Tätigkeit oder Zusammenarbeit mit einem Unternehmer erzielt. Der Gesundheitsversicherungsbeitrag wird in diesem Fall in einer Höhe bezahlt, die der einer gebührenden Anzahlung auf die Einkommensteuer für natürliche Personen gleicht. Eine weitere Sondervorschrift betrifft Geistliche. Wenn demnach eine geistliche Person kein Steuerzahler der pauschalen Einkommensteuer für die Einkünfte geistiger Personen ist und ein Einkommen aus im Gesetz genannten Quellen erzielt, ist für die Gesundheitsversicherung einzig ein Beitrag auf der Grundlage dieser Einkünfte zu zahlen.

Der Beitrag ist monatlich zu entrichten. Dies bedeutet, dass die Zahler von Beiträgen der Gesundheitsversicherung (z.B. nichtlandwirtschaftlich selbstständig Tätige, freiwillig Versicherte) und Personen, die für Versicherte Beiträge entrichten (z.B. der Arbeitgeber für seine Arbeitnehmer, der Auftraggeber für seine Auftragnehmer, das Rentenorgan für die Rentner) dazu verpflichtet sind, anfallende Beiträge für die Gesundheitsversicherung ohne vorherige Aufforderung für jeden Kalendermonat nach den für Sozialversicherungen vorgesehenen Verfahren, Grundlagen und Fristen $\mathrm{zu}$ entrichten. Im Falle einer Unanwendbarkeit der sozialversicherungsrechtlichen Vorschriften auf die gegebenen natürlichen oder juristischen Personen muss die Zahlung hingegen bis zum 15. Tag des darauffolgenden Monats ${ }^{71}$ erfolgen.

Der Beitrag ist überdies „unteilbar“. Der Grundsatz der Unteilbarkeit des Beitrags betrifft in erster Reihe Personen, die eine (nichtlandwirtschaftliche) selbstständige Tätigkeit führen. Bei ihnen stellen nicht etwa die tatsächliche erlangten Einnahmen die Bemessungsgrundlage für die Beiträge der Gesundheitsversicherung dar, sondern der Betrag aus ihrer eigenen Erklärung, der jedoch $75 \%$ des durchschnittlichen monatlichen

71 Vgl. Baka [et al.] (Fn.70), Kommentar zu Art. 79 Pkt. 5. 
Einkommens im Unternehmenssektor im vierten Quartal des Vorjahres nicht unterschreiten kann. ${ }^{72}$ Die Unteilbarkeit des Beitrags bedeutet, dass diese Versicherten sowohl dann denselben Beitrag zahlen werden, wenn sie über den gesamten Monat versichert bleiben, als auch dann, wenn sie dies lediglich über einige Tage des Monats sind (etwa weil sie ihre Tätigkeit erst während des Monats aufgenommen haben). Ähnlich verhält es sich bei Personen, deren Beiträge z.B. auf der Grundlage eines Betrags, der in seiner Höhe einer nach dem Gesetz vom 28. November 2003 über Familienleistungen erteilten Pflegeleistung entspricht, bemessen werden, obwohl die gegebene Person keine solche Leistungen empfängt. (Eine solche Bemessungsgrundlage wurde z.B. für Schüler und Studierende, für die auch sonst keine Grundlage zur Pflichtversicherung besteht, oder für Personen im Erziehungsurlaub, die ebenfalls aus keinem anderen Grund versicherungspflichtig sind, herangezogen). Für diese Personen werden Beiträge in derselben Höhe von den gesetzlich dazu verpflichteten Rechtssubjekten bezahlt, unabhängig davon, wie lange der konkrete Versicherte auf der gegebenen Grundlage versichert gewesen ist (den ganzen Monat lang oder lediglich über einige Tage des gegebenen Monats).

In Sachen der Beitragsbemessungsgrundlage ist - unter Berücksichtigung der Vielzahl und Vielfalt der verschiedenen Versicherungstitel zwischen drei Gruppen von Versicherten zu unterscheiden.

Für die erste bestimmt die gesetzliche Regelung als Beitragsbemessungsgrundlage einerseits die tatsächlich erzielten Einnahmen, in Gestalt von Lohn oder sonstigen Vergütungsbestandteilen im Beschäftigungsverhältnis (Arbeitsvertrag bzw. zivil-, verwaltungsrechtlicher oder der Staatsorganisation zuzuordnender Vertrag), andererseits Leistungen, die auf der Grundlage sozialrechtlicher Vorschriften (Alters- und Arbeitsunfähigkeitsrenten, Stipendien, Zuschüsse) ausgezahlt wurden. Bei der Bestimmung der Höhe des Gesundheitsversicherungsbeitrags bleiben jedoch außer Betracht: Erstens der Lohnausfall für die Zeit der Arbeitsunfähigkeit wegen Krankheit oder infektionskrankheitsbedingter Quarantäne und zweitens Einschränkungen gemäß Art. 19 Abs. 1 des Sozialversicherungsgesetzes, d.h. die Beschränkung der jährlichen Höchstbemessungsgrundlage auf das 30-fache des prognostizierten durchschnittlichen monatlichen Einkom-

72 Vertiefend zu diesem Problem Lach, Zasada równości a równy dostęp do świadczeń opieki zdrowotnej aspekcie finansowym w kontekście składek na „ubezpieczenie zdrowotne" in: Niedbała (Hrsg.), Prawo wobec dyskryminacji w życiu społecznym, gospodarczym i politycznym, Warschau 2011, S. 158-169. 
mens in der nationalen Wirtschaft für das gegebene Kalenderjahr (Beitragsbemessungsgrenze).

Die zweite Gruppe von Versicherten stellen Personen dar, für die zur Bemessung der Höhe ihrer Beiträge die Höhe der empfangenen Leistungen herangezogen werden kann, wohingegen das Gesetz in Situationen, in denen diese Personen wegen Zeitablaufs oder aus gesetzlich bestimmten Gründen ihr Leistungsrecht verloren haben, die rechtliche Fiktion der Anerkennung eines der Höhe dieser Leistungen entsprechenden Betrags als Beitragsbemessungsgrundlage konstruiert. Diese Vorschriften betreffen z.B. arbeitslose Personen.

Es lässt sich schließlich auch eine dritte - sehr mannigfaltige - Gruppe von Rechtssubjekten hervorheben, bei denen zur Bemessung der Höhe ihres Gesundheitsversicherungsbeitrags von der Heranziehung der von ihnen erzielten (oder auch nicht erzielten) Einkünfte gänzlich abgesehen wird. Die größte Gruppe dieser Versicherten stellen Personen da, die eine nichtlandwirtschaftliche selbstständige Tätigkeit ausüben oder mit diesen Personen zusammenarbeiten. In Bezug auf diese Personen regelt das Gesetz die Beitragsbemessungsgrundlage gänzlich anders, als dies bei den anderen beiden Gruppen der Fall war, und erweckt dabei größte Bedenken im Hinblick auf den Grundsatz des gleichen Zugangs zur Gesundheitsfürsorge. Ihre Grundlage stellt, wie bereits erwähnt, ein vom Versicherten erklärter Betrag dar, der $75 \%$ des durchschnittlichen monatlichen Einkommens im Unternehmenssektor im vierten Quartal des Vorjahres einschließlich Gewinnauszahlungen nicht unterschreiten kann. Das durchschnittliche Monatseinkommen wird durch den Vorsitzenden des Hauptamts für Statistik im Amtsblatt der Republik Polen „Monitor Polski“" veröffentlicht. Dies bedeutet, dass die Fragen, ob der betrachtete Unternehmer überhaupt Einnahmen erzielt hat bzw. in welcher Höhe, grundsätzlich irrelevant sind. Sollte nämlich eine wirtschaftliche Tätigkeit Verluste bringen, hat der Unternehmer gleichwohl die Pflicht, im System zu bleiben und Beiträge im gesetzlich festgesetzten minimalen Umfang zu zahlen.

Bezüglich der Frage der Rechtsnatur der Beiträge muss darauf hingewiesen werden, dass keine, gelegentlich in Bezug auf Sozialversicherungen geforderte ${ }^{73}$, privatrechtliche Gegenseitigkeit von gezahlten Beiträgen

73 Vgl. Szubert, Ubezpieczenie społeczne. Zarys systemu, Warschau 1987, S. 217; andere Ansicht vgl. Zieliński, Ubezpieczenia społeczne pracowników. Zarys systemu prawnego - Teil ogólna, Warschau - Krakau 1994, S. 189 f.; ebendieser, „Zasady” w teorii i prawie ubezpieczeń społecznych, in: Szurgacz (Hrsg.), Polskie 
und im Gegenzug erhaltene Garantien der Gesundheitsfürsorge gegeben sind. Dies ist nicht nur deswegen der Fall, weil das dem System zugrunde liegende Prinzip der sozialen Solidarität bewirkt, dass der Beitrag des Versicherten in keinem Verhältnis zu seinem individuellen Risiko eines Gesundheitsmangels (bedingt durch den aktuellen Gesundheitszustand, Alter, Geschlecht usw.) steht, sondern auch, weil jedem Versicherten Leistungen nach dem Kriterium seiner individualisierten Bedürfnisse, welches wiederum mit dem im gegebenen Fall verwirklichten Risiko eines Gesundheitsmangels einhergeht, zugesprochen werden. Die entscheidende Bedeutung kommt jedoch der fehlenden Verbindung zwischen dem Erwerb von Leistungsrechten (dem Einschluss in die gesetzliche Garantie) und der Pflicht zur Beitragszahlung zu (vgl. oben 3.c.). Der Gesetzgeber unterscheidet nämlich die „Erfüllung der Versicherungspflicht“, die mit der Anmeldung und der Entrichtung der Beiträge gegeben ist, von dem „Erwerb des Rechts auf Leistungen der Gesundheitsfürsorge“, dessen einzige Voraussetzung in der Erfüllung der Meldepflicht besteht. Das Unterbleiben von Beitragszahlungen wirkt sich in keiner Weise auf den Umfang der Gewährleistung im Rahmen des Systems aus, geschweige denn berührt es das Recht auf aus öffentlichen Mitteln finanzierte Leistungen der Gesundheitsfürsorge. Aus diesem Grund ist die Gegenseitigkeit von Leistungen des Versicherungsbeitrags und der Gewährleistung im Rahmen des Systems - in Gestalt eines synallagmatischen Verhältnisses nach Art. 487 ZGB, nach dem die eine Leistung der anderen zu entsprechen hat, in dieser Beziehung offensichtlich unanwendbar. Folglich lassen die Leistungen sich auch nicht auf eine etwaige Äquivalenz hin untersuchen, da eine Bewertung der Gleichwertigkeit von Leistungen nicht möglich ist, wenn zwischen ihnen kein Gegenseitigkeitsverhältnis nach dem do ut des- Prinzip besteht.

Dennoch sind Beitrag und Gewährleistung im Rahmen des Systems insoweit als gleichwertig anzusehen, dass sie jedem Berechtigten denselben Umfang und Standard von Leistungen, ungeachtet der Höhe der von ihnen entrichteten (oder auch nicht entrichteten) Beiträge, zusprechen. Die Gleichwertigkeit von Beitrag und Leistung i.S.e. Befreiung des Umfangs der gesetzlichen Gewährleistung von den bezahlten Beiträgen geht auf das Solidarprinzip zurück, welches mitunter in der Kollektivierung individuel-

Stowarzyszenie Ubezpieczenia Społecznego, Problemy ubezpieczenia spolecznego, Breslau 1988, S. 28; sowie Jędrasik-Jankowska, Pojęcia i konstrukcje prawne w ubezpieczeniach społecznych, Kielce 1998, S. 28. 
ler Risiken seinen Ausdruck findet. Die Vergemeinschaftung von Risiken führt ferner zum Verzicht auf die individuelle Äquivalenz zugunsten einer allgemeinen Gleichwertigkeit von Beitrag und Garantie im Rahmen des Systems. ${ }^{74}$ Vom Standpunkt des Rechnungswesens aus bedeutet die finanzielle Autonomie des Systems außerdem, dass man grundsätzlich von einer globalen ${ }^{75}$ oder kollektiven ${ }^{76}$ Äquivalenz (Grundsatz der Kostendeckung ${ }^{77}$ ) sprechen kann, da der alljährliche Finanzplan des Fonds im Hinblick auf seine Einkünfte und Ausgaben ausgewogen sein muss. Während die Haupteinnahmequelle des Fonds in den Beiträgen der Gesundheitsversicherung zu sehen ist, stellen die Kosten der Leistungen der Gesundheitsfürsorge die Hauptausgaben dar (vgl. oben II.3.).

Zusammenfassend lässt sich feststellen, dass ein Gesundheitsversicherungsbeitrag eine eng mit der Einkommensteuer natürlicher Personen verbundene Zwecksteuer sui generis zur Erhaltung der Gesundheitsfürsorge darstellt. ${ }^{78}$

\section{Die Beteiligung der Leistungsempfänger an den Kosten der Gesundheitsfürsorge}

Eine (Eigen-)Beteiligung eines Leistungsempfängers an den Kosten der Gesundheitsfürsorge ist eine von ihm erbrachte Geldleistung im Rahmen

74 Vgl. Lach, O solidarności społecznej w „ubezpieczeniu zdrowotnym” in: Skapski/ Ślebzak (Hrsg.), Aksjologiczne podstawy prawa pracy i ubezpieczeń społecznych, Posen 2014, S. 271-285.

75 Vgl. BVerfGE 76, 220, $236 \mathrm{ff}$.

76 Vgl. z.B. Krejci, Das Sozialversicherungsverhältnis, Wien 1977, S. 119.

77 Vgl. Kirchhof, Das Solidarprinzip im Sozialversicherungsbeitrag, in: Schulin (Hrsg.), Sozialfinanzverfassung: 5. Sozialrechtslehrertagung 6. bis 8. März 1991 in Göttingen, Wiesbaden 1992, S. 73.

78 Vertiefend zur Problematik der Rechtsnatur von Beiträgen Składki und zu der Kritik der gesetzlichen Lösungen vgl. Jończyk, Prawa pacjenta i odpowiedzialność za szkodę z leczenia, Prawo i Medycyna 1999, Nr. 2, S. 30; ebendieser, Ubezpieczenie zdrowotne, Praca i Zabezpieczenie Społeczne 2003, Nr. 4, S. 2-8; ders., Składka na ubezpieczenie zdrowotne, Praca i Zabezpieczenie Społeczne 2007, Nr. 8, S. 2-7; Lach, Zasada równości (Fn. 4), S. 307-336; Iżycka-Raczka, Składki na ubezpieczenie zdrowotne, Przegląd Ubezpieczeń Społecznych i Gospodarczych Nr. 1999, Nr. 6, S. 26-29; Malanowski, Ubezpieczenia zdrowotne - znaki zapytania i wątpliwości, Przegląd Ubezpieczeń Społecznych i Gospodarczych 1999, Nr. 5, S. 13-15. 
des Systems der Gesundheitsfürsorge, die mit der Nutzung von bestimmten garantierten Leistungen einhergeht.

Der Gesundheitsversicherungsbeitrag ist nicht die einzige mit der Nutzung von garantierten Leistungen im System der Gesundheitsfürsorge verbundene Geldleistung des Empfängers. Die Pflicht ihrer Zahlung trifft die Versicherten (bis auf gesetzliche Ausnahmen) unabhängig davon, ob (und gegebenenfalls inwiefern) sie auf die garantierte Fürsorge zurückgreifen oder nicht und stellt in diesem Sinne den „Preis“ für die Teilnahme am System dar. Derweil bedeutet der Zugang zu Leistungen der Gesundheitsfürsorge für Mitglieder (berechtigte Leistungsempfänger) nicht nur den Zugang zum System selbst, sondern auch den zur Gesundheitsfürsorge. Neben Beiträgen sieht das polnische System der Gesundheitsfürsorge ebenfalls die Pflicht des Leistungsempfängers zur Tragung der Kosten für ausgewählte Leistungen in der Verwirklichungsphase vor. Die Gesetze (über aus öffentlichen Mitteln finanzierte Leistungen der Gesundheitsfürsorge und über die Erstattung von Arzneimitteln, Lebensmitteln, die für eine besondere Ernährung bestimmt sind, und medizinischen Erzeugnissen) mitsamt der entsprechenden Durchführungsverordnungen regeln die „Teilentgeltlichkeit“ in Bezug auf: Kurbehandlungen und die Nutzung von Krankentransporten sowie die Grundsätze, Voraussetzungen und Verfahren über die Erteilung von Bescheiden über die Erstattung von Arzneimitteln, Lebensmitteln, die für eine besondere Ernährung bestimmt sind, medizinischen Erzeugnissen und die Aufhebung von solchen Bescheiden; die Grundsätze der Finanzierung von Arzneimitteln, Lebensmitteln, die für eine besondere Ernährung bestimmt sind, und medizinischen Erzeugnissen; die Kriterien zur Schaffung von Entgeltstufen und Gruppen von limitierten Arzneimitteln, Lebensmitteln, die für eine besondere Ernährung bestimmt sind, und medizinischen Erzeugnissen; die Grundsätze und Verfahren sowie Kriterien der Bestimmung von amtlichen Verkaufspreisen für Arzneimittel, Lebensmittel, die für eine besondere Ernährung bestimmt sind, und medizinische Erzeugnisse, wie auch die Höhe der amtlichen Margen für Groß- und Kleinhandel; die Grundsätze zur Bestimmung von Preisen für im Rahmen der Erteilung von garantierten Leistungen verwendete Arzneimittel und Lebensmittel, die für eine besondere Ernährung bestimmt sind, sowie die Grundsätze der Finanzierung von medizinischen Erzeugnissen, die den Leistungsempfängern aufgrund eines Auftrags einer berechtigten Person zustehen, aus öffentlichen Mitteln.

In Bezug auf Kurbehandlungen ist darauf hinzuweisen, dass die Kostenbeteiligung von Leistungsempfängern einzig und alleine die Verpfle- 
gungs- und Unterbringungskosten betrifft und demnach auf Begleitleistungen beschränkt bleibt. Die Kosten etwaiger gesundheitlicher Leistungen und gesundheitlicher Sachleistungen belasten hingegen den NFZ.

Wenn es stattdessen um den Krankentransport einschließlich des Luftwegs geht, übernimmt der NFZ die Kosten ausschließlich in den folgenden Fällen in voller Höhe: zunächst bei bestehender Notwendigkeit der Durchführung einer sofortigen Behandlung durch einen medizinischen Dienstleister oder weil die Kontinuität der Heilbehandlung erhalten bleiben muss, wobei eine Beschränkung auf den Transport zum nächstgelegenen medizinischen Dienstleister, der gemäß den Vorschriften über Heiltätigkeiten Leistungen im entsprechenden Bereich erbringt, sowie den Rückweg, erfolgt; des Weiteren bei Vornahme eines Transports aufgrund eines Auftrags eines (Truppen-) Arztes der Gesundheitsversicherung im Falle einer Dysfunktion des Bewegungsapparates, aufgrund derer eine Benutzung öffentlicher Transportmittel unmöglich bleibt, zum Zwecke der Durchführung einer Heilbehandlung. Der Transport erfolgt dann lediglich zum nächstgelegenen medizinischen Dienstleister, der Dienstleistungen im entsprechenden Bereich erteilt und zurück.

In allen sonstigen Fällen ist der Krankentransport teilweise oder sogar in vollem Umfang kostenpflichtig, selbst wenn er auf der Grundlage eines Auftrags eines (Truppen-) Arztes der Gesundheitsversicherung erfolgt.

In Bezug auf die Erstattung von Arzneimitteln, Lebensmitteln, die für eine besondere Ernährung bestimmt sind, und medizinischen Erzeugnissen bestimmt das Erstattungsgesetz unter anderem die Grundsätze, Voraussetzungen und Verfahren zur Erteilung von Bescheiden über die Erstattung der Arzneimittelkosten, die Grundsätze ihrer Finanzierung und die Kriterien der Bildung von Entgeltstufen sowie Gruppen von limitierten Arzneimitteln. Als erstes ist darauf hinzuweisen, dass in Bezug auf jedes Arzneimittel eine Einordnung in eine der vier Kategorien der Erstattungsfähigkeit stattfindet: 1) gleichzeitig apotheken- und verschreibungspflichtige Arzneimittel: a) im vollen Umfang der registrierten Anweisungen und Gebrauchsbestimmungen oder b) nach Anweisung gemäß dem klinischen Zustand; 2) im Rahmen eines Arzneimittelprogramms zur Anwendung kommende Arzneimittel; 3) im Rahmen einer Chemotherapie zur Anwendung kommende Arzneimittel: a) im vollen Umfang der registrierten Anweisungen und Gebrauchsbestimmungen und $b$ ) nach Anweisung gemäß des klinischen Zustands sowie 4) Arzneimittel, die im Rahmen der Erteilung von anderen als in den Punkten 1-3 genannten garantierten Leistungen zur Anwendung kommen. 
Wenn mit Blick auf das gegebene Arzneimittel ein Bescheid über die Erstattung seiner Kosten als gleichzeitig apotheken- und verschreibungspflichtiges Arzneimittel ergangen ist, kann es dem Leistungsempfänger kostenfrei, gegen eine Pauschale oder gegen ein Entgelt in Höhe von 30 \% oder $50 \%$ seines Finanzierungslimits bis zur Höhe des Limits und mit Zuzahlung in Höhe des Restbetrags zwischen dem Einzelhandelspreis und der Höhe des Finanzierungslimits, herausgegeben werden. Als Bezugspunkt für die Bestimmung, inwiefern ein gleichzeitig apotheken- und verschreibungspflichtiges Arzneimittel gebührenpflichtig ist, greift das Gesetz auf den von der Weltgesundheitsorganisation eingeführten Begriff der definierten Tagesdosis (defined daily dose, DDD) zurück. Im Falle eines Arzneimittels, für das keine DDD bestimmt wurde, bezieht sich die Pauschalgebühr auf eine für eine einmonatige Behandlung oder Anwendung ausreichende Einzelpackung des Arzneimittels. Auch pharmazeutische Zutaten und fertige Arzneimittel sowie erstellte Rezeptarzneimittel (d.h. Arzneimittel, die in der Apotheke auf der Grundlage eines ärztlichen Rezepts vorbereitet werden), die per Bescheid zu erstatten sind, werden dem Leistungsempfänger gegen Zahlung einer Pauschalgebühr herausgegeben, sofern die verschriebene Dosis eines solchen Rezeptarzneimittels geringer ausfällt als die Mindestdosis eines fertigen Arzneimittels in ständiger Form zur oralen Einnahme.

Wenn es um die Höhe der Pauschalgebühr geht, so wurde diese auf zweierlei Art bestimmt. Grundsätzlich beträgt sie $3,20 \mathrm{zl}$ (ungefähr $0,75 €$ ), während sie in Bezug auf Rezeptarzneimittel 0,50 \% der Höhe des Mindestlohns gemäß der jeweils aktuellen Bekanntmachung des Vorsitzenden des Ministerrates nach dem Gesetz vom 10. Oktober 2002 über den Mindestlohn beträgt, aufgerundet auf die erste Kommastelle. ${ }^{79}$ Das Verzeichnis von Arzneimitteln, die als pharmazeutische Zutaten für die Vorbereitung von Rezeptarzneimitteln verwendet werden können, die Menge des von der Pauschalgebühr betroffenen Rezeptarzneimittels und die Art und Weise der Berechnung der Vorbereitungskosten für das Rezeptarzneimittel bestimmt sich durch eine Verordnung des Gesundheitsministers.

Hinsichtlich der zwei weiteren Kategorien der Erstattungsfähigkeit, d.h. von im Rahmen eines Arzneimittelprogramms bzw. einer Chemotherapie

79 Da der Mindestlohn 2016 1.850,00 zł brutto betragen hat, belief sich das Pauschalentgelt für verschreibungspflichtige Arzneimittel auf 9,30 zł (etwa 2,10 €). 
zur Anwendung kommenden Arzneimitteln, besteht eine kostenfreie Herausgabe.

Die Grundlage für die Erstattung der Kosten eines Arzneimittels bildet ein Bescheid des Ministers für Gesundheit, in dem u.a. die Kategorie der Erstattungsfähigkeit, der Umfang der Gebührenpflicht und sog. Instrumente der Risikoteilung (zwischen dem Organisator des Systems und den Hersteller/Vertreiber des Arzneimittels) angegeben werden. Diese Instrumente können Folgendes beinhalten: Eine Bestimmung, nach der die Höhe der Einnahmen des Antragstellers von den erzielten Heilergebnissen abhängig gemacht wird; eine Bestimmung, nach der die Höhe des amtlichen Vertriebspreises von der Gewährleistung des Antragstellers, die besagten Arzneimittel, Lebensmittel, die für eine besondere Ernährung bestimmt sind, und medizinischen Erzeugnisse zu einem, im Ergebnis von Verhandlungen vereinbarten, niedrigeren Preis zu liefern beeinflusst wird; eine Bestimmung, nach der die Höhe des amtlichen Vertriebspreises vom Umsatzvolumen der gegebenen Arzneimittel, Lebensmittel, die für eine besondere Ernährung bestimmt sind, oder medizinischen Erzeugnisse abhängig gemacht wird; eine Bestimmung, nach der die Höhe des amtlichen Vertriebspreises von der Rückgabe eines Teils der erlangten Erstattung an das zur Finanzierung von Leistungen aus öffentlichen Mitteln verpflichtete Rechtssubjekt abhängig gemacht wird; eine Bestimmung sonstiger Voraussetzungen für Erstattungen, die sich auf die Zugänglichkeit von garantierten Leistungen und die Minderung ihrer Kosten auswirken.

Der Minister für Gesundheit erteilt seinen Erstattungsbescheid nicht nur unter Berücksichtigung der Erzielung der größtmöglichen positiven gesundheitlichen Effekte im Rahmen der zugänglichen öffentlichen Mittel, sondern auch in Hinblick auf eine Reihe von anderen, gesetzlich definierten Kriterien einschließlich des Einflusses auf die Ausgaben des zur Finanzierung von Leistungen aus öffentlichen Mitteln verpflichteten Rechtssubjekts und der Leistungsempfänger. Die Berücksichtigung der finanziellen Belastung der Leistungsempfänger ist eine offensichtliche Folgeerscheinung des Art. 68 Abs. 2 plVerf mit dem Grundsatz des gleichen $\mathrm{Zu}$ gangs zu aus öffentlichen Mitteln finanzierten Leistungen der Gesundheitsfürsorge. Wichtig ist, darauf hinzuweisen, dass das Erstattungsgesetz den Minister für Gesundheit dazu verpflichtet, jedes Arzneimittel mit erwiesener Wirkung bei der Behandlung von bösartigen Tumoren, psychotischen Störungen, geistiger Behinderung bzw. Entwicklungsstörung oder Infektionskrankheiten mit besonderer epidemiologischer Gefahr für die 
Bevölkerung sowie im Rahmen von Arzneimittelprogrammen angewandte Arzneimittel als gebührenfrei zu qualifizieren.

Weiterhin bestimmt das Gesetz die Regeln zur Einordnung von Arzneimitteln in die sonstigen Kategorien der Erstattungsfähigkeit und nimmt dabei auf das Kriterium der Behandlungskosten und deren Verhältnis zum Mindestlohn Bezug. Wenn ein Arzneimittel entsprechend dem aktuellen Stand der Medizin eine höchstens 30-tägige Einnahme erfordert, ist es dem Erstattungsniveau von 50 \% zuzurechnen. Sollte hingegen eine längere Therapie mit dem jeweiligen Arzneimittel erforderlich sein und gleichzeitig für den Leistungsempfänger bei der 30-prozentigen Erstattung des Finanzierungslimits monatliche Kosten in einer Höhe entstehen, die $5 \%$ des Mindestlohns überschreiten, sieht das Gesetz eine Pauschalgebühr (3,20 oder $0,50 \%$ vom Mindestlohn) vor. Die Qualifizierung als pauschalgebührenpflichtiges Arzneimittel betrifft auch Situationen, in denen, entsprechend dem aktuellen Stand der Medizin, die Anwendung eines Arzneimittels über nicht mehr als 30 Tage erforderlich ist und dessen Anwendungskosten für Leistungsempfänger bei der 50-prozentigen Erstattung des Finanzierungslimits $30 \%$ des Mindestlohns überschreiten würden.

Die Einordnung zur entsprechenden Gebührenpflicht erfolgt unter der Annahme der täglichen Anwendung von einer Tagesdosis des Arzneimittels. Wurde für das gegebene Arzneimittel keine Tagesdosis bestimmt, werden für seine Qualifikation die monatlichen Therapiekosten herangezogen. ${ }^{80}$

80 Vertiefend Lach, Refundacja leków a równy dostęp do świadczeń opieki zdrowotnej, „Ruch Prawniczy, Ekonomiczny i Socjologiczny” 2014, Heft 1, S. 119-131. 